\title{
RISKIND - A Computer Program for Calculating Radiological Consequences and Health Risks from Transportation of Spent Nuclear Fuel
}

by Y.C. Yuan, ${ }^{*}$ S.Y. Chen, B.M. Biwer, and D.J. LePoire

Environmental Assessment Division,

Argonne National Laboratory, 9700 South Cass Avenue, Argonne, Illinois 60439

November 1995

Work sponsored by United States Department of Energy,

Office of Civilian Radioactive Waste Management

Y.C. Yuan is affiliated with Square Y Consultants, Orchard Park, New York. 


\section{DISCLAMMIXR}

Portions of this document may be illegible in electronic image products. Images are produced from the best available original document. 


\section{DISCLAIMER}

This report was prepared as an account of work sponsored by an agency of the Uinited States Government. Neither the United States Government nor any agency thereof, nor any of their employees, make any warranty, express or implied, or assumes any legal liability or responsibility for the accuracy, completeness, or usefulness of any information, apparatus, product, or process disclosed, or represents that its use would not infiringe privately owned rights. Reference herein to any specific commercial product, process, or service by trade name, trademark, manufacturer, or otherwise does not necessarily constitute or imply its endorsement, recommendation, or favoring by the United States Government or any agency thereof. The views and opinions of authors expressed herein do not necescarily state or reflect those of the United States Government or any agency thereof. 


\section{CONTENTS}

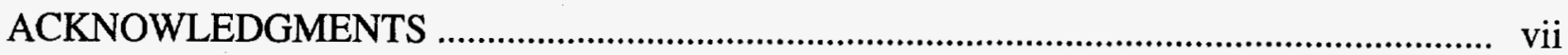

AVAILABILITY OF COMPUTER SOFTWARE .................................................................. viii

NOTATION

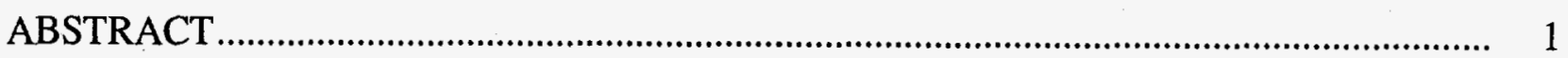

1 INTRODUCTION

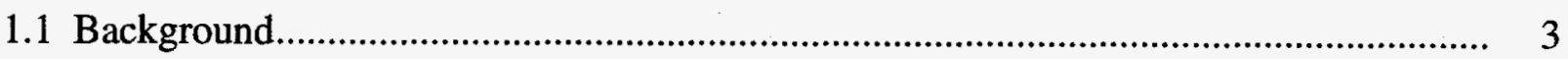

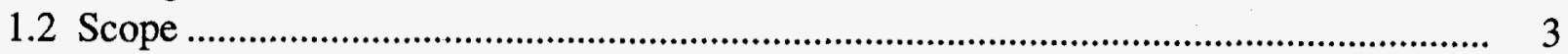

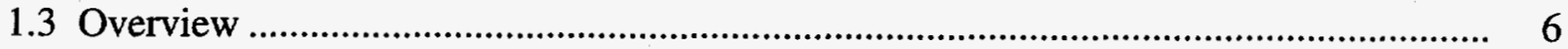

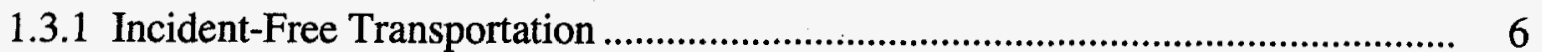

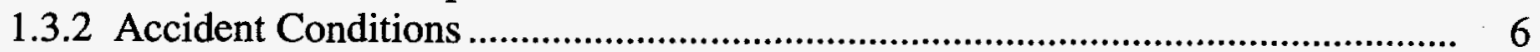

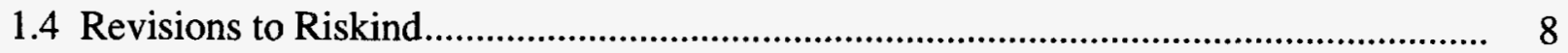

1.4.1 New User Interface ............................................................................... 9

1.4.2 Model Input Parameters................................................................................. 9

1.4.3 Enhanced Capabilities ...................................................................................... 10

1.4.4 Databases Revised and Updated................................................................... 10

1.4.5 Output Revised ............................................................................................ 11

1.4.6 On-Line Help Added ..................................................................................... 11

1.5 Report Organization ............................................................................................ 12

2 RADIOLOGICAL DOSE ASSESSMENT FOR INCIDENT-FREE TRANSPORT .............. 13

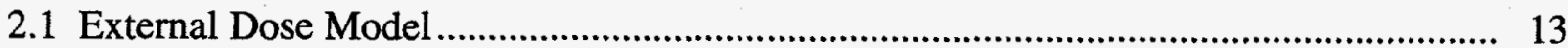

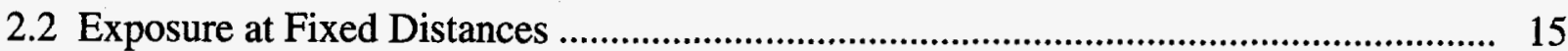

2.3 Exposure from a Passing Shipment................................................................... 17

3 RADIOLOGICAL HAZARD FROM ACCIDENTS ………….......................................... 21

3.1 Accident Response Model ....................................................................................... 21

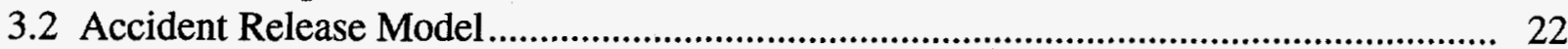

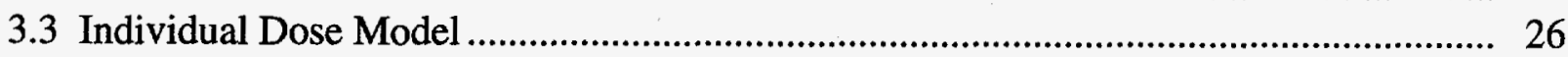

3.3.1 Atmospheric Transport Model ..................................................................... 26

3.3.1.1 Effective Release Height ................................................................... 26

3.3.1.2 Wind Power-Law Adjustment.............................................................. 29

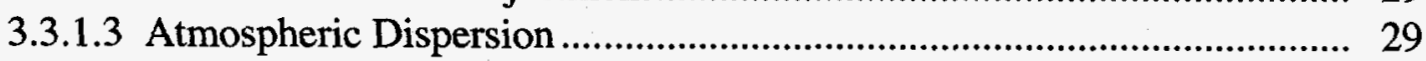

3.3.1.4 Plume Reflection ........................................................................... 31

3.3.1.5 Depletion Correction and Ground Contamination ................................. 32

3.3.1.6 Mixing Height ....................................................................................... 36

3.3.1.7 Meteorological Conditions ................................................................ 36

3.3.1.8 Initial Dispersion Geometry .............................................................. 38

3.3.1.9 Buoyancy-Induced Dispersion.............................................................. 41 


\section{CONTENTS (Cont.)}

3.3.2 Environmental Pathway and Dosimetry Models ................................................... 42

3.3.2.1 Short-Term Exposure .......................................................................... 44

3.3.2.2 Environmental Media Concentration Models ............................................ 47

3.3.2.3 Long-Term Dose Models........................................................................... 56

3.4 Population Dose Model …............................................................................................ 61

3.4.1 Contaminated Areas and Concentration Isopleths................................................. 62

3.4.2 Short-Term Exposure ……………………………............................................... 65

3.4.2.1 External Exposure from the Radioactive Cloud....................................... 65

3.4.2.2 External Exposure from Ground-Deposited Radionuclides...................... 66

3.4.2.3 Exposure from Inhaled Radionuclides .................................................... 67

3.4.2.4 External Exposure from Loss of Cask Shielding ....................................... 67

3.4.3 Long-Term Exposure......................................................................................... 68

3.4.3.1 External Doses from Resuspended Air Concentrations .................................... 69

3.4.3.2 External Exposure from Ground-Deposited Radionuclides ................................ 69

3.4.3.3 Inhalation Doses from Resuspended Air Concentrations .................................. 70

3.4.3.4 Ingestion Dose Model........................................................................................ 71

3.4.4 Protective Action Guidelines.............................................................................. 74

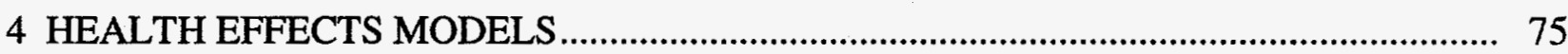

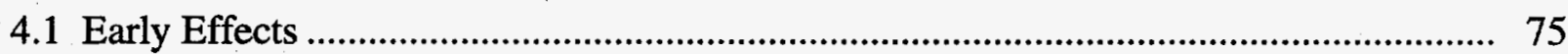

4.1.1 Dose and Dose Rate Estimation ..................................................................... 76

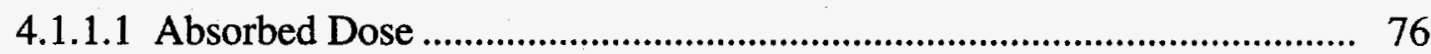

4.1.1.2 External Exposure ....................................................................... 76

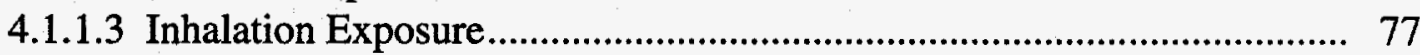

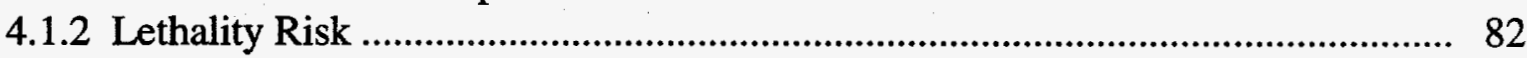

4.1.3 Dose Response............................................................................................. 85

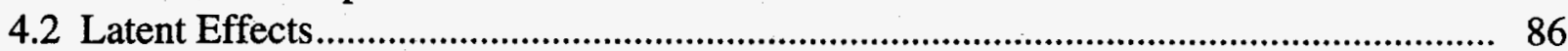

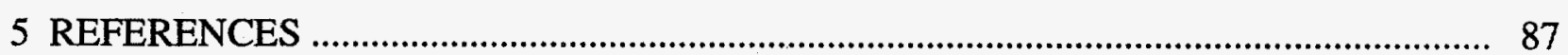

APPENDIX A: Description of Radionuclide Inventory Database for Spent Nuclear Fuels.................................................................................. A-1

APPENDIX B: Method for Adjusting Cask External Dose

Rates Relative to Cask Dimensions ................................................................. B-1

APPENDIX C: Method for Screening Radionuclides......................................................... C-1

APPENDIX D: Method for Estimating the Spallation of Crud Material ................................... D-1

APPENDIX E: Method for Estimating Cask Response from User-Specified Accident Scenarios........................................................................................ E-1

APPENDIX F: Program Structure ............................................................................ F-1 
APPENDIX G: Data Input Preparation G-1

APPENDIX H: Sample Problems H-1

APPENDIX I: Quality Assurance

\section{FIGURES}

1.1 Flow Diagram for Calculating the Radiological Risk to an Individual from Transportation of Spent Nuclear Fuel.

2.1 Configuration of Spent Fuel Cask Relative to the Receptor and Scattering Media

2.2 Schematic Diagram of External Exposures to Various Receptors from a Stationary Spent Fuel Shipment.

2.3 Schematic Diagram of External Exposures to Various Receptors from a Moving Spent Fuel Shipment

3.1 Matrix of Cask Response Regions and Probabilities of Occurrence for Combined Mechanical and Thermal Loads

3.2 Environmental Pathways and Exposure Modes for a Spent Nuclear Fuel

Cask Accident. 43

3.3 Areas of Estimated Air or Ground Concentration Contours for Population Dose Calculation

\section{TABLES}

2.1 Coefficients of the Fitted Equations for Neutron and Gamma Dose Rates from a Spent Fuel Cask, with Groundscattering.

3.1 Radioactive Material Release Fractions from Accidents Occurring under Various Cask Response Regions

3.2 Estimates of the Power (p) in Equation 3.10 for Population Zones as a Function of Stability Class

3.3 Pasquill-Gifford Dispersion Parameters for Ground-Level Releases. 38

3.4 Briggs Dispersion Coefficients for Elevated Releases 39

3.5 Shielding Values for Routine and Accident Exposures 45

3.6 Transfer Coefficients Applicable to Food Chain Pathways for Various Radionuclides

4.1 Retention Parameters for the Lungs for Each Translocation Class 78 
TABLES (Cont.)

4.2 Retention Parameters for Bone Marrow Dose Calculations............................................ 79

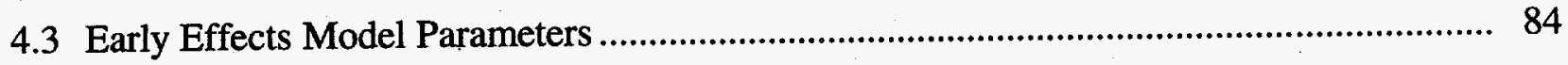

4.4 Latent Effects Health Risk Conversion Factors.................................................................... 86 


\section{ACKNOWLEDGMENTS}

The authors wish to express their thanks to the U.S. Department of Energy (DOE) Office of Civilian Radioactive Management (OCRWM) for funding of this project and to TRW Environmental Safety Systems, Inc. (TESS), for administering the program.

Leadership of this project has been provided by DOE program manager James Osborne and TESS administrator Edward McGuinn. Special thanks are due the following former OCRWM officials: Edwin Wilmot for inception of the program and Robert Rothman and Michael Conroy for their roles as program managers. Appreciation is also extended to Jeffrey Roberts and Michael Klimas of DOE Chicago for their continued administrative support.

The current version of the RISKIND code and its accompanying documentation has been substantially improved as the result of critical reviews and constructive comments from many experts. The authors wish to thank Steven Maheras (Science Applications International Corporation, Idaho); Michael Raddatz (U.S. Nuclear Regulatory Commission); Harold Gale and Larry Green (TESS); Jeremy Sprung, Sieglinde Neuhauser, Ruth Weiner, David Chanin, and Fran Kanipe (Sandia National Laboratories); William Andrews (University of Nevada at Las Vegas), Steven Oberg and Richard Brey (Idaho State Idaho National Engineering Laboratory Oversight Program/Idaho State University); and Gary DeMoss (Science Applications International Corporation, Maryland). Useful discussions and input have been provided by Dick Amato (Naval Reactor Program). Special thanks are due Dennis Williford (TESS) for his extraordinary efforts in soliciting and coordinating the review of the code and the documentation.

The authors also wish to thank their colleagues Frederick Monette, John Arnish, and Halil Avci for providing internal review and valuable suggestions. Thanks are extended to several program managers within the Environmental Assessment Division (EAD) for providing opportunities to use the code in various environmental assessment programs: Robert Browne, Kenneth Cornelius, Larry Gorenflo, Gary Marmer, Michael Lazaro, and Marsha Goldberg. The authors also thank EAD division management for constant encouragement and support.

Finally, we thank Pat Hollopeter for editorial assistance, B.J. Pruitt-Deal for secretarial assistance, and the Information and Publishing Division Document Processing and Control Center for document preparation. 


\section{AVAILABILITY OF COMPUTER SOFTWARE}

Electronic copies of the software described in this publication will be distributed with appropriate restrictions by:

Energy Science and Technology Software Center

P.O. Box 1020

Oak Ridge, Tennessee 37831-1020

For information regarding requests for software, please call (615) 576-2606. 


\section{NOTATION}

The following is a list of acronyms, initialisms, and abbreviations (including units of measure) used in this document. Some acronyms used in tables only are defined in the respective tables.

\section{ACRONYMS, INITIALISMS, AND ABBREVIATIONS}

ANL

BEIR

BWR

CFR

DCF

DOE

DOT

EPA

FGR

GI

ICRP

LET

LLI

LLNL

LWR

NEPA

NRC

OCRWM

ORNL

PAG

PWR

QA

SNF

UNSCEAR
Argonne National Laboratory

Committee on the Biological Effects of Ionizing Radiation

boiling-water reactor

Code of Federal Regulations

dose conversion factor

U.S. Department of Energy

U.S. Department of Transportation

U.S. Environmental Protection Agency

Federal Guidance Report

gastrointestinal

International Commission on Radiological Protection

linear energy transfer

lower large intestine

Lawrence Livermore National Laboratory

light-water reactor

National Environmental Policy Act

U.S. Nuclear Regulatory Commission

Office of Civilian Radioactive Waste Management

Oak Ridge National Laboratory

protective action guideline

pressurized-water reactor

quality assurance

spent nuclear fuel

United Nation's Scientific Committee on the Effects of Ionizing Radiation

\section{UNITS OF MEASURE}

$\mathrm{Bq}$ becquerel(s)

cal calorie(s)

$\mathrm{Ci} \quad$ curie(s)

$\mu \mathrm{Ci} \quad$ microcurie(s)

$\begin{array}{ll}\mathrm{cm} & \text { centimeter(s) } \\ \mathrm{cm}^{2} & \text { square centimeter(s) } \\ \mathrm{d} & \text { day(s) } \\ \mathrm{ft} & \text { foot (feet) }\end{array}$




$\begin{array}{llll}{ }^{\circ} \mathrm{F} & \text { degree(s) Fahrenheit } & \mathrm{mm} & \text { millimeter(s) } \\ \mathrm{g} & \text { gram(s) } & \mathrm{MB} & \text { megabyte(s) } \\ \text { gal } & \text { gallon(s) } & \mathrm{min} & \text { minute(s) } \\ \mathrm{Gy} & \text { gray(s) } & \mathrm{mph} & \operatorname{mile}(\mathrm{s}) \text { per hour } \\ \mathrm{h} & \text { hour(s) } & \mathrm{mrem} & \text { millirem(s) } \\ \text { in. } & \text { inch(es) } & \text { MTIHM } & \text { metric ton(s) of initial heavy metal } \\ \mathrm{kg} & \text { kilogram(s) } & \mathrm{MTU} & \text { metric ton(s) of uranium } \\ \mathrm{K} & \text { degree(s) Kelvin, kilobyte(s) } & \mathrm{MWd} & \text { megawatt-day(s) } \\ \mathrm{km} & \text { kilometer(s) } & \mathrm{rad} & \text { radiation absorbed dose(s) } \\ \mathrm{km} & \text { square kilometer(s) } & \mathrm{rem} & \text { roentgen-equivalent man } \\ \mathrm{L} & \text { liter(s) } & \mathrm{s} & \text { second(s) } \\ \mathrm{m} & \text { meter(s) } & \mathrm{s}^{2} & \text { second(s) squared } \\ \mathrm{m}^{2} & \text { square meter(s) } & \mathrm{s}^{3} & \text { second(s) to the third } \\ \mathrm{m}^{3} & \text { cubic meter(s) } & \mathrm{Sv} & \text { sievert(s) } \\ \mathrm{m}^{4} & \text { meters(s) to the fourth } & \mathrm{yr} & \text { year(s) }\end{array}$




\title{
RISKIND - A COMPUTER PROGRAM FOR CALCULATING RADIOLOGICAL CONSEQUENCES AND HEALTH RISKS FROM TRANSPORTATION OF SPENT NUCLEAR FUEL
}

\author{
by \\ Y.C. Yuan, S.Y. Chen, B.M. Biwer, and D.J. LePoire
}

\begin{abstract}
This report presents the technical details of RISKIND, a computer code designed to estimate potential radiological consequences and health risks to individuals and the collective population from exposures associated with the transportation of spent nuclear fuel. RISKIND is a user-friendly, interactive program that can be run on an IBM or equivalent personal computer under the Windows ${ }^{\mathrm{TM}}$ environment. Several models are included in RISKIND that have been tailored to calculate the exposure to individuals under various incidentfree and accident conditions. The incident-free models assess exposures from both gamma and neutron radiation and can account for different cask designs. The accident models include accidental release, atmospheric transport, and the environmental pathways of radionuclides from spent fuels; these models also assess health risks to individuals and the collective population. The models are supported by databases that are specific to spent nuclear fuels and include a radionuclide inventory and dose conversion factors. In addition, the flexibility of the models allows them to be used for assessing any accidental release involving radioactive materials. The RISKIND code allows for userspecified accident scenarios as well as receptor locations under various exposure conditions, thereby facilitating the estimation of radiological consequences and health risks for individuals. Median (50\% probability) and typical worst-case (less than 5\% probability of being exceeded) doses and health consequences from potential accidental releases can be calculated by constructing a cumulative dose/probability distribution curve for a complete matrix of site joint-wind-frequency data. These consequence results, together with the estimated probability of the entire spectrum of potential accidents, form a comprehensive, probabilistic risk assessment of a spent nuclear fuel transportation accident.
\end{abstract}




\section{INTRODUCTION}

The RISKIND computer program was developed by Argonne National Laboratory under the support of the U.S. Department of Energy (DOE) Office of Civilian Radioactive Waste Management (OCRWM). The program was developed for analyzing the potential radiological health consequences to individuals or specific population subgroups exposed to radiation associated with the transportation of spent nuclear fuel (SNF). RISKIND is designed to address the local, scenario-specific (i.e., "what if") concerns frequently encountered in environmental assessment activities (including public scoping processes) performed under the National Environmental Policy Act (NEPA) of 1969 or other environmental regulatory requirements.

\subsection{BACKGROUND}

Currently, RISKIND is used in conjunction with the latest version of RADTRAN, RADTRAN 4 (Neuhauser and Kanipe 1992), for performing comprehensive transportation risk assessments (DOE 1995; Chen et al. 1995). RADTRAN was originally developed pursuant to the U.S. Nuclear Regulatory Commission (NRC) report Final Environmental Statement on the Transportation of Radioactive Material by Air and Other Modes (NRC 1977b), which was issued to demonstrate compliance with NEPA.

The NRC report is primarily concerned with estimating the collective population risk from the transportation of radioactive materials under incident-free or accident conditions. Traditionally, such an analysis has been supplemented by other models so that consequences to individuals or population subgroups could be estimated. These latter analyses are documented in DOE environmental assessment reports (DOE 1986a,b,c,d, 1990, 1992b). However, different models were used in these reports, which has resulted in inconsistent approaches.

RISKIND was initially developed in 1993 (Version 0, Yuan et al. 1993), in light of public comments and the need for a more complete and consistent methodology for addressing radiological consequence issues. Since that time, RISKIND has undergone a number of substantial improvements and enhancements resulting from user feedback, new methodologies for some models, revised databases, and a peer review process. This latest version, Version 1, represents the updated program since its original release.

\subsection{SCOPE}

The major objective of RISKIND is to provide data for addressing public concern regarding the transport of SNF along a specific route. The data consist of calculations of incident-free and accident impacts for a particular radioactive material shipment at specific 
locations along a truck or rail transport route. Public comments on transportation risk analyses for individuals may include the following scenarios:

- An individual stuck in traffic next to a radioactive materials shipment;

- An individual working near heavily traveled transport routes;

- An individual living near heavily traveled transport routes, such as shipment origin or destination site entrances;

- An individual near rail grade-crossings where accident rates are higher;

- Individuals in an area near a postulated SNF transportation accident location;

- An individual eating locally grown food following a SNF transportation accident; and

- An individual drinking water that has been contaminated by an accidental release near a drinking water supply.

The radiological consequences and health risks from these "what if" situations are of great interest and concern to the public. These concerns can only be addressed on the basis of a methodology that analyzes the potential health risk of a specific situation. Substantial databases and technologies relevant to the transportation of SNF and other radioactive materials have been made available through the efforts of various research organizations. These databases and technologies were used to develop RISKIND in accordance with the needs of the local community.

The RISKIND code was implemented on the basis of five objectives:

1. Calculation of site- and route-specific radiological consequences and health risks to exposed individuals and the collective local population;

2. Modeling of the different exposure pathways for specific exposure scenarios;

3. Estimation of the amount of radioactive material released under potential accident scenarios;

4. Estimation of cask accident responses specific to the transportation of SNF; and 
5. Enhancement of risk communication, that is, to help the user better understand and appreciate the complexities of the problems to be analyzed and the relevant input parameters, as well as the resulting consequences.

To accomplish the first objective, RISKIND is designed to calculate radiological impacts at specific receptor locations for a variety of exposure scenarios. Comprehensive mathematical models capable of handling site-specific information at the time of exposure are used; such information includes specific receptor locations, exposure conditions (including individual air and food intake rates), and meteorological conditions. The model used to assess the potential acute health effects from short-term exposures is based on the model developed by Harvard University and the NRC (1985) and the revised model of Abrahamson et al. (1989, 1991). The dose-to-health-risk conversion factors for estimating latent health effects are taken from Publication 60 of the International Commission on Radiological Protection (ICRP 1991).

RISKIND meets the second objective by considering all environmental pathways, including short-term exposure from the initial passing radioactive cloud, accidental exposure from loss of the cask shield, and long-term exposure from ground deposition and ingestion from the food chain pathways. Pathway analysis can be tailored to model impacts in a wide range of locations, from large metropolitan areas to rural agricultural areas.

To meet the third objective, a radionuclide source inventory was compiled from the database developed by Oak Ridge National Laboratory (ORNL) in which the data are specific to the type of spent fuel (pressurized-water reactor [PWR] or boiling-water reactor [BWR]), cooling times, and burnup rates (DOE 1987b, 1992a). User-supplied inventories are also permitted for different spent fuel types and other radioactive materials.

To meet the fourth objective, the cask accident responses and the radionuclide release fractions modeled by Lawrence Livermore National Laboratory (LLNL) in its report for the NRC were incorporated into RISKIND as default values. This LLNLNRC report is commonly referred to as the "NRC modal study" (LLNL 1987). Other cask responses and release fractions supplied by the user may be used as input in place of the default values.

To meet the fifth objective, RISKIND was equipped with an easy to use Windows ${ }^{\mathrm{TM}}$ interface and a scenario-oriented program input structure with on-line help capabilities. The input is flexible enough to allow the user to model most plausible situations. Input parameters are grouped according to function, and the parameter definitions are available via on-line help. The on-line help also contains diagrams depicting scenarios with the relevant input parameters highlighted to aid the user in understanding how the input relates to the problem. Graphical output displays help convey the consequences in a more meaningful context. 


\subsection{OVERVIEW}

The RISKIND code was developed on the basis of the considerations discussed above. The primary function of this code is the estimation of radiological risk to individuals and to local population subgroups under various site-specific environmental settings. The radiological risks analyzed by RISKIND include incident-free transportation as well as accident conditions. The code is designed to be responsive to scenarios associated with truck or rail transport of SNF. Therefore, the coding approach in RISKIND emphasizes the scenario descriptions, environmental settings, receptor locations, and potential health effects. The code also incorporates the latest available methodologies and databases to facilitate the analysis of radiological risks. Figure 1.1 is a flow diagram of RISKIND showing the calculation of radiological risk to an individual from the transportation of SNF or other radioactive materials.

\subsubsection{Incident-Free Transportation}

Exposure from incident-free (i.e., routine) transportation results solely from the external doses received by individuals from the neutron and gamma radiation emitted from the SNF cask or other radioactive material shipping package. Incident-free exposure includes those occurrences when the transport vehicle is in transit (i.e., moving) or at a stop. The receptors for the in-transit exposure may include the residents living adjacent to a highway or railway and the passengers sharing the traffic route with the transport vehicle; exposed individuals at a stop may include the vehicle inspector, a gas station attendant, a nearby person in a traffic jam, and so forth.

The model used by RISKIND for predicting external exposure is based on dose rates (Chen and Yuan 1988) derived specifically for a spent fuel cask and takes into account the ground/air scattering of the emitted gamma or neutron radiation. The model also contains provisions for adjusting the dose rate for changes in cask sizes (i.e., outer radius and length) and provides a realistic, although still somewhat conservative, estimate of the external doses to a receptor.

\subsubsection{Accident Conditions}

Potential exposure to individuals under accident conditions can occur through many environmental pathways if an accident leads to the environmental release of the radioactive contents of the cask. In RISKIND, the estimated exposure and the resulting health effects are presented individually and for each potential pathway.

Various scenarios in RISKIND have been characterized according to an array of SNF cask responses as described in the NRC's modal study (LLNL 1987). In that study, all accidents are represented by discrete response regions (severity categories). These response regions range 


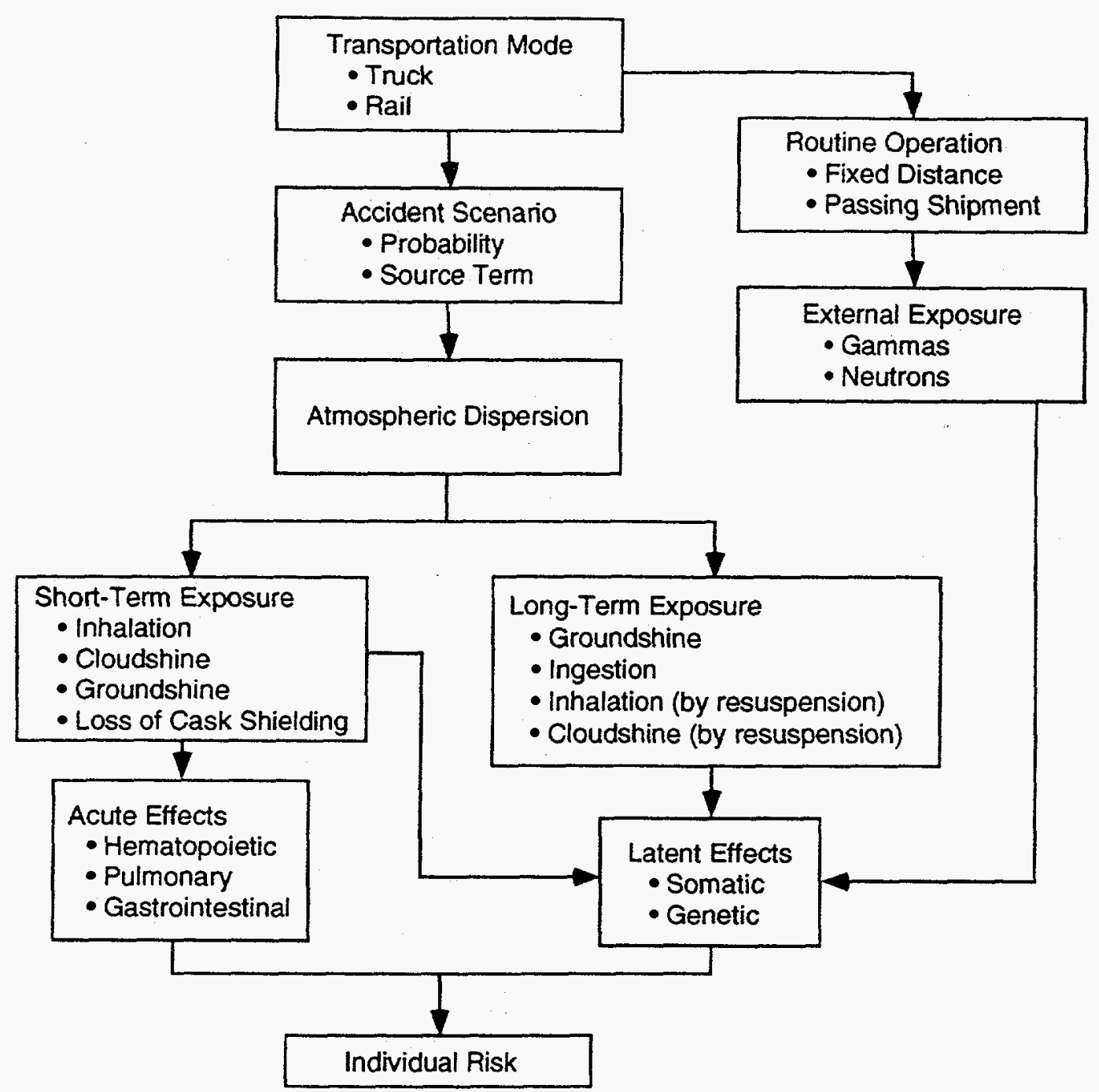

FIGURE 1.1 Flow Diagram for Calculating the Radiological Risk to an Individual from Transportation of Spent Nuclear Fuel

from likely events (with minor consequences) to highly unlikely events (with severe consequences). Twenty response regions are characterized according to two major accident parameters: impact force and thermal force (i.e., heat from a fire). Thus, accident conditions would be affected by vehicle speed, object hardness, impact angle and orientation, and fire duration and location. In the NRC modal study, the bounding case release fractions have also been estimated for each response region. All credible accident scenarios are thus fully represented by the 20 response regions.

To support the consistency of release estimates, the SNF radionuclide source inventory was derived from the database developed by ORNL (DOE 1987b, 1992a). In addition, potential release from crud (i.e., a mixture of reactor coolant corrosion products) spalling off (breaking 
loose from) the fuel rods is also incorporated. The estimate of crud release is based on a study by Sandia National Laboratories (Sandoval et al. 1991).

The atmospheric transport module in RISKIND includes models that simulate dispersion phenomena following a short release. RISKIND's transport model estimates levels of air and ground contamination on the basis of specific meteorological conditions, geometry, and elevation of the release. Plume rise from the thermal buoyancy of a release involving fire and dispersion effects near the release are also considered. The uncertainty of the effect of weather conditions on the calculated doses can be considered by constructing a cumulative probability distribution of dose values with wind-rose data for a given site. This probabilistic dose distribution is then used to determine the "median" (50\% weather probability) and reasonable "maximum" (95\% weather probability) dose values at a given receptor.

The pathway model includes exposure pathways from direct external radiation from the cask (due to loss of shielding), external exposure from the radioactive cloud and ground contamination, and internal exposure from inhalation of radionuclides in the air and potential ingestion of contaminated foods and water.

Health effects to individuals are estimated in terms of potential acute or latent fatalities, latent nonfatal cancer incidence, and latent adverse genetic effects from short-term exposure during initial plume passage and long-term exposure originating from deposited radioactive material. Acute fatalities are estimated using the latest NRC health effects model (NRC 1985; Abrahamson et al. 1989, 1991). The latent health effects are estimated using dose-to-health-risk conversion factors suggested in ICRP Publication 60 (ICRP 1991).

The consequence model of RISKIND includes provisions for incorporating the consequence reduction benefits of indoor shielding, evacuation, interdiction of contaminated foods, and other protective actions such as cleanup of contamination to comply with U.S. Environmental Protection Agency (EPA) protective action guide (PAG) levels (EPA 1991). Consequences can be presented either deterministically (i.e., with fixed accident parameters and weather conditions) or probabilistically (analyzed over the spectrum of accident response regions and weather conditions).

\subsection{REVISIONS TO RISKIND}

RISKIND, Version 1, incorporates a number of changes to the original code (Yuan et al. 1993) that increase the user-friendliness and flexibility of the program. Some of the major changes are listed in the following subsections. 


\subsubsection{New User Interface}

The user interface has been totally revamped. The original DOS menu system has been replaced by the now familiar look and feel of a Windows ${ }^{\mathrm{TM}}$ application. Even users unfamiliar with the Windows ${ }^{\mathrm{TM}}$ operating system will quickly become accustomed to the intuitive interface. The main input window provides for selection of the major input options and a quick visual summary of the case under analysis. All input parameters are grouped logically according to function and are only one or two windows away from the main input window. The use of a mouse is preferred for navigating the input windows and displaying results; however, input from the keyboard for navigation is also supported. Another benefit of the Windows ${ }^{\mathrm{TM}}$ interface is its support of graphics. The original graphical display of results for certain health risks has been enhanced and upgraded. The user is able to gain a better understanding of the results through studying the data in a clearer pictorial format.

\subsubsection{Model Input Parameters}

To enhance the flexibility of the program, the remaining model input parameters for dose calculations that were previously unmodifiable by the user have been made user accessible. The interface can now accept user-supplied receptor shielding values and dose rate curves for incident-free calculations, and, for accident calculations, user-supplied shipment inventories, release characteristics, the remaining ingestion pathway input parameters, and receptor shielding values.

Receptor shielding values for incident-free and accident calculations had been user selectable from a predefined list, but custom values could not be input. This restriction has been revoked, and users may now input their own shielding values for a custom analysis if the data are available.

Previously, the user was confined to the use of the default gamma and neutron dose rate curves for estimating external exposures from stopped or passing shipments. These dose rate curves are based on representative radiation spectra from commercial spent fuel. To accommodate fuel-specific dose rate curves, RISKIND, Version 1, is equipped to accept user input values for the dose rate curve coefficients. This new feature allows the user to input external dose rate information that can be derived from realistic data such as actual measurements. In addition, this capability provides the means for adjusting dose rates for nonstandard SNF or other radioactive materials.

Radionuclide shipment inventories input by the user are now supported by RISKIND, Version 1. This new feature offers additional capabilities to accommodate fuel types that are outside the spectrum represented by BWR or PWR fuels; thus, the user is able to input a set of specific radionuclides and their respective amounts for nonstandard spent fuel. Furthermore, 
inventories input by the user offer the flexibility of conducting analyses for shipments of radioactive materials other than SNF.

Shipping cask release characteristics (response region conditional probabilities and radionuclide release and dispersion fractions) can now be input by the user with RISKIND, Version 1. The user is able to use the latest available data and can evaluate results using different cask or shipping container designs. This new feature also permits user input of accident classification schemes other than those used in the modal study (LLNL 1987), such as that employed in NUREG 0170 (NRC 1977b).

\subsubsection{Enhanced Capabilities}

Potential accident consequences are highly dependent on weather conditions for the dispersion of released radioactivity. RISKIND is now capable of reading joint frequency data in Stability Array (STAR) format. Data in this standard format are widely available, and this new capability frees the user from having to convert data to the format used in RISKIND. The data from the STAR file are averaged over all directions for a complete health risk analysis, or, in keeping with the site-specific capabilities of RISKIND, the weather data for a particular direction may be selected for conducting a direction-specific risk analysis.

Deposition of radionuclides from the passing radioactive cloud after a potential radionuclide release caused by a possible accident would result in cloud depletion and ground contamination. The rate at which this deposition occurs is accounted for in the health risk calculations with the use of the radionuclide deposition velocity. A single deposition velocity had been used for all radionuclides with the exception of inert gases, which are assumed not to deposit. However, a radionuclide such as iodine deposits much more quickly than many other radionuclides. RISKIND, Version 1, assigns independent, user-accessible, deposition velocities to each of the five radionuclide types recognized by the program for individual receptor calculations. In addition, each radionuclide may be independently assigned to a particular radionuclide type. This flexibility permits the analyst to account for speciation of a particular radionuclide under the given circumstances, if the relevant data are available.

The health effects models have been revised. A new method for estimating acute dose rates and doses has been implemented, and updated latent health dose-to-health-risk conversion factors are used. Latent nonfatal cancer incidence has also been added to the effects estimated.

\subsubsection{Databases Revised and Updated}

The original SNF radionuclide database (Notz et al. 1987) has been updated in RISKIND, Version 1, with information from DOE (1992a). These updated data have been qualified by an OCRWM-sponsored peer review as meeting the requirements of the OCRWM 
Quality Assurance Program. More information on the radionuclide database can be found in Appendix A.

The dose conversion factor (DCF) file database has been revised and now reflects the values from EPA Federal Guidance Reports (FGR) 11 and 12 (Eckerman et al. 1988; Eckerman and Ryman 1993). Dose conversion factors for internal exposure from inhalation and ingestion are taken from FGR 11, and factors for external exposure are taken from FGR 12. The DCF data are now maintained in an ASCII text file that also contains the data format for those who wish to substitute custom values for exposure calculations. This accessibility allows for the analysis of sensitive populations, such as children or the elderly, if the appropriate DCFs are available.

\subsubsection{Output Revised}

The output file has been reformatted for a clearer presentation of results. In addition, a complete input echo of all RISKIND input parameters to the output file has been added in Version 1. The presence of the input echo adds a new level of quality assurance and provides a permanent record of the input data used to calculate the accompanying results.

Isopleth contours for ground-level air concentrations and ground contamination are determined for estimating the risks to a population subgroup from a potential accidental release of radioactivity. RISKIND, Version 1, reports the number of persons per isopleth and their associated risks separately on an isopleth-by-isopleth basis, as well as collectively. This breakdown of the results enables the user to better understand where the highest areas of risk are located in the affected area.

The calculations in RISKIND are now based on input parameters using the SI system of units. However, the doses estimated for receptors are presented in conventional units of rem rather than sieverts $(1 \mathrm{~Sv}=100 \mathrm{rem})$, since the rem is the more commonly reported unit.

\subsubsection{On-Line Help Added}

On-line help with explanatory diagrams and definitions of all input parameters has been added to aid the user in program input. Scenario diagrams are available under the Help menu to aid the user in visualizing the situation to be modeled and to inform the user of the pertinent input parameters. Other diagrams are available that depict various input parameters to help the user understand their meanings. Pressing the F1 function key while a certain input parameter is selected will bring up the Help support with a description of the parameter. Help on individual input parameters may be accessed from the main menu bar as well. 


\subsection{REPORT ORGANIZATION}

The information presented in this report is organized as follows:

- Incident-free transport models used in RISKIND - Section 2;

- Accident impact models used in RISKIND - Section 3;

- Health effects models used in RISKIND, including descriptions of the acute effects and latent health effects models - Section 4;

- Radionuclide inventory database specific to SNFs - Appendix A;

- Model for estimating the external dose rates for varying dimensions (radius and length) of the SNF cask - Appendix B;

- Method for screening the radionuclides that are significant for radiological risk analysis - Appendix C;

- Method for estimating the spallation of crud material during accidents - Appendix D

- Method for estimating the cask response from user-supplied accident scenarios - Appendix E;

- Program structure and data transfer used in RISKIND - Appendix F;

- Input required to execute RISKIND -Appendix G;

- Sample problems - Appendix H; and

- Quality assurance - Appendix I. 


\section{RADIOLOGICAL DOSE ASSESSMENT FOR INCIDENT-FREE TRANSPORT}

During incident-free transportation, individuals are exposed to the direct external radiation emitted from the shipping package, such as a spent fuel cask. The radiation may consist of gamma rays and neutrons.

\subsection{EXTERNAL DOSE MODEL}

The external dose model in RISKIND is based on dose rates (Chen and Yuan 1988) that have been calculated separately for gamma and neutron radiation for a specific spent fuel cask configuration (Figure 2.1). These dose rates represent the values at the midplane perpendicular to the cask axis and account for both air and ground scattering from the cask in a horizontal position. Doses derived from this approach can be adjusted to accommodate different cask dimensions, according to the method described in Appendix B. The total external radiation dose rate at a given location with respect to the cask can be derived from the following equation:

$$
\dot{D}(r)=\dot{D}_{g}(r)+\dot{D}_{n}(r)
$$

where

$$
\begin{aligned}
\dot{D}(r)= & \text { total dose rate }(\mathrm{rem} / \mathrm{h}) \text { at a distance } r \text { meters from the cask surface; } \\
\dot{D}_{i}(r)= & \text { dose rate }(\mathrm{rem} / \mathrm{h}) \text { from gamma }(i=g) \text { or neutron }(i=n) \text { radiation at } \\
& \text { a distance } r \text { meters from the cask surface; and } \\
r= & \text { distance in meters from the cask surface: } r=r_{0}+r_{1}, \text { where } r_{0} \text { is the } \\
& \text { distance from the outer lateral surface of the vehicle; and } r_{1} \text { is the } \\
& \text { distance between the cask surface and the outer lateral surface of the } \\
& \text { vehicle. }
\end{aligned}
$$

The default dose rates (rem/h) for gamma and neutron radiation were derived from a representative spent fuel cask (DOE 1987a) used in assessing radiation exposures from the transportation of spent fuel (Chen and Yuan 1988). Other scenario-specific dose rates can be calculated with existing codes such as MCNP (the Monte Carlo N-Particle Transport Code System) (Los Alamos National Laboratory [LANL] 1994) and SCALE 3 (ORNL 1986) for gamma or neutron radiation and Microshield (Negin and Worku 1992) for gamma radiation. The calculated dose rates can be expressed by the following empirical formula for input to RISKIND:

$$
\begin{aligned}
\log \left[\dot{D}_{i}(\mathrm{r})\right]= & A_{0_{i}}+A_{1 i} \log r+A_{2 i}(\log r)^{2}+A_{3 i}(\log r)^{3}+A_{4 i}(\log r)^{4} \\
& +A_{5 i}(\log r)^{5}+A_{6 i}(\log r)^{6}+A_{7 i}(\log r)^{7} .
\end{aligned}
$$




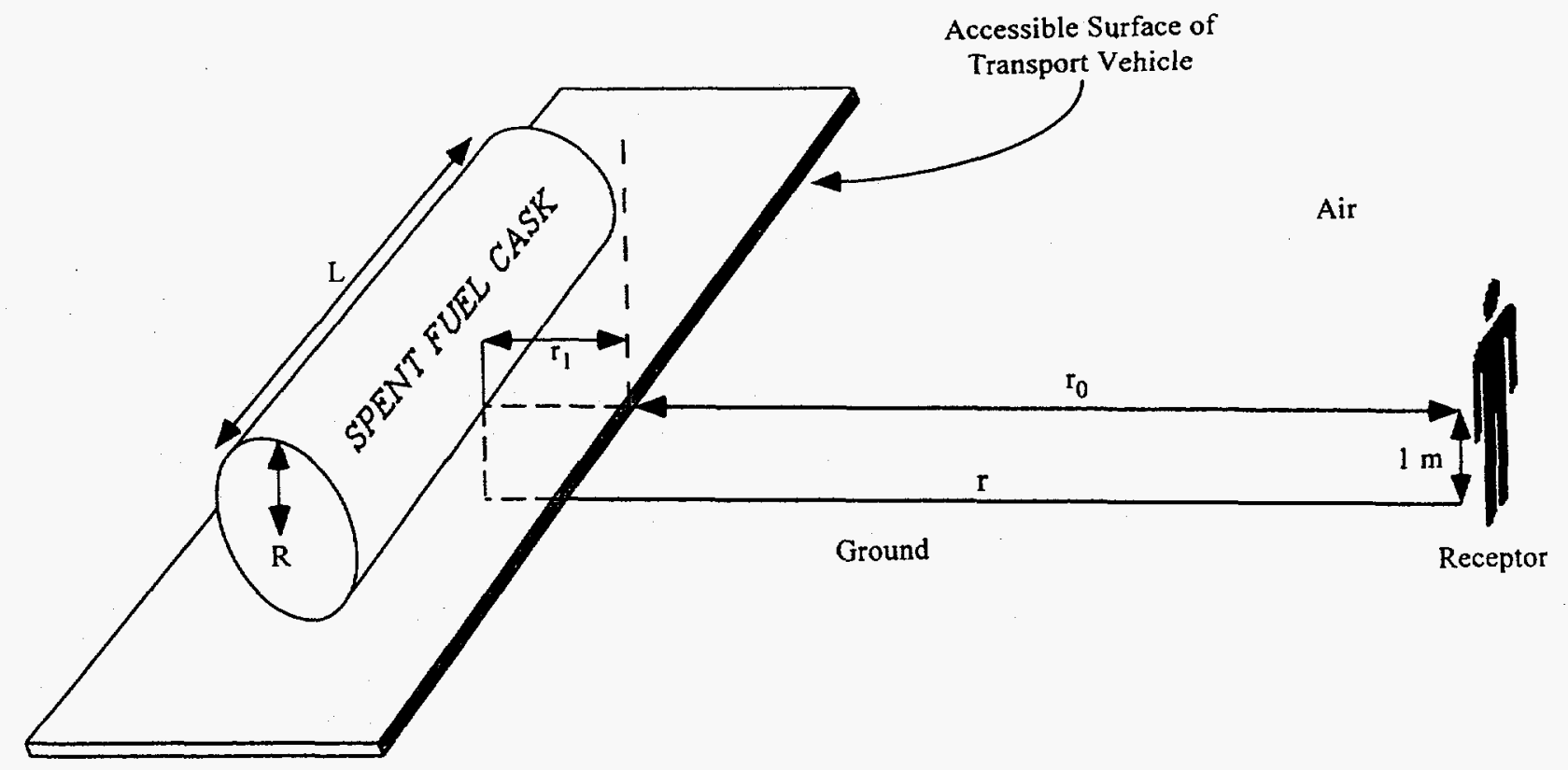

FIGURE 2.1 Configuration of Spent Fuel Cask Relative to the Receptor and Scattering Media (air and ground)

The coefficients $A_{0 i}$ to $A_{7 i}(i=g$ for gamma, $n$ for neutron [ACOEFU $(8, i)$ ]) are fitted coefficients in the applicable range of 1 to $1,000 \mathrm{~m}$. These coefficients were obtained from statistical dose rates calculated by using the Monte Carlo method, with an assumed air/ground environmental setting. A simple $1 / \mathrm{r}^{2}$ relationship is assumed to extrapolate the dose rates for distances exceeding $1,000 \mathrm{~m}$. These coefficients are normalized so that the dose rate is set at the regulatory limit ${ }^{1}$ of $0.01 \mathrm{rem} / \mathrm{h}(10 \mathrm{mrem} / \mathrm{h})$ at $2 \mathrm{~m}$ from the side of the transport vehicle or from the cask edge $\left(r_{1}=0 \mathrm{~m}\right.$ in Figure 2.1). The normalized coefficients are listed in Table 2.1.

The coefficients are adjusted accordingly, when other dose rates are specified. At $1 \mathrm{~m}$ $(r=1)$, Equation 2.2 reduces to

$$
\log \left[\dot{D}_{i}(1)\right]=A_{0_{i}}
$$

The coefficient $A_{0 i}$ is actually the logarithm of the dose rate due to gamma $(\mathrm{i}=\mathrm{g})$ or neutron $(i=n$ ) radiation, which, in RISKIND, is derived from the total dose rate and the fraction due to gamma radiation:

$$
\begin{aligned}
& A_{0_{g}}=\log \left[f_{g} \dot{D}(1)\right], \text { (gamma) } \\
& A_{0_{n}}=\log \left[\left(1-f_{g}\right) \dot{D}(1)\right], \text { (neutron) }
\end{aligned}
$$

1 The $10 \mathrm{mrem} / \mathrm{h}$ limit at $2 \mathrm{~m}$ is based on specifications of the Code of Federal Regulations (CFR), Title 10, Part 71 (NRC 1994), and Title 49, Part 173 (U.S. Department of Transportation [DOT] 1994). 
TABLE 2.1 Coefficients of the Fitted

Equations for Neutron and Gamma

Dose Rates from a Spent Fuel Cask, with Groundscattering

\begin{tabular}{ccc}
\hline Coefficients & $\begin{array}{c}\text { Gamma } \\
(\mathrm{i}=\mathrm{g})\end{array}$ & $\begin{array}{c}\text { Neutron } \\
(\mathrm{i}=\mathrm{n})\end{array}$ \\
\hline $\mathrm{A}_{0_{\mathrm{i}}}$ & 1.32271 & 1.29038 \\
$\mathrm{~A}_{1_{\mathrm{i}}}$ & -0.863263 & -0.97916 \\
$\mathrm{~A}_{2_{\mathrm{i}}}$ & -0.78497 & 0.855591 \\
$\mathrm{~A}_{3_{\mathrm{i}}}$ & 0.361914 & -3.77234 \\
$\mathrm{~A}_{4_{\mathrm{i}}}$ & -0.22023 & 4.27579 \\
$\mathrm{~A}_{5_{\mathrm{i}}}$ & 0.094219 & -2.36094 \\
$\mathrm{~A}_{6_{\mathrm{i}}}$ & -0.015457 & 0.650231 \\
$\mathrm{~A}_{3_{\mathrm{i}}}$ & -0.000746 & -0.072219 \\
\hline
\end{tabular}

Note: The dose rate is normalized to $10 \mathrm{mrem} / \mathrm{h}$ at $2 \mathrm{~m}$ from the cask surface.

Source: Chen and Yuan (1988). Extrapolation beyond $1,000 \mathrm{~m}$ is assumed to follow the $1 / r^{2}$ relationship.

where

$$
\begin{aligned}
& \dot{D}(1)=\text { total dose rate }(\mathrm{mrem} / \mathrm{h}) \text { at } 1 \mathrm{~m} \text { from the cask surface [TIDX]; and } \\
& f_{g}=\text { fraction of total dose rate due to gamma radiation [FRAD(1)]); the }
\end{aligned}
$$

\subsection{EXPOSURE AT FIXED DISTANCES}

For transportation vehicles at stops (Figure 2.2), radiation exposure concerns are usually limited to persons located at fixed distances from the cask. Such individuals would include truck drivers, train crews, inspectors, escorts, service attendants, and members of the public who are exposed at shipment stops or in traffic jams.

The radiation dose to an individual receptor exposed at a fixed distance can be calculated by

$$
D(r)=\left[\dot{D}_{g}(r)+\dot{D}_{n}(r)\right] S F(j) T(j),
$$


Population Subgroup

Individual

at Stop i

Receptor $\mathbf{j}$

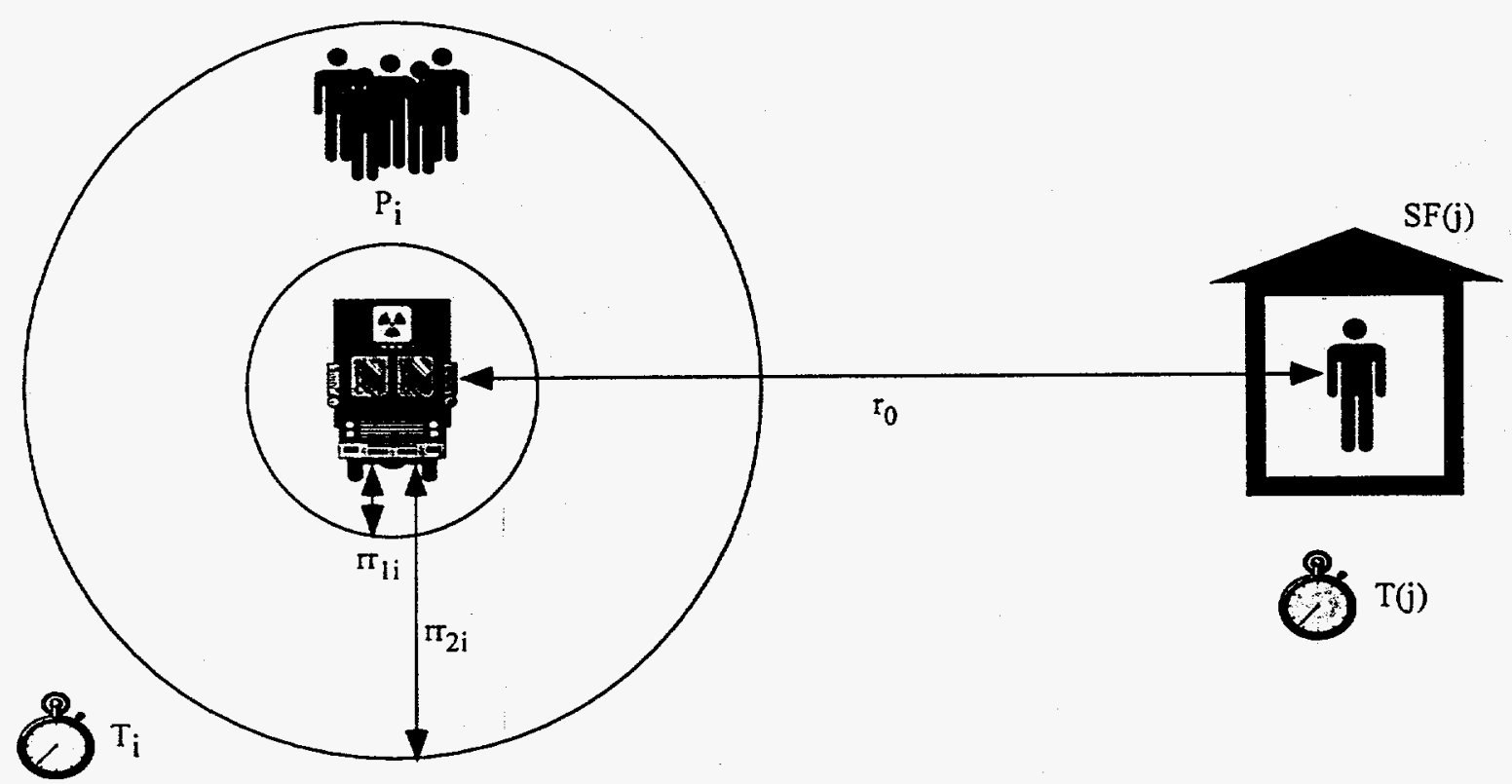

FIGURE 2.2 Schematic Diagram of External Exposures to Various Receptors from a Stationary Spent Fuel Shipment (Equation 2.5 for individuals, Equation 2.6 for a population subgroup).

where

$$
\begin{aligned}
D(r)= & \text { individual dose to receptor } j \text { at distance } r \text { (rem); } \\
r= & \text { distance in meters from the cask surface to receptor } j: r=r_{0}+r_{1}, \\
& \text { where } r_{0} \text { [DISTSTOP(j)] is the distance from the outer lateral } \\
& \text { surface of the vehicle to the receptor; and } r_{1}[\mathrm{TIOFF}] \text { is the distance } \\
& \text { between the cask surface and the outer lateral surface of the vehicle; } \\
S F(j)= & \text { shielding factor for receptor } j \text { for incident-free transportation: } 0= \\
& \text { full shielding, } 1=\text { no shielding (unitless) [set to the value in } \\
& \text { Table } 3.5 \text { as determined by ISHLT(j) (shelter type), which uses } \\
& \text { groundshine shielding factors]; and } \\
T(j)= & \text { time duration of exposure (h) for receptor } j[\mathrm{TSTP}(\mathrm{j})] .
\end{aligned}
$$

For exposure to a population subgroup, such as members of the public at shipment stops, the population density is assumed to be uniform within two concentric circles (representing minimum and maximum distances) around the cask. The dose received is

$$
D_{p s i}=2\left[P_{i} /\left(r_{2 i}^{2}-r_{1 i}^{2}\right)\right] N_{i} T_{i} \int_{r_{i i}}^{r_{2 i}} \dot{D}(r) r d r
$$


where

$$
\begin{aligned}
D_{p s i}= & \text { dose to population subgroup at stop } i \text { (person-rem); } \\
N_{i}= & \text { number of times at stop } i[\mathrm{NSTP}(\mathrm{i})] ; \\
P_{i}= & \text { number of persons at stop } i[\mathrm{PSTP}(\mathrm{i})] \\
r_{1 i}= & \text { minimum distance in meters from the cask surface at stop } i: r_{1 i}= \\
& r r_{1 i}+r_{1}, \text { where } r r_{1 i}[\mathrm{DSTP}(1, \mathrm{i})] \text { is the distance from the outer lateral } \\
& \text { surface of the vehicle; and } r_{1}[\mathrm{TIOFF}] \text { is the distance between the } \\
& \text { cask surface and the outer lateral surface of the vehicle }(\mathrm{m}) ; \\
r_{2 i}= & \text { maximum distance in meters from the cask surface at stop } i: r_{2 i}= \\
& \quad r r_{2 i}+r_{1}, \text { where } r r_{2 i}[\mathrm{DSTP}(2, \mathrm{i})] \text { is the distance from the outer lateral } \\
& \text { surface of the vehicle; and } r_{1}[\mathrm{TIOFF}] \text { is the distance between the } \\
& \text { cask surface and the outer lateral surface of the vehicle }(\mathrm{m}) ; \text { and }
\end{aligned}
$$

\subsection{EXPOSURE FROM A PASSING SHIPMENT}

An off-link individual (e.g., roadside resident) will experience a changing exposure field that is dictated by the constantly changing distance between a passing shipment vehicle and the individual, as shown in Figure 2.3. The total dose, $D(x)$, received by an individual at the nearest distance $x$ from the passing shipment is calculated by the integration of the dose rate, $\dot{D}(r)$, over the total exposure period:

$$
D(x)=2 S F(j) \int_{t=0}^{\infty} \dot{D}(r) d t
$$

From the relationship $y=v t$ (speed $\times$ traveling time), Equation 2.7 becomes

$$
D(x)=K_{0} S F(j) \frac{2}{v} \int_{0}^{\infty} \dot{D}(r) d y
$$

where

$$
\begin{aligned}
D(x)= & \text { total dose to receptor } j \text { at distance } x \text { (rem); } \\
x= & \text { nearest distance }(\mathrm{m}) \text { of receptor } j \text { to passing shipment [DISTPASS }(\mathrm{j})] \\
r= & \text { distance to cask surface }(\mathrm{m}) \text { given by } \\
& \quad r=\left[\left(x+r_{1}\right)^{2}+y^{2}\right]^{1 / 2} ; \\
r_{1}= & \text { distance between the cask surface and the outer lateral surface of the vehicle } \\
& (\mathrm{m})[\text { TIOFF }] \\
v= & \text { vehicle speed }(\mathrm{km} / \mathrm{h})[\text { SPEED }] ;
\end{aligned}
$$




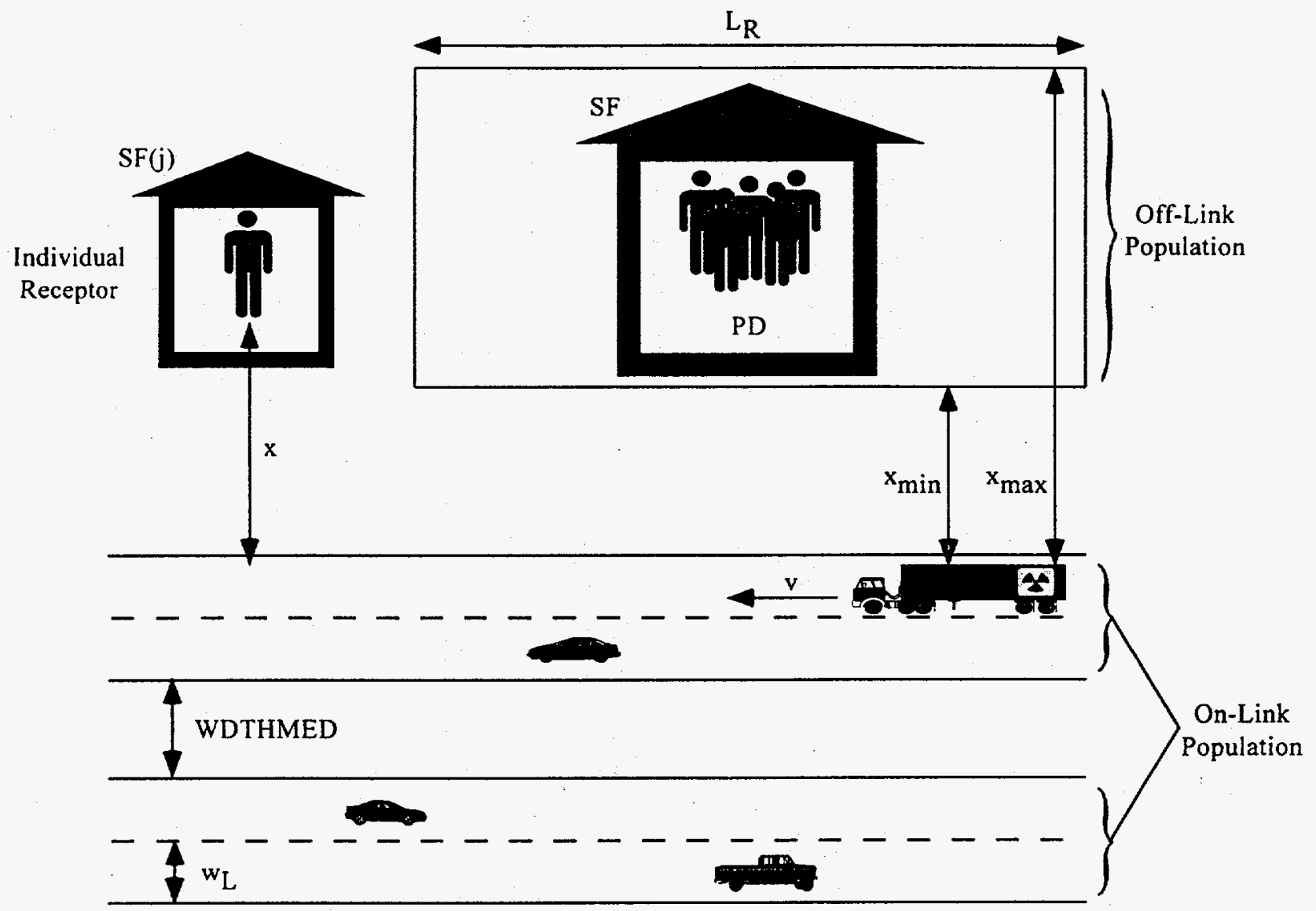

FIGURE 2.3 Schematic Diagram of External Exposures to Various Receptors from a Moving Spent Fuel Shipment (Equation 2.12 for individuals, Equations 2.14 and 2.16 for population groups)

$$
\begin{aligned}
& K_{0}=\text { unit conversion constant }\left(10^{-3} \mathrm{~km} / \mathrm{m}\right) ; \text { and } \\
& d y=v d t, \text { the distance traveled in time } d t(\mathrm{~m})
\end{aligned}
$$

Equation 2.8 can be rewritten (NRC 1977b) by substituting for $y$, according to Equation 2.9:

$$
D(x)=K_{0} \frac{2}{v} I(x),
$$

where

$$
I(x)=\int_{x}^{\infty} \dot{D}(r) \frac{r}{\sqrt{r^{2}-x^{2}}} d r
$$

Two different population groups are exposed during transit of a shipment, those off-link (e.g., roadside residents) and on-link (i.e., drivers and passengers). Figure 2.3 depicts the two groups and the relevant parameters for dose estimation. The off-link population dose from a passing shipment is an extension of Equation 2.10 to cover an area with a uniform population 
density from the minimum distance of the group $\left(x_{\min }\right)$ to the route, to a maximum distance from the route $\left(x_{\max }\right)$ for a distance $L_{R}$ :

$$
D_{\text {off }}=\left[\left(S F F_{i n}+\left(1-F_{i n}\right)\right] P D L_{R} K_{0} \frac{2}{v} \int_{x_{\min }}^{x_{\max }} I(x) d x\right.
$$

where

$$
\begin{aligned}
D_{\text {off }}= & \text { dose (person-rem) to off-link population in a given area from a } \\
& \text { passing shipment; } \\
F_{\text {in }}= & \text { fraction of people indoors while shipment passes by the area [RFIE]; } \\
P D= & \text { population density for the area (persons } \left./ \mathrm{km}^{2}\right) \text { [POPD]; } \\
L_{R}= & \text { length of the route along the area }(\mathrm{km})[\mathrm{SHIPDIST}] \\
x_{\min }= & \text { nearest distance of area to shipment route }(\mathrm{km})[\mathrm{XPZ}(1)] ; \\
x_{\max }= & \text { farthest distance of area to shipment route }(\mathrm{km})[\mathrm{XPZ}(2)] ; \text { and } \\
S F= & \text { shielding factor: } 0=\text { full shielding, } 1=\text { no shielding: } \\
& S F=\sum_{i=1 \text { to } 5} F r_{i} S F_{i} ;
\end{aligned}
$$

$F r_{i}=$ fraction of indoor population located in a given shelter type $i$ [WSHLT(i)]: frame house $(i=1)$, office building $(i=2)$, brick house $(i=3)$, automobile $(i=4)$, or other $(i=5$, user-defined); and

$S F_{i}=$ shielding factor for each shelter type $i$, values from (NRC 1975), userdefined type variable is SHLDVAL.

The dose is computed for three groups in on-link dose estimation. The estimated dose for those persons traveling in the same direction as the shipment is calculated for two groups - those traveling in adjacent lanes to the shipment and those in the same lane (in front and behind) as the shipment. The third group consists of those traveling in the opposing direction of the shipment.

For those persons traveling in the same direction and in the same lane as the shipment, the dose is estimated by

$$
D_{o n}=P D_{o n} L K K_{0}\left(\frac{2}{v}\right) w_{L} \int_{d_{0}}^{\infty} \dot{D}(r) d r
$$

where

$$
\begin{gathered}
D_{o n}=\text { dose (person-rem) to persons sharing the route (on-link population); } \\
P D_{o n}=\text { on-link population density for the route (persons } / \mathrm{km}^{2} \text { ) given by }
\end{gathered}
$$




$$
\begin{aligned}
& P D_{o n}=\frac{P_{v e h} T D K_{0}}{v w_{L}} ; \\
P_{v e h}= & \text { number of persons per vehicle [PPVH]; } \\
T D= & \text { traffic density for one lane (vehicles } / \mathrm{h}) \text { [TRAF_DEN]; } \\
L= & \text { length of travel assumed to be } 1 \mathrm{~km} ; \\
w_{L}= & \text { lane width (m) }[\mathrm{RDWTH}] \\
d_{0}= & 2 \text { m; and } \\
\dot{D}(r)= & \text { total dose rate (rem } / \mathrm{h}) \text { at a distance } r \text { meters from the cask surface, }
\end{aligned}
$$

For truck transport, the dose to an exposed population in lanes adjacent to the shipment traveling in the same direction and to those traveling in the opposite direction is calculated in a manner similar to the off-link population. The truck shipment is assumed to travel in the rightmost traffic lane. An average population density over the road width is assumed, and the dose is estimated by integration over the appropriate portion of the roadway:

$$
D_{o n}=P D_{o n} L K_{0} \frac{2}{v} \int_{x_{1}}^{x_{2}} I(x) d x,
$$

where

$$
\begin{aligned}
D_{o n}= & \text { dose to on-link population in adjacent lanes or opposing traffic } \\
& \text { (person-rem); } \\
x_{1}= & \text { nearest distance to traffic of interest }(\mathrm{m}) \text {, assumed to be } 1 \mathrm{~m} \text { for } \\
& \text { adjacent lanes or, for opposing traffic, the distance across the } \\
& \text { adjacent lanes and any median separating traffic traveling in opposite } \\
& \text { directions }[1+(\mathrm{NUMLANES}-1) \times \mathrm{RDWTH}+\text { WDTHMED]; and } \\
x_{2}= & \text { farthest distance to traffic of interest }(\mathrm{m}) \text { : for adjacent traffic, } \\
& \mathrm{x}_{1}+(\text { NUMLANES }-1) \times \text { RDWTH; for opposing traffic, } \mathrm{x}_{1}+ \\
& \text { NUMLANES } \times \text { RDWTH. }
\end{aligned}
$$

For rail transport, the on-link dose estimate is for opposing traffic on neighboring tracks. 


\section{RADIOLOGICAL HAZARD FROM ACCIDENTS}

Accidents associated with the transport of SNF are very rare. The probability has been estimated (Saricks and Kvitek 1994) to be on the order of one incident per ten million miles of truck or rail shipment in the United States. In addition, SNF is shipped in NRC-certified, or equivalent, casks that meet the extremely stringent safety standards of 10 CFR 71 (NRC 1994). Thus, even in the event of an accident, the robustness of such casks would adequately protect the health and safety of the public. However, as in the case of other existing regulations, cask certification procedures are designed to provide protection against "design-basis" accidents, the majority of all potential accidents. No radioactive contents, or an insignificant amount, would be released as the result of a design-basis accident. This section addresses the hypothetical, including the exceedingly rare "beyond-design-basis," accidents that could potentially release SNF radioactive contents to the atmosphere, thereby threatening public health and safety.

The fuel assemblies used in commercial power reactors contain solid ceramic uranium oxide $\left(\mathrm{UO}_{2}\right)$ fuel pellets. During reactor operation, the fission of uranium fuel creates a number of radioactive products. Physically, most of the radioactive material remains in solid form within the pellets, although the pellets may exhibit some degree of fracturing. A small fraction of the fission products, however, is in gaseous or volatile form. The radiological hazards that could conceivably be created by this material can occur through two distinct mechanisms: (1) a release of material from a damaged cask, or (2) an increase in the external radiation level emanating from material within a damaged cask. Material releases can occur in gaseous, volatile, or solid form. Significant hazards to humans can result from inhalation of the released material, ingestion of contaminated food, and exposure to external radiation from a passing cloud of the material or from the material deposited on the ground. Increased radiation levels from material still within the cask could occur as the result of voids in the cask shielding, which can result from mechanical forces or temperatures high enough to cause shield materials to melt. The following sections describe the methods used to assess these potential radiological hazards. Section 3.1 describes the cask accident response release model, Section 3.2 the accident release model, Section 3.3 the dose calculation model for individuals, and Section 3.4 the dose model for the collective local population. Further discussions on the models and the relevant input parameters can be found in Appendix G.

\subsection{ACCIDENT RESPONSE MODEL}

The response of SNF casks under a range of highway and railway accident conditions has been investigated by LLNL for the NRC. The results of this study are provided in detail in the NRC modal study (LLNL 1987). In the NRC modal study, all potential damage to a shipping cask during an accident is categorized according to two principal variables: the cask structural and thermal responses induced by cask impact and fire, respectively. Twenty cask response 
regions (or categories) based on varying levels of cask strain and temperature are categorized to represent the entire spectrum of transportation accidents. The regions range from those with high probability and low impacts to those with low probability and higher impacts. Figure 3.1 shows the cask response regions and the conditional probabilities of occurrence for combined mechanical and thermal loads [FSEV(i) for each response region $i$ ] should an accident occur.

The most important accident conditions used to define the mechanical loads imposed on a cask during an accident are those associated with various physical impacts. Because of the large weight, hardness, and rigidity of spent fuel casks, loads caused by crushing, projectiles, or other mechanisms have been demonstrated to be far less damaging than loads caused by impacts with hard, massive objects. As in any impact involving a motor vehicle or train, the damage sustained would depend on vehicle speed, angle of impact, hardness of the object struck, and orientation of the vehicle and object at the time of impact.

The temperature of an accident-generated fire is the most important consideration in assessing potential cask functional degradation. The cumulative heat affecting a cask depends not only on the temperature and duration of the fire but also on the extent to which the cask is exposed. Data on fire temperatures and durations are not readily available in accident records; however, conservative estimates of fire temperatures and durations can be calculated on the basis of pertinent information about the accident, such as the maximum fuel volume carried by a typical truck and the nature of the product being shipped. Another accident condition required to describe cask response is the location of a cask relative to the fire during an accident. Appendix E presents the method used in RISKIND for estimating the cask response from usersupplied accident scenarios.

\subsection{ACCIDENT RELEASE MODEL}

According to the NRC modal study (LLNL 1987), three mechanisms are necessary for establishing a release path from the spent fuel to the environment: (1) diffusion from cracked fuel pellets, (2) a leak from a breach of the fuel rod cladding, and (3) a leak through deteriorated cask seals. Before radioactive material is released into the cask cavity, the cladding must be breached during an accident as a result of high impact or high temperature. The percentage of fuel rods that may be breached under various impact and fire conditions in a transportation accident is estimated in the NRC modal study. After a fuel rod is breached, radioactive gases, volatiles, and solids can potentially escape into the cask cavity. Only rod burst and oxidation were considered significant release mechanisms in the NRC modal study. It was conservatively assumed that all the released materials in the cask cavity would be released to the environment if a leak path developed in the containment (LLNL 1987). A leak path is assumed to occur for any transportation accident resulting in a maximum strain in the inner containment shell greater than $0.2 \%$, or in a lead midlayer thickness temperature exceeding $500^{\circ} \mathrm{F}$. 


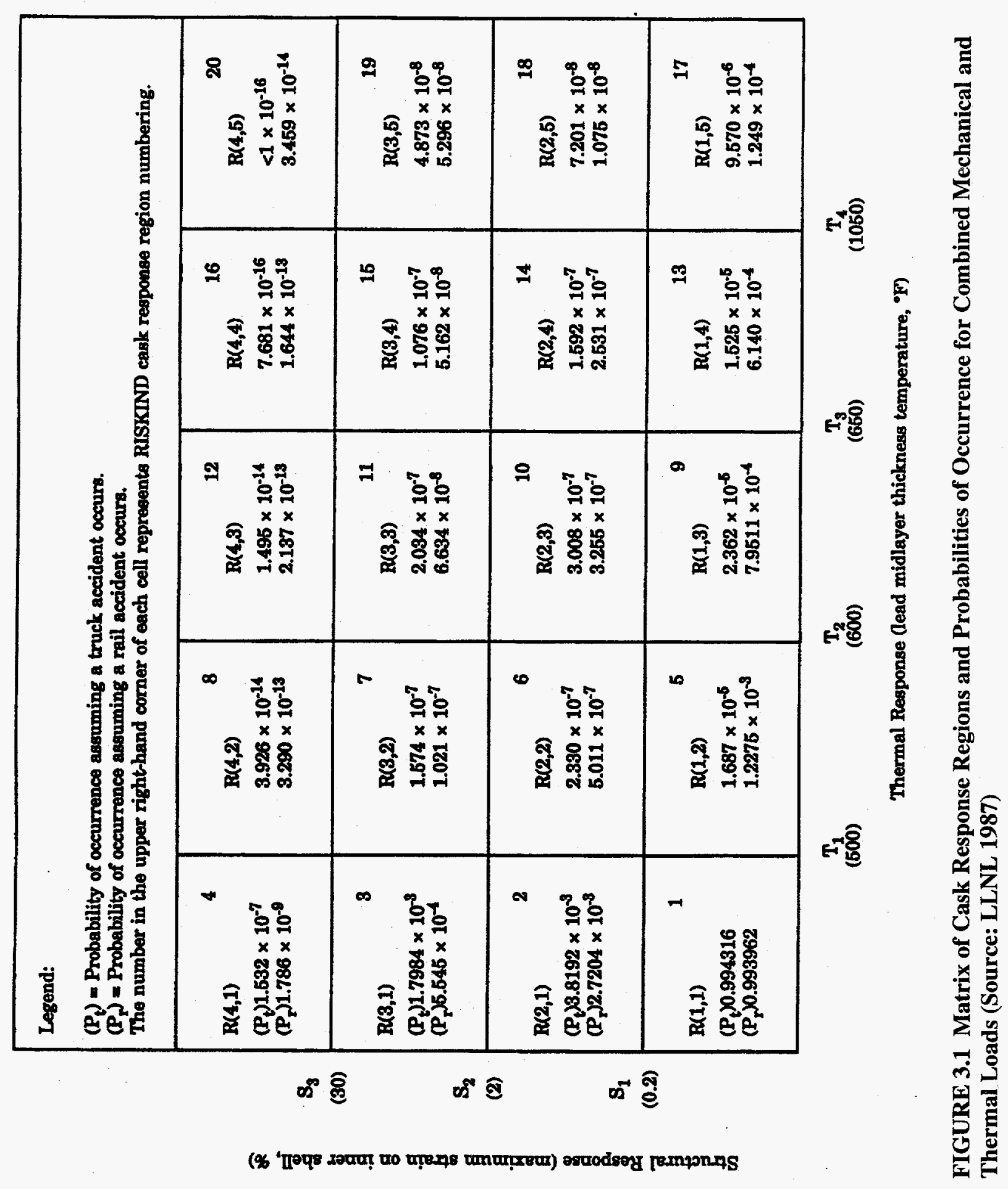


On the basis of the above assumptions, the radionuclide fractions released and dispersed to the atmosphere are presented in Table 3.1 for five types of radionuclides [NUTYPE(5)] and the 20 modal study cask response regions. Radionuclides are grouped by physical and chemical behavior: particulates; ruthenium, cesium, and iodine isotopes (considered to be in the form of vapors); and noble or inert gases. The total release to the environment for a radionuclide in a dispersed, respirable form is given by

$$
Q_{0_{i}}=Q_{i} F_{F A I L_{j}} F_{R E L_{j k}} F_{D I S P_{j k}},
$$

where

$$
\begin{aligned}
& Q_{0_{i}}= \text { initial amount of radionuclide } i \text { released }(\mathrm{Ci}) ; \\
& Q_{i}= \begin{array}{l}
\text { radionuclide } i \text { inventory amount in the spent fuel cask, which can } \\
\text { also be used for total shipment inventory of a multiple package } \\
\text { shipment (Ci); }
\end{array} \\
& F_{F A I L_{j}=}=\begin{array}{l}
\text { fraction of failed rods in the spent fuel cask that can also be used } \\
\text { for fraction of failed packages in a multiple package shipment for } \\
\text { other radioactive materials (unitless) [FAILS(j) for accident } \\
\text { response region } j] ;
\end{array} \\
& F_{R E L j k}=\begin{array}{l}
\text { fraction of inventory released from failed rods to the cask cavity, } \\
\text { which can also be used for the fraction released from the } \\
\text { shipping package (unitless) [FRELS(j,k) for accident response }
\end{array} \\
& \text { region } j \text { for radionuclide type } k \text { ]; and } \\
& F_{D I S P_{j k}=} \begin{array}{l}
\text { fraction of released inventory dispersed to the atmosphere as a } \\
\text { respirable aerosol for accident response region } j \text { for radionuclide } \\
\text { type } k \text { (unitless) [FDISP(j,k)]. }
\end{array}
\end{aligned}
$$

Appendix A describes the SNF radionuclide inventory derived for use in RISKIND. The program can perform an assessment with up to 100 radionuclides. A screening method is available, as described in Appendix $\mathrm{C}$, to limit the analysis to the most radiologically significant radionuclides.

The release of radioactivity in the crud is treated separately in RISKIND because crud is a mixture of reactor coolant corrosion products that have deposited on the surfaces of fuel rods and can be released during a transportation accident without severe damage to the fuel rods or cladding. The approach used in RISKIND to estimate the crud spalled (broken off) from the fuel rods during an accident is based on the method of Sandoval et al. (1991) and is described in Appendix D. All of the spalled crud material is conservatively assumed to be released to the environment for all accident response regions except $R(1,1)$, for which no release is assumed because there is no leak path to the environment. 
TABLE 3.1 Radioactive Material Release Fractions from Accidents Occurring under Various Cask Response Regions

\begin{tabular}{|c|c|c|c|c|c|c|}
\hline \multirow{2}{*}{\multicolumn{2}{|c|}{ Cask Response Region }} & \multicolumn{5}{|c|}{ Release Fraction $^{\mathrm{c}}$} \\
\hline & & \multirow[b]{2}{*}{ Inert Gas } & \multicolumn{3}{|c|}{ Vapors } & \multirow[b]{2}{*}{ Particulates } \\
\hline Modal Study ${ }^{2}$ & RISKIND $^{\mathbf{b}}$ & & Iodine & Cesium & Ruthenium & \\
\hline $\mathrm{R}(1,1)$ & (1) & 0.0 & 0.0 & 0.0 & 0.0 & 0.0 \\
\hline $\mathrm{R}(1,2), \mathbf{R}(1,3)$ & $(5,9)$ & $9.9 \times 10^{-3}$ & $7.5 \times 10^{-5}$ & $6.0 \times 10^{-6}$ & $8.1 \times 10^{-7}$ & $6.0 \times 10^{-8}$ \\
\hline $\mathbf{R}(2,1), \mathbf{R}(2,2), \mathbf{R}(2,3)$ & $(2,6,10)$ & $3.3 \times 10^{-2}$ & $2.5 \times 10^{-4}$ & $2.0 \times 10^{-5}$ & $2.7 \times 10^{-6}$ & $2.0 \times 10^{-7}$ \\
\hline $\mathbf{R}(1,4), \mathbf{R}(2,4), \mathbf{R}(3,4)$ & $(13,14,15)$ & $3.9 \times 10^{-1}$ & $4.3 \times 10^{-3}$ & $2.0 \times 10^{-4}$ & $4.8 \times 10^{-5}$ & $2.0 \times 10^{-6}$ \\
\hline $\mathrm{R}(3,1), \mathrm{R}(3,2), \mathrm{R}(3,3)$ & $(3,7,11)$ & $3.3 \times 10^{-1}$ & $2.5 \times 10^{-3}$ & $2.0 \times 10^{-4}$ & $2.7 \times 10^{-5}$ & $2.0 \times 10^{-6}$ \\
\hline $\begin{array}{l}\mathrm{R}(1,5), \mathrm{R}(2,5), \mathrm{R}(3,5), \\
\mathrm{R}(4,5), \mathrm{R}(4,1), \mathrm{R}(4,2), \\
\mathrm{R}(4,3), \mathrm{R}(4,4)\end{array}$ & $\begin{array}{c}(17,18,19 \\
20,4,8 \\
12,16) \\
\end{array}$ & $6.3 \times 10^{-1}$ & $4.3 \times 10^{-2}$ & $2.0 \times 10^{-3}$ & $4.8 \times 10^{-4}$ & $2.0 \times 10^{-5}$ \\
\hline
\end{tabular}

a $\mathrm{R}(\mathrm{N} 1, \mathrm{~N} 2)$ represents the NRC modal study designation of discrete severity (cask response) regions, with N1 representing the impact strain and $\mathrm{N} 2$ representing the temperature caused by fire (see Figure 3.1).

b The NRC modal study severity regions are represented in RISKIND by 20 discrete numbers (see Figure 3.1 ).

c The release fraction represents the fraction of the total fuel inventory in the cask that would be released into the atmosphere.

Source: LLNL (1987). 


\subsection{INDIVIDUAL DOSE MODEL}

RISKIND incorporates a standard Gaussian plume atmospheric dispersion model that also considers the effective emission height of a release (plume rise); corrects the wind speed according to height with a power law adjustment; and accounts for terrain height, the initial dispersion geometry of the waste package, and buoyancy-induced dispersion. Doses are calculated for individual exposure to external radiation from the shipping cask, the passing radioactive cloud following the accident, resuspended contamination, and radionuclides deposited on the ground; exposure from inhalation during the radioactive cloud passage following the accident; and exposure from ingestion of contaminated foodstuffs and water.

\subsubsection{Atmospheric Transport Model}

The atmospheric transport model used in RISKIND is a Gaussian puff dispersion model. Radionuclides released from a shipping cask are transported by the wind and are diffused as a result of atmospheric turbulence. The source must be described in terms of location and other physical parameters, type of radionuclide, and the amount released to the atmosphere. For individual receptors, the atmospheric transport model in RISKIND calculates concentrations in air at the specified downwind location for the five types of radionuclides identified in the NRC modal study: (1) particulate radionuclides; (2) ruthenium, (3) cesium, and (4) iodine vapors; and (5) inert gaseous radionuclides. RISKIND uses a plume-rise model developed by Briggs (1969) to estimate buoyancy-induced rise of the release, if applicable. An initial source dispersion parameter is used to model the source geometry of the release. Depending on circumstances, either the standard Pasquill-Gifford dispersion coefficients (Slade 1968; Eimutis and Konicek 1972) or the Briggs (1974) dispersion coefficients can be used. The former are suitable for ground-level releases; the latter are better for elevated releases. For vapor or particulate radionuclides, deposition of the plume content from the puff by dry and wet deposition is also considered for any user-specified receptor location. Both air and ground concentrations of radionuclides are calculated for the estimation of exposure via various pathways.

\subsubsection{Effective Release Height}

Material discharged to the atmosphere as a result of a transportation accident may rise above the release point as a result of thermal buoyancy. The thermal buoyancy is fire related in most accident cases. An effective release height $H$ is used in the atmospheric dispersion equations to account for the additional height of the release. The effective release height is the sum of the actual physical release height, $h$, and the thermally-induced plume rise, $\Delta h$, with an adjustment for terrain height:

$$
H=h+\Delta h-\left(1-P_{c}\right)\left[\min \left(h+\Delta h, E_{r}-E_{p}\right)\right],
$$


where

$$
\begin{aligned}
H= & \text { effective release height }(\mathrm{m}) ; \\
h= & \text { physical release height }(\mathrm{m})[\mathrm{HS}] \\
\Delta h= & \text { plume rise }(\mathrm{m})[\text { Equation } 3.3,3.4,3.5,3.6, \text { or } 3.7] \\
P_{c}= & \text { plume-path coefficient (unitless) }(\operatorname{Section} 3.3 .1 .1 .2) ; \\
E_{r}= & \text { receptor elevation }(\mathrm{m}) \quad[\mathrm{XRECEP}(3, \mathrm{i}) \text { for individual } i, 0 \text { for } \\
& \text { population]; and } \\
E_{p}= & \text { release elevation, the reference point for the release height }(\mathrm{m})[0] .
\end{aligned}
$$

3.3.1.1.1 Plume Rise. Plume rise is estimated in RISKIND with the formulas derived by Briggs (1969) for buoyant plumes. The rise from thermal buoyancy is seen to be dependent on stability class, wind speed, and receptor distance. For stability classes A, B, C, and D, the plume rise is given by

$$
\begin{gathered}
\Delta h=\frac{1.6 F^{1 / 3} x^{2 / 3}}{u_{H}}, \text { for } x \leq 10 h ; \\
\Delta h=\frac{1.6 F^{1 / 3}(10 h)^{2 / 3}}{u_{H}}, \text { for } x>10 h ;
\end{gathered}
$$

where

$$
\begin{aligned}
F= & 3.7 \times 10^{-5} Q_{\mathrm{h}}\left(\mathrm{m}^{4} / \mathrm{s}^{3}\right), \\
Q_{h}= & \text { heat flux from radionuclide release area (cal/s) [HEATF(i) for } \\
& \text { accident response region } i], \\
x= & \text { downwind receptor distance from release point }(m)[\mathrm{XRECEP}(1, \mathrm{i}) \text { for } \\
& \text { individual receptor } i, \mathrm{XPZ}(1) \text { to } \mathrm{XPZ}(2) \text { for population], and }
\end{aligned}
$$

For stability classes $\mathrm{E}$ and $\mathrm{F}$, the plume rise is calculated according to

$$
\Delta h=\frac{1.6 F^{1 / 3} x^{2 / 3}}{u_{H}}, \text { for } x \leq 2.4 \frac{u_{H}}{\sqrt{s}}
$$

or

$$
\Delta h=2.9\left(\frac{F}{u_{H} s}\right)^{1 / 3}, \text { for } x>2.4 \frac{u_{H}}{\sqrt{s}},
$$


except when the wind is so light that the plume rises vertically. Under such conditions, the final plume rise is given by Briggs as

$$
\Delta h=\frac{5.0 F^{1 / 4}}{s^{3 / 8}}, \text { when } u_{H} \leq u_{t e s t},
$$

where

$$
\begin{aligned}
s & =\frac{g}{T_{a}}\left(\frac{\partial T_{a}}{\partial z}+\ell\right) \\
u_{\text {test }} & =0.195 F^{1 / 4} s^{1 / 8} \\
s & =\text { stability parameter [Equation } 3.8] \\
g & =\text { gravitational acceleration }\left(9.80665 \mathrm{~m} / \mathrm{s}^{2}\right), \\
T_{a} & =\text { ambient air temperature }(\mathrm{K})[\mathrm{TABK}] \\
\ell & =\text { normal adiabatic lapse rate of the atmosphere }(0.0098 \mathrm{~K} / \mathrm{m}), \\
\frac{\partial T_{a}}{\partial z}+\ell & =\text { potential temperature lapse rate }[0.002 \text { and } 0.035 \text { for stability } \\
z & =\text { classes E and F respectively], and }
\end{aligned}
$$

As recommended by Briggs, Equations 3.3 to 3.6 contain wind speed in the denominator, which would produce unrealistically high values for very low wind speeds. Because the Briggs equations are applicable only to windy conditions, a minimum wind speed of $0.1 \mathrm{~m} / \mathrm{s}$ is imposed in the above plume-rise calculations.

3.3.1.1.2 Terrain Height Adjustment. Rising terrain downwind from a transportation accident requires that the release height derived for flat terrain be adjusted accordingly. Stabilitydependent plume-path coefficients are used in RISKIND to estimate the effects of terrain elevation on the height of the plume centerline. The correction to the release height for downwind elevations is the third term in Equation 3.2, as given in Ross et al. (1985).

An increase in receptor elevation downwind effectively reduces the release height if the release height is greater than zero. This condition is embodied in the $\min \left(h+\Delta h, E_{r}-E_{p}\right)$ portion of Equation 3.2. On the other hand, the radioactive puff will not travel straight into a hillside but will follow air currents part way up the hill on its approach. The portion of Equation 3.2 with the plume-path coefficient, $\left(1-P_{c}\right)$, partially defines the amount of the effective reduction in release height and assures that the terrain height adjustment is not too extreme. For neutral and unstable conditions (stability classes $\mathrm{A}, \mathrm{B}, \mathrm{C}$, and $\mathrm{D}$ ), $P_{c}$ is set to 0.5 so 
that the puff height remains at least one-half the distance above ground as it would be if no adjustment were made. Similarly for stable conditions (stability classes $\mathrm{E}$ and $\mathrm{F}$ ), $P_{c}$ is set to 0.3 so that the puff height remains at least one-third the height above ground as it would be if no adjustment were made. A plume path coefficient of 1 represents a nonterrain-lifted plume.

\subsubsection{Wind Power-Law Adjustment}

For atmospheric dispersion calculations, the measured average wind speed at the effective release height, $u_{H}$, is not always available. RISKIND uses a power-law function with the following form to estimate the wind speed at the desired height:

$$
\frac{u_{H}}{u_{a}}=\left(\frac{H}{z_{a}}\right)^{p}
$$

where

$$
\begin{aligned}
& u_{a}=\text { wind speed at measurement height }(\mathrm{m} / \mathrm{s})[\mathrm{WSM}] \\
& z_{a}=\text { height of anemometer for wind speed measurement (m) }[\mathrm{ANH}], \text { and } \\
& p=\text { power for height ratio (unitless) [Table 3.2]. }
\end{aligned}
$$

The wind speed of $u_{a}$ from the measurement height $z_{a}$ is adjusted to the effective release height $H$ of the plume for the dispersion calculations. Values for the exponent $p$ were taken from Irwin (1979), as modified by Hanna et al. (1982), for the different population zones and stability classes.

\subsubsection{Atmospheric Dispersion}

For a puff generated from a point source with an effective release height $H$ above ground level, the Gaussian time-dependent dispersion equation is (Pasquill 1974)

$$
C_{a}(i, x, y, z, t)=\frac{Q_{x_{i}}}{(2 \pi)^{3 / 2} \sigma_{y}^{2} \sigma_{z}} \exp \left(\frac{-r^{2}}{2 \sigma_{y}^{2}}\right)\left[\exp \left(\frac{-(z-H)^{2}}{2 \sigma_{z}^{2}}\right)+\exp \left(\frac{-(z+H)^{2}}{2 \sigma_{z}^{2}}\right)\right]
$$

where

$$
\begin{aligned}
C_{a}(i, x, y, z, t)= & \text { air concentration of radionuclide } i \text { at } x, y, z \text { from a release at } \\
& 0,0, H \text { at time } t \text { after release }\left(\mathrm{Ci}^{3} / \mathrm{m}^{3}\right) ; \\
Q_{x_{i}}= & \text { depleted source strength of nuclide } i \text { at distance } x \\
& \text { [Equation 3.27]; } \\
\sigma_{y}= & \text { horizontal dispersion coefficient [Equation 3.46]; }
\end{aligned}
$$




$$
\begin{aligned}
\sigma_{z}= & \text { vertical dispersion coefficient [Equation 3.44]; } \\
r^{2}= & \left(x-u_{H}\right)^{2}+y^{2}, \text { assumes Gaussian symmetry, that is, } \\
& h_{x}=h_{y}\left(\mathrm{~m}^{2}\right) ; \\
x= & \text { downwind receptor distance from the release point (m) } \\
& {[\mathrm{XRECEP}(1, \mathrm{i}) \text { for individual receptor } i] ; } \\
y= & \text { crosswind receptor distance from the plume centerline (m) } \\
& {[\mathrm{XRECEP}(2, \mathrm{i}) \text { for receptor } i] ; } \\
u_{H}= & \text { average wind speed at the effective release height }(\mathrm{m} / \mathrm{s}) \\
& {[\text { Equation. } 3.10] ; } \\
t= & \text { time following accidental release(s); and } \\
H= & \text { effective release height }(\mathrm{m}) \text { [Equation } 3.2] .
\end{aligned}
$$

The ground-level air concentration $\left(\mathrm{Ci} / \mathrm{m}^{3}\right)$ for a discrete puff is obtained by setting $z=0$ in Equation 3.11.

$$
C_{a}(i, x, y, 0, t)=\frac{2 Q_{x_{i}}}{(2 \pi)^{3 / 2} \sigma_{y}^{2} \sigma_{z}}\left\{\exp -\left(\frac{r^{2}}{2 \sigma_{y}^{2}}+\frac{H^{2}}{2 \sigma_{z}^{2}}\right)\right\}
$$

As a conservative measure, the receptor is assumed to be located downwind of the plume throughout the entire course of plume passage; radionuclide decay is ignored during this time period. Thus, the time-integrated ground-level air concentration $\left(\mathrm{Ci}-\mathrm{s} / \mathrm{m}^{3}\right)$ from the time of release to infinity at the receptor location is used for the dose estimation and is calculated as

$$
\bar{C}_{a}(i, x, y)=\int_{0}^{\infty} C_{a}(i, x, y, 0, t) d t,
$$

TABLE 3.2 Estimates of the Power (p) in Equation 3.10 for Population Zones as a Function of Stability Class

\begin{tabular}{lccccccc}
\hline & \multicolumn{8}{c}{ Stability Class } \\
\cline { 2 - 7 } \multicolumn{1}{c}{$\begin{array}{c}\text { Population } \\
\text { Zone }\end{array}$} & A & B & C & D & E & F \\
\hline & & & & & & \\
Rural & 0.07 & 0.07 & 0.10 & 0.15 & 0.35 & 0.55 \\
Suburban/urban & 0.15 & 0.15 & 0.20 & 0.25 & 0.40 & 0.60 \\
\hline
\end{tabular}


which can be shown to be (Slade 1968)

$$
\bar{C}_{a}(i, x, y)=\frac{Q_{x_{i}}}{\pi \sigma_{y} \sigma_{z} u_{H}}\left[\exp -\left(\frac{y^{2}}{2 \sigma_{y}^{2}}+\frac{H^{2}}{2 \sigma_{z}^{2}}\right)\right],
$$

where $Q_{x_{i}}$ is the initial source term for radionuclide $i$, corrected for wet and dry deposition from the puff (Equation 3.27).

\subsubsection{Plume Reflection}

The existence of a stable air layer at higher altitudes under unstable and neutral atmospheric conditions affects the atmospheric dispersion at great distances from the release point. The upward dispersion of the plume is eventually restricted when the plume encounters an elevated stable layer (or lid) or a mixing height at some height $L$. In RISKIND, the plume is assumed to be reflected by this stable layer at these distances. With vertical distribution limited by reflections, Equation 3.14 becomes

$$
\bar{C}_{a}(i, x, y)=\frac{Q_{x_{i}}}{\sqrt{2 \pi} \sigma_{y} u_{H} L} \exp -\left(\frac{y^{2}}{2 \sigma_{y}^{2}}\right),
$$

where

$L=$ mixing layer height sometimes referred to as lid height (m) [DMIX].

The following conditions (Powell et al. 1979) are used to determine which of these two equations, Equation 3.14 or 3.15 , is used for the dispersion calculation.

Equation 3.14 is used for distances where $\sigma_{z}$ is small compared to $L$, when

$$
\frac{\sigma_{z}}{L} \leq \frac{\sqrt{1-\frac{H}{L}}}{1.2}
$$

Equation 3.15 is used when $\sigma_{z}$ is of the same order as $L$ and a uniform distribution can be assumed, when

$$
\begin{gathered}
(1) 0 \leq H / L<0.5, \text { and } \\
\frac{\sigma_{z}}{L} \geq-2.37\left(\frac{H}{L}\right)^{2}+0.489\left(\frac{H}{L}\right)+0.756
\end{gathered}
$$


or

$$
\begin{gathered}
\text { (2) } 0.5 \leq H / L<1.0 \text {, and } \\
\frac{\sigma_{z}}{L} \geq-2.37\left(\frac{H}{L}\right)^{2}+4.25\left(\frac{H}{L}\right)-1.13
\end{gathered}
$$

At downwind distances between the no-mixing (Equation 3.16) and the total-mixing (Equations 3.17 and 3.18 ) conditions, the concentration is determined by a linear interpolation between Equations 3.14 and 3.15 .

\subsubsection{Depletion Correction and Ground Contamination}

As a radioactive plume travels downwind, its radionuclide content decreases as the result of ground deposition. Two deposition mechanisms, dry and wet, account for this radionuclide depletion from the plume. This section describes the methods used in RISKIND for calculating plume depletion and ground contamination from radionuclide deposition.

3.3.1.5.1 Dry Deposition. With the exception of inert gases, all fission products released from a shipping cask will primarily be in particulate form. Unless the shipping casks are severely damaged, these particulates are generally released in small sizes (i.e., less than a few microns). The vertical movement of these small particles is largely dependent on the vertical turbulence and mean motion of the air; settling of the particles by gravity is minimal. Deposition of such small particles on the ground surface is the result of turbulent diffusion and Brownian motion. Chemical absorption, impaction, and other physical and chemical processes cause the material to be retained at the surface. Such a deposition mechanism depletes the amount of radioactivity in the plume, causing ground contamination, and thus affects the potential radiological hazards as the plume travels farther downwind. Radiological hazards to individuals occur by way of either direct exposure from the ground or indirect exposure via the ingestion of contaminated foodstuff.

Calculation of the dry deposition rate involves the concept of deposition velocity, that is, the ratio of the deposition rate to the air concentration expressed in units of velocity. The time-integrated ground surface concentration is given by

$$
C_{g}(i, x, y)=\bar{C}_{a}(i, x, y) V_{d_{j}},
$$

where

$$
\begin{aligned}
C_{g}(i, x, y)= & \text { initial ground concentration of radionuclide } i \text { at receptor } \\
& \text { location } x, y \text { after plume passage }\left(\mathrm{Ci} / \mathrm{m}^{2}\right)
\end{aligned}
$$




$$
\begin{aligned}
& \bar{C}_{a}(i, x, y)=\text { time-integrated ground-level air concentration }\left(\mathrm{Ci}-\mathrm{s} / \mathrm{m}^{3}\right) \\
& \text { [Equation } 3.14 \text { or 3.15], and } \\
& V_{d_{j}}=\text { deposition velocity }(\mathrm{m} / \mathrm{s}) \text { [VDEPNUC }(\mathrm{j}) \text { for nuclide class } j \text { ]. }
\end{aligned}
$$

The deposition velocity is determined from either field or laboratory measurements of air and ground concentrations.

When plume depletion by dry deposition is considered, the initial source term, $Q_{0_{i}}$ at the release point can be replaced by a depleted source term $Q_{x_{i}}$ along the downwind sector. In this approach, known as the source depletion model, it is assumed that the depletion reduces only the effective source strength and that the vertical Gaussian profile remains unchanged. In this derivation, the total activity has been conserved.

The reduced source strength, $Q_{x_{i}}$, as the result of deposition is calculated from the following equation (Slade 1968):

$$
Q_{x_{i}}=Q_{0_{i}} \exp \left[-\frac{V_{d_{j}}}{\left(\frac{\pi}{2}\right)^{1 / 2} u_{H}} \int_{0}^{x} F(x) d x\right],
$$

where

$$
\begin{aligned}
Q_{x_{i}}= & \text { depleted source strength of nuclide } i \text { at distance } x(\mathrm{Ci}), \\
Q_{0_{i}}= & \text { initial amount of radionuclide } i \text { released (Ci) [Equation 3.1], } \\
F(x)= & \text { Equation } 3.21 \text { or } 3.22(1 / \mathrm{m}), \text { and } \\
u_{H}= & \text { average wind speed at effective release height }(\mathrm{m} / \mathrm{s}) \\
& \text { [Equation } 3.10] .
\end{aligned}
$$

At downwind distances not affected by the presence of a mixing layer,

$$
F(x)=\frac{\exp \left(\frac{-H^{2}}{2 \sigma_{z}^{2}}\right)}{\sigma_{z}},
$$

where

$$
\begin{aligned}
H & =\text { effective release height (m) [Equation 3.2], and } \\
\sigma_{z} & =\text { vertical dispersion coefficient [Equation 3.44]. }
\end{aligned}
$$


At downwind distances where total mixing by the presence of a mixing layer can be assumed (Powell et al. 1979),

$$
F(x)=\frac{1}{L}
$$

where

$$
L=\text { mixing layer height sometimes referred to as lid height (m) [DMIX]. }
$$

At downwind distances between the no-mixing (Equation 3.16) and total-mixing (Equations 3.17 and 3.18) conditions, $F(x)$ is determined by a linear combination of Equations 3.21 and 3.22. The integral expressions in Equation 3.20 are evaluated numerically in RISKIND with a Simpson's rule subroutine.

3.3.1.5.2 Wet Deposition. Radionuclides can also be removed from a plume by rain or snowfall. In wet deposition, the depletion mechanism of radionuclides is such that the plume is "washed out" by rain or snow. Thus, the wet deposition rate is dependent on the total amount of radioactivity contained in the plume, in contrast to dry deposition for which the depletion is closely related to the air concentration at ground level. The fraction of material removed per unit time by wet deposition is known as the "washout coefficient," $V_{w}$, and is defined as follows:

$$
V_{w}=-\frac{1}{C_{a}} \frac{d C_{a}}{d t}
$$

where

$$
\begin{aligned}
& V_{w}=\text { washout coefficient }(1 / \mathrm{s}), \text { and } \\
& C_{a}=\text { local air concentration }\left(\mathrm{Ci} / \mathrm{m}^{3}\right) .
\end{aligned}
$$

Calculated and measured values of the washout coefficient range from about $1.0 \times 10^{-5}$ to $1.0 \times 10^{-2}$ per second (Ritchie et al. 1978; McMahon and Dennison 1979). The value of the washout coefficient increases with an increasing rainfall rate and is linearly dependent on the rainfall rate:

$$
V_{w}=W_{C} R \text {, }
$$

where

$$
\begin{aligned}
W_{C}= & 1.0 \times 10^{-3}(1 / \mathrm{s})(\mathrm{mm} / \mathrm{h})^{-1} \text { for stability classes } A \text { to } \mathrm{D} \text { and } 1.0 \times 10^{-4} \\
& (1 / \mathrm{s})(\mathrm{mm} / \mathrm{h})^{-1} \text { for stability classes } \mathrm{E} \text { and } \mathrm{F}[\text { Ritchie et al. } 1978], \text { and } \\
R= & \text { rainfall rate }(\mathrm{mm} / \mathrm{h})[\mathrm{RAIN}] .
\end{aligned}
$$


The ground concentration in the precipitation region is given by (Slade 1968):

$$
C_{W E T_{g}}(i, x, y)=\frac{Q_{W E T_{x i}} V_{w}}{\sqrt{2 \pi} \sigma_{y} u_{H}} \exp \left(\frac{-y^{2}}{2 \sigma_{y}^{2}}\right)
$$

where

$$
\begin{aligned}
C_{\text {WET }}(i, x, y)= & \text { initial ground concentration from wet deposition for } \\
& \text { nuclide } i \text { at location } x, y \text { after plume passage }\left(\mathrm{Ci} / \mathrm{m}^{2}\right) .
\end{aligned}
$$

The depleted source strength from wet deposition, assuming a steady rainfall rate and wind speed is given by

$$
Q_{W E T_{x_{i}}}=Q_{0_{i}} \exp \left(-\frac{V_{w} x}{u_{H}}\right) .
$$

For low rainfall rates (i.e., a few millimeters per hour), Equations 3.24 and 3.25 are adequate. For high rainfall rates, the redistribution of the deposited radioactivity from surface runoff should be taken into account while evaluating the ground contamination from washed activity. Such conditions are not accounted for in RISKIND.

3.3.1.5.3 Dry and Wet Deposition. Dry deposition is always considered in RISKIND. When wet deposition is also considered, the depleted source strength at a distance $x$ downwind becomes a function of both dry and wet deposition. The depleted source strength becomes a combination of Equations 3.20 and 3.26 and is calculated according to

$$
Q_{x_{i}}=Q_{0_{i}} \exp \left\{-\left[\frac{V_{w} x}{u_{H}}+\frac{V_{d_{j}}}{\left(\frac{\pi}{2}\right)^{1 / 2} u_{H}} \int_{0}^{x} F(x) d x\right]\right\} \text {. }
$$

Likewise, the initial ground concentration $\left(\mathrm{Ci} / \mathrm{m}^{2}\right)$ from wet and dry deposition for nuclide $i$ at location $x, y$ after plume passage becomes

$$
C_{g}(i, x, y)=C_{D R Y_{g}}(i, x, y)+C_{W E T_{g}}(i, x, y),
$$

and can be written as

$$
C_{g}(i, x, y)=\frac{Q_{x_{i}}}{\sqrt{\pi} \sigma_{y} u_{H}}\left[\frac{V_{w}}{\sqrt{2}}+\frac{V_{d_{i}}}{\sqrt{\pi} \sigma_{z}} \exp \left(\frac{-H^{2}}{2 \sigma_{z}^{2}}\right)\right] \exp \left(\frac{-y^{2}}{2 \sigma_{y}^{2}}\right),
$$


when the plume vertical distribution is not limited by a stable layer (Equation 3.16 holds), or as

$$
C_{g}(i, x, y)=\frac{Q_{x_{i}}\left(V_{w}+V_{d_{i}} / L\right)}{\sqrt{2 \pi} \sigma_{y} u_{H}} \exp \left(\frac{-y^{2}}{2 \sigma_{y}^{2}}\right),
$$

when there is uniform mixing between the ground and the mixing layer (Equation 3.17 or 3.18 holds).

Use of the above methodologies allows the total activity of the plume to be conserved when estimating risks.

\subsubsection{Mixing Height}

The value of the mixing height $(L)$ is either a direct input value (DMIX) for a userspecified weather condition or estimated from the annual average input values for morning and afternoon (Holzworth 1972). In the latter case, the mixing height is estimated from the following equation:

$$
L=\left\{\begin{array}{l}
1.5 L_{\mathrm{pm}} \text { for an extremely unstable atmosphere (stability class A) } \\
\left.0.5\left(L_{\mathrm{am}}+L_{\mathrm{pm}}\right) \text { for a neutral atmosphere (stability class } \mathrm{D}\right)
\end{array}\right.
$$

where

$$
\begin{aligned}
& L_{\mathrm{am}}=\text { mean annual morning mixing height }(\mathrm{m})[\mathrm{AMIX}], \text { and } \\
& L_{\mathrm{pm}}=\text { mean annual afternoon mixing height }(\mathrm{m})[\mathrm{PMIX}]
\end{aligned}
$$

For other unstable situations (stability classes B and C), $L$ is taken to be equal to $L_{\mathrm{pm}}$. The mixing height does not apply to stable atmospheric conditions.

\subsubsection{Meteorological Conditions}

As presented in the previous sections, the dispersion model in RISKIND requires the following meteorological data:

1. Stability class (A through F),

2. Wind speed $(\mathrm{m} / \mathrm{s})$,

3. Mixing height (m) (for stability classes A through D),

4. Ambient temperature $(\mathrm{K})$, and

5. Rainfall rate $(\mathrm{mm} / \mathrm{h})$. 
Either a single stability class and wind speed can be used, or joint-frequency data on weather conditions over a period of time (e.g., annual data) can be input manually or read from a STAR format data file.

The atmospheric stabilities are classified into six categories $(\mathrm{A}, \mathrm{B}, \mathrm{C}, \mathrm{D}, \mathrm{E}$, and $\mathrm{F}$ ) in order of increasing stability on the basis of criteria established by Pasquill (1974). The dispersion equations in the models used are generic to all stability categories and empirical in nature. For each stability category, a set of dispersion coefficients, $\sigma_{y}$ and $\sigma_{z}$, were derived for use in the equations.

For accidental releases at or near ground level, the values for $\sigma_{y}$ and $\sigma_{z}$ are initially calculated on the basis of the Pasquill-Gifford curves (Eimutis and Konicek 1972) and later adjusted for the initial dispersion geometry (Section 3.3.1.8) and buoyancy-induced dispersion (Section 3.3.1.9). The Pasquill-Gifford dispersion coefficients are calculated according to

$$
\sigma_{y}^{\prime}=\left(0.000246 \sigma_{\theta}^{2}+0.00576 \sigma_{\theta}+0.066\right) x_{Y e f f}^{0.9031},
$$

and

$$
\sigma_{z}=a x_{\mathrm{Zeff}}^{b}+c
$$

Table 3.3 contains the values for the unitless dispersion parameters $\sigma_{\theta}, a, b$, and $c$ as a function of stability class. The variables $x_{Y \text { eff }}$ and $x_{Z \text { eff }}$ are defined below.

Briggs (1974) developed formulas for the dispersion coefficients on the basis of data collected from elevated releases:

$$
\sigma_{y} \text { or } \sigma_{z}=a x_{\text {eff }}\left(1+b x_{e f f}\right)^{c} \text {, }
$$

where

$$
\begin{aligned}
& x_{Y e f f}=x+x_{Y v i r t} \\
& x_{\text {Zeff }}=x+x_{\text {Zvirt }} \\
& x_{\text {Yeff }}=\text { effective receptor distance downwind from virtual point source for } \\
& \text { horizontal dispersion coefficient calculation (m), } \\
& x_{y_{v i r}}=\text { distance from source location to virtual point source for horizontal } \\
& x_{\text {Zeff }}=\text { effective receptor distance downwind from virtual point source for }
\end{aligned}
$$


TABLE 3.3 Pasquill-Gifford Dispersion Parameters for Ground-Level Releases

\begin{tabular}{|c|c|c|c|c|c|}
\hline \multirow{2}{*}{$\begin{array}{c}\text { Applicable Range } \\
\text { (downwind distance, } \mathrm{m} \text { ) }\end{array}$} & \multirow{2}{*}{$\begin{array}{c}\text { Stability } \\
\text { Class }\end{array}$} & \multicolumn{4}{|c|}{ Coefficients } \\
\hline & & $\sigma_{\theta}$ & $\mathbf{a}$ & $\mathrm{b}$ & $\mathrm{c}$ \\
\hline \multirow[t]{6}{*}{$x>1,000$} & A & 25 & 0.00024 & 2.094 & -9.6 \\
\hline & B & 20 & 0.055 & 1.098 & 2.0 \\
\hline & $\mathrm{C}$ & 15 & 0.133 & 0.911 & 0.0 \\
\hline & $\mathrm{D}$ & 10 & 1.26 & 0.516 & -13.0 \\
\hline & $\mathrm{E}$ & 5 & 6.73 & 0.305 & -34.0 \\
\hline & F & 1.5 & 18.05 & 0.18 & -48.6 \\
\hline \multirow[t]{6}{*}{$100 \leq x \leq 1,000$} & A & 25 & 0.00066 & 1.941 & 9.27 \\
\hline & B & 20 & 0.0382 & 1.149 & 3.3 \\
\hline & $\mathrm{C}$ & 15 & 0.113 & 0.911 & 0.0 \\
\hline & D & 10 & 0.222 & 0.725 & -1.7 \\
\hline & $\mathrm{E}$ & 5 & 0.211 & 0.678 & -1.3 \\
\hline & $\mathrm{F}$ & 1.5 & 0.086 & 0.74 & -0.35 \\
\hline \multirow[t]{6}{*}{$x<100$} & A & 25 & 0.192 & 0.936 & 0.0 \\
\hline & B & 20 & 0.156 & 0.922 & 0.0 \\
\hline & $\mathrm{C}$ & 15 & 0.116 & 0.905 & 0.0 \\
\hline & $\mathrm{D}$ & 10 & 0.079 & 0.881 & 0.0 \\
\hline & $\mathrm{E}$ & 5 & 0.063 & 0.871 & 0.0 \\
\hline & $\mathrm{F}$ & 1.5 & 0.053 & 0.814 & 0.0 \\
\hline
\end{tabular}

Source: Data from Eimutis and Konicek (1972).

$x_{y_{\text {vir }}}=$ distance from source location to virtual point source for vertical dispersion coefficient calculation $(\mathrm{m}$ ) [see Section 3.3.1.8 on initial dispersion geometry; Equation 3.40 for Pasquill-Gifford coefficients and Equation 3.42 for Briggs coefficients].

In addition, Briggs coefficients have been derived for rural and urban population zones. The urban values are also used in suburban population zone calculations in RISKIND. See Table 3.4 for values of $a, b$, and $c$.

\subsubsection{Initial Dispersion Geometry}

The initial dispersion of the puff at the source is modeled by using a virtual point source as implemented by Petersen and Lavdas (1986). The size of the source is first estimated in the 
TABLE 3.4 Briggs Dispersion Coefficients for Elevated Releases

\begin{tabular}{|c|c|c|c|c|c|c|c|}
\hline \multirow[b]{3}{*}{ Weather Conditions } & \multirow{3}{*}{$\begin{array}{c}\text { Stability } \\
\text { Class }\end{array}$} & \multicolumn{6}{|c|}{$\sigma_{y}$} \\
\hline & & \multicolumn{3}{|c|}{ Rural } & \multicolumn{3}{|c|}{ Urban } \\
\hline & & $\mathbf{a}$ & $\mathrm{b}$ & c & $\mathrm{a}$ & $\mathrm{b}$ & c \\
\hline Extremely unstable & A & 0.22 & 0.0001 & -0.5 & 0.32 & 0.0004 & -0.5 \\
\hline Moderately unstable & $\mathrm{B}$ & 0.16 & 0.0001 & -0.5 & 0.32 & 0.0004 & -0.5 \\
\hline Slightly unstable & $\mathrm{C}$ & 0.11 & 0.0001 & -0.5 & 0.22 & 0.0004 & -0.5 \\
\hline Neutral & $\mathrm{D}$ & 0.08 & 0.0001 & -0.5 & 0.16 & 0.0004 & -0.5 \\
\hline Moderately stable & $\mathrm{E}$ & 0.06 & 0.0001 & -0.5 & 0.11 & 0.0004 & -0.5 \\
\hline \multirow[t]{3}{*}{ Very stable } & $\mathrm{F}$ & 0.04 & 0.0001 & -0.5 & 0.11 & 0.0004 & -0.5 \\
\hline & & \multicolumn{6}{|c|}{$\sigma_{z}$} \\
\hline & & \multicolumn{3}{|c|}{ Rural } & \multicolumn{3}{|c|}{ Urban } \\
\hline Weather Conditions & $\begin{array}{c}\text { Stability } \\
\text { Class }\end{array}$ & a & b & $\mathrm{c}$ & $\mathrm{a}$ & $\mathrm{b}$ & $c$ \\
\hline Extremely unstable & A & 0.20 & 0.0 & 0.0 & 0.24 & 0.001 & 0.5 \\
\hline Moderately unstable & B & 0.12 & 0.0 & 0.0 & 0.24 & 0.001 & 0.5 \\
\hline Slightly unstable & $\mathrm{C}$ & 0.08 & 0.0002 & -0.5 & 0.20 & 0.0 & 0.0 \\
\hline Neutral & $\mathrm{D}$ & 0.06 & 0.0015 & -0.5 & 0.14 & 0.0003 & -0.5 \\
\hline Moderately stable & $\mathrm{E}$ & 0.03 & 0.0003 & -1.0 & 0.08 & 0.00015 & -0.5 \\
\hline Very stable & $\mathrm{F}$ & 0.016 & 0.0003 & -1.0 & 0.08 & 0.00015 & -0.5 \\
\hline
\end{tabular}

Source: Briggs (1974).

form of initial values for $\sigma_{y}$ and $\sigma_{z}$. Since the dispersion equations are based on a point source model, these initial dispersion coefficient values are then used to back calculate the distance upwind from the source, which would correspond to an equivalent (virtual) point source. The distance that generates the initial value of a dispersion coefficient is called the virtual distance. The virtual distance is added to the distance of the receptor from the release before calculating the dispersion coefficients for that location, thereby adjusting for the initial size of the source.

For releases at high elevations, the initial dispersion usually has little influence on downwind concentrations. However, if the source is large enough or close enough to the ground, then the initial size of the release is important in determining ground-level concentrations near the source. For a cask near the ground, the initial horizontal dispersion coefficient is calculated according to (Martin 1979; Petersen and Lavdas 1986)

$$
\sigma_{y_{0}}=L_{\text {cask }} / 4.3
$$


where

$$
\begin{aligned}
\sigma_{y_{0}} & =\text { initial value for } \sigma_{y} \text { at the source location (m), and } \\
L_{\text {cask }} & =\text { horizontal length of the shipping cask (m) [HSIZE]. }
\end{aligned}
$$

The initial vertical dispersion parameter is estimated by (Martin 1979; Petersen and Lavdas 1986)

$$
\sigma_{z_{0}}=2 R_{\text {cask }} / 2.15
$$

where

$$
\begin{aligned}
\sigma_{z_{0}} & =\text { initial value for } \sigma_{z} \text { at the source location }(\mathrm{m}), \text { and } \\
R_{\text {cask }} & =\text { radius of the shipping cask }(\mathrm{m})[\mathrm{RSIZE}]
\end{aligned}
$$

These initial dispersion parameters are then used to estimate the virtual source location. Rearranging Equations 3.32 and 3.33, the virtual distances for Pasquill-Gifford coefficients are calculated as

$$
x_{Y_{v i r t}}=\left(\frac{\sigma_{y_{0}}}{0.000246 \sigma_{\theta}^{2}+0.00576 \sigma_{\theta}+0.066}\right)^{1 / 0.9031}
$$

where

$$
x_{v_{v i n}}=\text { virtual distance for } \sigma_{y}(\mathrm{~m})
$$

and

$$
x_{z_{\text {virt }}}=\left(\frac{\sigma_{z_{0}}-\mathrm{c}}{a}\right)^{1 / b}
$$

where

$$
x_{z_{\text {vin }}}=\text { virtual distance for } \sigma_{z}(\mathrm{~m})
$$

For Briggs dispersion coefficients (Equation 3.34), no simple analytical solution is available for solving $x$. A simple iterative method to reach convergence is used in RISKIND for estimating the virtual distances in this case. The equations used are

$$
x_{Y_{v i n}}=\frac{\sigma_{y_{0}}}{a\left(1+b x_{Y_{v i n}}\right)^{c}} \text {, }
$$

and 


$$
x_{z_{n i n}}=\frac{41}{a\left(1+b x_{Z_{n i n}}\right)^{c}} .
$$

This method of accounting for the cask size of a near-ground-level release gives reasonable concentration estimates at downwind distances greater than approximately five times the initial horizontal dimension of the cask.

\subsubsection{Buoyancy-Induced Dispersion}

Buoyancy-induced dispersion is considered in RISKIND because emitted plumes undergo a certain amount of growth during the plume-rise phase as a result of turbulent motions associated with plume release conditions and turbulent entrainment of ambient air. Pasquill (1976) suggests that this induced dispersion, $\sigma_{z b}$, can be approximated by the following equation:

$$
\sigma_{z b}=\frac{\Delta h}{3.5}
$$

where

$$
\sigma_{z b}=\text { buoyancy-induced vertical dispersion (m). }
$$

The effective dispersion coefficient used in RISKIND calculations can then be determined by adding variances such as

$$
\sigma_{z}=\left(\sigma_{z b}^{2}+\sigma_{z}^{2}\right)^{1 / 2}
$$

At the distance of final plume rise and beyond, $\sigma_{z b}$ becomes constant.

Because the plume can be assumed to be symmetrical about its centerline in the initial growth phases of release, the calculation assumes that buoyancy-induced dispersion in the horizontal direction is equal to that in the vertical direction:

$$
\sigma_{y b}=\frac{\Delta h}{3.5}
$$

where

$$
\sigma_{y b}=\text { buoyancy-induced vertical dispersion (m). }
$$

This expression is combined with that for dispersion resulting from ambient turbulence, in the same manner described above for the horizontal direction, to give the vertical dispersion coefficient used in the RISKIND calculations for estimating air and ground concentrations:

$$
\sigma_{y}=\left(\sigma_{y b}^{2}+\sigma_{y}^{\prime 2}\right)^{1 / 2}
$$


In general, buoyancy-induced dispersion has little effect on maximum concentrations unless the release height is small compared with the plume rise. Also, buoyancy-induced dispersion is most effective in simulating concentrations near plume centerlines close to the source, where treating the emission as a point source confines the plume to a volume much smaller than the actual plume.

\subsubsection{Environmental Pathway and Dosimetry Models}

Two basic elements are necessary to assess human health hazards from released radioactivity. First, the concentrations of radioactive material in the surrounding environment must be determined. Second, the pathways of exposure that should be considered must be selected. Figure 3.2 shows the environmental pathways following an accidental release and the potential exposure modes. For an accidental release over a short duration, such as that considered in RISKIND, the concentrations of contaminants along the dispersive paths generally build up to a maximum value shortly after the release and decrease steadily thereafter.

Adequate prediction of health hazards to an individual depends on an accurate description of the time-dependent behavior of contaminants in the environment. A small change in a time constant can significantly affect the magnitude of exposure. Following an airborne release of relatively short duration, radioactive material becomes airborne as the "radioactive cloud" is dispersed and diluted by turbulent diffusion. When the cloud passes over an area, the people occupying that area may be exposed to radiation emanating from the cloud and may also inhale radioactive material suspended in air.

In RISKIND, exposure resulting from the initial passing plume is categorized as shortterm because it is of relatively short duration, and the radioactive material is relatively concentrated. In addition to the exposure received from the passing plume, external exposure resulting from the loss of cask shielding may also contribute to short-term exposure. Section 3.3.2.1 describes modeling of short-term radiation exposure. Exposure to radionuclides depleted from the cloud is categorized as long-term because the ground-deposited contaminant may persist in the environment over a prolonged period of time following the initial release. In general, the radiological hazards to individuals tend to be lower from long-term exposures than short-term because the radionuclide concentrations in the environmental media are diluted further. However, the cumulative dose to the exposed individual over the long term could be potentially significant for cases in which no remediation is taken following an accident.

Several environmental pathways are identified for long-term exposures: exposure from the contaminated ground, inhalation of radioactive materials resuspended in the air, and ingestion of contaminated foodstuffs. In addition, initial deposition onto surface water bodies may also result in dose exposure via the drinking water pathway. Section 3.3.2.2 describes the models 


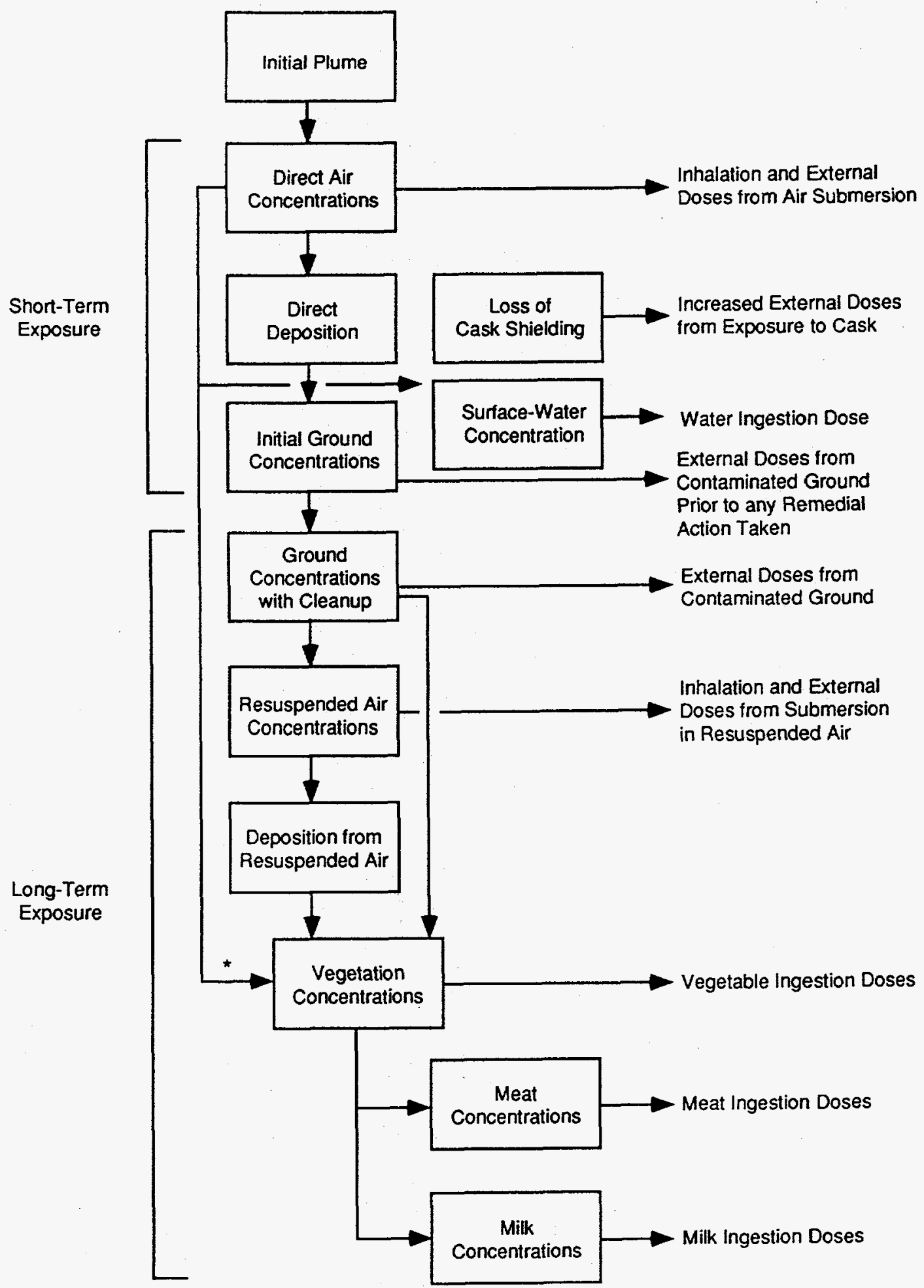

- Pathway is not applicable if food interdiction takes place.

FIGURE 3.2 Environmental Pathways and Exposure Modes for a Spent Nuclear Fuel Cask Accident 
used to calculate long-term environmental media concentrations. Once the radionuclide concentrations in the environmental media are determined, the doses to individuals can be calculated. Section 3.3.2.3 describes the modeling of the long-term radiation exposure.

Radiation doses are calculated only for individuals at each receptor location defined by the user. These receptor locations are normally defined to represent locations where potentially higher exposures are likely as the result of a release. The estimate of early health effects is dependent on the exposure information from short-term exposures; the estimate for latent health effects is dependent on the total dose from both short- and long-term exposures. A discussion of health effects models is presented in Section 4.

\subsubsection{Short-Term Exposure}

The model to calculate short-term radiation doses is described in this section. Such doses include external radiation from radionuclides in the passing cloud and radionuclides deposited on the ground, external exposure from loss of cask shielding, and internal radiation from inhaled radioactive material.

3.3.2.1.1 External Exposure from the Radioactive Cloud. External radiation doses received from a radioactive cloud are calculated as the product of the time-integrated air concentration and the cloud gamma DCF and take into account any shielding at the receptor location:

$$
D(j)_{A i r S T}=S F(j)_{A i r S T} K_{1} \sum_{i} \bar{C}_{a}(i, x, y) D C F_{A i r}(i)
$$

where

$$
\begin{aligned}
& D(j)_{A i r S T}=\text { dose to receptor } j \text { from inhalation during plume passage (rem); } \\
& D C F_{A i r}(i)=\text { dose conversion factor for air submersion for radionuclide } i \\
& \left(\mathrm{~Sv} / \mathrm{Bq}-\mathrm{s} / \mathrm{m}^{3}\right) \text {; } \\
& \bar{C}_{a}(i, x, y)=\text { time-integrated ground-level air concentration }\left(\mathrm{Ci}-\mathrm{s} / \mathrm{m}^{3}\right) \\
& \text { [Equation } 3.14 \text { or } 3.15 \text { ]; } \\
& K_{1}=\text { conversion factor, } 3.7 \times 10^{12} \mathrm{rem}-\mathrm{Bq} / \mathrm{Sv}-\mathrm{Ci} \text {; and } \\
& S F(j)_{A i r S T}=\text { short-term shielding factor for air immersion: } 0=\text { full } \\
& \text { shielding, } 1 \text { = no shielding (unitless) [set to the value in } \\
& \text { Table } 3.5 \text { as determined by ISHLT(j) (shelter type) for }
\end{aligned}
$$

The cloud DCFs are taken from External Exposure to Radionuclides in Air, Water, and Soil, EPA Federal Guidance Report No. 12 (FGR 12) (Eckerman and Ryman 1993). 
TABLE 3.5 Shielding Values for Routine and Accident Exposures

\begin{tabular}{lccc}
\hline & \multicolumn{3}{c}{ Shielding Factor } \\
\cline { 2 - 4 } \multicolumn{1}{c}{ Structure } & Inhalation & Cloudshine & Groundshine \\
\hline & & & \\
Outdoors & 1.0 & 1.0 & 1.0 \\
Frame house & 1.0 & 0.9 & 0.4 \\
Brick house & 1.0 & 0.6 & 0.2 \\
Office building & 1.0 & 0.2 & 0.02 \\
Car & 1.0 & 1.0 & 0.5 \\
\hline
\end{tabular}

Source: NRC (1975).

3.3.2.1.2 External Exposure from Ground-Deposited Radionuclides. A passing cloud of radioactive material can deposit its radioactive contents on the ground by dry and wet deposition, as described in Section 3.3.1.5. The deposited radioactive material can become a source of external radiation. The external exposure dose from radioactive material deposited on the ground is calculated by

$$
D(j)_{G n d S T}=S F(j)_{G n d S T} K_{2} \sum_{i} C_{g}(i, x, y) D C F_{G n d}(i) T_{E x t}(j)
$$

where

$$
\begin{aligned}
& D(j)_{G n d S T}=\text { short-term external dose for receptor } j \text { from ground-deposited } \\
& \text { radionuclide } i \text { (rem); } \\
& D C F_{G n d}(i)=\text { dose conversion factor for external radiation from the ground } \\
& \text { for radionuclide } i\left(\mathrm{~Sv} / \mathrm{Bq}-\mathrm{s} / \mathrm{m}^{2}\right) \text {; } \\
& K_{2}=\text { conversion factor, } 1.332 \times 10^{16} \mathrm{rem}-\mathrm{Bq}-\mathrm{s} / \mathrm{Sv}-\mathrm{Ci}-\mathrm{h} \text {; } \\
& S F(j)_{G n d S T}=\text { short-term shielding factor for external ground radiation: } \\
& 0=\text { full shielding, } 1=\text { no shielding (unitless) [set to the value } \\
& \text { in Table } 3.5 \text { as determined by ISHLT(j) (shelter type) for } \\
& \text { receptor } j \text {, which uses the groundshine shielding factors]; and } \\
& T_{E x t}(j)=\text { short-term exposure time for receptor } j \text { at location } x, y \text { after } \\
& \text { plume passage (h) [TEXT(j)]. }
\end{aligned}
$$

The DCFs used for this mode of exposure are also taken from EPA FGR 12 (Eckerman and Ryman 1993). Additional factors required are the time of exposure, $T_{E x t}(j)$, and a shielding factor, as appropriate, to account for any protective structures; see Table 3.5 for the shielding options provided by RISKIND. 
3.3.2.1.3 External Exposure from Loss of Cask Shielding. Loss of cask shielding in a transportation accident may result in increased external exposure to the affected individuals. Such an event may involve, for example, the loss of neutron shielding in an accident involving fire, or the loss of gamma shielding because of the lead slump resulting from severe impact.

Doses from such accident exposures are modeled after Equation 2.5, routine dose to an individual during a shipment stop, and can be expressed as

$$
D(j)_{E x t S T}=S F_{E x t S T}\left[M_{g}(k) \dot{D}_{g}(j)+M_{n}(k) \dot{D}_{n}(j)\right] T_{E x t}(j)
$$

where

$$
\begin{aligned}
D(j)_{E x t S T}= & \begin{array}{l}
\text { short-term external dose for receptor } j \text { from the shipping cask } \\
(\text { rem) } ;
\end{array} \\
\dot{D}_{i}(j)= & \begin{array}{l}
\text { dose rate }(\mathrm{rem} / \mathrm{h}) \text { from gamma }(i=\mathrm{g}) \text { and neutron }(i=\mathrm{n}) \\
\text { radiation at the location of receptor } j \text { [Equation } 2.1 \text { where } \\
\left.r^{2}=\left(x^{2}+y^{2}\right)^{1 / 2}\right] ;
\end{array} \\
S F_{E x t S T}= & \begin{array}{l}
\text { shielding factor for external radiation at receptor location: } \\
0=\text { full shielding, } 1=\text { no shielding (unitless [set to the value in }
\end{array} \\
& \begin{array}{l}
\text { Table } 3.5 \text { as determined by ISHLT(j) (shelter type) for } \\
\text { receptor } j, \text { which uses the groundshine shielding factors]; }
\end{array} \\
M_{g}(k)= & \begin{array}{l}
\text { dose multiplication factor for gamma radiation due to loss of } \\
\text { shielding (unitless) [SEXT(k,1) for accident response region } k \text { ]; } \\
\text { and }
\end{array} \\
M_{n}(k)= & \begin{array}{l}
\text { dose multiplication factor for neutron radiation due to loss of } \\
\text { shielding (unitless) [SEXT(k,2) for accident response region } k \text { ]. }
\end{array}
\end{aligned}
$$

The only major difference between Equation 2.5 and Equation 3.49 is the addition of the dose multiplication factors for gamma and neutron radiation due to loss of shielding. The dose multiplication factors are the increased dose rates measured in multiples of the original external cask dose rates for incident-free conditions. Methods for calculating such factors can be based on estimates using the codes mentioned in Section 2.1 .

3.3.2.1.4 Exposure from Inhaled Radionuclides. Individuals can be exposed to radiation by inhaling radionuclides. Although some of this inhaled material is immediately exhaled, a fraction is retained in the individual's body. The fraction retained depends on the particle size distribution, the radionuclide's solubility in body fluid, and the individual's breathing rate. The inhalation dose is calculated as follows:

$$
D(j)_{\mathrm{InhST}}=S F(j)_{I n h S T} K_{3} B R(j) \sum_{i} \bar{C}_{a}(i, x, y) D C F_{I n h}(i)
$$


where

$$
\begin{aligned}
& D(j)_{\text {InhST }}=\text { short-term inhalation dose for receptor } j \text { from radionuclide } i \\
& \text { (rem); } \\
& D C F_{l n h}(i)=\text { dose conversion factor for inhalation for radionuclide } i \\
& (\mathrm{~Sv} / \mathrm{Bq}) \text {; } \\
& \bar{C}_{a}(i, x, y)=\text { time-integrated ground-level air concentration }\left(\mathrm{Ci}-\mathrm{s} / \mathrm{m}^{3}\right) \\
& \text { [Equation } 3.14 \text { or } 3.15 \text { ]; } \\
& K_{3}=\text { conversion factor, } 1.172 \times 10^{5} \mathrm{rem}-\mathrm{Bq}-\mathrm{yr} / \mathrm{Sv}-\mathrm{Ci}-\mathrm{s} \text {; } \\
& S F(j)_{I n h S T}=\text { short-term shielding factor for inhalation: } 0=\text { full shielding, } \\
& 1=\text { no shielding (unitless) [set to the value in Table } 3.5 \text { as } \\
& \text { determined by ISHLT(j) (shelter type) for receptor } j \text {, which } \\
& \text { uses the inhalation shielding factors]; and } \\
& B R(j)=\text { breathing rate for receptor } j\left(\mathrm{~m}^{3} / \mathrm{yr}\right)[\mathrm{BRTIND}(\mathrm{j})] \text {. }
\end{aligned}
$$

In RISKIND, all particle sizes are assumed to be respirable. The DCFs are taken from Limiting Values of Radionuclide Intake and Air Concentration and Dose Conversion Factors for Inhalation, Submersion, and Ingestion, EPA Federal Guidance Report No. 11 (FGR 11) (Eckerman et al. 1988). The DCFs for each radionuclide were selected from the solubility class that would yield the highest effective dose equivalent.

\subsubsection{Environmental Media Concentration Models}

This section describes the models, equations, and data employed in the determination of the radionuclide concentrations in the environmental media following a release. Initial concentrations following passage of the radioactive cloud are derived. These concentrations are then integrated over the exposure period of interest for an individual to obtain the time-integrated concentrations used in the calculation of long-term doses (described in Section 3.3.2.3), that is, those doses resulting from the deposition and reconcentration of radionuclides in environmental media subsequent to the passing of the initial plume. These media include ground surface; resuspended contamination in air; and vegetation, meat, and milk. For convenience, symbols representing time-integrated media concentrations are capped with a bar [e.g., $\left.\bar{C}_{a}(i, x, y)\right]$; symbols representing instantaneous concentrations are not capped.

Long-term environmental media concentrations are calculated as functions of the ground concentrations (Section 3.3.2.2.1) that result directly from deposition of radionuclides from the passing cloud and the amount of time that an individual is exposed to these concentrations. The ground concentrations related to these pathways can be calculated from the time-integrated air concentrations described in Section 3.3.1. Figure 3.2 shows the environmental pathways 
following an accidental release and the exposure modes. Long-term concentrations in air are produced by ground disturbance, which causes resuspension of the deposited radionuclides as described in Section 3.3.2.2.2. Deposition of resuspended contamination is also considered in calculating accumulated concentrations in various types of vegetation, including hay and forage (animal-consumed vegetation). Section 3.3.2.2.3 covers the calculation of radionuclide concentrations in vegetation followed by the description of calculations for radionuclide concentrations in meat and milk in Section 3.3.2.2.4. Section 3.3.2.2.5 concludes with calculations for radionuclide concentrations in water.

3.3.2.2.1 Ground Surface Concentrations. Initial ground surface concentrations are calculated from time-integrated air concentrations arising directly from accidental releases (Section 3.3.1.5.3). The concentration of radionuclide $i$ on a ground surface at time $t$ following a release is related to the initial concentration as

$$
C_{g}(i, x, y, t)=C_{g}(i, x, y)\left[\exp \left\{-\left[\lambda(i)+\lambda_{g}\right] t\right\}\right],
$$

where

$$
\begin{aligned}
C_{g}(i, x, y, t)= & \text { ground concentration of radionuclide } i \text { at receptor location } x, y \\
& \text { after time } t \text { following release }\left(\mathrm{Ci} / \mathrm{m}^{2}\right), \\
\lambda(i)= & \text { radioactive decay constant for radionuclide } i(1 / \mathrm{yr}), \text { and } \\
\lambda_{g}= & \text { rate constant for environmental loss }(1 / \mathrm{yr})[0.693 / \mathrm{PHALF}] \\
& \text { PHALF is the removal half-life of any radionuclide from } \\
& \text { the soil. }
\end{aligned}
$$

The environmental loss rate constant $\lambda_{g}$ is derived from an assumed half-life in the soil with respect to environmental availability. This parameter is used to account for loss through chemical binding during downward migration in soil and other environmental loss mechanisms such as wind or water erosion. It is assumed that this parameter applies to all radionuclides subject to ground deposition.

For long-term dose calculations, the time-integrated ground concentration is used. Equation 3.51 is integrated from the time of the accident $(t=0)$ to time $T(\mathrm{yr})$ to cover the length of exposure:

$$
\bar{C}_{g}(i, x, y, T)=C_{g}(i, x, y)\left[1-\frac{\exp \left\{-\left[\lambda(i)+\lambda_{g}\right] T\right\}}{\lambda(i)+\lambda_{g}}\right],
$$


where

$$
\begin{aligned}
\bar{C}_{8}(i, x, y, T)= & \text { time-integrated ground concentration of radionuclide } i \text { at } \\
& \text { receptor location } x, y \text { at time } T \text { following a release }\left(\mathrm{Ci}-\mathrm{s} / \mathrm{m}^{2}\right), \\
& \text { and }
\end{aligned}
$$

3.3.2.2.2 Resuspended Air Concentrations. Resuspended air concentrations are calculated with a time-dependent resuspension factor, which, for deposits of age $t$ years, is

$$
R_{A t o G}(t)=\left\{\begin{array}{l}
F I \exp \left(-\lambda_{\mathrm{r}} t\right), \text { for } t \leq T_{a} \\
F E, \text { for } t>T_{a}
\end{array},\right.
$$

where

$$
\begin{aligned}
R_{A t o G}(t)= & \begin{array}{l}
\text { ratio of resuspended air concentration to ground concentration } \\
\text { for a ground concentration at time } t \mathrm{yr}(1 / \mathrm{m}) ;
\end{array} \\
F I= & \begin{array}{l}
\text { initial value of the resuspension factor for fresh deposits }(1 / \mathrm{m}) \\
{[\mathrm{SUF}] ;}
\end{array} \\
\lambda_{r}= & \begin{array}{l}
\text { resuspension decay constant }(1 / \mathrm{yr})[0.693 / \mathrm{RSALF}] ; \mathrm{RSALF} \text { is } \\
\text { the resuspension factor decay half-life; }
\end{array} \\
F E= & \text { final value of the resuspension factor }(1 / \mathrm{yr}) \text { [SUFF]; and } \\
T_{a}= & \text { time required for the resuspension factor to decrease from its } \\
& \text { initial to final value }(\mathrm{yr}) ; t=\mathrm{T}_{\mathrm{a}} \text { when } \\
& F E=F I \exp \left(-\lambda_{r} T_{a}\right) \\
& \text { and rearranging, } \\
& T_{a}=-\frac{1}{\lambda_{r}} \ln \left(\frac{F E}{F I}\right) .
\end{aligned}
$$

The formulation of the above expression for the resuspension factor is based on work in NRC (1974) and Anspaugh et al. (1974).

The resuspended air concentration may be estimated with the following equation:

$$
C_{r}(i, x, y, t)=C_{g}(i, x, y, t) R_{A t o G}(t),
$$

where

$$
\begin{aligned}
C_{r}(i, x, y, t)= & \begin{array}{l}
\text { resuspended air concentration of radionuclide } i \text { at receptor } \\
\text { location } x, y \text { after time } t \text { following release }\left(\mathrm{Ci} / \mathrm{m}^{3}\right), \text { and }
\end{array}
\end{aligned}
$$




$$
\begin{aligned}
R_{A t o G}(t)= & \text { ratio of resuspended air concentration to ground concen- } \\
& \text { tration for a ground concentration at time } t \text { yr }(1 / \mathrm{m}) \\
& \text { [Equation 3.53]. }
\end{aligned}
$$

This approach has been shown to predict results consistent with the recent data collected from Europe after the Chernobyl accident (International Atomic Energy Agency [IAEA] 1992).

The time-integrated resuspended air concentration is derived from Equation 3.56 and is found to be

$$
\bar{C}_{r}(i, x, y, T)=\left\{\begin{array}{c}
F I C_{g}(i, x, y)\left[1-\frac{\exp \left\{-\left[\lambda(\mathrm{i})+\lambda_{g}+\lambda_{r}\right] T\right\}}{\lambda(\mathrm{i})+\lambda_{g}+\lambda_{r}}\right], T \leq T_{a} \\
F I C_{g}(i, x, y)\left[1-\frac{\exp \left\{-\left[\lambda(i)+\lambda_{g}+\lambda_{r}\right] T_{a}\right\}}{\lambda(i)+\lambda_{g}+\lambda_{r}}\right] \\
+F E\left[\bar{C}_{g}(i, x, y, T)-\bar{C}_{g}\left(i, x, y, T_{a}\right)\right], T>T_{a},
\end{array}\right.
$$

where

$$
\begin{aligned}
\bar{C}_{r}(i, x, y, T)= & \text { time-integrated resuspended air concentration of radio- } \\
& \text { nuclide } i \text { at receptor location } x, y \text { at time } T \text { following a release } \\
& \left(\mathrm{Ci}-\mathrm{s} / \mathrm{m}^{3}\right) .
\end{aligned}
$$

3.3.2.2.3 Concentrations in Vegetation. Concentrations in vegetation may be the result of direct depositon from the initial passing plume (short-term) or of root uptake from soil and deposition of resuspended contamination (long-term). Therefore, these concentrations are derived from the previously derived air and ground concentrations. Ground concentrations are used to determine concentrations in vegetation that are the result of root uptake of soil radioactivity; air concentrations are used to determine concentrations in vegetation that are the result of foliar retention of deposited radioactivity. Two categories of vegetation are treated in RISKIND: vegetables consumed by humans and pasture grass (or hay) that is fed to animals that provide food for human consumption (NRC 1977a). The concentration on vegetation from the initial direct deposition from the passing radioactive cloud is expressed as (NRC 1977a)

$$
C_{V_{d e p}}(i, x, y)=\frac{\bar{C}_{a}(i, x, y) V_{d}(m) F_{r} E_{V_{k}} \exp \left(-\lambda_{v_{w}} T_{V_{k}}\right)}{Y_{V_{k}}},
$$


where

$$
\begin{aligned}
& \begin{array}{c}
C_{v_{\text {dep }}}(i, x, y)=\quad \begin{array}{l}
\text { vegetation concentration of radionuclide } i \text { at location } x, y \text { from } \\
\text { direct deposition from the passing plume }(\mathrm{Ci} / \mathrm{kg})
\end{array}
\end{array} \\
& V_{d}(m)=\text { deposition velocity for radionuclide type } m(\mathrm{~m} / \mathrm{s}) \\
& \text { [VDEPNUC(m)], } \\
& F_{r}=\text { fraction of deposition retained on the plant (unitless) } \\
& \text { [F_RETAIN], } \\
& E_{v_{k}}=\text { fraction of foliar deposition reaching edible portions of } \\
& \text { vegetation type } k \text { (for human consumption or pasture grass } \\
& \text { for animal consumption) (unitless) [F_EDBL_HUM or } \\
& \text { F_EDBL_COW], } \\
& \lambda_{V_{w}}=\operatorname{decay}_{\text {[DECAY_WEATHER] }} \text { constant for weathering losses } \\
& T_{v_{k}}=\text { time from accidental release to first harvest of vegetation } \\
& \text { type } k \text { (d) [T_HARVEST_HUM or T_HARVEST_COW], } \\
& \text { and }
\end{aligned}
$$

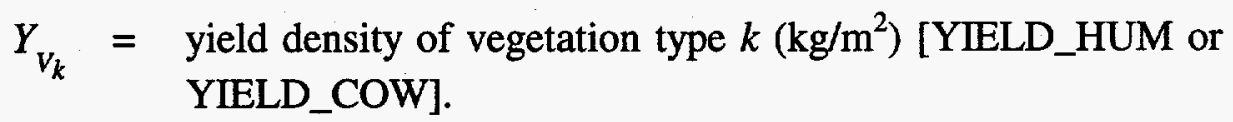

Equation 3.58 is used to calculate the radionuclide concentration in vegetation from the first harvest following an accidental release. If the initially contaminated vegetation is interdicted, this concentration would be zero.

The vegetation concentration over the long term resulting from ground concentration can be expressed by

$$
C_{V_{t}}(i, x, y, t)=\frac{C_{g}(i, x, y, t) B_{V}(i)}{\rho}+C_{r}(i, x, y, t) V_{d}(m) F_{r} E_{V_{k}}\left[1-\frac{\exp \left(-\lambda_{V_{w}} \mathrm{t}_{\mathrm{V}_{k}}\right)}{Y_{V_{k}} \lambda_{V_{w}}}\right],
$$

where

$$
\begin{aligned}
C_{V_{u}}(i, x, y, t)= & \text { long-term vegetation concentration of radionuclide } i \text { at receptor } \\
& \text { location } x, y \text { after time } t \text { following release }(\mathrm{Ci} / \mathrm{kg}), \\
C_{g}(i, x, y, t)= & \text { ground concentration of radionuclide } i \text { at receptor location } x, y \\
& \text { after time } \left.t \text { following release }\left(\mathrm{Ci} / \mathrm{m}^{2}\right) \text { [Equation } 3.51\right], \\
B_{V}(i)= & \text { soil-to-plant transfer factor for radionuclide } i \text { (unitless), }
\end{aligned}
$$




$$
\begin{aligned}
C_{r}(i, x, y, t)= & \text { resuspended air concentration of radionuclide } i \text { at receptor } \\
& \text { location } x, y \text { after time } t \text { following release }\left(\mathrm{Ci} / \mathrm{m}^{3}\right) \\
& {[\text { Equation 3.56], and }} \\
t_{v_{k}}= & \text { time duration for growing season for vegetation type } k \text { (days) } \\
& {[\mathrm{T} \text { _GROW_HUM or T_GROW_COW]. }}
\end{aligned}
$$

The first term in Equation 3.59 represents the root uptake mechanism; the second term represents the resuspension and redeposition. The soil-to-plant transfer factors, $B_{v}(i)$, are listed in Table 3.6.

Starting with Equations 3.58 and 3.59, the time-integrated vegetation concentrations over the exposure period of interest are calculated as

$$
\begin{aligned}
& \bar{C}_{V_{k}}(i, x, y, T)=\frac{\bar{C}_{a}(i, x, y) V_{d}(m) F_{r} E_{V_{k}} \exp \left(-\lambda_{V_{w}} T_{V_{k}}\right)}{Y_{V_{k}}}+ \\
& \frac{\bar{C}_{g}(i, x, y, T) B_{V}(i)}{\rho}+\bar{C}_{r}(i, x, y, T) V_{d}(m) F_{r} E_{V_{k}}\left[1-\frac{\exp \left(-\lambda_{V_{w}} t_{V_{k}}\right)}{Y_{V_{k}} \lambda_{V_{w}}}\right],
\end{aligned}
$$

where

$$
\begin{aligned}
\bar{C}_{V_{k}}(i, x, y, T)= & \text { time-integrated radionuclide } i \text { concentration in vegetation } \\
& \text { type } k \text { at location } x, y \text { at time } T \text { after an accidental release } \\
& (\mathrm{Ci}-\mathrm{s} / \mathrm{kg}) .
\end{aligned}
$$

3.3.2.2.4 Concentrations in Meat and Milk. Radionuclides deposited on hay or pasture grass can be ingested by animals whose meat or milk is consumed by man. The equation used to estimate radionuclide concentrations in meat is

$$
\bar{C}_{b}(i, x, y, T)=\bar{C}_{V_{a}}(i, x, y, T) Q_{a} F_{b}(i),
$$

where

$$
\begin{aligned}
& \bar{C}_{b}(i, x, y, T)=\text { time-integrated concentration in meat }(b) \text { for radionuclide } i \\
& \text { at location } x, y \text { at time } T \text { after accidental release (Ci-s/kg), } \\
& \bar{C}_{V_{a}}(i, x, y, T)=\text { time-integrated radionuclide concentration in vegetation for } \\
& Q_{a}=\text { animal feed ingestion rate }(\mathrm{kg} / \mathrm{d})[\mathrm{QA}] \text {, and } \\
& F_{b}(i)=\text { feed-to-meat transfer factor for radionuclide } i(\mathrm{Ci} / \mathrm{kg} \text { per }
\end{aligned}
$$


TABLE 3.6 Transfer Coefficients Applicable to Food Chain Pathways for Various Radionuclides

Transfer Coefficients

\begin{tabular}{|c|c|c|c|c|}
\hline $\begin{array}{c}\text { Index } \\
\text { (i) }\end{array}$ & Element & $\begin{array}{c}\text { Soil-to-Plant } \\
\mathrm{B}_{\mathbf{v}}(\mathrm{i}) \\
\text { (dimensionless) }\end{array}$ & $\begin{array}{c}\text { Grass-to-Meat } \\
\mathrm{F}_{\mathrm{b}}(\mathrm{i}) \\
(\mathrm{d} / \mathrm{kg}) \\
\end{array}$ & $\begin{array}{c}\text { Grass-to-Milk } \\
F_{\mathrm{m}}(\mathrm{i}) \\
(\mathrm{d} / \mathrm{L}) \\
\end{array}$ \\
\hline 1 & Hydrogen & 4.8 & $1.2 \times 10^{-2}$ & $1.0 \times 10^{-2}$ \\
\hline 2 & Helium & 0.0 & 0.0 & 0.0 \\
\hline 3 & Lithium & $8.3 \times 10^{-4}$ & $1.0 \times 10^{-2}$ & $5.0 \times 10^{-2}$ \\
\hline 4 & Beryllium & $4.2 \times 10^{-4}$ & $1.0 \times 10^{-3}$ & $1.0 \times 10^{-4}$ \\
\hline 5 & Boron & $1.2 \times 10^{-1}$ & $8.0 \times 10^{-4}$ & $2.7 \times 10^{-3}$ \\
\hline 6 & Carbon & 5.5 & $3.1 \times 10^{-2}$ & $1.2 \times 10^{-2}$ \\
\hline 7 & Nitrogen & 7.5 & $7.7 \times 10^{-2}$ & $2.2 \times 10^{-2}$ \\
\hline 8 & Oxygen & 1.6 & $1.6 \times 10^{-2}$ & $2.0 \times 10^{-2}$ \\
\hline 9 & Fluorine & $6.5 \times 10^{-4}$ & $1.5 \times 10^{-1}$ & $1.4 \times 10^{-2}$ \\
\hline 10 & Neon & $1.4 \times 10^{-1}$ & $2.0 \times 10^{-2}$ & $2.0 \times 10^{-2}$ \\
\hline 11 & Sodium & $5.2 \times 10^{-2}$ & $3.0 \times 10^{-2}$ & $4.0 \times 10^{-2}$ \\
\hline 12 & Magnesium & $1.3 \times 10^{-1}$ & $5.0 \times 10^{-3}$ & $1.0 \times 10^{-2}$ \\
\hline 13 & Aluminum & $1.8 \times 10^{-4}$ & $1.5 \times 10^{-3}$ & $5.0 \times 10^{-4}$ \\
\hline 14 & Silicon & $1.5 \times 10^{-4}$ & $4.0 \times 10^{-5}$ & $1.0 \times 10^{-4}$ \\
\hline 15 & Phosphorous & 1.1 & $4.6 \times 10^{-2}$ & $2.5 \times 10^{-2}$ \\
\hline 16 & Sulfur & $5.9 \times 10^{-1}$ & $1.0 \times 10^{-1}$ & $1.8 \times 10^{-2}$ \\
\hline 17 & Chlorine & 5.0 & $8.0 \times 10^{-2}$ & $5.0 \times 10^{-2}$ \\
\hline 18 & Argon & 0.0 & 0.0 & 0.0 \\
\hline 19 & Potassium & $3.7 \times 10^{-1}$ & $1.2 \times 10^{-2}$ & $1.0 \times 10^{-2}$ \\
\hline 20 & Calcium & $3.6 \times 10^{-2}$ & $4.0 \times 10^{-3}$ & $8.0 \times 10^{-3}$ \\
\hline 21 & Scandium & $1.1 \times 10^{-3}$ & $1.6 \times 10^{-2}$ & $5.0 \times 10^{-6}$ \\
\hline 22 & Titanium & $5.4 \times 10^{-5}$ & $3.1 \times 10^{-2}$ & $5.0 \times 10^{-6}$ \\
\hline 23 & Vanadium & $1.3 \times 10^{-3}$ & $2.3 \times 10^{-3}$ & $1.0 \times 10^{-3}$ \\
\hline 24 & Chromium & $2.5 \times 10^{-4}$ & $2.4 \times 10^{-3}$ & $2.2 \times 10^{-3}$ \\
\hline 25 & Manganese & $2.9 \times 10^{-2}$ & $8.0 \times 10^{-4}$ & $2.5 \times 10^{-4}$ \\
\hline 26 & Iron & $6.6 \times 10^{-4}$ & $4.0 \times 10^{-2}$ & $1.2 \times 10^{-3}$ \\
\hline 27 & Cobalt & $9.4 \times 10^{-3}$ & $1.3 \times 10^{-2}$ & $1.0 \times 10^{-3}$ \\
\hline 28 & Nickel & $1.9 \times 10^{-2}$ & $5.3 \times 10^{-3}$ & $6.7 \times 10^{-3}$ \\
\hline 29 & Copper & $1.2 \times 10^{-1}$ & $8.0 \times 10^{-3}$ & $1.4 \times 10^{-2}$ \\
\hline 30 & Zinc & $4.0 \times 10^{-1}$ & $3.0 \times 10^{-2}$ & $3.9 \times 10^{-2}$ \\
\hline 31 & Gallium & $2.5 \times 10^{-4}$ & 1.3 & $5.0 \times 10^{-5}$ \\
\hline 32 & Germanium & $1.0 \times 10^{-1}$ & $2.0 \times 10^{-1}$ & $5.0 \times 10^{-4}$ \\
\hline 33 & Arsenic & $1.0 \times 10^{-2}$ & $2.0 \times 10^{-3}$ & $6.0 \times 10^{-3}$ \\
\hline 34 & Selenium & 1.3 & $1.5 \times 10^{-2}$ & $4.5 \times 10^{-3}$ \\
\hline 35 & Bromine & $7.6 \times 10^{-1}$ & $2.6 \times 10^{-2}$ & $5.0 \times 10^{-2}$ \\
\hline
\end{tabular}


TABLE 3.6 (Cont.)

Transfer Coefficients

\begin{tabular}{|c|c|c|c|c|}
\hline $\begin{array}{c}\text { Index } \\
\text { (i) }\end{array}$ & Element & $\begin{array}{c}\text { Soil-to-Plant } \\
\mathrm{B}_{\mathrm{v}}(\mathrm{i}) \\
\text { (dimensionless) }\end{array}$ & $\begin{array}{c}\text { Grass-to-Meat } \\
F_{\mathrm{b}}(\mathrm{i}) \\
(\mathrm{d} / \mathrm{kg}) \\
\end{array}$ & $\begin{array}{c}\text { Grass-to-Milk } \\
F_{\mathrm{m}}(\mathrm{i}) \\
(\mathrm{d} / \mathrm{L}) \\
\end{array}$ \\
\hline 36 & Krypton & 0.0 & 0.0 & 0.0 \\
\hline 37 & Rubidium & $1.3 \times 10^{-1}$ & $3.1 \times 10^{-2}$ & $3.0 \times 10^{-2}$ \\
\hline 38 & Strontium & $1.7 \times 10^{-2}$ & $6.0 \times 10^{-4}$ & $8.0 \times 10^{-4}$ \\
\hline 39 & Yttrium & $2.6 \times 10^{-3}$ & $4.6 \times 10^{-3}$ & $1.0 \times 10^{-5}$ \\
\hline 40 & Zirconium & $1.7 \times 10^{-4}$ & $3.4 \times 10^{-2}$ & $5.0 \times 10^{-6}$ \\
\hline 41 & Niobium & $9.4 \times 10^{-3}$ & $2.8 \times 10^{-1}$ & $2.5 \times 10^{-3}$ \\
\hline 42 & Molybdenum & $1.2 \times 10^{-1}$ & $8.0 \times 10^{-3}$ & $7.5 \times 10^{-3}$ \\
\hline
\end{tabular}

Source: NRC (1977a)

The corresponding equation to estimate radionuclide concentrations in milk is

$$
\bar{C}_{m}(i, x, y, T)=\bar{C}_{V_{a}}(i, x, y, T) Q_{a} F_{m}(i),
$$

where

$$
\begin{aligned}
\bar{C}_{m}(i, x, y, T)= & \begin{array}{l}
\text { time-integrated concentration in milk }(m) \text { for radionuclide } i \\
\text { at location } x, y \text { at time } T \text { after accidental release (Ci-s/kg), }
\end{array} \\
\bar{C}_{V_{a}}(i, x, y, T)= & \begin{array}{l}
\text { time-integrated radionuclide concentration in vegetation for } \\
\text { animal consumption (hay or pasture grass) at location } x, y \text { at }
\end{array} \\
& \text { time } T \text { after accidental release (Ci-s/kg) [Equation } 3.60], \text { and } \\
F_{m}(i)= & \text { feed-to-milk transfer factor for radionuclide } i \text { (Ci } / \mathrm{kg} \\
& \text { per Ci/d). }
\end{aligned}
$$

3.3.2.2.5 Concentrations in Drinking Water. Surface water contamination can result from the deposition of radionuclides onto the water bodies that serve as potential sources of drinking water. Contamination may also occur by rain washoff and runoff from contaminated land areas. In RISKIND, the drinking water pathway considered is via fresh surface water, which could occur within a short period (e.g., a week) following an accidental release. Other water pathways requiring a longer period - such as irrigation of farmland, water ingestion by animals that serve as food sources (meat or milk), and ingestion of aquatic food - are not included in the current version of RISKIND. 
The calculation of doses from drinking water is based on a model that requires the deposition of radionuclides onto the water body, individual water consumption rates, duration of water consumption from the contaminated water body, and water treatment efficiency. In the current version of RISKIND, all materials deposited onto the water body are assumed to be thoroughly mixed with portions of or all of the water body. The removal of radionuclides by sedimentation is not considered, thus yielding a conservative estimate of the radionuclide concentrations in water.

The initial radionuclide concentration in a drinking water body from deposition from the passage of the radioactive cloud is estimated as

$$
C_{w}(i, x, y)=\frac{\text { Amount }}{\text { Volume }}=\frac{C_{g}(i, x, y) A_{w}^{\prime}(x, y)}{A_{w}(x, y) W_{d}(x, y)}=\frac{C_{g}(i, x, y) F_{a}(x, y)}{W_{d}(x, y)},
$$

where

$$
\begin{aligned}
& C_{w}(i, x, y)=\text { initial water concentration from wet and dry deposition for } \\
& \text { nuclide } i \text { at location } x, y \text { after plume passage }\left(\mathrm{Ci} / \mathrm{m}^{3}\right) \text {; } \\
& C_{g}(i, x, y)=\text { initial areal (ground) concentration from wet and dry deposition } \\
& \text { for nuclide } i \text { at location } x, y \text { after plume passage }\left(\mathrm{Ci} / \mathrm{m}^{2}\right) \\
& \text { [Equation } 3.29 \text { or 3.30]; } \\
& A_{w}^{\prime}(x, y)=\text { area of water body at location } x, y \text { subject to contaminant } \\
& \text { deposition from the passing puff }\left(\mathrm{m}^{2}\right) \text {; } \\
& A_{w}(x, y)=\text { area of water body at location } x, y\left(\mathrm{~m}^{2}\right) \text {; } \\
& W_{d}(x, y)=\text { effective mixing depth of the water body at location } x, y(\mathrm{~m}) \\
& \text { [WBDYD(j) for receptor } j \text { ]; } \\
& F_{a}(x, y)=\text { fraction of the water body at location } x, y \text { covered by the passing } \\
& \text { puff, assumes puff travels the full distance across the water body } \\
& \text { in the downwind direction (unitless), where } \\
& F_{a}(x, y)=\left\{\begin{array}{l}
1, \text { if } F_{w}(x, y) \geq 1 \\
F_{w}(x, y), \text { if } F_{w}(x, y)<1,
\end{array}\right.
\end{aligned}
$$

and

$$
F_{w}(x, y)=\frac{\sqrt{2 \pi} \sigma_{y}}{W_{c}(x, y)} ;
$$

$\sigma_{y}=$ horizontal dispersion coefficient [Equation 3.46]; and

$$
\begin{aligned}
W_{c}(x, y)= & \text { crosswind width of the water body at location } x, y \text { (m) } \\
& {[\text { WBDYW(j) for receptor } j] . }
\end{aligned}
$$


At time $t$ following an accidental release, the drinking water radionuclide concentration is estimated as

$$
C_{w}(i, x, y, t)=\frac{C_{g}(i, x, y) F_{a}(x, y)\left(1-E_{w}\right) \exp \left\{-\left[\lambda(i)+\lambda_{w}(x, y)\right] t\right\}}{W_{d}(x, y)},
$$

where

$$
\begin{aligned}
& C_{w}(i, x, y, t)=\text { radionuclide } i \text { concentration in water body at location } x, y \text { at } \\
& \text { time } t \text { after puff passage }\left(\mathrm{Ci} / \mathrm{m}^{3}\right) \text {; } \\
& E_{w}=\text { water treatment efficiency, fraction of contamination removed } \\
& \text { by water treatment facilities before use }(0=\text { no contamination } \\
& \text { removed, } 1 \text { = all contamination removed) [TREATM]; } \\
& \lambda(i)=\text { radioactive decay constant for radionuclide } i(1 / \mathrm{yr}) \text {. } \\
& \lambda_{w}(x, y)=\text { water exchange rate for water body at location } x, y(1 / y r) \\
& \text { [WEXCG(j) for receptor } j] \text {; and }
\end{aligned}
$$

Equation 3.66 is derived from Equation 3.63 by including the efficiency of water treatment systems for removing the contamination and accounting for the concentration dependencies on radionuclide decay and dilution. For dose calculations, the time-integrated drinking water concentration is calculated from Equation 3.66 as

$$
\bar{C}_{w}(i, x, y, T)=\frac{C_{g}(i, x, y) F_{a}(x, y)\left(1-E_{w}\right)\left(1-\exp \left\{-\left[\lambda(i)+\lambda_{w}(x, y)\right] T\right\}\right)}{W_{d}(x, y)\left[\lambda(i)+\lambda_{w}(x, y)\right]},
$$

where

$$
\begin{aligned}
\bar{C}_{w}(i, x, y, T)= & \text { time-integrated radionuclide } i \text { concentration in water body at } \\
& \text { location } x, y \text { at time } T \text { after puff passage }\left(\mathrm{Ci}-\mathrm{yr} / \mathrm{m}^{3}\right), \text { and } \\
T= & \text { time following accidental release }(\mathrm{yr})[\mathrm{YEVD}] .
\end{aligned}
$$

\subsubsection{Long-Term Dose Models}

The long-term dose from a given release is calculated by integrating the dose over a period of $T$ years following the release and using the time-integrated media concentrations developed in Section 3.3.2.2. Doses to individuals can be calculated for all known significant pathways: inhalation; external exposure to air and ground contamination; and ingestion of vegetables, meat, and milk. Internal doses from inhalation and ingestion pathways are calculated with DCFs. Because radionuclides taken into the body via ingestion or inhalation will continue to irradiate the body as long as they exist and are retained by the body, these internal DCFs 
represent the committed dose (ICRP 1977), that is, the dose integrated over an interval of 50 years.

3.3.2.3.1 External Doses from Resuspended Air Concentrations. External radiation doses received from resuspended air concentrations are the product of the time-integrated resuspended air concentrations, the cloud gamma DCF, and shielding considerations:

$$
D(j)_{A i r L T}=S F(j)_{A i r L T} K_{1} \sum_{i} \bar{C}_{r}(i, x, y, T) D C F_{A i r}(i),
$$

where

$$
\begin{aligned}
D(j)_{A i r L T}= & \begin{array}{l}
\text { dose to receptor } j \text { from long-term external radiation exposure } \\
\text { from resuspended contamination (rem); }
\end{array} \\
S F(j)_{A i r L T}= & \begin{array}{l}
\text { long-term shielding factor for air immersion for receptor } j: \\
0=\text { full shielding, } 1=\text { no shielding (unitless), where }
\end{array} \\
& S F(j)_{\text {AirLT }}=O F_{\text {out }}(j)+O F_{\text {in }}(j) S F_{k A i r}(j) ; \\
O F_{o u t}(j)= & \text { fraction of time spent outdoors by receptor } j \text { (unitless) } \\
& {[\text { OCUPF }(\mathrm{j}, 1)] ; } \\
O F_{i n}(j)= & \text { fraction of time spent indoors by receptor } j \text { (unitless) } \\
& {[\text { OCUPF }(\mathrm{j}, 2)] ; } \\
S F_{k A i r}(j)= & \text { shielding factor afforded receptor } j \text { by shelter type } k \text { for air } \\
& \text { immersion }[\text { set to the value in Table } 3.5 \text { as determined by } \\
& \text { LSHLT(k)]; } \\
K_{1}= & \text { conversion factor, } 3.7 \times 10^{12} \text { rem-Bq/Sv-Ci; } \\
\bar{C}_{r}(i, x, y, T)= & \text { time-integrated ground-level air concentration (Ci-s/m } \left.{ }^{3}\right) \\
& {[\text { Equation } 3.57] ; \text { and } } \\
D C F_{A i r}(i)= & \text { dose conversion factor for air submersion for radionuclide } i \\
& \left(S v / B q-s / m^{3}\right) .
\end{aligned}
$$

The cloud DCFs used by RISKIND are those published in FGR 12 (Eckerman and Ryman 1993).

3.3.2.3.2 External Exposure from Ground-Deposited Radionuclides. Radioactively contaminated ground provides a long-term source of gamma radiation for individuals residing near contamination. For long-term exposure, the external doses from radioactive material deposited on the ground are calculated as the product of the time-integrated ground concentrations, the ground DCFs, and shielding considerations:

$$
D(j)_{G n d L T}=S F(j)_{G n d L T} K_{1} \sum_{i} \bar{C}_{g}(i, x, y, T) D C F_{G n d}(i)
$$


where

$$
\begin{aligned}
D(j)_{G n d L T}= & \begin{array}{l}
\text { dose to receptor } j \text { from long-term external radiation exposure } \\
\text { from ground contamination (rem); }
\end{array} \\
S F(j)_{G n d L T}= & \begin{array}{l}
\text { long-term shielding factor for external ground radiation for } \\
\text { receptor } j: 0=\text { full shielding, } 1=\text { no shielding (unitless), } \\
\text { where }
\end{array} \\
& S F(j)_{G n d L T}=O F_{\text {out }}(j)+O F_{i n}(j) S F_{k G n d}(j) ; \\
S F_{k G n d}(j)= & \begin{array}{l}
\text { shielding factor afforded receptor } j \text { by shelter type } k \text { for } \\
\text { external ground radiation [set to the value in Table } 3.5 \text { as }
\end{array} \\
& \text { determined by LSHLT(k)]; } \\
\bar{C}_{g}(i, x, y, T)= & \begin{array}{l}
\text { time-integrated ground concentration of radionuclide } i \text { at } \\
\text { receptor location } x, y \text { at time } T \text { following a release }\left(\mathrm{Ci}-\mathrm{s} / \mathrm{m}^{2}\right) \\
\text { [Equation } 3.52] ; \text { and }
\end{array} \\
D C F_{G n d}(i)= & \begin{array}{l}
\text { dose conversion factor for external radiation from the ground } \\
\text { for radionuclide } i\left(S v / B q-\mathrm{s} / \mathrm{m}^{2}\right) .
\end{array}
\end{aligned}
$$

The ground DCFs used in RISKIND are also from FGR 12 (Eckerman and Ryman 1993).

3.3.2.3.3 Inhalation Doses from Resuspended Air Concentrations. Long-term inhalation doses are calculated using the time-integrated resuspended air concentrations, individual receptor breathing rates, 50-year committed inhalation DCFs from FGR 11 (Eckerman et al. 1988), and shielding factors. The equation used is

$$
D(j)_{I n h L T}=S F(j)_{I n h L T} K_{3} B R(j) \sum_{i} \bar{C}_{r}(i, x, y, T) D C F_{I n h}(i),
$$

where

$$
\begin{aligned}
D(j)_{I n h L T}= & \begin{array}{l}
\text { dose to receptor } j \text { from long-term inhalation of resuspended } \\
\text { contamination (rem); }
\end{array} \\
S F(j)_{I n h L T}= & \begin{array}{l}
\text { long-term shielding factor for resuspended contaminant } \\
\text { inhalation for receptor } j: 0=\text { full shielding, } 1=\text { no shielding } \\
\text { (unitless), where }
\end{array} \\
& S F(j)_{I n h L T}=O F_{\text {out }}(j)+O F_{i n}(j) S F_{k l n h}(j) ; \\
S F_{k I n h}(j)= & \text { shielding factor afforded receptor } j \text { by shelter type } k \text { for } \\
& \text { inhalation [set to the value in Table } 3.5 \text { as determined by } \\
& \text { LSHLT(k)]; } \\
K_{3}= & \text { conversion factor, } 1.172 \times 10^{5} \text { rem-Bq-yr/Sv-Ci-s; }
\end{aligned}
$$




$$
\begin{aligned}
B R(j) & =\text { breathing rate for receptor } j\left(\mathrm{~m}^{3} / \mathrm{yr}\right)[\operatorname{BRTIND}(\mathrm{j})] ; \text { and } \\
D C F_{I n h}(i) & =\text { dose conversion factor for inhalation for radionuclide } i(\mathrm{~Sv} / \mathrm{Bq}) .
\end{aligned}
$$

3.3.2.3.4 Ingestion Doses from Agricultural Products. Ingestion doses are calculated for vegetables, meat, and milk on the basis of the time-integrated concentrations derived in Sections 3.3.2.2.3 and 3.3.2.2.4. The 50-year committed ingestion DCFs used in RISKIND are those in FGR 11 (Eckerman et al. 1988).

Vegetable ingestion doses are calculated by

$$
D(j)_{V e g}=D F \quad U_{V} C F_{V} K_{4} \sum_{i} \bar{C}_{V_{h}}(i, x, y, T) D C F_{\text {Ing }}(i),
$$

where

$$
\begin{aligned}
D(j)_{V e g}= & \begin{array}{l}
\text { dose to receptor } j \text { from ingestion of contaminated vegetables } \\
(\text { rem }) ;
\end{array} \\
D F= & \begin{array}{l}
\text { decontamination factor, that is, the fraction of contamination } \\
\text { remaining on vegetation after food preparation at time of } \\
\text { consumption (unitless) [DFACT]; }
\end{array} \\
U_{V}= & \text { human consumption rate of vegetables }(\mathrm{kg} / \mathrm{d})[\mathrm{XIN}(1)] ; \\
C F_{V}= & \text { fraction of consumed vegetables that are contaminated } \\
& \text { (unitless), [PFIN(1)]; } \\
K_{4}= & \text { conversion factor, } 4.282 \times 10^{7} \text { rem-Bq-d/Sv-Ci-s; } \\
\bar{C}_{V_{h}}(i, x, y, T)= & \text { time-integrated radionuclide } i \text { concentration in vegetation for } \\
& \text { human consumption at location } x, y \text { at time } T \text { after an } \\
& \text { accidental release (Ci-s/kg) [Equation 3.60]; and } \\
D C F & \text { dose conversion factor for ingestion for radionuclide } i \\
& (\mathrm{~Sv} / \mathrm{Bq}) .
\end{aligned}
$$

Doses from meat ingestion are calculated by

where

$$
D(j)_{\text {Meat }}=U_{b} C F_{b} K_{4} \sum_{i} \bar{C}_{b}(i, x, y, T) D C F_{\text {Ing }}(i),
$$

$$
\begin{aligned}
D(j)_{\text {Meat }}= & \text { dose to receptor } j \text { from ingestion of contaminated meat } \\
& (\text { rem }) ; \\
U_{b}= & \text { human consumption rate of meat }(\mathrm{kg} / \mathrm{d})[\mathrm{XIN}(2)]
\end{aligned}
$$




$$
\begin{aligned}
& C F_{b}=\text { fraction of consumed meat that is contaminated (unitless) } \\
& \text { [PFIN(2)]; and }
\end{aligned}
$$

The dose to an individual from milk ingestion is given by

$$
D(j)_{\text {Milk }}=U_{m} C F_{m} K_{4} \sum_{i} \bar{C}_{m}(i, x, y, T) D C F_{\text {Ing }}(i)
$$

where

$$
\begin{aligned}
& \begin{aligned}
D(j)_{\text {Milk }}= & \text { dose to receptor } j \text { from ingestion of contaminated milk } \\
& \text { (rem); }
\end{aligned} \\
& U_{m}=\text { human consumption rate of milk }(\mathrm{kg} / \mathrm{d})[\mathrm{XIN}(3)] \text {; } \\
& C F_{m}=\text { fraction of consumed milk that is contaminated (unitless) } \\
& \text { [PFIN(3)]; } \\
& K_{4}=\text { conversion factor, } 4.282 \times 10^{7} \mathrm{rem}-\mathrm{Bq}-\mathrm{d} / \mathrm{Sv}-\mathrm{Ci}-\mathrm{s} \text {; } \\
& \bar{C}_{m}(i, x, y, T)=\text { time-integrated concentration in milk (m) for radionuclide } i \\
& \text { at location } x, y \text { at time } T \text { after accidental release }(\mathrm{Ci}-\mathrm{s} / \mathrm{kg}) \\
& \text { [Equation 3.62]; and } \\
& \begin{aligned}
D C F_{\text {Ing }}(i)= & \text { dose conversion factor for ingestion for radionuclide } i \\
& (\mathrm{~Sv} / \mathrm{Bq}) .
\end{aligned}
\end{aligned}
$$

3.3.2.3.5 Ingestion Doses from Drinking Water. The dose to an individual from drinking contaminated surface water is calculated by

$$
D(j)_{\text {Water }}=U_{w} C F_{w} K_{5} \sum_{i} \bar{C}_{w}(i, x, y, T) D C F_{\text {Ing }}(i)
$$

where

$$
\begin{aligned}
D(j)_{\text {Water }}= & \text { dose to receptor } j \text { from ingestion of contaminated water } \\
& (\text { rem); } \\
U_{w}= & \text { human consumption rate of water }(\mathrm{L} / \mathrm{d})[\mathrm{XIN}(5)] ; \\
C F_{w}= & \text { fraction of consumed water that is contaminated (unitless) } \\
& {[\mathrm{PFIN}(5)] } \\
K_{5}= & \text { conversion factor, } 1.351 \times 10^{12} \mathrm{rem}-\mathrm{Bq}-\mathrm{d}-\mathrm{m}^{3} / \mathrm{Sv}-\mathrm{Ci}-\mathrm{yr}-\mathrm{L} ;
\end{aligned}
$$




$$
\begin{aligned}
\bar{C}_{w}(i, x, y, T)= & \begin{array}{l}
\text { time-integrated radionuclide } i \text { concentration in water body at } \\
\text { location } x, y \text { at time } T \text { after puff passage }\left(\mathrm{Ci}-\mathrm{yr} / \mathrm{m}^{3}\right)
\end{array} \\
& \text { [Equation 3.67]; and } \\
D C F_{\text {Ing }}(i)= & \text { dose conversion factor for ingestion for radionuclide } i \\
& (\mathrm{~Sv} / \mathrm{Bq}) .
\end{aligned}
$$

The total long-term ingestion dose to an individual for an exposure period of $\mathrm{T}$ years following an accidental release is obtained by summing the vegetable, meat, milk, and water ingestion doses per the following equation:

$$
D(j)_{\text {Ing }}=D(j)_{\text {Veg }}+D(j)_{\text {Meat }}+D(j)_{\text {Milk }}+D(j)_{\text {Water }},
$$

where

$$
\begin{aligned}
D(j)_{I n g}= & \begin{array}{l}
\text { Dose to receptor } j \text { from ingestion of contaminated food and water } \\
(\mathrm{rem}) .
\end{array}
\end{aligned}
$$

3.3.2.3.6 Analysis of Weather Uncertainty on Individual Doses. Weather conditions and their frequency of occurrence at a site can be characterized by site-specific wind-rose data. These data are in joint-frequency form, that is, the fraction of time the wind is blowing at a given wind speed in a given stability category for each of six average wind speed groups and six Pasquill weather stability categories.

When the risk over all weather conditions is selected, the uncertainty of the effect of weather conditions during an accident on the calculated individual dose consequences is estimated by constructing a cumulative probability distribution of dose values by using seasonal or annual joint-frequency data for a given region. This probabilistic dose distribution is then used to determine the "median" ( $50 \%$ weather probability) and reasonable "maximum" (95\% weather probability) dose values for each receptor of interest when the joint frequency wind speed/stability class options are used. The $50 \%$ weather probability dose value calculated for a receptor is one that is not exceeded approximately $50 \%$ of the time (50\% of the time a higher dose would be expected). Similarly, the $95 \%$ weather probability dose value calculated for a receptor is one that is not exceeded $95 \%$ of the time (5\% of the time a higher dose would be expected).

\subsection{POPULATION DOSE MODEL}

A population dose model was developed for RISKIND to assess the potential collective doses to the exposed population as the result of a release associated with a radioactive material transportation accident. The population dose model implemented in RISKIND calculates the total collective dose based on the average individual doses and the distribution of doses in the exposed population within the specific area of interest. The same weather uncertainty 
calculations discussed in Section 3.3.2.3.6 for individual risks can be selected for population risks also.

To calculate the distribution of radiation doses to the exposed population from a release, the areas and magnitudes of air and ground concentrations in the downwind direction are needed. This information is calculated with the equations developed for atmospheric transport in Section 3.3.1 for determining individual receptor concentrations. Section 3.4.1 gives the approach implemented in RISKIND for estimating the area and concentration. The collective dose models are based on those for individual receptors and are described in Sections 3.4 .2 and 3.4.3. Section 3.4.4 discusses the auxiliary PAG calculations performed in RISKIND to estimate soil cleanup levels that would result in doses below the suggested limits.

\subsubsection{Contaminated Areas and Concentration Isopleths}

In Section 3.3.1, contaminant radionuclide concentrations in the environmental media were calculated for specific receptor locations. For a population dose calculation, it is necessary and more expedient to determine concentrations on a broader scale and to portion the affected area into isopleths on the basis of air and ground concentrations. Because of the assumptions made in the air transport models, air and ground concentration isopleths will coincide in space (not magnitude) when there is no wet deposition. However, the location of the isopleths is calculated separately for the air and ground concentrations since their locations will not coincide if rainfall is present (greater than $0 \mathrm{~mm} / \mathrm{h}$ ).

Beginning at the accident location, air and ground concentrations will generally increase to a maximum and then decrease as the distance downwind increases. Where the maximum concentrations occur strongly depends on the effective release height and atmospheric conditions at the time of release. In RISKIND, up to 20 isopleths in the direction downwind of the release at the time of the accident are calculated from a nearest distance, $x_{\min }$, up to a maximum distance, $x_{\text {max }}$, as specified by the user (see Figure 3.3 ).

The first step in determining the isopleths is to find the maximum concentration between $x_{\min }[\mathrm{XPZ}(1)]$ and $x_{\max }[\mathrm{XPZ}(2)]$ that will occur along the plume centerline $(y=0)$. A variation of Brent's method (Press 1986) is used to find the maximum concentrations; Equation 3.14 or 3.15 can be used for air concentrations and Equation 3.29 or 3.30 for ground concentrations. The surrounding contour $\left(C_{1}\right)$ for the innermost isopleth is then defined by a concentration value $\sqrt{10}$ smaller than the maximum concentration. The contour for groundlevel air concentrations where no mixing with the stable layer has occurred is a rearrangement of Equation 3.14 and is given by

$$
y_{a}(x)= \pm \sigma_{y}\left[2 \ln \left(\frac{Q_{x_{i}}}{\pi \sigma_{y} \sigma_{z} u_{H} \bar{C}_{a}(i, x, y, t)}\right)-\frac{H^{2}}{\sigma_{z}^{2}}\right]^{1 / 2}
$$




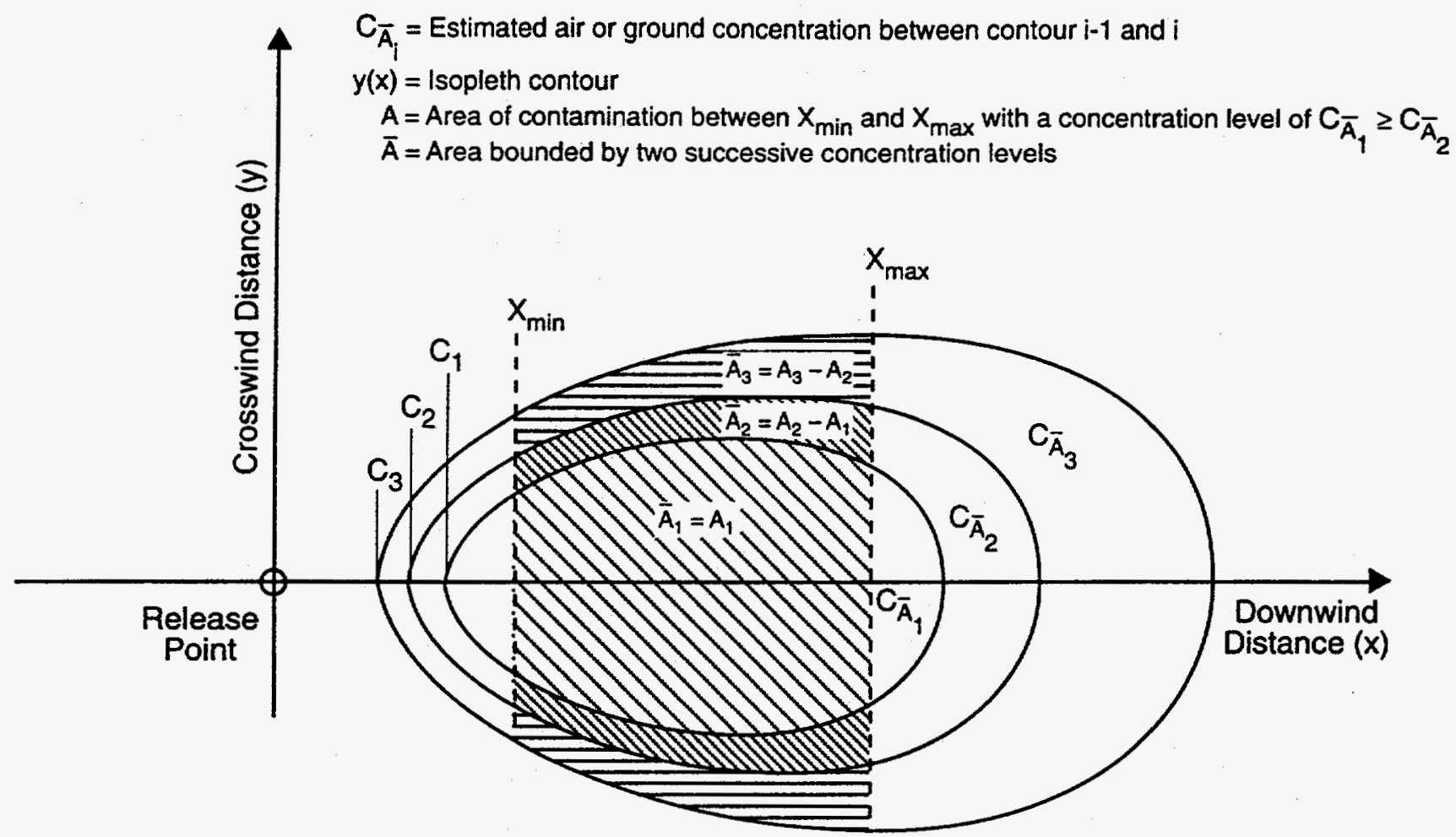

FIGURE 3.3 Areas of Estimated Air or Ground Concentration Contours for Population Dose Calculation

between $x_{\min }$ and $x_{\max }$. If the puff is limited by a stable layer and mixing has occurred, the contour is derived from Equation 3.15 and given by

$$
y_{a}(x)= \pm \sigma_{y}\left[2 \ln \left(\frac{Q_{x_{i}}}{\sqrt{2 \pi} \sigma_{y} u_{H} L \bar{C}_{a}(i, x, y, t)}\right)\right]^{1 / 2}
$$

Similarly, for ground concentration isopleths, the isopleth contour will be given by

$$
y_{g}(x)= \pm \sigma_{y}\left(2 \ln \left\{\frac{Q_{x_{i}}}{\sqrt{\pi} \sigma_{y} u_{H} C_{g}(i, x, y)}\left[\frac{V_{w}}{\sqrt{2}}+\frac{V_{d e p}}{\sqrt{\pi} \sigma_{z}} \exp \left(\frac{-H^{2}}{2 \sigma_{z}^{2}}\right)\right]\right\}^{1 / 2}\right.
$$

for the no-mixing condition (from Equation 3.29), or by

$$
y_{g}(x)= \pm \sigma_{y}\left\{2 \ln \left[\frac{Q_{x_{i}}\left(V_{w}+V_{d e p} / L\right)}{\sqrt{2 \pi} \sigma_{y} u_{H} C_{g}(i, x, y)}\right]\right\}^{1 / 2},
$$

if the plume is limited by the stable layer (from Equation 3.30) and mixing has occurred. The total area of contamination within the isopleth contour for a given ground or air concentration is then 


$$
A=2 \int_{X_{\min }}^{X_{\max }} y(x) d x
$$

where $y(x)$ is given by Equation $3.79,3.80,3.81$, or 3.82 .

Now that the innermost isopleth and its surrounding contour, which defines the area of maximum concentration, have been defined, the next larger isopleth is defined in a similar manner. A contour $\left(C_{2}\right)$ is defined, by using a concentration value of $\sqrt{10}$ smaller than the previous contour, and so on, until the number of specified isopleths is achieved (maximum of 20):

$$
C_{i}=\sqrt{10} C_{i-1}
$$

where

$C_{i}=\quad$ air or ground concentration for the $i$ th isopleth contour.

The isopleth areas are calculated from the total areas within the isopleth contours by

$$
\overline{A_{i}}=A_{i}-A_{i-1}
$$

where

$$
\begin{aligned}
& \left.\bar{A}_{i}=\quad \text { isopleth area (area between concentration contours } C_{i} \text { and } C_{i-1}\right)\left(\mathrm{m}^{2}\right), \\
& A_{i}=\quad \begin{array}{l}
\text { total area within contour } i \text { for isopleth } i \text { where } i \text { ranges from } 1 \text { for the } \\
\text { innermost isopleth to NISOPL (number of isopleths) for the } \\
\text { outermost isopleth [Equation 3.83], and }
\end{array} \\
& \bar{A}_{1}=\begin{array}{l}
\text { (the area for the innermost isopleth) is determined directly by using } \\
\text { Equation 3.83. }
\end{array}
\end{aligned}
$$

The air and ground concentration values to be used for each isopleth are determined from the isopleth contours by using the geometric mean

$$
C_{\bar{A}_{i}}=\sqrt{C_{i} C_{i-1}}
$$

where

$$
C_{\bar{A}_{i}}=\text { ground or air concentration of interest for the area } \bar{A}_{i} \text {. }
$$

For the innermost isopleth,

$$
C_{\bar{A}_{1}}=\sqrt{C_{1} C_{\max }}
$$

where

$$
C_{\max }=\text { maximum ground or air concentration within } x_{\min } \text { and } x_{\max } \text {. }
$$


For dose calculations, the number of persons present in each isopleth is given by

$$
P_{i}=P D \bar{A}_{i},
$$

where

$$
P D=\text { population density (persons } / \mathrm{km}^{2} \text { ) [POPD]. }
$$

\subsubsection{Short-Term Exposure}

For short-term exposures, the dose to an individual in each isopleth from inhalation and external radiation is calculated according to the methodology in Section 3.3.2.1 for individual doses by using the isopleth concentration values discussed in Section 3.4.1. The dose to each isopleth is determined by multiplying the total individual dose in each by the number of persons in the respective isopleth. The total collective population dose is obtained by summing over all isopleths.

\subsubsection{External Exposure from the Radioactive Cloud}

The external radiation dose to an individual in isopleth $j$ from the passing radioactive cloud is calculated as

$$
D_{\text {AirST }}(j)=S F_{A i r S T} K_{1} \sum_{\mathbf{i}} C_{\bar{A}_{i j}} D C F_{A i r}(i)
$$

where

$$
\begin{aligned}
D_{\text {AirST }}(j)= & \begin{array}{l}
\text { short-term external cloudshine (immersion) dose to an } \\
\text { individual in isopleth } j \text { (rem); }
\end{array} \\
S F_{\text {AirST }}= & \begin{array}{l}
\text { short-term shielding factor for air immersion: } 0=\text { full shielding, } \\
1=\text { no shielding (unitless), where }
\end{array} \\
& S F_{\text {AirST }}=O F_{\text {out } T}+O F_{\text {inST }} S F_{\text {Air }} ; \\
O F_{\text {outST }}= & \text { short-term fraction of population outdoors (unitless) [1-RFIE]; } \\
O F_{i n S T}= & \text { short-term fraction of population indoors (unitless) [RFIE]; } \\
S F_{A i r}= & \text { shielding factor afforded by various shelter types from } \\
& \text { cloudshine for different people, where } \\
& S F_{\text {Air }}=\sum_{k} F P_{k} S F_{k A i r} ; \\
F P_{k}= & \text { fraction of indoor population afforded shielding by shelter type } k \\
& {[\text { WSHLT(k)]; }} \\
S F_{k A i r}= & \text { shielding factor for shelter type } k \text { for cloudshine, } 0=\text { full } \\
& \text { shielding, } 1=\text { no shielding (unitless) [Table 3.5]; }
\end{aligned}
$$




$$
\begin{aligned}
K_{1}= & \text { conversion factor, } 3.7 \times 10^{12} \mathrm{rem}-\mathrm{Bq} / \mathrm{Sv}-\mathrm{Ci} ; \\
C_{\bar{A}_{i}}= & \text { time-integrated ground-level air concentration for radionuclide } i \\
& \text { in isopleth } j\left(\mathrm{Ci}-\mathrm{s} / \mathrm{m}^{3}\right) \text { [Equation } 3.86 \text { in conjunction with } \\
& \text { Equation } 3.14 \text { or } 3.15] ; \text { and } \\
D C F_{A i r}(i)= & \text { dose conversion factor for air submersion for radionuclide } i \\
& \left(\mathrm{~Sv} / \mathrm{Bq}-\mathrm{s} / \mathrm{m}^{3}\right) .
\end{aligned}
$$

\subsubsection{External Exposure from Ground-Deposited Radionuclides}

The external dose to an individual in isopleth $j$ from ground contamination following an accidental release is calculated as

$$
D_{G n d S T}(j)=S F_{G n d S T} T_{E x t} K_{2} \sum_{\mathrm{i}} C_{\bar{A}_{i j}} D C F_{G n d}(i),
$$

where

$$
\begin{aligned}
& D_{\text {GndST }}(j)=\text { short-term external groundshine dose to an individual in } \\
& \text { isopleth } j \text { (rem); } \\
& S F_{\text {GndST }}=\text { short-term shielding factor for external ground radiation: } 0=\text { full } \\
& \text { shielding, } 1=\text { no shielding (unitless), where } \\
& S F_{\text {GndST }}=O F_{\text {outST }}+O F_{\text {inST }} S F_{\text {Gnd }} \text {; } \\
& S F_{\text {Gnd }}=\text { shielding factor afforded by various shelter types from } \\
& \text { groundshine for different people, where } \\
& S F_{G n d}=\sum_{k} F P_{k} S F_{k G n d} \text {; } \\
& S F_{k G n d}=\text { shielding factor for shelter type } k \text { for groundshine: } 0=\text { full } \\
& \text { shielding, } 1 \text { = no shielding (unitless) [see Table 3.5]; } \\
& T_{E x t}=\text { short-term exposure time after plume passage }(h) \text { [HTEXP]; } \\
& K_{2}=\text { conversion factor, } 1.332 \times 10^{16} \mathrm{rem}-\mathrm{Bq}-\mathrm{s} / \mathrm{Sv}-\mathrm{Ci}-\mathrm{h} \text {; } \\
& C_{\bar{A}_{i j}}=\text { initial ground concentration from wet and dry deposition for } \\
& \text { radionuclide } i \text { in isopleth } j \text { after plume passage }\left(\mathrm{Ci} / \mathrm{m}^{2}\right) \\
& \text { [Equation } 3.86 \text { in conjunction with Equation } 3.29 \text { or 3.30]; and } \\
& D C F_{G n d}(i)=\text { dose conversion factor for external radiation from the ground for }
\end{aligned}
$$




\subsubsection{Exposure from Inhaled Radionuclides}

The inhalation dose to an individual in isopleth $j$ from the passing radioactive cloud is calculated as

$$
D_{I n h S T}(j)=S F_{I n h S T} K_{3} B R \sum_{\mathrm{i}} C_{\bar{A}_{i j}} D C F_{I n h}(i)
$$

where

$$
\begin{aligned}
& D_{\text {InhST }}(j)=\text { short-term inhalation dose to an individual in isopleth } j(\mathrm{rem}) \text {; } \\
& S F_{\text {InhST }}=\text { short-term shielding factor for inhalation: } 0=\text { full shielding, } \\
& 1=\text { no shielding (unitless), where } \\
& S F_{\text {InhST }}=O F_{\text {outST }}+O F_{\text {insT }} S F_{\text {Inh }} \text {; } \\
& S F_{I n h}=\text { shielding factor afforded by various shelter types from } \\
& \text { inhalation for different people, where } \\
& S F_{\text {lnh }}=\sum_{k} F P_{k} S F_{k n h h} \text {; } \\
& \begin{aligned}
S F_{k l n h}= & \text { shielding factor for shelter type } k \text { for inhalation: } 0=\text { full } \\
& \text { shielding, } 1=\text { no shielding (unitless) [Table 3.5]; }
\end{aligned} \\
& K_{3}=\text { conversion factor, } 1.172 \times 10^{5} \mathrm{rem}-\mathrm{Bq}-\mathrm{yr} / \mathrm{Sv}-\mathrm{Ci}-\mathrm{s} \text {; } \\
& B R=\text { individual breathing rate for population calculations }\left(\mathrm{m}^{3} / \mathrm{yr}\right) \\
& \text { [BRTPOP]; }
\end{aligned}
$$

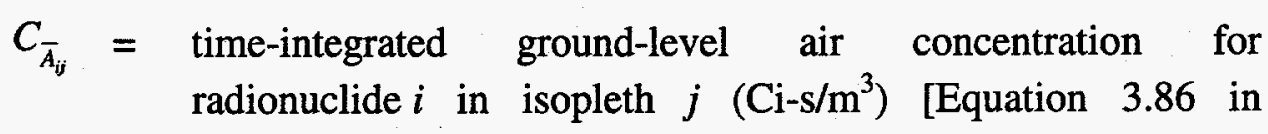

$$
\begin{aligned}
& \text { conjunction with Equation } 3.14 \text { or 3.15]; and } \\
& D C F_{I n h}(i)=\text { dose conversion factor for inhalation for radionuclide } i
\end{aligned}
$$

\subsubsection{External Exposure from Loss of Cask Shielding}

The shielding on the shipping cask may be compromised in an accident, resulting in increased levels of radiation. The collective dose is calculated for an annular region from $x_{\min }[\mathrm{XPZ}(1)]$ to $x_{\max }[\mathrm{XPZ}(2)]$ about the cask location in a manner similar to that for routine stops (Equation 2.6). The dose is calculated by

$$
D_{\text {caskST }}=2 \pi P D S F_{G n d S T} T_{E x t} \int_{x_{\min }}^{x_{\max }}\left[S L_{g} \dot{D}_{g}(r)+S L_{n} \dot{D}_{n}(r)\right] r d r,
$$


where

$$
\begin{aligned}
& D_{\text {casksT }}=\text { short-term external dose to population around the shipping cask } \\
& \text { following an accident (person-rem); } \\
& P D=\text { population density }\left(\text { persons } / \mathrm{km}^{2}\right)[\mathrm{POPD}] \\
& S F_{\text {GndST }}=\text { short-term shielding factor for external ground radiation: } 0=\text { full } \\
& \text { shielding, } 1 \text { = no shielding (unitless) [Equation 3.93]; } \\
& T_{E x t}=\text { short-term exposure time after plume passage (h) [HTEXP]; } \\
& \dot{D}_{i}(r)=\text { dose rate from gamma }(i=\mathrm{g}) \text { or neutron }(i=\mathrm{n}) \text { radiation at a } \\
& \text { distance } r \text { meters from the cask surface (rem/h) [Equation 2.2]; } \\
& S L_{i}=\text { shielding loss factor for gamma }(i=g) \text { or neutron }(i=\mathrm{n}) \\
& \text { radiation from the cask, an integral multiple of the original } \\
& \text { routine dose rate }[\operatorname{SEXT}(\mathrm{i})] \text {; } \\
& x_{\min }=\text { minimum distance from the cask surface }(\mathrm{m})[\mathrm{XPZ}(1)] \text {; and } \\
& x_{\max }=\text { maximum distance from the cask surface }(\mathrm{m})[\mathrm{XPZ}(2)] \text {. }
\end{aligned}
$$

The total short-term dose to the collective population is the external dose from the shipping cask plus the sum of the doses over all isopleths, which in turn is the sum of the individual dose for each exposure pathway in a given isopleth times the number of persons in that isopleth.

$$
P D O S E_{S T}=\sum_{j} P_{j}\left[D_{A i r S T}(j)+D_{G n d S T}(j)+D_{l n h S T}(j)\right]+D_{C a s k S T}
$$

where

$$
\begin{aligned}
P D O S E_{S T}= & \text { collective dose from short-term exposure to an accidental } \\
& \text { release (person-rem). }
\end{aligned}
$$

\subsubsection{Long-Term Exposure}

For long-term exposures, the dose to an individual in each isopleth from inhalation and external radiation is calculated according to the methodology in Section 3.3.2.3 for individual doses by using the isopleth concentration values discussed in Section 3.4.1. The ingestion dose model described in Section 3.4.3.4 is similar to that used for individuals but is a societal dose model and is based on the amount of contaminated food produced. The dose to each isopleth is determined by multiplying the total individual dose (excluding the ingestion dose) in each isopleth by the number of persons in the respective isopleth and then adding the ingestion dose for that isopleth. The total collective population dose is obtained by summing over all isopleths. 


\subsubsection{External Doses from Resuspended Air Concentrations}

Long-term exposure to external radiation from resuspended air concentrations for an individual in isopleth $j$ is calculated according to

$$
D_{\text {AirLT }}(j)=S F_{\text {AirLT }} K_{1} \sum_{i} C_{\bar{A}_{i j}} D C F_{A i r}(i),
$$

where

$$
\begin{aligned}
& D_{\text {AirLT }}(j)=\text { long-term external cloudshine (immersion) dose to an individual } \\
& S F_{\text {AirLT }}=\text { long-term shielding factor for air immersion: } 0=\text { full shielding, } \\
& 1 \text { = no shielding (unitless), where } \\
& S F_{\text {AirLT }}=O F_{\text {out }}+O F_{\text {in }} S F_{\text {Air }} \text {; } \\
& O F_{\text {out }}=\text { long-term fraction of population outdoors (unitless) } \\
& \text { [OCUPF }(1,1)] \text {; } \\
& O F_{i n}=\text { long-term fraction of population indoors (unitless) } \\
& \text { [OCUPF }(1,2)] \text {; } \\
& S F_{A i r}=\text { shielding factor afforded by various shelter types from } \\
& \text { cloudshine for different people, where } \\
& S F_{A i r}=\sum_{k} F P_{k} S F_{k A i r} \\
& K_{1}=\text { conversion factor, } 3.7 \times 10^{12} \mathrm{rem}-\mathrm{Bq} / \mathrm{Sv}-\mathrm{Ci} \text {; } \\
& C_{\overline{A_{i j}}}=\text { time-integrated ground-level resuspended air concentration for } \\
& \text { radionuclide } i \text { in isopleth } j\left(\mathrm{Ci}-\mathrm{s} / \mathrm{m}^{3}\right) \text { [Equation } 3.86 \text { in } \\
& \text { conjunction with Equation 3.57]; and } \\
& D C F_{A i r}(i)=\text { dose conversion factor for air submersion for radionuclide } i
\end{aligned}
$$

\subsubsection{External Exposure from Ground-Deposited Radionuclides}

The long-term dose to an individual in isopleth $j$ from ground-deposited radionuclides is given by

$$
D_{G n d L T}(j)=S F_{G n d L T} K_{1} \sum_{i} C_{\bar{A}_{i j}} D C F_{G n d}(i)
$$


where

$$
\begin{aligned}
& \begin{aligned}
D_{G n d L T}(j)= & \text { long-term external groundshine dose to an individual in } \\
& \text { isopleth } j(\mathrm{rem}) ;
\end{aligned} \\
& S F_{\text {GndLT }}=\text { long-term shielding factor for external ground radiation: } \\
& 0=\text { full shielding, } 1=\text { no shielding (unitless), where } \\
& S F_{\text {GndLT }}=O F_{\text {out }}+O F_{\text {in }} S F_{\text {Gnd }} ; \\
& S F_{G n d}=\text { shielding factor afforded by various shelter types from } \\
& \text { groundshine for different people, where } \\
& S F_{\text {Gnd }}=\sum_{k} F P_{k} S F_{k G n d} ; \\
& K_{1}=\text { conversion factor, } 3.7 \times 10^{12} \mathrm{rem}-\mathrm{Bq} / \mathrm{Sv}-\mathrm{Ci} \text {; } \\
& C_{\bar{A}_{i j}}=\text { time-integrated ground concentration for radionuclide } i \text { in }
\end{aligned}
$$

\subsubsection{Inhalation Doses from Resuspended Air Concentrations}

The long-term inhalation dose from resuspended air concentrations to an individual in isopleth $j$ is calculated by

$$
D_{I n h L T}(j)=S F_{\text {InhLT }} K_{3} B R \sum_{i} C_{\bar{A}_{i j}} D C F_{l n h}(i),
$$

where

$$
\begin{aligned}
D_{I n h L T}(j)= & \text { long-term inhalation dose to an individual in isopleth } j(\mathrm{rem}) ; \\
S F_{I n h L T}= & \text { long-term shielding factor for inhalation: } 0=\text { full shielding, } 1= \\
& \text { no shielding (unitless), where } \\
& S F_{\text {InhLT }}=O F_{\text {out }}+O F_{\text {in }} S F_{\text {Inh }} ; \\
S F_{I n h}= & \text { shielding factor afforded by various shelter types from } \\
& \text { inhalation for different people, where } \\
& S F_{I n h}=\sum_{k} F P_{k} S F_{k n h} ; \\
K_{3}= & \text { conversion factor, } 1.172 \times 10^{5} \text { rem-Bq-yr/Sv-Ci-s; } \\
B R= & \text { individual breathing rate for population calculations }\left(\mathrm{m}^{3} / \mathrm{yr}\right) \\
& {[\text { BRTPOP]; }}
\end{aligned}
$$




\section{$C_{\bar{A}_{i j}}=$ time-integrated resuspended ground-level air concentration for radionuclide $i$ in isopleth $j\left(\mathrm{Ci}-\mathrm{s} / \mathrm{m}^{3}\right)$ [Equation 3.86 in conjunction with Equation 3.57]; and \\ $D C F_{\text {Inh }}(i)=$ dose conversion factor for inhalation for radionuclide $i$ $(\mathrm{Sv} / \mathrm{Bq})$.}

\subsubsection{Ingestion Dose Model}

Unlike the other population dose models, the ingestion dose model is based on the societal dose concept. The total collective dose from ingestion pathways is calculated on the basis of regional agricultural productivity rather than the local population because the total radioactive contamination in the food determines the potential collective doses. Because all food may not be consumed locally, ingestion population doses are calculated by using the following procedures.

The annual productivity $\left(\mathrm{kg} / \mathrm{km}^{2}\right.$-yr) of each food category (vegetables, meat, and milk) is assigned by the user; these productivity values can be either site-specific data or the default state average values. For each nested isopleth, the mean radionuclide concentrations in each food type are calculated by using the approach in Section 3.3.2.2. The values are then multiplied by the farm production rate and the farm area to find the total radioactive contamination in each food for each area $\left(A_{j}\right)$. Collective doses are then determined by assuming that either all or some fraction of the food produced in the contaminated region of interest is eventually consumed.

First, the total amount of radioactive contamination in each food type is calculated according to

$$
Q_{f}(i, j)=K_{6} G_{f} \bar{A}_{j} F_{f a r m} U F_{f} C_{\bar{A}_{\bar{b}}},
$$

where

$$
\begin{aligned}
Q_{f}(i, j)= & \begin{array}{l}
\text { gross content of radionuclide } i \text { produced in isopleth } j \text { in food type } f, \\
\text { where } f \text { represents } v \text { for vegetables, } b \text { for meat, and } m \text { for milk } \\
(\text { Ci }) ;
\end{array} \\
K_{6}= & \text { conversion constant, } 1 /\left(3.156 \times 10^{7} \mathrm{~s} / \mathrm{yr}\right) ; \\
G_{f}= & \text { farm production rate of food type } f\left(\mathrm{~kg} / \mathrm{yr}-\mathrm{km}^{2}\right) \text { [GVEGE, } \\
& \text { GMEAT, or GMILK]; } \\
\bar{A}_{j}= & \text { area encompassed by isopleth } j\left(\mathrm{~km}^{2}\right) \text { [Equation 3.85]; } \\
F_{f a r m}= & \text { fraction of land that is farmland (unitless) [FARM]; }
\end{aligned}
$$




$$
\begin{aligned}
U F_{f}= & \text { fraction of contaminated food type } f \text { produced that is consumed by } \\
& \text { humans (unitless) [UF(f)]; and } \\
C_{\bar{A}_{\mathfrak{f}}}= & \text { time-integrated concentration of radionuclide } i \text { in food type } f \text { in } \\
& \text { isopleth } j \quad(\mathrm{Ci}-\mathrm{s} / \mathrm{kg}) \text { [Equation } 3.86 \text { in conjunction with } \\
& \text { Equation } 3.60,3.61 \text {, or } 3.62] .
\end{aligned}
$$

Next, the dose from each food category is calculated for each isopleth. The societal dose from vegetables grown in isopleth $j$ is calculated as

$$
P D O S E_{V e g}(j)=D F K_{1} \sum_{i} Q_{v}(i, j) D C F_{\text {Ing }}(i)
$$

where

$$
\begin{aligned}
& P D O S E_{V e g}(j)=\text { societal dose from ingestion of contaminated vegetables } \\
& \text { produced in isopleth } j \text { (person-rem); } \\
& D F=\text { decontamination factor, that is, fraction of contamination } \\
& K_{1}=\text { conversion factor, } 3.7 \times 10^{12} \mathrm{rem}-\mathrm{Bq} / \mathrm{Sv}-\mathrm{Ci} \text {; } \\
& Q_{v}(i, j)=\text { gross content of radionuclide } i \text { produced in isopleth } j \text { in } \\
& \text { vegetables (Ci) [Equation 3.109]; and } \\
& \begin{aligned}
D C F_{\text {Ing }}(i)= & \text { dose conversion factor for ingestion for radionuclide } i \\
& (\mathrm{~Sv} / \mathrm{Bq}) .
\end{aligned}
\end{aligned}
$$

The societal dose from meat products is calculated as

$$
P D O S E_{\text {Meat }}(j)=K_{1} \sum_{i} Q_{b}(i, j) D C F_{\text {Ing }}(i)
$$

where

$$
\begin{aligned}
P D O S E_{\text {Meat }}(j)= & \text { societal dose from ingestion of contaminated meat grown in } \\
& \text { isopleth } j \text { (person-rem); and } \\
Q_{b}(i, j)= & \text { gross content of radionuclide } i \text { produced in isopleth } j \text { in } \\
& \text { meat (Ci) [Equation 3.109]. }
\end{aligned}
$$

The societal dose from milk products is calculated as

$$
P D O S E_{\text {Milk }}(j)=K_{1} \sum_{i} Q_{m}(i, j) D C F_{\text {lng }}(i),
$$


where

$$
\begin{aligned}
P D O S E_{\text {Milk }}(j)= & \text { societal dose from ingestion of contaminated milk produced } \\
& \text { in isopleth } j \text { (person-rem); and } \\
Q_{m}(i, j)= & \text { gross content of radionuclide } i \text { produced in isopleth } j \text { in } \\
& \text { milk }(\mathrm{Ci}) \text { [Equation 3.109]. }
\end{aligned}
$$

If water ingestion for a population analysis is specified, water ingestion doses are calculated in a manner similar to that for individuals in Section 3.3.2.3.5. The only real difference is the multiplication of the individual dose by the number of persons drinking from a specific water body.

$$
P D O S E_{\text {Water }}(k)=P_{\text {Water }}(k) U_{w} K_{5} \sum_{i} \bar{C}_{w}(i, x, y, T) D C F_{\text {Ing }}(i),
$$

where

$$
\begin{aligned}
P D O S E_{\text {Water }}(k)= & \begin{array}{l}
\text { dose to receptors from ingestion of contaminated water } \\
\text { from water body } k \text { (person-rem); }
\end{array} \\
P_{\text {water }}(k)= & \begin{array}{l}
\text { number of persons drinking from water body } k \\
{[\mathrm{POPW}(\mathrm{k})] ;}
\end{array} \\
U_{w}= & \text { human consumption rate of water }(\mathrm{L} / \mathrm{d})[\mathrm{XING}(5)] ; \\
K_{5}= & \text { conversion factor, } 1.351 \times 10^{12} \mathrm{rem}-\mathrm{Bq}-\mathrm{d}-\mathrm{m}^{3} / \mathrm{Sv}-\mathrm{Ci}-\mathrm{yr}-\mathrm{L} ; \\
\bar{C}_{w}(i, x, y, T)= & \begin{array}{l}
\text { time-integrated radionuclide } i \text { concentration in water body } \\
\text { at location } x, y \text { at time } T \text { after puff passage }\left(\mathrm{Ci}-\mathrm{yr} / \mathrm{m}^{3}\right)
\end{array} \\
& {[\text { Equation } 3.67] ; \text { and } } \\
D C F_{\text {Ing }}(i)= & \begin{array}{l}
\text { dose conversion factor for ingestion for radionuclide } i \\
\end{array}
\end{aligned}
$$

The total ingestion dose is given by the summation over the food categories in each isopleth, added to the sum over all water bodies selected:

$$
P D O S E_{\text {Ing }}=\sum_{j}\left\{\left[P D O S E_{V e g}(j)+P D O S E_{\text {Meat }}(j)+P \operatorname{POSE} E_{\text {Milk }}(j)\right]\right\}+\sum_{j} P D O S E_{\text {Water }}(k),(3.114)
$$

where

$$
\begin{aligned}
P D O S E_{\text {lng }}= & \begin{aligned}
& \text { societal ingestion dose following an accidental release (person- } \\
& \text { rem) }
\end{aligned} \\
j= & \text { index over isopleths, and } \\
k= & \text { index over water bodies. }
\end{aligned}
$$


In turn, the total collective long-term dose is the sum of all pathways over all isopleths, plus the societal ingestion dose and is calculated as

$$
P D O S E_{L T}=\sum_{j} P_{j}\left[D_{\text {AirLT }}(j)+D_{G n d L T}(j)+D_{\text {InhLT }}(j)\right]+P D O S E_{\text {Ing }},
$$

where

$$
\begin{aligned}
P D O S E_{L r}= & \text { collective dose from long-term exposure to an accidental } \\
& \text { release (person-rem). }
\end{aligned}
$$

Finally, the total collective population dose (person-rem) is calculated as the sum of the doses from short- and long-term exposures:

$$
P D O S E=P D O S E_{S T}+P D O S E_{L T} .
$$

\subsubsection{Protective Action Guidelines}

The EPA has published suggested PAGs dealing with exposure to accidental radioactive releases (EPA 1991). These guidelines deal with the early (short-term) and later (long-term) phases following an accidental release. Early phase considerations are not implemented in RISKIND because forewarning (i.e., time to mitigate potential exposure) of an accidental transport-related release may not be likely. On the other hand, cleanup of soil contamination to safer levels might be a viable solution over the long term. On the basis of a PAG value input by the user, the program will estimate the maximum soil concentrations necessary to maintain radiation exposure over the long term at the PAG limit. These concentrations are calculated to give the user an assessment of the amount of cleanup necessary to achieve the specified PAG limit, not for analyzing mitigative cleanup actions.

RISKIND performs an auxiliary set of calculations for a given population isopleth if an average individual in that isopleth were to receive a long-term dose greater than the userspecified PAG over the course of the specified exposure time [YEVD]. Calculations are then performed to determine the maximum contaminant ground concentrations allowable that will still meet the PAG limit. A second table of isopleth ground concentration values after cleanup is listed in the program output for comparison with the levels calculated following release. Shortterm and water ingestion doses are not considered in the calculations. 


\section{HEALTH EFFECTS MODELS}

This section discusses the health effects models and parameters used in RISKIND. Potential early health effects from acute, short-term high dose rate exposures from a hypothetical severe accident scenario are addressed, as well as the latent health effects from short- and longterm low dose rate exposures incurred during routine transport or from potential accident events.

Early health effects are nonstochastic effects that are associated with the degree of radiation trauma received by such vital body organs as the bone marrow, the lungs, or the gastrointestinal (GI) tract (Evans et al. 1985; Abrahamson et al. 1989, 1991). These effects exhibit a nonlinear, threshold relationship with dose and are typically measured in acute lethality. Absorbed dose is used for assessing the early health effects. Section 4.1 describes the method for estimating the absorbed doses and assessing early health effects.

Latent health effects, on the other hand, are stochastic effects where the chance of contracting such an effect increases with the radiation dose received by the organs. Stochastic health effects exhibit a linear, nonthreshold relationship with dose (National Research Council 1990) and are typically measured in cancer incidence, cancer fatality, or genetic effects. Because of the assumed linear relationship with dose, latent health effects are conveniently related to the dose (in terms of effective dose equivalent) by simple health effects conversion factors (ICRP 1991) described in Section 4.2.

\subsection{EARLY EFFECTS}

A health effects model was developed for early (acute) effects of short-term exposure to radiation from transportation accidents involving radioactive materials. The model applies to hypothetical accident conditions in which individuals would be exposed to relatively large doses in a short period of time. The early effects estimated are fatalities that might occur within the first year after radiation exposure. The model is based on the NRC health effects study (Evans et al. 1985; Abrahamson et al. 1989, 1991). The fatalities modeled are the result of injury to the (1) bone marrow (hematopoietic syndrome), (2) GI tract (GI syndrome), and (3) lungs (pulmonary syndrome). Dose responses for basic first aid and more extensive medical treatment are provided. Also, options are available for bounding model parameters at three estimation levels - lower, central (assumed to be the most realistic), and upper - to compensate for uncertainty associated with the model.

Two basic categories of acute dose are considered: brief and protracted. Brief dose is due to sudden exposure during the short-term period immediately following an accidental release. The brief dose includes the dose received from inhalation within the first 24 hours of a release, as well as the external dose due to external gamma rays from a passing radioactive cloud, the radionuclide-contaminated ground surface, or loss of cask shielding. Protracted dose is the 
dose due to internal exposure from inhaled radionuclides during the short-term period, up to one year from the time of release. For radiation exposure resulting from SNF transportation accidents, the first dose category is usually not as significant as the second because SNFs generally contain a significant portion of radionuclides that can potentially deliver internal doses over a longer period of time after intake.

\subsubsection{Dose and Dose Rate Estimation}

For the health risk calculation, radiation dose refers to the average absorbed dose (units of $\mathrm{rad}$ or $\mathrm{Gy}, 1 \mathrm{~Gy}=100 \mathrm{rad}$ ) to the specific organ of interest. Dose rate refers to the average absorbed dose rate to the target organ of interest over a given time period from external and inhalation exposure. The early effects of exposure are generally associated only with relatively high radiation dose rates $\geqq 0.06 \mathrm{~Gy} / \mathrm{h}$ ); the severity of these effects diminishes with lower dose levels. This dose-response relationship implies a dose threshold below which no early effects are apparent.

\subsubsection{Absorbed Dose}

The radiation trauma, that is, physical damage, induced by high dose rates can be quantified in terms of the absorbed dose. The doses estimated in Sections 2 and 3 are in terms of the effective dose equivalent (units of $\mathrm{Sv}$ or rem, $1 \mathrm{~Sv}=100 \mathrm{rem}$ ), which considers both physical and biological factors. The effective dose equivalent is a weighted average of organ dose equivalents. The dose equivalent is estimated by multiplying the absorbed dose by a weighting factor, referred to as the quality factor $(Q$, International Commission on Radiation Units and Measurements 1993), since some types of radiation are more destructive than others. The quality factor takes into account the relative biological effectiveness (RBE) of different radiation types and energies. Weighting factors of 1,10 , and 20 are recommended by the ICRP (1991) for gamma, neutron, and alpha radiation, respectively. Therefore, an absorbed dose of 1 rad from gamma radiation is equivalent to an equivalent dose of $1 \mathrm{rem}$; an absorbed dose of $1 \mathrm{rad}$ from neutron radiation is equivalent to an equivalent dose of $10 \mathrm{rem}$.

As discussed in the following subsections, the methodology for estimating some absorbed doses will be similar to that used in Section 3. However, organ-specific dose DCFs are used in place of the effective DCFs, and the estimated dose is then adjusted by using the suggested $Q$ weighting factors, if the dose is a result of alpha or neutron radiation.

\subsubsection{External Exposure}

The brief external doses to the three target organs can be calculated according to Equations 3.47 and 3.48 in Section 3 for radioactive cloud and contaminated ground exposure, respectively, by substituting organ-specific DCFs (Eckerman and Ryman 1993) for whole body 
DCFs. The dose rates to each organ are calculated by dividing the individual organ doses by the short-term exposure time used in Equations 3.47 and 3.48. For exposure from loss of cask shielding, the equivalent dose to each organ is calculated according to Equation 3.49. The neutron radiation portion of the dose is adjusted by the weighting factor of 10 to obtain the absorbed dose. The dose rate is calculated by dividing the absorbed dose by the time of exposure $\left[T_{\text {ext }}(j)\right]$.

\subsubsection{Inhalation Exposure}

Currently, no published DCFs are available for the target organs and specific time intervals of interest for estimating early effects from accidental radionuclide exposure from inhalation. The shortest time period for which DCFs are available is 1 year for selected target organs, as derived by Dunning (1986). A simplified method is used in RISKIND to interpolate doses and dose rates from Dunning's 1-year DCFs to factors for shorter, specified periods of time.

The inhalation dose rate to a target organ (and therefore the resulting dose) following an acute radionuclide exposure may be related to the rate of clearance or the retention function of the body. The radionuclide metabolic model and model parameters have been described in various sections of ICRP Publication 30 (ICRP 1979-1982). The ICRP model assumes that radionuclide retention in the lungs and other organs can be represented by either a single or linear combination of up to five exponential functions, except for the alkaline earth elements (calcium, strontium, barium, and radium). For these elements, a combination of exponential and power functions were considered more appropriate (ICRP 1972).

In RISKIND, as in the ICRP model, retention of radionuclides in all organs or tissues is assumed to be a single or linear combination of exponential functions. For the alkaline earth elements, the retention in the body over the first 365 days following exposure is represented by the sum of two exponential functions. This expression is constructed from a least-squares fit of the retention data given in ICRP Publication 20 (ICRP 1972). The retention function for any radionuclide in one of the three target organs is given by a single exponential function $(j=1)$ or a linear combination of exponential functions $(j>1)$ of the form

$$
R(i, k, t)=\sum_{j} a(i, j, k) \exp \left\{-\left[\lambda_{b}(i, j, k)+K_{6} \lambda(i)\right] t\right\},
$$

where

$$
\begin{aligned}
R(i, k, t)= & \text { retention of radionuclide } i \text { in organ } k \text { after time } t \text { (unitless); } \\
a(i, j, k)= & \text { fraction of radionuclide } i \text { originally absorbed in subcompart- } \\
& \text { ment } j \text { of organ } k \text { (unitless) [Tables } 4.1 \text { and 4.2], where }
\end{aligned}
$$




$$
\begin{aligned}
& \sum_{j} a(i, j, k)=1 \\
\lambda_{b}(i, j, k)= & \text { biological removal constant for radionuclide } i \text { in subcompartment } \\
& j \text { of organ } k, 0.693 / T_{b}(i, j, k)(1 / \mathrm{d}) \text { [Tables } 4.1 \text { and } 4.2 \text { for values of } \\
& \left.T_{b}(i, j, k)\right] ; \\
K_{6}= & \text { conversion constant, } 1 / 365.25(\mathrm{yr} / \mathrm{d}) ; \\
\lambda(i)= & \text { radioactive decay constant for radionuclide } i(1 / \mathrm{yr}) ; \text { and } \\
t= & \text { time since exposure }(\mathrm{d}) ;
\end{aligned}
$$

The retention parameters for the lungs and bone marrow are given in Tables 4.1 and 4.2, respectively. The dose rate and dose to each part of the GI tract (i.e., stomach, small intestine, upper large intestine, and lower large intestine [LLI]) are a function of the radionuclide residence

\begin{tabular}{|c|c|c|c|c|c|c|}
\hline \multirow[b]{2}{*}{ Subcompartment (j) } & \multicolumn{2}{|c|}{ Translocation Class $Y$} & \multicolumn{2}{|c|}{ Translocation Class W } & \multicolumn{2}{|c|}{ Translocation Class D } \\
\hline & $\begin{array}{l}\text { Fraction } \\
\text { Absorbed } \\
{[\mathrm{a}(\mathrm{i}, \mathrm{j}, 1)]^{\mathrm{a}}}\end{array}$ & $\begin{array}{c}\text { Biological } \\
\text { Half-Life } \\
{\left[\mathrm{T}_{\mathrm{b}}(\mathrm{i}, \mathrm{j}, 1)\right]^{\mathrm{b}}} \\
\text { (days) }\end{array}$ & $\begin{array}{c}\text { Fraction } \\
\text { Absorbed } \\
{[\mathrm{a}(\mathrm{i}, \mathrm{j}, 1)]}\end{array}$ & $\begin{array}{c}\text { Biological } \\
\text { Half-Life } \\
{\left[\mathrm{T}_{\mathrm{b}}(\mathrm{i}, \mathrm{j}, 1)\right]} \\
\text { (days) }\end{array}$ & $\begin{array}{c}\text { Fraction } \\
\text { Absorbed } \\
{[\mathrm{a}(\mathrm{i}, \mathrm{j}, 1)]}\end{array}$ & $\begin{array}{c}\text { Biological } \\
\text { Half-Life } \\
{\left[\mathrm{T}_{\mathrm{b}}(\mathrm{i}, \mathrm{j}, 1)\right]} \\
\text { (days) } \\
\end{array}$ \\
\hline 1 & 0.6 & 500 & 0.6 & 50 & 1 & 0.5 \\
\hline 2 & 0.4 & 1 & 0.4 & 1 & & \\
\hline
\end{tabular}
period and the quantity absorbed from the gut into the blood pool. Of the four parts of the GI tract, the LLI is considered to be the critical section because it has the longest transit time. The retention function for the GI tract consists of one exponential $[a(i, 1,3)=1]$ that uses a biological half-life of 0.75 days $\left[\lambda_{b}(i, 1,3)\right]$, which corresponds to a mean residence time of 18 hours in the LLI.

TABLE 4.1 Retention Parameters for the Lungs for Each Translocation Class

a $a$ fraction of radionuclide originally absorbed in subcompartment of the lungs.

b $\mathrm{T}_{\mathrm{b}}=$ biological half-life of radionuclide in subcompartment $j$ of the lungs.

Source: ICRP (1972). 
TABLE 4.2 Retention Parameters for Bone Marrow Dose Calculations

\begin{tabular}{|c|c|c|c|c|c|c|c|c|}
\hline \multirow[b]{2}{*}{ Element } & \multicolumn{2}{|c|}{ Subcompartment 1} & \multicolumn{2}{|c|}{ Subcompartment 2} & \multicolumn{2}{|c|}{ Subcompartment 3} & \multicolumn{2}{|c|}{ Subcompartment 4} \\
\hline & $\begin{array}{l}\text { Fraction } \\
\text { Absorbed } \\
{\left[\mathrm{a}(\mathrm{i}, 1,2)^{\mathrm{a}}\right]}\end{array}$ & $\begin{array}{c}\text { Biological } \\
\text { Half-Life } \\
{\left[\mathrm{T}_{\mathrm{b}}(\mathrm{i}, 1,2)^{\mathrm{b}}\right.} \\
\text { (days)] }\end{array}$ & $\begin{array}{l}\text { Fraction } \\
\text { Absorbed } \\
{[\mathrm{a}(\mathrm{i}, 2,2)]}\end{array}$ & $\begin{array}{c}\text { Biological } \\
\text { Half-Life } \\
{\left[\mathrm{T}_{b}(\mathrm{i}, 2,2)\right.} \\
\text { (days)] }\end{array}$ & $\begin{array}{l}\text { Fraction } \\
\text { Absorbed } \\
{[\mathrm{a}(\mathrm{i}, 3,2)]}\end{array}$ & $\begin{array}{c}\text { Biological } \\
\text { Half-Life } \\
{\left[\mathrm{T}_{\mathrm{b}}(\mathrm{i}, 3,2)\right.} \\
\text { (days)] } \\
\end{array}$ & $\begin{array}{l}\text { Fraction } \\
\text { Absorbed } \\
{[a(i, 4,2)]}\end{array}$ & $\begin{array}{c}\text { Biological } \\
\text { Half-Life } \\
{\left[T_{b}(i, 4,2)\right.} \\
\text { (days) }] \\
\end{array}$ \\
\hline $\mathbf{H}$ & 1 & 0 & 0 & 0 & 0 & 0 & 0 & 0 \\
\hline $\mathrm{Be}$ & 1 & 0 & 0 & 0 & 0 & 0 & 0 & 0 \\
\hline C & 1 & 40 & 0 & 0 & 0 & 0 & 0 & 0 \\
\hline $\mathbf{N}$ & 1 & 0 & 0 & 0 & 0 & 0 & 0 & 0 \\
\hline $\mathrm{F}$ & 1 & 0 & 0 & 0 & 0 & 0 & 0 & 0 \\
\hline $\mathrm{Na}$ & $\mathbf{l}$ & 10 & 0 & 0 & 0 & 0 & 0 & 0 \\
\hline $\mathbf{P}$ & 1 & 0 & 0 & 0 & 0 & $\mathbf{0}$ & $\mathbf{0}$ & 0 \\
\hline $\mathbf{S}$ & 0.75 & 20 & 0.25 & 2,000 & 0 & 0 & 0 & 0 \\
\hline $\mathrm{Cl}$ & 1 & 10 & 0 & 0 & 0 & 0 & $\mathbf{0}$ & 0 \\
\hline $\mathrm{Ca}$ & 0.5 & 6.9 & 0.5 & 1,650 & $\mathbf{0}$ & 0 & 0 & 0 \\
\hline Sc & 0.1 & 5 & 0.9 & 1,500 & 0 & 0 & 0 & 0 \\
\hline $\mathrm{Cr}$ & 0.62 & 6 & 0.38 & 80 & $\mathbf{0}$ & 0 & 0 & 0 \\
\hline $\mathbf{M n}$ & 1 & 0 & 0 & 0 & 0 & 0 & 0 & 0 \\
\hline $\mathrm{Fe}$ & 1 & 2,000 & 0 & 0 & 0 & 0 & 0 & 0 \\
\hline $\mathrm{Co}$ & 0.6 & 6 & 0.2 & 60 & 0.2 & 800 & 0 & 0 \\
\hline $\mathrm{Ni}$ & 1 & 1,200 & 0 & 0 & 0 & 0 & 0 & 0 \\
\hline $\mathrm{Cu}$ & 1 & 40 & 0 & 0 & 0 & 0 & 0 & 0 \\
\hline $\mathrm{Zn}$ & 0.3 & 20 & 0.7 & 400 & 0 & 0 & 0 & 0 \\
\hline $\mathrm{Se}$ & 0.1 & 3 & 0.4 & 30 & 0.5 & 160 & 0 & 0 \\
\hline $\mathrm{Br}$ & 1 & 10 & 0 & 0 & 0 & 0 & 0 & 0 \\
\hline $\mathrm{Kr}$ & 1 & 0 & 0 & 0 & 0 & 0 & 0 & 0 \\
\hline $\mathbf{R b}$ & 1 & 44 & 0 & 0 & 0 & 0 & 0 & 0 \\
\hline Sr & 0.78 & 3 & 0.22 & 963 & 0 & 0 & 0 & 0 \\
\hline $\mathbf{Y}$ & 1 & 36,500 & 0 & 0 & 0 & 0 & 0 & 0 \\
\hline $\mathrm{Zr}$ & 1 & 7 & 0 & 0 & 0 & 0 & 0 & 0 \\
\hline $\mathrm{Nb}$ & 0.5 & 6 & 0.5 & 200 & 0 & 0 & 0 & 0 \\
\hline Mo & 0.1 & 1 & 0.9 & 50 & 0 & 0 & 0 & 0 \\
\hline Tc & 1 & 1.6 & 0 & 3.7 & 0 & 22 & 0 & 0 \\
\hline $\mathbf{R u}$ & 0.15 & 0.3 & 0.35 & 8 & 0.3 & 35 & 0.2 & 1,000 \\
\hline $\mathbf{R h}$ & 0.15 & 0.3 & 0.35 & 8 & 0.3 & 35 & 0.2 & 1,000 \\
\hline Pd & 1 & 15 & 0 & 0 & 0 & 0 & 0 & 0 \\
\hline $\mathrm{Ag}$ & 0.1 & 3.5 & 0.9 & 50 & 0 & 0 & 0 & 0 \\
\hline $\mathrm{Cd}$ & 1 & 2.5 & 0 & 0 & 0 & 0 & 0 & 0 \\
\hline In & 1 & 36,500 & 0 & 0 & 0 & 0 & 0 & 0 \\
\hline Sn & 0.2 & 4 & 0.2 & 25 & 0.6 & 400 & 0 & 0 \\
\hline $\mathrm{Sb}$ & 0.95 & 5 & 0.05 & 100 & 0 & 0 & 0 & 0 \\
\hline $\mathrm{Te}$ & 1 & 20 & 0 & 0 & 0 & 0 & 0 & 0 \\
\hline I & 1 & 0 & 0 & 0 & 0 & 0 & 0 & 0 \\
\hline Cs & 0.1 & 2 & 0.9 & 110 & 0 & 0 & 0 & 0 \\
\hline $\mathbf{B a}$ & 0.92 & 0.9 & 0.09 & 592 & 0 & 0 & 0 & 0 \\
\hline $\mathrm{La}$ & 1 & 3,500 & 0 & 0 & 0 & 0 & 0 & 0 \\
\hline Ce & 1 & 3,500 & 0 & 0 & 0 & 0 & 0 & 0 \\
\hline Pr & 1. & 3,500 & 0 & 0 & 0 & 0 & 0 & 0 \\
\hline Nd & 1 & 3,500 & 0 & 0 & 0 & 0 & 0 & 0 \\
\hline Pm & 1 & 3,500 & 0 & 0 & 0 & 0 & 0 & 0 \\
\hline Sm & 1 & 3,500 & 0 & 0 & 0 & 0 & 0 & 0 \\
\hline $\mathrm{Eu}$ & 1 & 3,500 & 0 & 0 & 0 & 0 & 0 & 0 \\
\hline Gd & 1 & 3,500 & 0 & 0 & 0 & 0 & 0 & 0 \\
\hline $\mathrm{Tb}$ & 1 & 3,500 & 0 & 0 & 0 & 0 & 0 & 0 \\
\hline Ho & 1 & 3,500 & 0 & 0 & 0 & 0 & 0 & 0 \\
\hline $\mathrm{Tm}$ & 1 & 3,500 & 0 & 0 & 0 & 0 & 0 & 0 \\
\hline Hf & 1 & 7 & 0 & 0 & 0 & 0 & 0 & 0 \\
\hline $\mathrm{Ta}$ & 0.5 & 4 & 0.5 & 100 & 0 & 0 & 0 & 0 \\
\hline W & 1 & 0 & 0 & 0 & 0 & 0 & 0 & 0 \\
\hline $\mathbf{R e}$ & 0.75 & 1.6 & 0.2 & 3.7 & 0.05 & 22 & 0 & 0 \\
\hline
\end{tabular}


TABLE 4.2 (Cont.)

\begin{tabular}{|c|c|c|c|c|c|c|c|c|}
\hline \multirow[b]{2}{*}{ Element } & \multicolumn{2}{|c|}{ Subcompartment 1} & \multicolumn{2}{|c|}{ Subcompartment 2} & \multicolumn{2}{|c|}{ Subcompartment 3} & \multicolumn{2}{|c|}{ Subcompartment 4} \\
\hline & $\begin{array}{l}\text { Fraction } \\
\text { Absorbed } \\
{\left[\mathrm{a}(\mathrm{i}, 1,2)^{\mathrm{a}}\right]}\end{array}$ & $\begin{array}{c}\text { Biological } \\
\text { Half-Life } \\
{\left[\mathrm{T}_{\mathrm{b}}(\mathrm{i}, 1,2)^{\mathrm{b}}\right.} \\
\text { (days)] } \\
\end{array}$ & $\begin{array}{c}\text { Fraction } \\
\text { Absorbed } \\
{[\mathrm{a}(\mathrm{i}, 1,2)]}\end{array}$ & $\begin{array}{c}\text { Biological } \\
\text { Half-Life } \\
{\left[T_{b}(i, 1,2)\right.} \\
\text { days })] \\
\end{array}$ & $\begin{array}{l}\text { Fraction } \\
\text { Absorbed } \\
{[a(i, 1,2)]}\end{array}$ & $\begin{array}{c}\text { Biological } \\
\text { Half-Life } \\
{\left[\mathrm{T}_{\mathrm{b}}(\mathrm{i}, 1,2)\right.} \\
\text { days })]\end{array}$ & $\begin{array}{c}\text { Fraction } \\
\text { Absorbed } \\
{[\mathrm{a}(\mathrm{i}, 1,2)]}\end{array}$ & $\begin{array}{c}\text { Biological } \\
\text { Half-Life } \\
{\left[\mathrm{T}_{\mathrm{b}}(\mathrm{i}, 1,2)\right.} \\
\text { days })] \\
\end{array}$ \\
\hline $\mathrm{Pb}$ & 0.8 & 12 & 0.18 & 180 & 0.02 & 10,000 & 0 & 0 \\
\hline $\mathrm{Bi}$ & 0.6 & 0.6 & 0.4 & 5 & 0 & 0 & 0 & 0 \\
\hline Po & 1 & 50 & 0 & 0 & 0 & 0 & 0 & 0 \\
\hline $\mathbf{R n}$ & 1 & 0 & 0 & 0 & 0 & 0 & 0 & 0 \\
\hline $\mathbf{R a}$ & 0.92 & 1.3 & 0.08 & 413 & 0 & 0 & 0 & 0 \\
\hline Ac & 1 & 36,500 & 0 & 0 & 0 & 0 & 0 & 0 \\
\hline Th & 1 & 700 & 0 & 0 & 0 & 0 & 0 & 0 \\
\hline $\mathrm{Pa}$ & 1 & 36,500 & 0 & 0 & 0 & 0 & 0 & 0 \\
\hline $\mathrm{U}$ & 1 & 6 & 0 & 0 & 0 & 0 & 0 & 0 \\
\hline Np & 1 & 36,500 & 0 & 0 & $\mathbf{0}$ & 0 & 0 & 0 \\
\hline $\mathrm{Pu}$ & 1 & 18,200 & 0 & 0 & 0 & 0 & 0 & 0 \\
\hline Am & 1 & 18,200 & 0 & 0 & 0 & 0 & 0 & 0 \\
\hline $\mathrm{Cm}$ & 1 & 18,200 & 0 & 0 & 0 & 0 & 0 & 0 \\
\hline Cf & 1 & 18,200 & 0 & 0 & 0 & 0 & 0 & 0 \\
\hline
\end{tabular}

a $a=$ fraction of radionuclide originally absorbed in subcompartment of the bone marrow.

b $T_{b}=$ biological half-life of radionuclide in subcompartment of the bone marrow.

Source: ICRP (1972).

The dose received from a given radionuclide in the target organ over a period of time will be proportional to the time-integrated retention function:

$$
\bar{R}(i, k, t)=\sum_{j} \frac{a(i, j, k)\left\{1-\exp \left(-\left[\lambda_{b}(i, j, k)+K_{6} \lambda(i)\right] t\right)\right\}}{\lambda_{b}(i, j, k)+K_{6} \lambda(i)},
$$

where

$$
\begin{aligned}
& \bar{R}(i, k, t)=\text { time-integrated retention of radionuclide } i \text { in organ } k \text { after time } t \\
& \text { (unitless). }
\end{aligned}
$$

For any particular organ $k$ and radionuclide $i$, the ratio of time-integrated doses, $D\left(i, k, t_{1}\right)$ and $D\left(i, k, t_{2}\right)$, for time periods $t_{1}$ and $t_{2}$ following exposure is given by

$$
\frac{D\left(i, k, t_{1}\right)}{D\left(i, k, t_{2}\right)}=\frac{\bar{R}\left(i, k, t_{1}\right)}{\bar{R}\left(i, k, t_{2}\right)}=\frac{\sum_{j} \frac{a(i, j, k)\left(1-\exp \left\{-\left[\lambda_{b}(i, j, k)+K_{6} \lambda(i)\right] t_{1}\right\}\right)}{\lambda_{b}(\mathrm{i}, \mathrm{j}, \mathrm{k})+K_{6} \lambda(i)}}{\sum_{j} \frac{a(i, j, k)\left(1-\exp \left\{-\left[\lambda_{\mathrm{b}}(i, j, k)+K_{6} \lambda(i)\right] t_{2}\right\}\right)}{\lambda_{b}(i, j, k)+K_{6} \lambda(i)}} .
$$


Rearranging results in

$$
D\left(i, k, t_{1}\right)=D\left(i, k, t_{2}\right) \frac{\sum_{j} \frac{a(i, j, k)\left(1-\exp \left\{-\left[\lambda_{b}(i, j, k)+K_{6} \lambda(i)\right] t_{1}\right\}\right)}{\lambda_{b}(i, j, k)+K_{6} \lambda(i)}}{\sum_{j} \frac{a(i, j, k)\left(1-\exp \left\{-\left[\lambda_{b}(i, j, k)+K_{6} \lambda(i)\right] t_{2}\right\}\right)}{\lambda_{b}(i, j, k)+K_{6} \lambda(i)}},
$$

where

$$
\begin{aligned}
& D\left(i, k, t_{1}\right)= \text { acute absorbed dose from radionuclide } i \text { to target organ } k \text { from } \\
& \text { time period of interest } t_{1}(\mathrm{rad}) ; \text { and }
\end{aligned}
$$

$D\left(i, k, t_{2}\right)=$ acute absorbed dose from radionuclide $i$ to target organ $k$ from time period of interest $t_{2}$; in RISKIND, $t_{2}$ is set to 1 year and the 1 -year dose equivalent conversion factors for the target organs given by Dunning (1986), who used a quality factor of 20 for alpha radiation, are used to estimate the acute inhalation according to Equation 3.50 (rad). A weighting factor of $1 / 20$ is used to reduce the dose for those radionuclides emitting alpha radiation to obtain the absorbed dose.

Once the dose to the target organ is determined, the average dose rate to the target organ is calculated as

$$
D R\left(i, k, t_{1}\right)=\frac{D\left(i, k, t_{1}\right)}{t_{1}},
$$

where

$$
\begin{aligned}
D R\left(i, k, t_{1}\right)= & \text { average dose rate to target organ } k \text { during time period of interest } \\
& t_{1}(\mathrm{rad} / \mathrm{d}) .
\end{aligned}
$$

As described in Section 4.1.2, the dose rate is used in the determination of the lethality risk.

In the above calculations, $t_{1}$ and $t_{2}$ are assumed to be functions of radionuclide $i$ and target organ $k$ where

$$
t_{2}(i, k)=\left\{\begin{array}{cl}
365 \text { days, } & \text { if } \frac{1}{\lambda_{m}(i, j, k)}>365 \text { days } \\
\frac{1}{\lambda_{m}(i, j, k)}, & \text { if } \frac{1}{\lambda_{m}(i, j, k)}<365 \text { days } .
\end{array}\right.
$$


For brief exposures,

$$
t_{1}(i, k)=\left\{\begin{array}{cl}
1 \text { day, } & \text { if } \frac{1}{\lambda_{\mathrm{m}}(i, j, k)}>1 \text { day } \\
\frac{1}{\lambda_{\mathrm{m}}(i, j, k)}, & \text { if } \frac{1}{\lambda_{\mathrm{m}}(i, j, k)}<1 \text { day } .
\end{array}\right.
$$

For protracted exposures,

$$
t_{1}(i, k)=\left\{\begin{array}{cl}
T P(k), & \text { if } \frac{1}{\lambda_{\mathrm{m}}(i, j, k)}>\operatorname{TP}(k) \\
\frac{1}{\lambda_{\mathrm{m}}(i, j, k)}, & \text { if } \frac{1}{\lambda_{\mathrm{m}}(i, \mathrm{j}, \mathrm{k})}<\operatorname{TP}(k),
\end{array}\right.
$$

where

$$
\begin{aligned}
& T P(k)=\text { time periods of exposure of } 30,365 \text {, and } 7 \text { days, respectively, } \\
& \text { for organs }(k) \text {, bone marrow, lungs, and GI tract; and } \\
& \lambda_{m}(i, j, k)=\text { minimum decay constant (longest half-life) of radionuclide } i \\
& \text { from all subcompartments } j \text { from organ } k(1 / \mathrm{d}) \text {; minimum value } \\
& \text { of } \lambda_{b}(i, j, k) \text { over all } j \text {. }
\end{aligned}
$$

\subsubsection{Lethality Risk}

In this section, the term lethality risk represents the probability of fatality from an incurred radiation dose. A hazard-function approach is used to derive fatality risk estimates for effects in the three target organs of the body and to determine the total risk resulting from exposure of these organs. The lethality is calculated from the cumulative hazard $H$ (Evans et al. 1985; Abrahamson et al. 1989). The general expression used for the lethality hazard is the following two-parameter Weibull function:

$$
H_{A}(k)=\ln (2) X(k)^{V},
$$

where

$$
\begin{aligned}
H_{A}(k)= & \text { lethality hazard for organ } k \text { (unitless); } \\
X(k)= & \frac{D(k)}{D_{50}(k)} ; \\
D(k)= & \begin{array}{l}
\text { acute dose to organ } k, \text { sum of pathway doses (external radiation } \\
\text { from passing radioactive cloud, contaminated ground, and loss of }
\end{array} \\
& \text { cask shielding; and time-integrated dose from inhalation) (Gy); }
\end{aligned}
$$




$$
\begin{aligned}
D_{50}(k)= & \text { median lethal dose, dose to organ } k \text { that produces the effect of } \\
& \text { interest in } 50 \% \text { of the population at risk (Gy) [Table 4.3]; and } \\
V= & \text { shape parameter [Table } 4.3]:
\end{aligned}
$$

The lethality risk is then related to $H_{A}$ by the expression (Abrahamson et al. 1989, 1991)

$$
\text { Lethality } \operatorname{risk}(k)=1-\exp \left[-H_{A}(k)\right]
$$

where

Lethality $\operatorname{risk}(k)=$ risk of lethality from organ $k$.

The total lethality risk from all acute effects considered is calculated by summing the cumulative hazards for each lethal mode of injury, that is, the hematopoietic syndrome (bone marrow), the gastrointestinal syndrome (intestines), and the pulmonary syndrome (lungs). The estimated lethality risk from these three competing injuries can be calculated as follows (Abrahamson et al. 1989, 1991):

$$
\text { Lethality risk }=1-\exp \left\{-\left[H_{A}(\text { bone })+H_{A}(\text { lung })+H_{A}(G I)\right]\right\} .
$$

Application of this method is based on the calculation of $X(k)$, which is the dose to organ $k$ normalized to the $D_{50}$ value (the dose that is expected to cause death in $50 \%$ of the persons receiving such a dose). Ideally, $X(k)$ would be calculated according to (Abrahamson et al. 1989)

$$
X(k)=\int_{0}^{t} \frac{\dot{D}(k)}{D_{50}(\dot{D}(k))} d t
$$

where $\dot{D}(k)$ is the instantaneous absorbed dose rate to organ $k$ at time $t$, and the $D_{50}$ value is dependent on the dose rate. The exact form of Equation 4.15 cannot be used because of the lack of data for $D_{50}$ values. A simplified fixed parameter approach is used in the NRC health effects study (Abrahamson et al. 1989, 1991). In this approach, the model parameter $D_{50}$ is assumed to change only when the dose rate enters specific ranges. Two dose rate categories are defined: brief high dose rates $(>0.06 \mathrm{~Gy} / \mathrm{h})$ and protracted long-term dose rates $(\leq 0.06 \mathrm{~Gy} / \mathrm{h})$. Protracted exposures are treated as less effective than brief exposures. Table 4.3 lists the $D_{50}$ values used in the calculations for specific dose rates for the three target organs.

In RISKIND, $X(k)$ is approximated by an expression of the form (Abrahamson et al. 1989)

$$
X(k)=\frac{D_{B}(k)}{D_{50, B}}+\frac{D_{P}(k)}{D_{50, P}}
$$


TABLE 4.3 Early Effects Model Parameters

\begin{tabular}{|c|c|c|c|c|c|c|c|c|c|c|}
\hline \multirow[b]{2}{*}{ Target Organ ${ }^{a}$} & \multirow[b]{2}{*}{$\begin{array}{c}\text { Dose Rate } \\
(\mathrm{Gy} / \mathrm{h})\end{array}$} & \multicolumn{3}{|c|}{ Median Lethal Dose $\left(D_{50}, G y\right)$} & \multicolumn{3}{|c|}{ Shape Parameter (V) } & \multicolumn{3}{|c|}{ Threshold $(X=0.5)$} \\
\hline & & Central & Lower & Upper & Central & Lower & Upper & Central & Lower & Upper \\
\hline \multirow{2}{*}{$\begin{array}{l}\text { Bone marrow } \\
\text { (minimum } \\
\text { treatment) }\end{array}$} & $>10$ & 3 & 2.5 & 3.5 & 6 & 4 & 8 & 1.5 & 1.2 & 1.8 \\
\hline & $\begin{array}{c}1 \\
0.1 \\
0.05 \\
0.01 \\
\end{array}$ & $\begin{array}{l}3.1 \\
3.7 \\
4.4 \\
10\end{array}$ & $\begin{array}{c}2.5 \\
3.1 \\
3.6 \\
8 \\
\end{array}$ & $\begin{array}{l}3.7 \\
4.3 \\
5.2 \\
12 \\
\end{array}$ & $\begin{array}{l}6 \\
6 \\
6 \\
6 \\
\end{array}$ & $\begin{array}{l}4 \\
4 \\
4 \\
4 \\
\end{array}$ & $\begin{array}{l}8 \\
8 \\
8 \\
8 \\
\end{array}$ & $\begin{array}{c}1.6 \\
1.9 \\
2.2 \\
5\end{array}$ & $\begin{array}{c}1.3 \\
1.6 \\
1.8 \\
4 \\
\end{array}$ & $\begin{array}{c}1.9 \\
2.2 \\
2.6 \\
6 \\
\end{array}$ \\
\hline Pulmonary & $\begin{array}{c}100 \\
10 \\
1 \\
0.5 \\
0.1 \\
0.05 \\
\end{array}$ & $\begin{array}{c}10 \\
15 \\
40 \\
70 \\
310 \\
610 \\
\end{array}$ & $\begin{array}{c}8 \\
10 \\
20 \\
40 \\
160 \\
310 \\
\end{array}$ & $\begin{array}{c}12 \\
20 \\
60 \\
100 \\
460 \\
910 \\
\end{array}$ & $\begin{array}{l}12 \\
12 \\
12 \\
12 \\
12 \\
12 \\
\end{array}$ & $\begin{array}{l}12 \\
12 \\
12 \\
12 \\
12 \\
12 \\
\end{array}$ & $\begin{array}{l}12 \\
12 \\
12 \\
12 \\
12 \\
12 \\
\end{array}$ & $\begin{array}{c}5 \\
7 \\
20 \\
40 \\
160 \\
310 \\
\end{array}$ & $\begin{array}{c}4 \\
5 \\
10 \\
20 \\
80 \\
160 \\
\end{array}$ & $\begin{array}{c}6 \\
9 \\
30 \\
60 \\
230 \\
460 \\
\end{array}$ \\
\hline GI tract & $\begin{array}{l}>0.06 \\
<0.06\end{array}$ & $\begin{array}{l}15 \\
35 \\
\end{array}$ & $\begin{array}{l}10 \\
25 \\
\end{array}$ & $\begin{array}{l}20 \\
50 \\
\end{array}$ & $\begin{array}{l}10 \\
10 \\
\end{array}$ & $\begin{array}{l}10 \\
10 \\
\end{array}$ & $\begin{array}{l}10 \\
10 \\
\end{array}$ & $\begin{array}{c}8 \\
18 \\
\end{array}$ & $\begin{array}{c}5 \\
13 \\
\end{array}$ & $\begin{array}{l}10 \\
25 \\
\end{array}$ \\
\hline
\end{tabular}

a Multiply dose values by 1.5 or 2 for supportive treatment for bone marrow or pulmonary calculations, respectively. Brief exposure: dose received within the first day following initial exposure. Protracted exposure: dose received from inhalation within the first 30 days for bone marrow, 365 days for lungs, and 7 days for GI tract.

Source: Abrahamson et al. $(1989,1991)$.

where

$$
\begin{aligned}
D_{B}(k)= & \text { dose to target organ } k \text { during the brief exposure time (Gy), } \\
D_{P}(k)= & \text { dose to target organ } k \text { during the protracted exposure time (Gy), } \\
D_{50, B}= & D_{50} \text { value for target organ } k \text { for dose rate during brief exposure } \\
& \text { time (Gy), and } \\
D_{50, P}= & D_{50} \text { value for target organ } k \text { for dose rate during protracted } \\
& \text { exposure time (Gy). }
\end{aligned}
$$

A threshold effect is assumed to be operative, and the value for $X(k)$ is set to 0.0 if the calculated value from Equation 4.15 is less than 0.5 (Abrahamson et al. 1989, 1991). Exposure due to external gamma rays from the passing radioactive cloud, the radionuclide-contaminated ground surface, and loss of cask shielding is evaluated for the brief exposure period that is considered to be the short-term exposure time [TEXT(j) for individuals or HEXT for population calculations]. Exposure from inhaled radionuclides is included in the brief dose by using an exposure time of 
24 hours. The protracted dose is calculated from the exposure from inhaled radionuclides for periods of 30,365 , and 7 days, respectively, for the bone marrow, lungs, and GI tract.

\subsubsection{Dose Response}

Two types of dose responses are used for modeling the levels of medical treatment: minimal and supportive. Minimal treatment assumes that no extraordinary means of medical treatment are administered outside of basic first aid. Depending on the affected organ(s), supportive treatment includes such measures as hospitalization with state-of-the-art antibiotic therapy, blood transfusions, electrolyte replacement, and intravenous feeding. If supportive medical treatment is considered [ITREAT $=1$ ], the $D_{50}$ values used by RISKIND (Table 4.3) are increased by a factor of 1.5 for bone marrow and 2 for pulmonary calculations (Abrahamson et al. 1989).

\subsection{LATENT EFFECTS}

Latent effects may result from cumulative exposures, including the short- and long-term exposures discussed in Section 3. As a conservative measure, no credit is given for exposures resulting in acute fatalities, and the entire cumulative dose received is used in estimating the latent health effects. Three latent health effects are considered in RISKIND: (1) nonfatal cancer occurrence, (2) fatal cancer occurrence, and (3) genetic effects manifested in the exposed individual's descendants.

The latent effects are calculated with dose-to-health risk conversion factors (Table 4.4) suggested by the ICRP (ICRP 1991). Two sets of conversion factors are provided, one for occupational workers and the other, with higher values, for the general public. Workers are assumed to be in better physical condition and, therefore, better able to tolerate exposure to radiation than the population as a whole.

As was the case with the early effects, higher dose rates are more effective in inducing adverse effects. The ICRP (ICRP 1991) recommends that the health risk conversion factors be doubled for equivalent doses resulting from absorbed doses greater than or equal to $20 \mathrm{rad}$ (20 rem for gamma exposure), when the dose rate is greater than or equal to $10 \mathrm{rad} / \mathrm{h}$. RISKIND doubles the risk conversion factors in Table 4.4 when the estimated cumulative dose exceeds 20 rem per individual, regardless of the dose rate. This approach may overestimate the health effects when the dose exceeds 20 rem. It will, however, account for situations where higher dose rates occur in the short-term, and the cumulative exposure includes a long-term component at relatively low dose rates. 
TABLE 4.4 Latent Effects Health Risk Conversion Factors

\begin{tabular}{lccc}
\hline Exposed Population & $\begin{array}{c}\text { Fatal Cancers } \\
\text { per Person-Rem }\end{array}$ & $\begin{array}{c}\text { Nonfatal Cancers } \\
\text { per Person-Rem }\end{array}$ & $\begin{array}{c}\text { Genetic Effects } \\
\text { per Person-Rem }\end{array}$ \\
\hline Occupational workers & $4.0 \times 10^{-4}$ & $8.0 \times 10^{-5}$ & $8.0 \times 10^{-5}$ \\
General public & $5.0 \times 10^{-4}$ & $1.0 \times 10^{-4}$ & $1.3 \times 10^{-4}$ \\
\hline
\end{tabular}

Source: ICRP (1991). 


\section{REFERENCES}

Abrahamson, S., et al., 1989, Health Effects Model for Nuclear Power Accident Consequence Analysis, Low LET Radiation, rev. 1, NUREG/CR-4214, U.S. Nuclear Regulatory Commission, Washington, D.C.

Abrahamson, S., et al., 1991, Health Effects Model for Nuclear Power Plant Accident Consequence Analysis, Modifications of Models Resulting from Recent Reports on Health Effects of Ionizing Radiation, rev. 1, Part II, Addendum 1, NUREG/CR-4214, U.S. Nuclear Regulatory Commission, Washington, D.C.

Anspaugh, L.R., et al., 1974, "Resuspension Element Status Report," in The Dynamics of Plutonium in Desert Environments, NVO-142, U.S. Department of Energy, Nevada Operations Office, Las Vegas, Nev.

Babcock and Wilcox, 1990, BR-100 100-Ton Rail/Barge Spent Fuel Shipping Casks: Preliminary Design Report, February 1990, B\&W Document 51-1177082-02, Lynchburg, Va.

Briggs, G.A., 1969, Plume Rise, U.S. Atomic Energy Commission Critical Review Series, prepared for Nuclear Safety Information Center, Oak Ridge National Laboratory, reprinted by the National Technical Information Service, Springfield, Va.

Briggs, G.A., 1974, Diffusion Estimation for Small Emissions, Environmental Research Laboratories Atmospheric Turbulence and Diffusion Laboratory 1973 Annual Report, Report No. ATDL-106, National Oceanic and Atmospheric Administration, Washington, D.C.

Chen, S.Y., and Y.C. Yuan, 1988, "Calculation of Radiation Dose Rates from a Spent Nuclear Fuel Shipping Cask," Transactions of American Nuclear Society 56:110-112.

Chen, S.Y., et al, 1995, Assessment of Transportation Risk for the U.S. Department of Energy Environmental Management Programmatic Environmental Impact Statement, proceedings of Waste Management '95, February 26-March 2, 1995, Tucson, Arizona, CD-ROM, Folio Infobase.

DOE: See U.S. Department of Energy.

Dunning, D.E., 1986, Estimates of Internal-Dose Equivalent from Inhalation and Ingestion of Selected Radionuclides, WIPP-DOE-176, prepared by U.S. Department of Energy, Washington, D.C., for Westinghouse Electric Corporation, Albuquerque, N.M. 
Eckerman, K.F., et al., 1988, Limiting Values of Radionuclide Intake and Air Concentration and Dose Conversion Factors for Inhalation, Submersion, and Ingestion, EPA-520/1-88-020, Federal Guidance Report No. 11, prepared by Oak Ridge National Laboratory, Oak Ridge, Tenn., for U.S. Environmental Protection Agency, Office of Radiation Programs, Washington, D.C.

Eckerman, K.F., and J.C. Ryman, 1993, External Exposure to Radionuclides in Air, Soil, and Water: Exposure to Dose Coefficients for General Application Based on the 1987 Federal Radiation Protection Guidance, EPA 402-R-93-076, Federal Guidance Report No. 12, prepared by Oak Ridge National Laboratory, Oak Ridge, Tenn., for U.S. Environmental Protection Agency, Office of Radiation and Indoor Air, Washington, D.C.

Eimutis, E.C., and M.G. Konicek, 1972, "Derivation of Continuous Functions for the Lateral and Vertical Dispersion Coefficients," Atmospheric Environment 6:859-863.

EPA: See U.S. Environmental Protection Agency.

Evans et al., 1985, Health Effects Model for Nuclear Power Accidents Consequence Analysis, NUREG/CR-4214, U.S. Nuclear Regulatory Commission, Washington, D.C.

Hanna, S.R., et al., 1982, Handbook on Atmospheric Diffusion, DOE/TIC-11223, Technical Information Center, U.S. Department of Energy, Washington, D.C.

Holzworth, G., 1972, Mixing Heights, Wind Speeds, and Potential for Urban and Air Pollution throughout the Contiguous United States, AP-101, U.S. Environmental Protection Agency, Washington, D.C.

ICRP: See International Commission on Radiological Protection.

International Atomic Energy Agency and Commission of the European Communities, 1992, VAMP, Co-ordinated Research Program on Validation of Environmental Model Prediction: Multiple Pathways Assessment, Vienna, Austria, May.

International Commission on Radiation Units and Measurements, 1993, Quantities and Units in Radiation Protection Dosimetry, ICRU Report 51, Bethesda, Md.

International Commission on Radiological Protection, 1972, Alkaline Earth Metabolism in Adult Man, ICRP Publication 20, Pergamon Press, New York, N.Y.

International Commission on Radiological Protection, 1977, Recommendations of the ICRP, ICRP Publication 26, Pergamon Press, New York, N.Y. 
International Commission on Radiological Protection, 1979-1982, Limits for Intakes of Radionuclides by Workers, a report of Committee 2 of the International Commission on Radiological Protection, adopted by the Commission in July 1978, ICRP Publication 30, Part 1 (and Supplement), Part 2 (and Supplement), Part 3 (and Supplements A and B), and Index, Annals of the ICRP, Pergamon Press, New York, N.Y.

International Commission on Radiological Protection, 1991, 1990 Recommendations of the International Commission on Radiological Protection, ICRP Publication 60, Pergamon Press, New York, N.Y.

Irwin, J.S., 1979, "A Theoretical Variation of the Wind Profile Power-Law Exponent as a Function of Surface Roughness and Stability," Atmospheric Environment 13:191-194.

Lawrence Livermore National Laboratory, 1987, Shipping Container Response to Severe Highway and Railway Accident Conditions, NUREG/CR-4829, UCID-20733, prepared by Lawerence Livermore National Laboratory, Livermore, Calif., for U.S. Nuclear Regulatory Commission, Washington, D.C., Feb.

Los Alamos National Laboratory, 1994, "MCNP 4A: Monte Carlo N-Particle Transport Code System," RSIC Computer Code Collection, CCC-200, Radiation Shielding Information Center, Oak Ridge, Tenn.

Martin, J.R., ed., 1979, Recommended Guide for the Prediction of the Dispersion of Airborne Effluents, 3rd ed., The American Society of Mechanical Engineers, New York, N.Y.

McMahon, T.A., and P.J. Dennison, 1979, "Empirical Atmospheric Deposition Parameters - A Survey," Atmospheric Environment 13:571-585.

National Research Council, 1988, Health Risks of Radon and Other Internally Deposited AlphaEmitters, BEIR IV, Committee on the Biological Effects of Ionizing Radiation, National Academy Press, Washington, D.C.

Negin, C.A., and G. Worku, 1992, Microshield, Version 4: User's Manual, Grove 92-2, Grove Engineering, Inc., Rockville, Md.

Neuhauser, K.S., and F.L. Kanipe, 1992, RADTRAN 4: Volume 3, User Guide, SAND-89-2370, Sandia National Laboratories, Albuquerque, N.M.

Notz, K.J., et al., 1987, Characteristics of Potential Repository Wastes, vols. 1-6, DOE/RW0184, prepared by Oak Ridge National Laboratory, Oak Ridge, Tenn., for U.S. Department of Energy, Office of Civilian Radioactive Waste Management, Washington, D.C.

NRC: See U.S. Nuclear Regulatory Commission. 
Oak Ridge National Laboratory, 1986, SCALE-3, A Modular Code System for Performing Standardized Computer Analyses for Licensing Evaluation, Oak Ridge, Tenn.

Pasquill, F., 1974, Atmospheric Diffusion, 2nd ed., John Wiley \& Sons, New York, N.Y.

Pasquill, F., 1976, Atmospheric Dispersion Parameters in Gaussian Plume Modeling. Part II. Possible Requirements for Change in the Turner Workbook Values, EPA-600/4-76-03b, U.S. Environmental Protection Agency, Washington, D.C.

Petersen, W.B., and L.G. Lavdas, 1986, INPUFF 2.0A - Multiple Source Gaussian Puff Dispersion Algorithm User's Guide, EPA/600/8-86/024, U.S. Environmental Protection Agency, Washington, D.C.

Powell, D.C., et al., 1979, MESODIF-II: A Variable Trajectory Plume Segment Model to Assess Ground-Level Air Concentrations and Deposition of Effluent Releases from Nuclear Power Facilities, NUREG/CR-0523, U.S. Nuclear Regulatory Commission, Washington, D.C.

Press, W.H., 1986, Numerical Recipes: The Art of Scientific Computing, Cambridge University Press, New York, N.Y.

Ritchie, L.T., et al., 1978, "Effects of Rainstorms and Runoff on Consequences of Atmospheric Releases from Nuclear Reactor Accidents," Nuclear Safety 19:220-238.

Ross, D.G., et al., 1985, CITPUFF: A Gaussian Puff Model for Estimating Pollutant Concentration in Complex Terrain, RM-261, U.S. Department of Agriculture, Rocky Mountain Forest and Range Experimentation Station, Ft. Collins, Colo., July.

Sandoval, R.P., et al., 1991, Estimate of CRUD Contribution to Shipping Cask Containment Requirements, SAND-88-1358, Sandia National Laboratories, Albuquerque, N.M., Jan.

U.S. Department of Energy, 1986a, Environmental Assessment, Deaf Smith Site, Texas, DOE/RW-0069, vols. 1-3, Office of Civilian Radioactive Waste Management, Washington, D.C., May.

U.S. Department of Energy, 1986b, Environmental Assessment, Reference Repository Location, Hanford Site, Washington, DOE/RW-0070, vols. 1-3, Office of Civilian Radioactive Waste Management, Washington, D.C., May.

U.S. Department of Energy, 1986c, Environmental Assessment: Yucca Mountain, Nevada, Nuclear Waste Policy Act, DOE/RW-0073, Office of Civilian Radioactive Waste Management, Washington, D.C., May. 
U.S. Department of Energy, 1986d, Environmental Assessment, Yucca Mountain Site, Nevada Research and Development Area, Nevada, DOE/RW-0071, vols. 1-3, Office of Civilian Radioactive Waste Management, Washington, D.C., May.

U.S. Department of Energy, 1987a, Analysis of Radiation Doses from Operation of Postulated Commercial Spent Fuel Transportation Systems, DOE-CH/TPO-001, Washington, D.C.

U.S. Department of Energy, 1987b, Characteristics of Spent Fuel, High-Level Waste, and Other Radioactive Wastes Which May Require Long-Term Isolation, DOE/RW-0184, ORNLTM10213, prepared by Oak Ridge National Laboratory, Oak Ridge, Tenn., for U.S. Department of Energy Office of Civilian Radioactive Waste Management, Washington, D.C,

U.S. Department of Energy, 1990, Supplemental Environmental Impact Statement, Waste Isolation Pilot Plant, DOE/EIS-0026-FS, Washington, D.C., Jan.

U.S. Department of Energy, 1992a, Characteristics of Potential Repository Wastes, DOE/RW184-R1, prepared by Oak Ridge National Laboratory, Oak Ridge, Tenn., for U.S. Department of Energy, Office of Civilian Radioactive Waste Management, Washington, D.C.

U.S. Department of Energy, 1992b, Environmental and Other Evaluations of Alternatives for Siting, Constructing, and Operating New Production Reactor Capacity, DOE/NP-0014, vol. 1, Office of New Production Reactors, Washington, D.C.

U.S. Department of Energy, 1995, Department of Energy Programmatic Spent Nuclear Fuel Management and Idaho National Engineering Laboratory Environmental Restoration and Waste Management Programs Final Environmental Impact Statement, DOE/EIS-0203-F, Office of Environmental Management, Idaho Operations Office, Idaho Falls, Idaho.

U.S. Department of Transportation, 1994, "Shippers - General Requirements for Shipments and Packages," Code of Federal Regulations, title 49, part 173, pp. 603-635.

U.S. Environmental Protection Agency, 1991, Manual of Protective Action Guides and Protective Actions for Nuclear Incidents, EPA 400-R-92-001, Washington, D.C.

U.S. Environmental Protection Agency, 1992, User's Guide for CAP 88-PC, version 1.0, 402-B92-001, Washington, D.C.

U.S. Nuclear Regulatory Commission, 1975, Reactor Safety Study; An Assessment of Accident Risks in U.S. Commercial Nuclear Power Plants, Appendix G: Calculation of Reactor Accident Consequences, WASH-1400 (NUREG 75/014), Washington, D.C. 
U.S. Nuclear Regulatory Commission, 1977a, Calculation of Annual Dose to Man from Routine Releases of Reactor Effluents for the Purpose of Evaluating Compliance with 10 CFR Part 50, Appendix I, Rev. 1, Regulatory Guide 1.109, Washington, D.C.

U.S. Nuclear Regulatory Commission, 1977b, Final Environmental Statement on the Transportation of Radioactive Material by Air and Other Modes, NUREG-0170, Washington, D.C.

U.S. Nuclear Regulatory Commission, 1985, Health Effects Model for Nuclear Power Plant Accident Consequence Analysis, NUREG/CR-4214, prepared by Harvard School of Public Health.

U.S. Nuclear Regulatory Commission, 1994, "Packaging and Transportation of Radioactive Material," Code of Federal Regulations, title 10, part 71, pp. 203-239.

Yuan, Y.C., et al., 1993, RISKIND - A Computer Program for Calculating Radiological Consequences and Health Risks from Transportation of Spent Nuclear Fuel, ANL/EAIS-6, rev. 0, Argonne National Laboratory, Argonne, Ill. 
APPENDIX A:

DESCRIPTION OF RADIONUCLIDE INVENTORY

DATABASE FOR SPENT NUCLEAR FUELS 
A-2 


\title{
CONTENTS
}

\begin{abstract}
APPENDIX A: DESCRIPTION OF RADIONUCLIDE INVENTORY DATABASE FOR SPENT NUCLEAR FUELS.......................................................... A-5

APPENDIX A REFERENCES .............................................................................. A-5
\end{abstract}

TABLE

A.1 Sample Radionuclide Inventory A-6 
A-4 


\section{APPENDIX A:}

\section{DESCRIPTION OF RADIONUCLIDE INVENTORY DATABASE FOR SPENT NUCLEAR FUELS}

A radionuclide inventory database specific to spent nuclear fuels was derived from the computerized databases developed by Oak Ridge National Laboratory (ORNL) (Notz et al. 1987; DOE 1992). These databases were developed for the U.S. Department of Energy (DOE), Office of Civilian Radioactive Waste Management (OCRWM), to establish reference characteristics of radioactive waste materials that may be accepted by DOE for emplacement in the mined geologic disposal system developed under the Nuclear Waste Policy Act of 1982.

The inventory data applicable to spent fuels have been generated by the ORIGEN2 computer code (Croff 1980) and are contained in the Light-Water Reactor (LWR) Radiological Quantities Database of DOE (DOE 1992). Specifically, the radioactivity, given in curies per metric ton of initial heavy metal (Ci/MTIHM), is provided for a detailed list of radionuclides for significant activation- and fission-product nuclides as well as actinides. The inventory data are compiled according to reactor type, fuel burnup, and fuel cooling period. Two reference LWRs were used, a pressurized-water reactor (PWR) (Westinghouse) and a boiling-water reactor (BWR) (General Electric).

For application to the RISKIND code described in the main body of this report, a somewhat condensed inventory database was compiled from the DOE database. This condensed database contains inventory information for all isotopes contributing more than $0.01 \%$ to the total inventory data. The burnup levels are $10,000,20,000,30,000,40,000,50,000$, and $60,000 \mathrm{MWd} / \mathrm{MTIHM}$ for the PWRs, and 7,500, 15,000, 22,500, 30,000, 40,000, and $50,000 \mathrm{MWd}$ /MTIHM for the BWRs. The cooling periods selected were $1,2,3,5,10,15,20$, $30,50,100,200,300$, and 500 years. A sample of such inventory data is given in Table A.1.

\section{APPENDIX A REFERENCES}

Croff, A.G., 1980, ORIGEN2 Isotope Generation and Depletion Code Matrix Exponential Method, User's Manual, ORNL/TM-7175, Oak Ridge National Laboratory, Oak Ridge, Tenn.

Notz, K.J., et al., 1987, Characteristics of Potential Repository Wastes, vols. 1-6, DOE/RW-0184, prepared by Oak Ridge National Laboratory, Oak Ridge, Tenn., for U.S. Department of Energy, Office of Civilian Radioactive Waste Management, Washington, D.C.

U.S. Department of Energy, 1992, Characteristics of Potential Repository Wastes, DOE/RW-184-R1, prepared by Oak Ridge National Laboratory, Oak Ridge, Tenn., for U.S. Department of Energy, Office of Civilian Radioactive Waste Management, Washington, D.C. 
TABLE A.1 Sample Radionuclide Inventory (Variations in Radioactivity for Significant Activation- and FissionProduct Nuclides as a Function of Time Since Discharge) ${ }^{\text {a }}$

\begin{tabular}{|c|c|c|c|c|c|c|c|c|}
\hline \multirow[b]{2}{*}{ Isotope } & \multicolumn{8}{|c|}{ Concentration (Ci/MTIHM) at Time Since Discharge } \\
\hline & $1 \mathrm{yr}$ & $5 \mathrm{yr}$ & $10 \mathrm{yr}$ & $20 \mathrm{yr}$ & $30 \mathrm{yr}$ & $50 \mathrm{yr}$ & $100 \mathrm{yr}$ & $500 \mathrm{yr}$ \\
\hline Hydrogen-3 & $7.03 \times 10^{2}$ & $5.62 \times 10^{2}$ & $4.25 \times 10^{2}$ & $2.42 \times 10^{2}$ & $1.38 \times 10^{2}$ & $4.50 \times 10^{1}$ & 0.0 & 0.0 \\
\hline Carbon-14 & 0.0 & 0.0 & 0.0 & 0.0 & 0.0 & 0.0 & 0.0 & 1.13 \\
\hline Iron-55 & $2.50 \times 10^{3}$ & $8.61 \times 10^{2}$ & $2.27 \times 10^{2}$ & 0.0 & 0.0 & 0.0 & 0.0 & 0.0 \\
\hline Cobalt -60 & $7.29 \times 10^{3}$ & $4.31 \times 10^{3}$ & $2.23 \times 10^{3}$ & $5.99 \times 10^{2}$ & $1.61 \times 10^{2}$ & 0.0 & 0.0 & 0.0 \\
\hline Nickel-59 & 0.0 & $0.0 x$ & 0.0 & 0.0 & 0.0 & 0.0 & 0.0 & 2.50 \\
\hline Nickel-63 & $4.12 \times 10^{2}$ & $4.00 \times 10^{2}$ & $3.85 \times 10^{6}$ & $3.57 \times 10^{2}$ & $3.31 \times 10^{2}$ & $2.85 \times 10^{2}$ & $1.96 \times 10^{2}$ & 9.60 \\
\hline Selenium-79 & 0.0 & 0.0 & 0.0 & 0.0 & 0.0 & 0.0 & 0.0 & $370 \times 10^{-1}$ \\
\hline Krypton-85 & $8.03 \times 10^{3}$ & $6.20 \times 10^{3}$ & $4.49 \times 10^{3}$ & $2.35 \times 10^{3}$ & $1.23 \times 10^{3}$ & $3.38 \times 10^{2}$ & $1.33 \times 10^{1}$ & 0.0 \\
\hline Strontium-89 & $5.24 \times 10^{3}$ & 0.0 & 0.0 & 0.0 & 0.0 & 0.0 & 0.0 & 0.0 \\
\hline Strontium-90 & $6.56 \times 10^{4}$ & $5.96 \times 10^{4}$ & $5.29 \times 10^{4}$ & $4.17 \times 10^{4}$ & $3.29 \times 10^{4}$ & $2.04 \times 10^{4}$ & $6.21 \times 10^{3}$ & $4.56 \times 10^{-1}$ \\
\hline Yttrium-90 & $6.56 \times 10^{4}$ & $5.96 \times 10^{4}$ & $5.29 \times 10^{4}$ & $4.17 \times 10^{4}$ & $3.29 \times 10^{4}$ & $2.04 \times 10^{4}$ & $6.22 \times 10^{3}$ & $4.56 \times 10^{-1}$ \\
\hline Yttrium-91 & $1.36 \times 10^{4}$ & 0.0 & 0.0 & 0.0 & 0.0 & 0.0 & 0.0 & 0.0 \\
\hline Zirconium-93 & 0.0 & 0.0 & 0.0 & 0.0 & 0.0 & 0.0 & 0.0 & 1.92 \\
\hline Zirconium-95 & $2.84 \times 10^{4}$ & 0.0 & 0.0 & 0.0 & 0.0 & 0.0 & 0.0 & 0.0 \\
\hline Niobium-93m & 0.0 & 0.0 & 0.0 & 0.0 & 0.0 & 0.0 & 0.0 & 1.82 \\
\hline Niobium-94 & 0.0 & 0.0 & 0.0 & 0.0 & 0.0 & 0.0 & 0.0 & $9.09 \times 10^{-1}$ \\
\hline Niobium-95 & $6.38 \times 10^{4}$ & 0.0 & 0.0 & 0.0 & 0.0 & 0.0 & 0.0 & 0.0 \\
\hline Technetium-99 & 0.0 & 0.0 & 0.0 & 0.0 & 0.0 & $1.21 \times 10^{1}$ & $1.21 \times 10^{1}$ & $1.21 \times 10^{1}$ \\
\hline Ruthenium-103 & $2.25 \times 10^{3}$ & 0.0 & 0.0 & 0.0 & 0.0 & 0.0 & 0.0 & 0.0 \\
\hline Ruthenium-106 & $2.36 \times 10^{5}$ & $1.51 \times 10^{4}$ & $4.84 \times 10^{2}$ & 0.0 & 0.0 & 0.0 & 0.0 & 0.0 \\
\hline Rhodium- $103 \mathrm{~m}$ & $2.03 \times 10^{3}$ & 0.0 & 0.0 & 0.0 & 0.0 & 0.0 & 0.0 & 0.0 \\
\hline Rhodium-106 & $2.36 \times 10^{5}$ & $1.51 \times 10^{4}$ & $4.84 \times 10^{2}$ & 0.0 & 0.0 & 0.0 & 0.0 & 0.0 \\
\hline Silver-110m & $1.15 \times 10^{3}$ & 0.0 & 0.0 & 0.0 & 0.0 & 0.0 & 0.0 & 0.0 \\
\hline Tin- $119 m$ & $2.04 \times 10^{3}$ & 0.0 & 0.0 & 0.0 & 0.0 & 0.0 & 0.0 & 0.0 \\
\hline $\operatorname{Tin}-123$ & $4.92 \times 10^{2}$ & 0.0 & 0.0 & 0.0 & 0.0 & 0.0 & 0.0 & 0.0 \\
\hline Tin-126 & 0.0 & 0.0 & 0.0 & 0.0 & 0.0 & 0.0 & 0.0 & $6.82 \times 10^{-1}$ \\
\hline Antimony-125 & $1.10 \times 10^{4}$ & $4.03 \times 10^{3}$ & $1.15 \times 10^{3}$ & $9.43 \times 10^{1}$ & 0.0 & 0.0 & 0.0 & 0.0 \\
\hline Antimony-126m & 0.0 & 0.0 & 0.0 & 0.0 & 0.0 & 0.0 & 0.0 & $6.82 \times 10^{-1}$ \\
\hline Tellurium-125m & $2.67 \times 10^{3}$ & $9.83 \times 10^{2}$ & $2.81 \times 10^{2}$ & 0.0 & 0.0 & 0.0 & 0.0 & 0.0 \\
\hline Tellurium-127 & $1.25 \times 10^{3}$ & 0.0 & 0.0 & 0.0 & 0.0 & 0.0 & 0.0 & 0.0 \\
\hline Tellurium-127m & $1.28 \times 10^{3}$ & 0.0 & 0.0 & 0.0 & 0.0 & 0.0 & 0.0 & 0.0 \\
\hline
\end{tabular}


TABLE A.1 (Cont.)

\begin{tabular}{|c|c|c|c|c|c|c|c|c|}
\hline \multirow[b]{2}{*}{ Isotope ${ }^{b}$} & \multicolumn{8}{|c|}{ Concentration (Ci/MTIHM) at Time Since Discharge } \\
\hline & $1 \mathrm{yr}$ & $5 \mathrm{yr}$ & $10 \mathrm{yr}$ & $20 \mathrm{yr}$ & $30 \mathrm{yr}$ & $50 \mathrm{yr}$ & $100 \mathrm{yr}$ & $500 \mathrm{yr}$ \\
\hline Cesium-134 & $9.43 \times 10^{4}$ & $2.46 \times 10^{4}$ & $4.58 \times 10^{3}$ & $1.59 \times 10^{2}$ & 0.0 & 0.0 & 0.0 & 0.0 \\
\hline Cesium-135 & 0.0 & 0.0 & 0.0 & 0.0 & 0.0 & 0.0 & 0.0 & $3.55 \times 10^{-1}$ \\
\hline Cesium-137 & $9.19 \times 10^{4}$ & $8.38 \times 10^{4}$ & $7.47 \times 10^{4}$ & $5.93 \times 10^{4}$ & $4.70 \times 10^{4}$ & $2.96 \times 10^{4}$ & $9.33 \times 10^{3}$ & $9.04 \times 10^{-1}$ \\
\hline Barium-137m & $8.70 \times 10^{4}$ & $7.93 \times 10^{4}$ & $7.07 \times 10^{4}$ & $5.61 \times 10^{4}$ & $4.45 \times 10^{4}$ & $2.80 \times 10^{4}$ & $8.83 \times 10^{3}$ & $8.55 \times 10^{-1}$ \\
\hline Cerium-141 & $6.10 \times 10^{2}$ & 0.0 & 0.0 & 0.0 & 0.0 & 0.0 & 0.0 & 0.0 \\
\hline Cerium-144 & $4.19 \times 10^{5}$ & $1.19 \times 10^{4}$ & $1.38 \times 10^{2}$ & 0.0 & 0.0 & 0.0 & 0.0 & 0.0 \\
\hline Praseodymium-144 & $4.19 \times 10^{5}$ & $1.19 \times 10^{4}$ & $1.38 \times 10^{2}$ & 0.0 & 0.0 & 0.0 & 0.0 & 0.0 \\
\hline Praseodymium-144m & $5.03 \times 10^{3}$ & $1.43 \times 10^{2}$ & 0.0 & 0.0 & 0.0 & 0.0 & 0.0 & 0.0 \\
\hline PM-147 & $9.89 \times 10^{4}$ & $3.44 \times 10^{4}$ & $9.17 \times 10^{3}$ & $6.53 \times 10^{2}$ & $4.65 \times 10^{1}$ & 0.0 & 0.0 & 0.0 \\
\hline Samarium-151 & $3.55 \times 10^{2}$ & $3.44 \times 10^{2}$ & $3.31 \times 10^{2}$ & $3.06 \times 10^{2}$ & $2.84 \times 10^{2}$ & $2.43 \times 10^{2}$ & $1.65 \times 10^{2}$ & 7.60 \\
\hline Europium-154 & $7.04 \times 10^{3}$ & $5.10 \times 10^{3}$ & $3.41 \times 10^{3}$ & $1.52 \times 10^{3}$ & $6.79 \times 10^{2}$ & $1.36 \times 10^{2}$ & 0.0 & 0.0 \\
\hline Europium-155 & $4.31 \times 10^{3}$ & $2.46 \times 10^{3}$ & $1.22 \times 10^{3}$ & $3.03 \times 10^{2}$ & $7.48 \times 10^{1}$ & 0.0 & 0.0 & 0.0 \\
\hline Thorium-234 & 0.0 & 0.0 & 0.0 & 0.0 & 0.0 & 0.0 & 0.0 & $3.19 \times 10^{-1}$ \\
\hline Protactinum-233 & 0.0 & 0.0 & 0.0 & 0.0 & 0.0 & 0.0 & 0.0 & $7.32 \times 10^{-1}$ \\
\hline Protactinium-234m & 0.0 & 0.0 & 0.0 & 0.0 & 0.0 & 0.0 & 0.0 & $3.19 \times 10^{-1}$ \\
\hline Uranium-234 & 0.0 & 0.0 & 0.0 & 0.0 & 0.0 & 0.0 & 0.0 & 1.84 \\
\hline Uranium-238 & 0.0 & 0.0 & 0.0 & 0.0 & 0.0 & 0.0 & 0.0 & $3.19 \times 10^{-1}$ \\
\hline Neptunium-237 & 0.0 & 0.0 & 0.0 & 0.0 & 0.0 & 0.0 & 0.0 & $7.32 \times 10^{-1}$ \\
\hline Neptunium-239 & 0.0 & 0.0 & 0.0 & 0.0 & 0.0 & $1.40 \times 10^{1}$ & $1.40 \times 10^{1}$ & $1.35 \times 10^{1}$ \\
\hline Plutonium-238 & $2.06 \times 10^{3}$ & $2.03 \times 10^{3}$ & $1.95 \times 10^{3}$ & $1.81 \times 10^{3}$ & $1.67 \times 10^{3}$ & $1.43 \times 10^{3}$ & $9.64 \times 10^{2}$ & $4.30 \times 10^{1}$ \\
\hline Plutonium-239 & $3.20 \times 10^{2}$ & $3.20 \times 10^{2}$ & $3.20 \times 10^{2}$ & $3.20 \times 10^{2}$ & $3.20 \times 10^{2}$ & $3.20 \times 10^{2}$ & $3.19 \times 10^{2}$ & $3.16 \times 10^{2}$ \\
\hline Plutonium-240 & $4.46 \times 10^{2}$ & $4.47 \times 10^{2}$ & $4.47 \times 10^{2}$ & $4.47 \times 10^{2}$ & $4.48 \times 10^{2}$ & $4.47 \times 10^{2}$ & $4.45 \times 10^{2}$ & $4.27 \times 10^{2}$ \\
\hline Plutonium-241 & $1.13 \times 10^{5}$ & $9.31 \times 10^{4}$ & $7.31 \times 10^{4}$ & $4.52 \times 10^{4}$ & $2.79 \times 10^{4}$ & $1.07 \times 10^{4}$ & $9.61 \times 10^{2}$ & 0.0 \\
\hline Plutonium-242 & 0.0 & 0.0 & 0.0 & 0.0 & 0.0 & 0.0 & 0.0 & 1.50 \\
\hline
\end{tabular}


TABLE A.1 (Cont.)

\begin{tabular}{|c|c|c|c|c|c|c|c|c|}
\hline \multirow[b]{2}{*}{ Isotope ${ }^{b}$} & \multicolumn{8}{|c|}{ Concentration (Ci/MTIHM) at Time Since Discharge } \\
\hline & $1 \mathrm{yr}$ & $5 \mathrm{yr}$ & $10 \mathrm{yr}$ & $20 \mathrm{yr}$ & $30 \mathrm{yr}$ & $50 \mathrm{yr}$ & $100 \mathrm{yr}$ & $500 \mathrm{yr}$ \\
\hline Americium-241 & $3.07 \times 10^{2}$ & $9.61 \times 10^{2}$ & $1.61 \times 10^{3}$ & $2.51 \times 10^{3}$ & $3.04 \times 10^{3}$ & $3.51 \times 10^{3}$ & $3.55 \times 10^{3}$ & $1.88 \times 10^{3}$ \\
\hline Americium-242 & 0.0 & 0.0 & 0.0 & 0.0 & 0.0 & 0.0 & 9.01 & 1.45 \\
\hline Americium-242m & 0.0 & 0.0 & 0.0 & 0.0 & 0.0 & 0.0 & 9.05 & 1.46 \\
\hline Americium-243 & 0.0 & 0.0 & 0.0 & 0.0 & 0.0 & $1.40 \times 10^{1}$ & $1.40 \times 10^{1}$ & $1.40 \times 10^{1}$ \\
\hline Curium-242 & $7.48 \times 10^{3}$ & 0.0 & 0.0 & 0.0 & 0.0 & 0.0 & 7.45 & 1.20 \\
\hline Curium-244 & $1.43 \times 10^{3}$ & $1.22 \times 10^{3}$ & $1.01 \times 10^{3}$ & $6.89 \times 10^{2}$ & $4.70 \times 10^{2}$ & $2.18 \times 10^{2}$ & $3.22 \times 10^{1}$ & 0.0 \\
\hline TOTAL & $2.11 \times 10^{6}$ & $5.19 \times 10^{5}$ & $3.59 \times 105$ & $2.56 \times 10^{5}$ & $1.94 \times 10^{5}$ & $1.16 \times 10^{5}$ & $3.73 \times 10^{4}$ & $2.75 \times 10^{3}$ \\
\hline
\end{tabular}

a Discharge from a 33,000-MWd/MTIHM PWR.

b Nuclides contributing greater than $0.01 \%$ are listed.

Source: DOE (1992). 
$B-1$

APPENDIX B:

METHOD FOR ADJUSTING CASK EXTERNAL DOSE RATES RELATIVE TO CASK DIMENSIONS 
B-2 


\section{CONTENTS}

APPENDIX B: METHOD FOR ADJUSTING CASK EXTERNAL DOSE RATES RELATIVE TO CASK DIMENSIONS.................................................. B-5

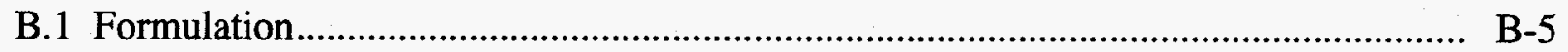

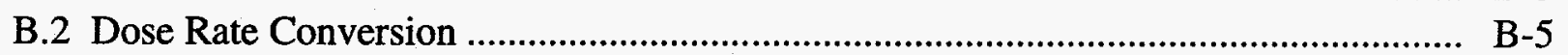

B.3 Dose Rate Adjustment ............................................................................................ B-7

APPENDIX B REFERENCE ……............................................................................ B-8

FIGURE

B.1 Schematic Diagram Correlating Doses to Cask Dimensions ........................................... B-6 
B-4 


\section{APPENDIX B: \\ METHOD FOR ADJUSTING CASK EXTERNAL DOSE RATES RELATIVE TO CASK DIMENSIONS}

This appendix describes a method developed for adjusting the cask external dose rates when different cask dimensions are used in place of a reference cask.

\section{B.1 FORMULATION}

In this method, the radiation source from the cask is approximated by a uniform surfacesource cylinder characterized by a radius $R$ and length $L$ and a surface source strength $S_{a}$, as shown in Figure B.1. For a receptor $P$ located at a distance $r$ from the centerline of the cask (Figure B.1), the radiation (neutron or gamma) flux $f$ at the receptor can be calculated by (Jaeger 1968)

$$
\phi(r)=\frac{2 S_{a} R}{R+r} F(\Psi, k),
$$

where

$$
\begin{aligned}
\psi & =\tan ^{-1}\left(\frac{L / 2}{r-R}\right), \\
k & =\frac{2(r R)^{1 / 2}}{(r+R)}, \text { and } \\
F(\psi, k) & =\int_{0}^{\psi}\left(1-k^{2} \sin ^{2} \theta\right)^{-1 / 2} d \theta,
\end{aligned}
$$

where $\psi$ is the angle subtended by the centerline and the edge of the cask, as viewed by the receptor (Figure B.1); $L$ equals the length of the cask; $R$ equals the radius of the cask; and $r$ equals the distance of the receptor measured from the center of the cask.

\section{B.2 DOSE RATE CONVERSION}

In the above calculations, it is assumed that the dose rate is directly proportional to the flux at the receptor. If $K_{0}$ is the flux-to-dose-rate conversion factor, then the dose rate at receptor $P$ is approximated by

$$
\dot{D}(r)=K_{0} \Phi(r) .
$$




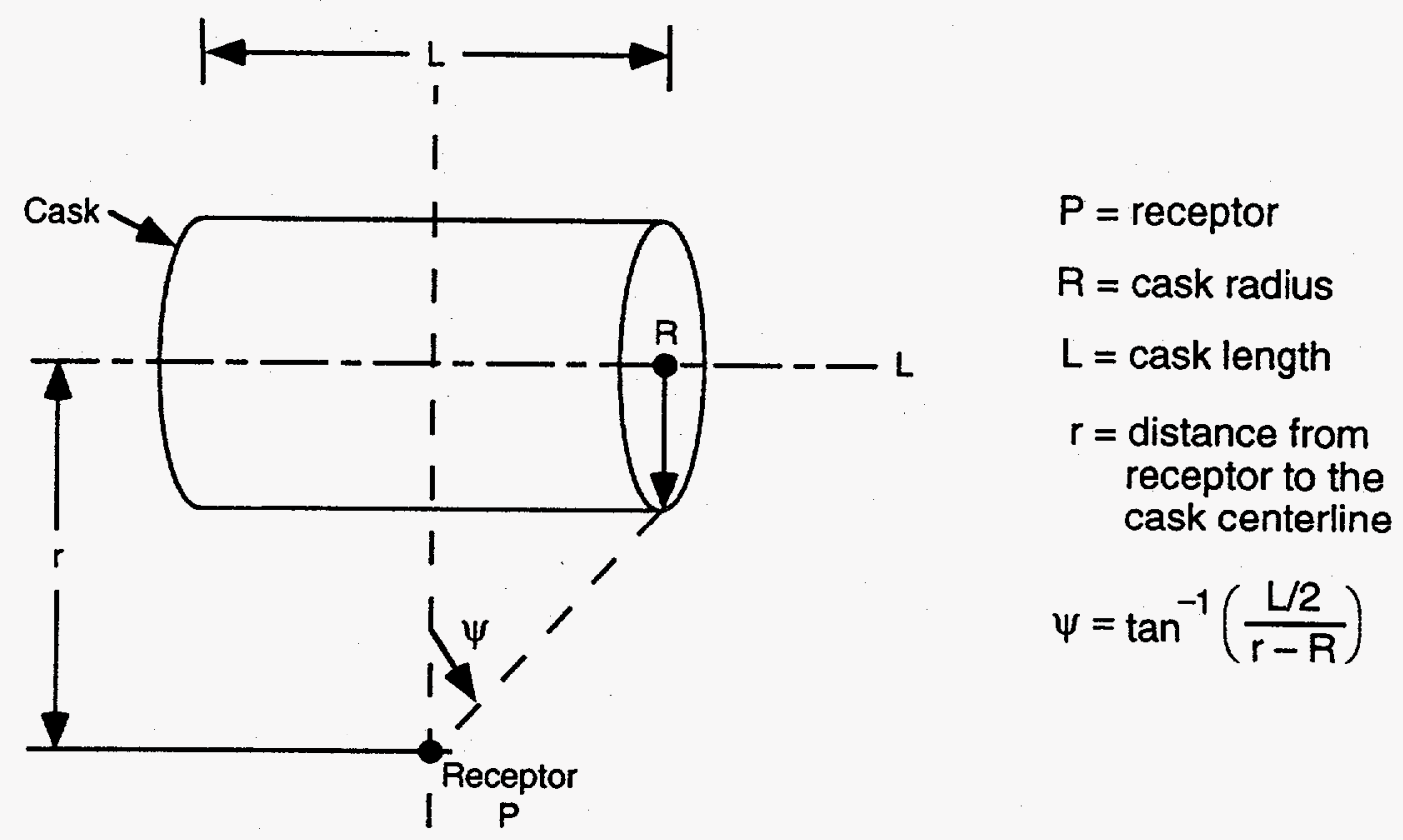

FIGURE B.1 Schematic Diagram Correlating Doses to Cask Dimensions

If $\dot{D}_{0}(r)$ represents the dose rate at $r$ for the reference cask with dimensions $R_{0}$ and $L_{0}$, and $\dot{D}_{1}(r)$ represents the dose rate at $r$ for a new cask with dimensions $R_{1}$ and $L_{1}$, the adjusted dose rate will be $\dot{D}_{1}$ because of the dimension changes. The dose rates at the reference distance $(D, 1 \mathrm{~m}$ or $2 \mathrm{~m}$ ) for both casks are assumed to be equal to the dose rate input by the user. The reference distance includes the offset of the cask's outer surface from the transport vehicle outer lateral surface. From Equation B.1, the following equations can be derived:

$$
\dot{D}_{0}\left(R_{0}+D\right)=\frac{S_{a 0} R_{0} K_{0}}{\left(2 R_{0}+D\right)} F\left(\Psi_{0 D}, k_{0 D}\right)
$$

and

$$
\dot{D}_{1}\left(R_{1}+D\right)=\frac{S_{a 1} R_{1} K_{0}}{2 R_{1}+D} F\left(\Psi_{1 D}, k_{1 D}\right)
$$

where

$$
\begin{aligned}
& \psi_{0 D}=\tan ^{-1}\left(L_{0} / 2 D\right), \\
& \psi_{1 D}=\tan ^{-1}\left(L_{1} / 2 D\right), \\
& k_{0 D}=\frac{2\left[\left(R_{0}+D\right) R_{0}\right]^{1 / 2}}{\left(2 R_{0}+D\right)}, \text { and }
\end{aligned}
$$




$$
k_{1 D}=\frac{2\left[\left(R_{1}+D\right) R_{1}\right]^{1 / 2}}{\left(2 R_{1}+D\right)},
$$

where $\psi$ and $k$ are evaluated at the reference distance from the surfaces of the two casks.

Thus, the dose rate at a distance $d$ from the surfaces of the two casks is

$$
\dot{D}_{0}\left(d+R_{0}\right)=\frac{S_{a 0} R_{0} K_{0}}{d+2 R_{0}} F\left(\Psi_{0}, k_{0}\right)
$$

and

$$
\dot{D}_{1}\left(d+R_{1}\right)=\frac{S_{a 1} R_{1} K_{0}}{d+2 R_{1}} \mathrm{~F}\left(\psi_{1}, k_{1}\right)
$$

where

$$
\begin{aligned}
\psi & =\tan ^{-1}\left(\frac{L_{0}}{2 d}\right), \\
\psi_{1} & =\tan ^{-1}\left(\frac{L_{1}}{2 d}\right), \\
k_{0} & =\frac{2\left[\left(R_{0}+d\right) R_{0}\right]^{1 / 2}}{\left(2 R_{0}+d\right)}, \text { and } \\
k_{1} & =\frac{2\left[\left(R_{1}+d\right) R_{1}\right]^{1 / 2}}{\left(2 R_{1}+d\right)} .
\end{aligned}
$$

\section{B.3 DOSE RATE ADJUSTMENT}

By using the relationship of $S_{\mathrm{a} 0}$ and $S_{\mathrm{a} 1}$ from Equations B.6 and B.7, $\dot{D}_{0}\left(R_{0}+D\right)=\dot{D}_{1}\left(R_{1}+D\right)$, and substituting Equations B.12 and B.13, the ratio $Q(d)$ of the dose rates at a distance $d$ meters from the surfaces of the two casks becomes

$$
\begin{gathered}
Q(d)=\frac{\dot{D}_{1}\left(d+R_{0}\right)}{\dot{D}_{0}\left(d+R_{1}\right)} \\
Q(d)=\frac{\left(2 R_{0}+d\right)}{\left(2 R_{1}+d\right)} \times \frac{F\left(\psi_{1}, k_{1}\right)}{F\left(\Psi_{0}, k_{0}\right)} \times \frac{\left(2 R_{1}+D\right)}{\left(2 R_{0}+D\right)} \times \frac{F\left(\psi_{0_{\mathrm{D}}}, k_{0_{\mathrm{D}}}\right)}{F\left(\Psi_{1_{\mathrm{D}}}, k_{1 \mathrm{D}}\right)} .
\end{gathered}
$$

The ratio $Q(d)$ depends on the reference cask dimensions, $R_{0}$ and $L_{0}$, and the new cask dimensions, $R_{1}$ and $L_{1}$. The ratio $Q(d)$ can be used to adjust the dose rates obtained from 
B-8

Equation 2.1 due to changes in cask dimensions. That is, the adjusted dose rate $\dot{D}_{1}(d)$ for a receptor at a distance $d$ meters from the cask surface can be obtained by

$$
\dot{D}_{1}(d)=\dot{D}_{0}(d) Q(d)
$$

where $\dot{D}_{0}(d)$ is the known dose rate for the reference cask, and $Q(d)$ is the dose-rate ratio obtained from Equation B.19.

APPENDIX B REFERENCE

Jaeger, R.G., ed., 1968, Engineering Compendium on Radiation Shielding, vol. I, SpringerVerlag, Berlin, West Germany. 
$C-1$

\section{APPENDIX C:}

METHOD FOR SCREENING RADIONUCLIDES 
C-2 


\section{CONTENTS}

APPENDIX C: METHOD FOR SCREENING RADIONUCLIDES .................................... C-5

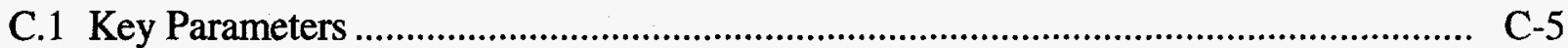

C.2 Pathway Considerations....................................................................................... C-6

C.3 Screening Parameters ................................................................................................ C-6

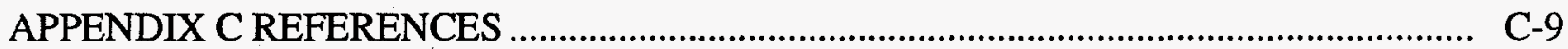


C-4 


\section{APPENDIX C: \\ METHOD FOR SCREENING RADIONUCLIDES}

Spent nuclear fuels (SNFs) are usually irradiated in nuclear reactors for many hundreds of hours before they are removed for refueling. Thus, even after years of cooling, the spent fuels may still contain several hundred different radionuclides. Because it is necessary to limit the number of nuclides for each assessment when using RISKIND (up to 100 nuclides), and because not all of these radionuclides are radiologically significant in the environment, selecting radionuclides of potential importance becomes an essential task. With careful screening, the number of nuclides selected can be reduced to a manageable size without sacrificing accuracy in dose calculations. This appendix describes the process used to select radionuclides for dose calculations.

\section{C.1 KEY PARAMETERS}

The relative importance of the various radionuclides contained in SNFs is evaluated by considering (1) the quantity of each radionuclide present, (2) the fraction of each radionuclide that would be released to the atmosphere during an accident, and (3) the various exposure pathway-dependent factors. The latter includes soil-to-vegetation transfer factors, vegetation-tomeat and -milk transfer factors and human and animal food ingestion rates; the dose conversion factors for each exposure pathway; and the radionuclide decay constant and weathering removal parameter that determines how long deposited radioactive material remains on the ground. Only key parameters that are the most important in determining the relative radiological impacts to humans are considered.

The quantity of each radionuclide present in the spent fuel is dependent on characteristics such as fuel burnup, type of reactor (pressurized-water reactor [PWR] or boilingwater reactor [BWR]), and age of fuel (cooling time). Oak Ridge National Laboratory (ORNL) has compiled a spent fuel radionuclide database (Notz et al. 1987) with the ORIGEN2 code (Croff 1980). The results of the ORNL data compilation are given in the U.S. Department of Energy (DOE) report Characteristics of Potential Repository Wastes (DOE 1992). In RISKIND, the radionuclide source term in the spent fuel, $Q(i)$, is calculated on the basis of the user's input values for fuel burnup, type of reactor, and age of fuel.

The amount of a radionuclide that can be released to the atmosphere during an accident is usually represented by the release fraction of the total source inventory in the cask. Because the amount of radioactivity that could be released to the atmosphere is highly dependent on the severity of the accident, accurate calculation of doses requires that this value be determined for each accident scenario. In the RISKIND code, the screening process is calculated for each of the 20 cask response regions defined in the U.S. Nuclear Regulatory Commission (NRC) modal 
study (Lawrence Livermore National Laboratory [LLNL] 1987). For convenience, radionuclides are grouped by physical and chemical behavior: particulates; ruthenium, cesium, and iodine isotopes; and noble or inert gases. The release parameters for these five types of radionuclides have been discussed in Section 3.2 of this document.

\section{C.2 PATHWAY CONSIDERATIONS}

In RISKIND, three pathways that would lead to human exposure following atmospheric release of radionuclides are used to determine the relative health hazards of one radionuclide versus others in the shipping cask. The first pathway (I) is the short-term exposure from air immersion and inhalation during plume passage; it is used to determine the relative importance of nuclides in causing individual doses from the passing plume. The second pathway (II) is the long-term external radiation exposure from contaminated ground; it is used to screen each nuclide's relative importance with respect to the long-term hazard of residing on the contaminated land. The third pathway (III) is the long-term internal radiation exposure from ingestion of contaminated foods; it is used to screen each nuclide relative to the hazard from eating or drinking contaminated food products and water.

\section{C.3 SCREENING PARAMETERS}

The dose received from pathway I at a particular location from radionuclide $i$ can be expressed as

$$
D \mathrm{I}(i)=\sum_{j=1,2} D F \mathrm{I}(i, j) Q(i) R S(i) \bar{C}_{a}(i),
$$

where

$$
\begin{aligned}
D \mathrm{I}(i)= & \text { dose from pathway } \mathrm{I} \text { (short-term) exposure for radionuclide } i ; \\
D F \mathrm{I}(i, j)= & \text { appropriate dose conversion factor for radionuclide } i \text {, exposure } \\
& \text { pathway } j ; \\
j= & 1, \text { for inhalation; } j=2, \text { for air immersion; } \\
Q(i)= & \text { source inventory of radionuclide } i ; \\
R S(i)= & \text { expected fraction of radionuclide } i \text { released to the atmosphere; and } \\
\bar{C}_{a}(i)= & \text { time-integrated air concentration factor at a reference location for } \\
& \text { radionuclide } i, \bar{C}_{a}(i) \text { is assumed to be independent of radio- } \\
& \text { nuclide } i, \text { i.e., } \bar{C}_{a}(i)=\bar{C}_{a} .
\end{aligned}
$$


The relative importance of a radionuclide for pathway I exposure is calculated as

$$
F \mathrm{I}(i)=\frac{D \mathrm{I}(i)}{\sum_{i} D \mathrm{I}(i)} .
$$

Equation C.2 can be expressed as

$$
F \mathrm{I}(i)=\frac{\sum_{j=1,2} Q(i) R S(i) D F \mathrm{I}(i, j)}{\sum_{i} \sum_{j=1,2} Q(i) R S(i) D F \mathrm{I}(i, j)} .
$$

The dose received from pathway II (long-term external exposure from ground contamination) can be written as

$$
\begin{gathered}
D \Pi(i)=D F \Pi(i) \bar{C}_{\mathrm{g}}(i) \\
\bar{C}_{\mathrm{g}}(i)=Q(i) R S(i) \bar{C}_{\mathrm{a}}(i) V_{d}(i) T G(i),
\end{gathered}
$$

where

$$
\begin{aligned}
D \Pi(i)= & \text { dose from external exposure to ground contamination for } \\
& \text { radionuclide } i ; \\
D F \amalg(i)= & \text { dose conversion factor for ground external exposure; } \\
\bar{C}_{g}(i)= & \text { time-integrated ground concentration for radionuclide } i \\
T G(i)= & {\left[1-\exp \left(-\lambda_{\mathrm{g}}(i) \mathrm{T}\right)\right] / \lambda_{\mathrm{g}}(i) ; } \\
V_{d}(i)= & \text { deposition velocity for radionuclide } i ; \\
\lambda_{g}(i)= & \text { effective removal constant, including radioactive decay and } \\
& \text { weathering, for radionuclide } i \text {; and } \\
T= & \text { total time period for ground external exposure (default: } 50 \mathrm{yr}) .
\end{aligned}
$$

The relative radiation hazard of a radionuclide from pathway II exposure is calculated as

$$
F \Pi(i)=\frac{D \Pi(i)}{\sum_{i} D \Pi(i)} .
$$


Explicitly,

$$
F \amalg(i)=\frac{Q(i) R S(i) V_{d}(i) D F \amalg(i) T G(i)}{\sum_{i} Q(i) R S(\mathrm{i}) V_{d}(i) D F \amalg(i) T G(i)}
$$

Pathway III accounts for long-term food ingestion. The amount of radioactivity ingested over time through the food pathway is difficult to assess. A simplified approach is used for screening purposes. The dose received from ingestion of food is approximated by estimating radionuclides in foodstuff via root uptake mechanisms from soil. The dose received from pathway III is approximated by

$$
\begin{gathered}
D \mathrm{II}(i)=D F \mathrm{II}(i) S_{v}(i)[F 1(i)+F 2(i)+F 3(i)] \bar{C}_{g}(i) \\
F 1(i)=F_{b}(i) Q_{a} U_{b} / \rho \\
F 2(i)=F_{m}(i) Q_{a} U_{m} / \rho \\
F 3(i)=0.5 U_{v} / \rho
\end{gathered}
$$

where

$$
\begin{aligned}
D I I I(i)= & \text { ingestion dose factor for pathway III exposure; } \\
D F \amalg(i)= & \text { ingestion dose conversion factor for radionuclide } i \\
S_{v}(i)= & \text { soil-to-vegetation transfer factor for radionuclide } i \\
F_{b}(i)= & \text { meat transfer factor for radionuclide } i \\
F_{m}(i)= & \text { milk transfer factor for radionuclide } i \\
U_{b}, U_{m}, U_{v}= & \text { human food ingestion rate for meat, milk, and vegetables, } \\
& \text { respectively; } \\
Q_{a}= & \text { animal pasture ingestion rate for meat cattle and milk cows; and } \\
\rho= & \text { vegetation yield density of pastureland or a vegetable garden. }
\end{aligned}
$$

The relative importance of radionuclide $i$ for pathway III exposure can be expressed by

$$
F \mathrm{III}(i)=\frac{D \Pi \mathrm{II}(i)}{\sum_{i} D \mathrm{III}(i)}
$$


Explicitly,

$$
F \mathrm{III}(i)=\frac{D F \mathrm{III}(i) Q(i) R S(i) V_{d}(i) S_{v}(i)[F 1(i)+F 2(i)+F 3(i)] T G(i)}{\sum_{i} D F \mathrm{III}(i) Q(i) R S(i) V_{d}(i) S_{v}(i)[F 1(i)+F 2(i)+F 3(i)] T G(i)}
$$

The radionuclide selection criterion in RISKIND is based on the calculated relative importance of the values of $F \mathrm{I}(i), F \amalg(i)$, and $F \amalg(i)$. The screening procedure is such that radionuclides are selected as

$$
F \mathrm{I}(i)>S \text {, or } F \Pi(i)>S, \text { or } F \Pi(i)>S \text {, }
$$

where $S$ is the radionuclide selection criterion (default: 0.01 , or $99 \%$ ). In using RISKIND, the radionuclide selection process follows the procedures described above until the total number of selected nuclides exceeds the prescribed limit of 100 . If the number of nuclides selected exceeds this limit, it is recommended that the user change the input value of $S$ to a smaller value so that the dose calculation will cover the whole range of nuclides in the spent fuel. By selecting an appropriate $S$ value, the number of radionuclides considered can be reduced while maintaining a high degree of accuracy in the calculated results.

The resulting impacts, which are estimated by RISKIND with the radionuclides selected with a particular value of the radionuclide selection criterion, will not exactly match the accuracy specified by the criterion. The selection criterion is only an approximate value since the radionuclides are selected on the basis of general principles and not on the actual calculations used. To ensure a given accuracy, the selection criterion should be set to a lower value. For example, $S$ should be set to $0.001(99.9 \%)$ to ensure that $99 \%$ of the estimated dose is reported.

\section{APPENDIX C REFERENCES}

Croff, A.G., 1980, ORIGEN2 Isotope Generation and Depletion Code Matrix Exponential Method, User's Manual, ORNL/TM-7175, Oak Ridge National Laboratory, Oak Ridge, Tenn.

Lawrence Livermore National Laboratory, 1987, Shipping Container Response to Severe Highway and Railway Accident Conditions, NUREG/CR-4829, UCID-20733, prepared by Lawrence Livermore National Laboratory, Livermore, Calif., for U.S. Nuclear Regulatory Commission, Washington, D.C., Feb.

Notz, K.J., et al., 1987, Characteristics of Potential Repository Wastes, vols. 1-6, DOE/RW-0184, prepared by Oak Ridge National Laboratory, Oak Ridge, Tenn., for U.S. Department of Energy, Office of Civilian Radioactive Waste Management, Washington, D.C. 
U.S. Department of Energy, 1992, Characteristics of Potential Repository Wastes, DOE/RW-184-R1, prepared by Oak Ridge National Laboratory, Oak Ridge, Tenn., for U.S. Department of Energy, Office of Civilian Radioactive Waste Management, Washington, D.C. 
APPENDIX D:

METHOD FOR ESTIMATING THE SPALLATION OF CRUD MATERIAL 
D-2 


\section{CONTENTS}
APPENDIX D: METHOD FOR ESTIMATING THE SPALLATION
OF CRUD MATERIAL
D.1 Characteristics of Crud
D. 2 Crud Inventory
D.3 Crud Release.

\section{TABLES}

D.1 General Crud Characteristics

D-6

D. 2 Current Cask and Fuel Assembly Design Parameters.

D-7

D.3 Radionuclides Found in Crud.

D-9

D.4 Maximum Radioisotope Activity Density

D-9

D.5 Spallation Values for NRC Modal Study Cask Response Regions 
D-4 


\section{APPENDIX D:}

\section{METHOD FOR ESTIMATING THE SPALLATION OF CRUD MATERIAL}

This appendix describes the method used to estimate the amount of crud material that could be released from a shipping cask during a transportation accident. The method follows that described in a recent Sandia National Laboratory report by Sandoval et al. (1991). During shipment, crud may spall from the rods, become airborne in the cask cavity, and be released to the environment should a leak path develop in the cask containment system. Because of the sparsity of experimental data on (1) crud activity levels, (2) crud spallation fractions from the fuel rods, and (3) the resulting particle size distributions of the spalled crud necessary for estimating airborne fractions, the results presented in Sandoval et al. (1991) are of limited use and are upper bound estimates. Further experimental and analytical analyses are required for a more accurate prediction of crud release.

\section{D.1 CHARACTERISTICS OF CRUD}

Crud is a mixture of reactor primary cooling system corrosion products that have deposited on fuel rod surfaces. These deposits contain neutron-activated nuclides and may also contain fissile particles and fission products. Limited studies suggest that deposits on assembly skeletons are similar to, if not the same, as on the fuel rods themselves.

Two types of crud are observed. Some crud can be easily removed from the fuel rod with a soft brush. This flocculent form is the dominant one found on boiling-water reactor (BWR) fuel rods and was noted to constitute approximately $65 \%$ of the crud samples removed from a set of BWR fuel rods (Asay and Blok 1978). This easily removed crud is mostly hematite $\left(\mathrm{Fe}_{2} \mathrm{O}_{3}\right)$, generally of a porous, hydrated nature. The other form of crud is more tenacious, usually found on pressurized-water reactor (PWR) fuel rods, and is not readily removed from the fuel rods. This latter form is composed of crystalline oxides, mainly a nickel-substituted spinel $\left(\mathrm{Ni}_{\mathrm{x}} \mathrm{Fe}_{3-\mathrm{x}} \mathrm{O}_{4}\right)$. These two types of crud usually develop in layers and may form a sandwich-like structure. The differences between the two types of fuel rods have been attributed to different oxygen levels in the primary coolant water of the two reactor types (Strasser et al. 1985). Rods currently being discharged from reactors tend to have less crud than before because of better control of the reactor coolant chemistry. Even in the past, most fuel rods were visually observed to have little or no crud. Those rods without visual crud deposits are expected to have a thin crud film, because iron has been detected on the surface of some fuel rods without visual amounts of crud. Table D.1 summarizes the general characteristics of crud found on BWR and PWR fuel rods. 
TABLE D.1 General Crud Characteristics ${ }^{a}$

\begin{tabular}{|c|c|c|}
\hline Feature & PWR & BWR \\
\hline Color & $\begin{array}{l}\text { Gray, reddish orange, } \\
\text { brown, tan, black, } \\
\text { reddish brown }\end{array}$ & $\begin{array}{l}\text { Orange, brown, } \\
\text { reddish brown }\end{array}$ \\
\hline \multicolumn{3}{|l|}{ Thickness } \\
\hline Maximum $^{b}$ & $4 \mathrm{mil}$ & $10 \mathrm{mil}$ \\
\hline Average $^{c}$ & $<1$ mil & 1 to $3 \mathrm{mil}$ \\
\hline Peak to average axial variation & $\approx 2$ & $\approx 2$ \\
\hline \multicolumn{3}{|l|}{ Chemical composition } \\
\hline Major elements & $\mathrm{Ni}, \mathrm{Fe}, \mathrm{Cr}$ & $\mathrm{Ni}, \mathrm{Fe}, \mathrm{Cr}, \mathrm{Cu}$ \\
\hline $\mathrm{Ni} / \mathrm{Fe}$ ratio & $<1$ & $\ll<1$ or $>1$ \\
\hline Structure & $\mathrm{Ni}_{\mathrm{x}} \mathrm{Fe}_{3-\mathrm{x}} \mathrm{O}_{4}$ & $\mathrm{Fe}_{2} \mathrm{O}_{3}, \mathrm{NiO}$ \\
\hline Axial variation & $\approx 2$ & $\approx 2$ \\
\hline \multicolumn{3}{|l|}{ Radioactivity } \\
\hline Maximum observed Co-60 $\left(\mu \mathrm{Ci} / \mathrm{cm}^{2}\right)$ & 140 & 1,250 \\
\hline Range of $\mathrm{Co}-60\left(\mu \mathrm{Ci} / \mathrm{cm}^{2}\right)^{d}$ & 0.1 to 140 & 11 to 1,250 \\
\hline Major component after 10 years & Co-60 & Co-60 \\
\hline
\end{tabular}

a $\mathrm{Co}=$ cobalt, $\mathrm{Cr}=$ chromium, $\mathrm{Cu}=$ copper, $\mathrm{Fe}=$ iron, $\mathrm{Fe}_{2} \mathrm{O}_{3}=$ hematite, $\mathrm{Ni}=$ nickel, $\mathrm{Ni}_{\mathrm{x}} \mathrm{Fe}_{3-\mathrm{x}} \mathrm{O}_{4}=$ nickel-substituted spinel, and $\mathrm{NiO}=$ nickel oxide.

b Maximum thickness measured on any rod regardless of location.

c Average of all the maximum thicknesses measured.

d Maximum densities observed.

Source: Sandoval et al. (1991).

\section{D.2 CRUD INVENTORY}

The total crud inventory inside a shipping cask is the product of the total surface area of the fuel rods and the crud surface activity density. The total surface area of the fuel rods inside a cask is a function of the cask design, the number of fuel assemblies, and the type of fuel. Table D.2 presents the total surface area of the cask cavity and the number and type of fuel rods normally shipped in currently used casks. The default value for cask cavity surface area used in RISKIND is for the NLI-1/2 truck cask or for the IF-300 rail cask, depending on the transportation mode selected. 
TABLE D.2 Current Cask and Fuel Assembly Design Parameters $^{\text {a }}$

\begin{tabular}{llccc}
\hline \multicolumn{1}{c}{ Cask Type } & $\begin{array}{c}\text { Fuel } \\
\text { Type }\end{array}$ & $\begin{array}{c}\mathrm{V} \\
\left(\mathrm{m}^{3}\right)\end{array}$ & $\begin{array}{c}\mathrm{A}_{\mathrm{t}} \\
\left(\mathrm{m}^{2}\right)\end{array}$ & $\mathrm{N}_{\mathrm{a}}$ \\
\hline NLI-1/2 & PWR & 0.155 & 39.0 & 1 \\
NLI-1/2 & BWR & 0.129 & 26.7 & 2 \\
TN-8 $^{\mathrm{b}}$ & PWR & 0.151 & 37.0 & 3 \\
TN-9 $^{\text {b }}$ & BWR & 0.070 & 13.6 & 7 \\
NAC-1/NFS-4 & PWR & 0.257 & 39.5 & 1 \\
NAC-1/NFS-4 & BWR & 0.268 & 27.2 & 2 \\
IF-300 & PWR & 2.32 & 251.6 & 7 \\
IF-300 & BWR & 2.34 & 209.5 & 18 \\
NLI-10/24 & PWR & 3.27 & 357.4 & 10 \\
NLI-10/24 & BWR & 3.27 & 227.6 & 24 \\
\hline
\end{tabular}

${ }^{\text {a }} \mathrm{V}=$ void volume of loaded cask; $A_{t}=$ total surface area of cask cavity, including fuel rods; and $\mathrm{N}_{\mathrm{a}}=$ number of assemblies that can be shipped in cask.

bN-8 has three compartments; TN-9 has seven compartments; values given are per compartment.

Source: Sandoval et al. (1991).

The crud surface activity density, as discussed in Sandoval et al. (1991), is a function of fuel type, fuel age, isotope composition, and reactor system chemistry. Sufficient data are not available to completely specify the crud activity characteristics for each type of fuel. Therefore, the conservatively estimated average maximum surface activity densities measured on the fuel rods and tabulated in Sandoval et al. (1991) are used by RISKIND for estimating the total crud inventory in a cask. Table D.1 lists the range of crud activity densities found on spent fuel rods. Because these density values are the maximums found on the fuel rods analyzed, many rods will have substantially lower values, particularly since most rods in the studies analyzed were chosen because of abnormal operating conditions, poor water chemistry, or heavy visual deposits of crud. In addition, the average activity density for a given fuel rod will be much less than the reported maximum spot density. Axially averaged values of 18 and $235 \mu \mathrm{Ci} / \mathrm{cm}^{2}$ for PWR and BWR maximum spot densities of 140 and $1,250 \mu \mathrm{Ci} / \mathrm{cm}^{2}$, respectively, are used as defaults in RISKNND.

The surface activity value input to RISKIND is adjusted by the decay of cobalt-60, according to the age of the fuel in the cask at the time of the accident. It is assumed that the total crud activity can be attributed to cobalt- 60 because it accounts for $99 \%$ of the activity at 8 years from fuel discharge for PWR fuel, and $98 \%$ of the activity at 5 years from fuel discharge for 
BWR fuel. The other isotopes commonly found in crud material are not considered because of their small concentrations after the initial few years following discharge, primarily because of their short half-lives (Table D.3). However, if fresh spent fuel is considered, isotopes such as cobalt-58 and manganese-54 should be considered. Table D.4 lists maximum activity densities measured for the different isotopes on both BWR and PWR fuel rods. Again, these are maximum spot densities on fuel rods with quantifiable amounts of crud material. The majority of fuel rods will contain much lower levels of crud.

\section{D.3 CRUD RELEASE}

The maximum amount of crud-borne activity that could be released to the environment because of a breach in the integrity of the shipping cask is the total crud inventory in the cask. For crud to be released, it must spall from the fuel rods, remain airborne, and pass through a leak path (breach in the cask confinement) to the environment.

Crud can spall from the fuel rods as a result of mechanical force on the rods or from expansion of the rods from heating (i.e., a fire). Because of insufficient data on crud particle spallation due to impact- or shock-related force on the cask during transport, spallation fractions of 1.0 were conservatively assumed by Sandoval et al. (1991) for all impact-related releases. Such a value may significantly overestimate the amount spalled from PWR fuel rods where the more tenacious form of crud dominates. In RISKIND, a spallation fraction of 1.0 is also assumed for all levels of mechanical loads above $0.2 \%$ strain because of lack of data. A spallation fraction of 0.15 was estimated as the upper bound for crud particle spallation fractions for the regulatory fire accident condition (30-minute exposure to a fire of approximately $1,100 \mathrm{~K}$ $\left.\left[1,500^{\circ} \mathrm{F}\right]\right)$. This value is assumed for all levels of thermal loads above a $530 \mathrm{~K}\left(500^{\circ} \mathrm{F}\right)$ lead midlayer thickness temperature. Table D.5 gives the default values of the spallation fraction assumed for the 20 accident response regions.

If crud is to be released during a transportation accident, it must remain airborne once it has spalled off the fuel rods in order to pass through a potential leak path to the environment. The ability of the crud to remain airborne once it has spalled from the fuel rods depends on its particle size distribution. Very little information is available for crud particle size distribution on BWR fuel and none is available for PWR fuel. No data are available on the particle size distribution of the spalled crud. In RISKIND, all of the spalled crud material is conservatively assumed to be released to the environment for all U.S. Nuclear Regulatory Commission (NRC) modal study response regions (Lawrence Livermore National Laboratory [LLNL 1987]) except region $\mathrm{R}(1,1)$, for which no release is assumed because no leak path has been identified (see Section 3.1). A number of attenuation mechanisms can significantly mitigate this source term. These include deposition and gravitational settling of the particulates during transport from their point of origin to a breach point in the shipping package, the mode and duration of the driving 
TABLE D.3 Radionuclides Found in Crud ${ }^{\mathrm{a}}$

\begin{tabular}{|c|c|c|}
\hline Parent & Radionuclide & $\begin{array}{c}\text { Half-Life, } t_{1 / 2} \\
\text { (days) }\end{array}$ \\
\hline \multirow[t]{2}{*}{$\mathrm{Cr}-50$} & $\mathrm{Cr}-51$ & 27.7 \\
\hline & $\mathrm{Nb}-95$ & 35 \\
\hline \multirow[t]{3}{*}{$\mathrm{Fe}-58$} & $\mathrm{Fe}-59$ & 44.6 \\
\hline & Sb-124 & 60.2 \\
\hline & $\mathrm{Zr}-95$ & 64 \\
\hline \multirow[t]{2}{*}{$\mathrm{Ni}-58$} & Co-58 & 70.8 \\
\hline & $\mathrm{Sn}-113$ & 115 \\
\hline $\mathrm{Zn}-64$ & $\mathrm{Zn}-65$ & 244 \\
\hline \multirow[t]{2}{*}{$\mathrm{Fe}-54$} & Mn-54 & 312 \\
\hline & Sb-125 & 996 \\
\hline $\mathrm{Co}-59$ & $\mathrm{Co}-60$ & 1,935 \\
\hline
\end{tabular}

Source: Sandoval et al. (1991).

TABLE D.4 Maximum Radioisotope Activity Density (corrected to fuel discharge)

\begin{tabular}{|c|c|c|c|c|c|c|c|c|}
\hline Reactor & Co-50 & $\mathrm{Co}-60$ & Mn-54 & $\mathrm{Cr}-51$ & $\mathrm{Fe}-59$ & Zr-95 & Sb-125 & $\mathrm{Zn}-65$ \\
\hline \multicolumn{9}{|l|}{ PWR $\left(\mu \mathrm{Ci} / \mathrm{cm}^{2}\right)$} \\
\hline Yankee Rowe & 1,400 & 140 & 380 & 240 & 300 & & & \\
\hline B\&W Reactors [ZI78] & 400 & 100 & & 170 & 30 & 1 & & \\
\hline Oconee 1 & 42 & 10 & 2 & & & & & \\
\hline Point Beach 1 & 13 & 2 & 2 & 16 & 2 & & & \\
\hline Benzau 1 & 215 & 16 & 13 & 391 & 25 & & & \\
\hline Zion 1 EOC-3 Grid $6 / 7$ & 346 & 73 & 43 & 127 & 25 & 36 & & \\
\hline H. B. Robinson & & 19 & 1 & & & & & \\
\hline \multicolumn{9}{|l|}{$\mathrm{BWR}\left(\mu \mathrm{Ci} / \mathrm{cm}^{2}\right)$} \\
\hline Peach Bottom & & 11 & 5 & & & & & \\
\hline Monticello & 21 & 350 & 57 & & 48 & 58 & & 121 \\
\hline Tsuruga & & 1,250 & 625 & & & & & \\
\hline Millstone 1 & 63 & 595 & 85 & 35 & 87 & & & 25 \\
\hline GE Reactors & 50 & 180 & 90 & 80 & & & & \\
\hline
\end{tabular}

Source: Sandoval et al. (1991). 
TABLE D.5 Spallation Values for NRC Modal Study Cask Response Regions

\begin{tabular}{cccc}
\hline $\begin{array}{c}\text { Response } \\
\text { Region }\end{array}$ & $\begin{array}{c}\text { Spallation } \\
\text { Fraction }\end{array}$ & $\begin{array}{c}\text { Response } \\
\text { Region }\end{array}$ & $\begin{array}{c}\text { Spallation } \\
\text { Fraction }\end{array}$ \\
\hline 1 & 0.15 & 11 & 1 \\
2 & 1 & 12 & 1 \\
3 & 1 & 13 & 0.15 \\
4 & 1 & 14 & 1 \\
5 & 0.15 & 15 & 1 \\
6 & 1 & 16 & 1 \\
7 & 1 & 17 & 0.15 \\
8 & 1 & 18 & 1 \\
9 & 0.15 & 19 & 1 \\
10 & 1 & 20 & 1 \\
\hline
\end{tabular}

force that affects such transport, and the possibility that the spalled crud particles themselves could plug the leak path.

\section{APPENDIX D REFERENCES}

Asay, R. H., and J. Blok, 1978, Brunswick-2 Fuel Deposit: Analysis Report, NEDC-21840, General Electric Company, San Jose, Calif.

Lawrence Livermore National Laboratory, 1987, Shipping Container Response to Severe Highway and Railroad Accident Conditions, NUREG/CR-4829, UCID-20733, prepared by Lawrence Livermore National Laboratory, Livermore, Calif., for U.S. Nuclear Regulatory Commission, Washington, D.C., Feb.

Sandoval, R.P., et al., 1991, Estimate of CRUD Contribution to Shipping Cask Containment Requirements, SAND-88-1358, Sandia National Laboratories, Albuquerque, N.M., Jan.

Strasser, A.K., et al., 1985, Corrosion Product Buildup in LWR Fuel Rods, EPRI NP-3789, Electric Power Research Institute, Palo Alto, Calif. 
APPENDIX E:

METHOD FOR ESTIMATING CASK RESPONSE FROM USER-SPECIFIED ACCIDENT SCENARIOS 


$$
\text { E-2 }
$$




\section{CONTENTS}

\section{APPENDIX E: METHOD FOR ESTIMATING CASK RESPONSE FROM}

E.1 Mechanical Loads

E.2 Thermal Loads

\section{FIGURES}

E.1 Representative Truck Cask Design Used for Dynamic Structural and Thermal Response Studies

E.2 Representative Rail Cask Design Used for Dynamic Structural and Thermal Response Studies

E.3 Three Impact Loading Parameters Considered in the Response Analysis for Impacts on Surfaces

E.4 Flow Diagram Used in RISKIND to Determine Cask Response Regions E-13

\section{TABLES}

E.1 Impact Velocities Required to Attain 0.2\%, 2\%, and 30\% Strain Levels for Objects Impacted in Highway and Railway Accidents

E.2 Fire Duration Required to Reach the Four Levels of Lead Midlayer Thickness Temperatures for a 1,200 K Engulfing Fire

E.3 Heat Flux Factors for Flame Temperatures

E.4 Response Regions Categorized by Vessel Strain and Lead Midlayer Thickness Temperature 
E-4 


\section{APPENDIX E:}

\section{METHOD FOR ESTIMATING CASK RESPONSE FROM USER-SPECIFIED ACCIDENT SCENARIOS}

In a shipping accident involving spent nuclear fuel, mechanical or thermal cask response, or both, can be generated and the cask can be damaged. The response depends on many factors described in the modal study of the U.S. Nuclear Regulatory Commission (Lawrence Livermore National Laboratory [LLNL] 1987). Such factors include the mechanical loadings generated by the accident impact velocity and the object that is struck and, in the event of a fire, the thermal loadings generated by flame temperature and duration of the fire. This appendix describes the subroutine implemented in RISKIND to determine the magnitude of the cask response on the basis of user-specified accident scenarios. The subroutine incorporates the parameters developed for the reference casks in the modal study. Because the response can be different for various cask designs subjected to the same accident conditions, reevaluation of the cask response may be necessary for a more accurate assessment of the potential radiation hazards when cask designs significantly different from those of the reference casks are involved. In the modal study, an analytical method based on various computer codes was used to estimate cask responses. These computer codes have been benchmarked or validated against experimental data. ${ }^{1}$

Two representative cask designs were developed in the modal study (LLNL 1987): one for truck shipments and the other for rail shipments of spent fuel. The configurations of these representative casks are shown in Figure E.1 for a truck cask and Figure E.2 for a rail cask. The truck cask is designed to allow for transport of a single pressurized-water reactor (PWR) fuel assembly; the rail cask capacity is 21 PWR fuel assemblies. Detailed descriptions of the designs are provided in the modal study (LLNL 1987).

The cask response state during an accident is categorized in terms of the magnitude of the mechanical and thermal loads that could be received by a spent fuel cask. Both loads generate response states for a cask that could result in damage to the cask and the release of radioactive material. Because specific mechanical and thermal loading conditions can affect the cask under a variety of accident conditions, identifying the loading parameters is an essential task.

1 The RISKIND program uses SI units $(\mathrm{km} / \mathrm{h}$ and $\mathrm{K}$ ) in the user interface for consistency across all models. However, the model and algorithms in the modal study (LLNL 1987) use units of mph for speed and ${ }^{\circ} \mathrm{F}$ for temperature to determine the accident response region. Both sets of units are provided in this appendix for the user's convenience. 

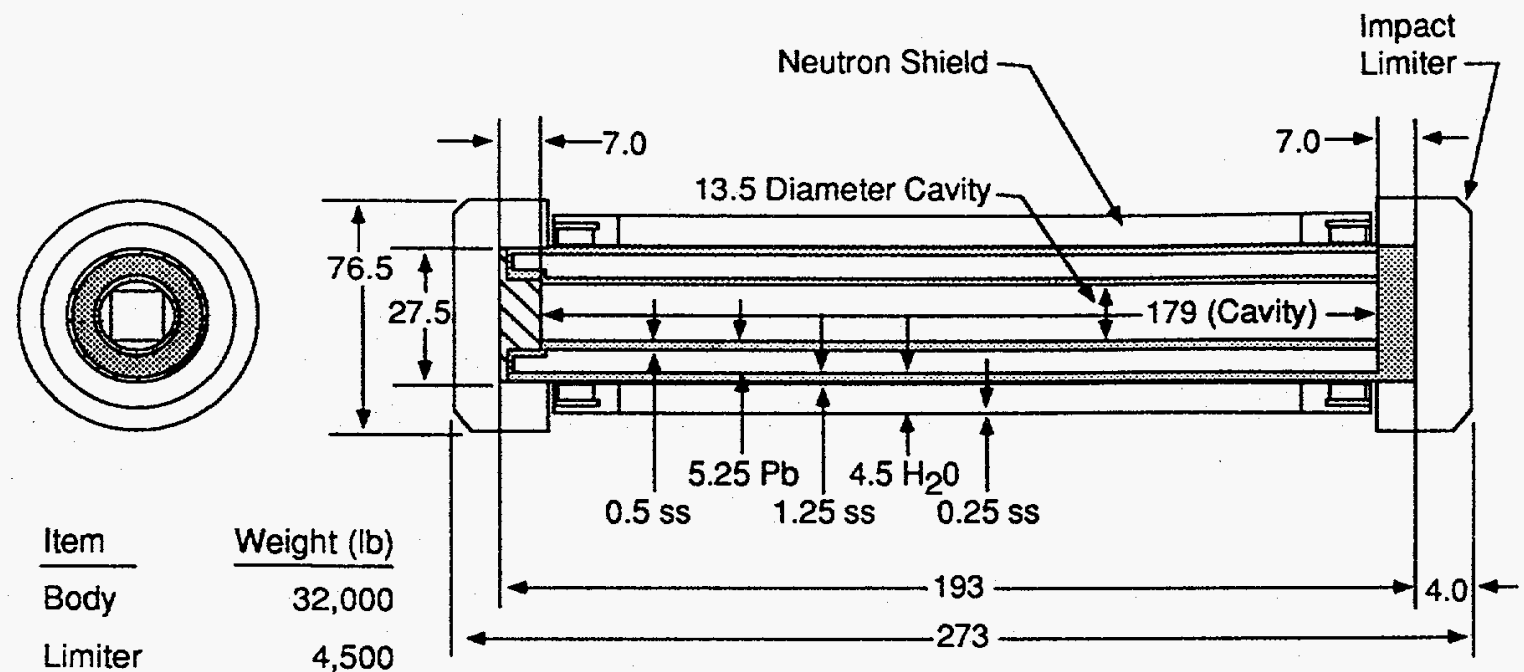

\begin{tabular}{lr} 
Limiter & 4,500 \\
Contents & 2,500 \\
\hline & 39,000
\end{tabular}

All dimensions are in inches.

$$
\begin{aligned}
\mathrm{Pb} & =\text { Lead } \\
\mathrm{H}_{2} \mathrm{O} & =\text { Water } \\
\mathrm{SS} & =\text { Stainless Steel }
\end{aligned}
$$

FIGURE E.1 Representative Truck Cask Design Used for Dynamic Structural and Thermal Response Studies (Source: Modified from LLNL 1987)
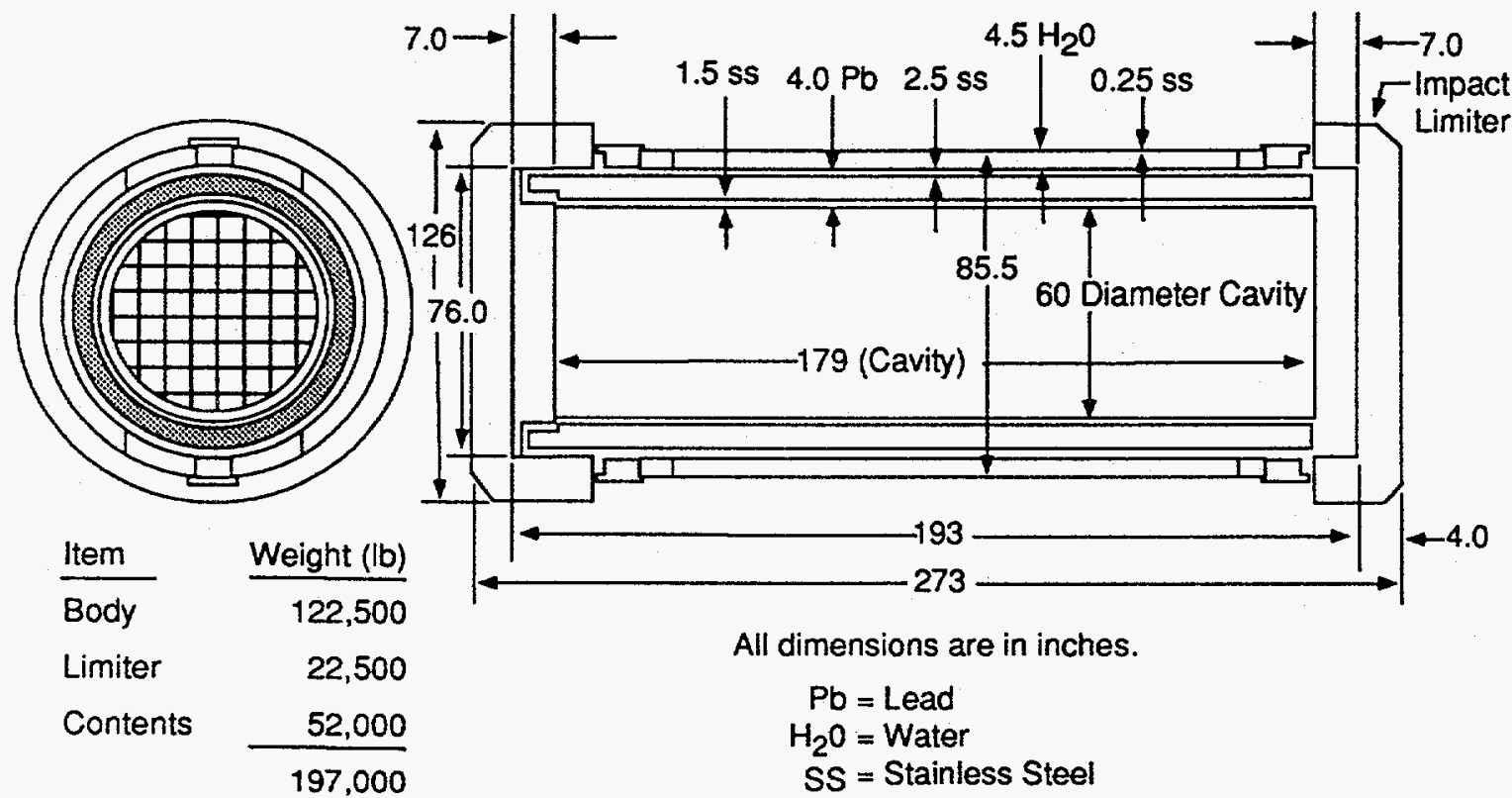

All dimensions are in inches.

$$
\begin{aligned}
\mathrm{Pb} & =\text { Lead } \\
\mathrm{H}_{2} \mathrm{O} & =\text { Water } \\
\mathrm{SS} & =\text { Stainless Steel }
\end{aligned}
$$

FIGURE E.2 Representative Rail Cask Design Used for Dynamic Structural and Thermal Response Studies (Source: Modified from LLNL 1987) 


\section{E.1 MECHANICAL LOADS}

The dominant mechanical loads have been identified as the forces on the cask caused by impact with a surface or hard object. Three major accident parameters have been identified that affect the cask mechanical response and may cause damage: (1) impact velocity, (2) orientation of the cask, and (3) hardness of the object impacted.

The impact velocity depends on the relative velocity of the cask and the angle of impact with respect to the object impacted. The relative velocity is the velocity of the cask relative to the impact object at the time of impact. The impact angle $(\alpha)$ is the angle between the cask velocity (direction along which the cask is traveling) and the plane of the surface struck. The impact velocity can be calculated as

$$
\text { Impact velocity }=\text { Cask velocity } \times \sin \alpha .
$$

The cask orientation angle $(\beta)$ is the angle between the cask's longitudinal axis and the impact surface; Figure E. 3 shows the interrelationship of these accident parameters. The impact on a surface with a $0^{\circ}$ cask orientation constitutes a sidewise impact, whereas a $90^{\circ}$ cask orientation constitutes an endwise impact.

The object hardness is the hardness of the object impacted during the accident. Four increasing levels of object hardness are categorized in the modal study (LLNL 1987): very soft (water), soft (tillable soil), medium (hard soil/soft rock), and unyielding (hard rock).

The strain on the inner shell of the shipping cask was selected as the single parameter in the modal study (LLNL 1987) to characterize mechanical load response states. The relationships between the strain and various accident parameters such as cask velocity, impact angle, cask orientation, and object hardness were investigated extensively. Three discrete levels of maximum strain on the inner shell were used to relate ranges of response states and mechanical loads to potential radiological hazards: $0.2 \%$ (elastic), $2 \%$ (plastic), and $30 \%$ (plastic) strain at the inner shell. The relationship between strain and impact velocity has been developed for various object hardnesses and cask orientations. The impact velocities required to reach the three discrete levels of maximum strain on the inner shell for the representative truck and rail casks are given in Table E.1. By using the bounding impact velocities for various cask orientations and impact surfaces, the response regions for the representative truck and rail casks can be determined by interpolation for any combination of impact velocity, cask orientation, and impact hardness. 

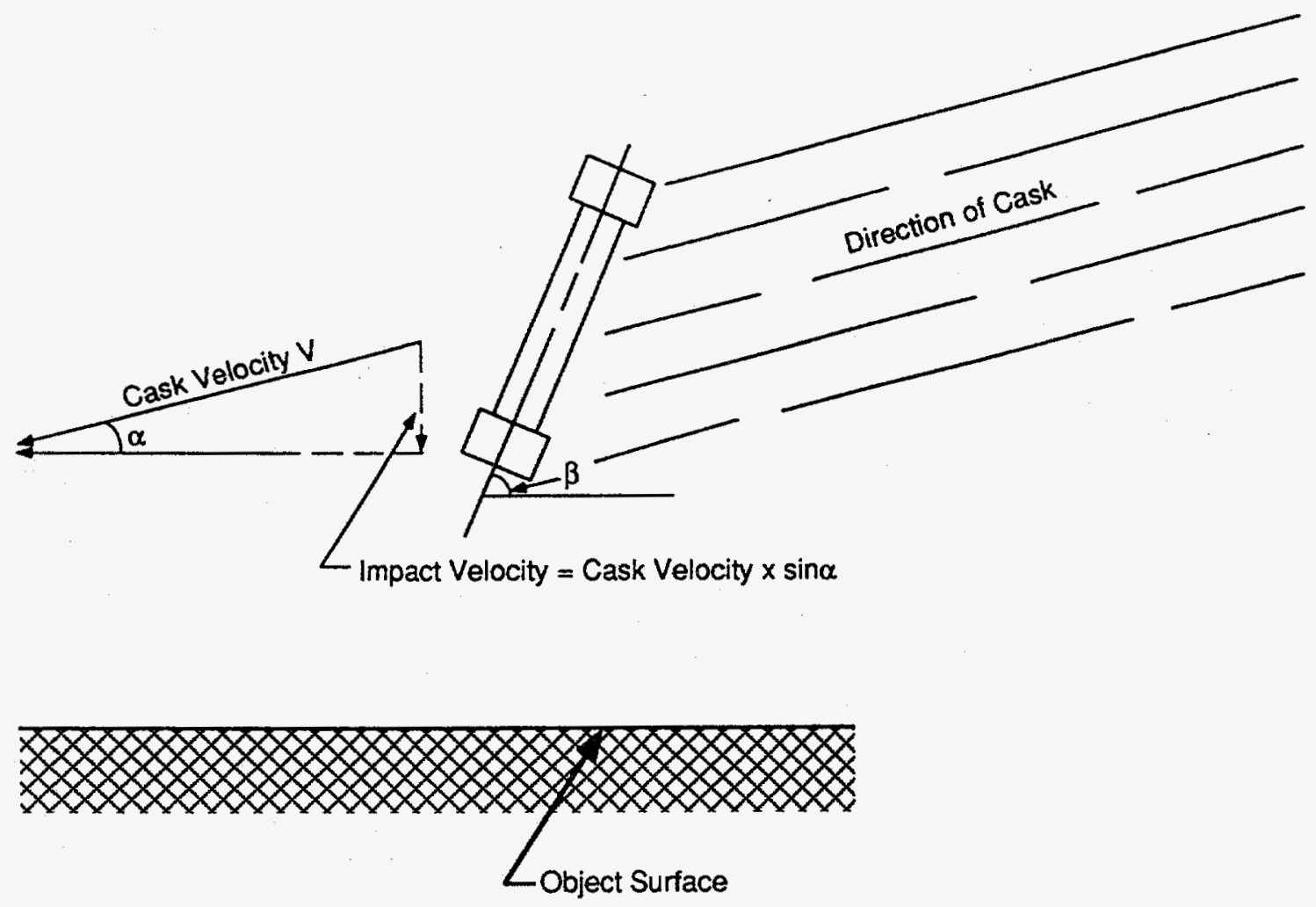

FIGURE E.3 Three Impact Loading Parameters Considered in the Response Analysis for Impacts on Surfaces (Modified from LLNL 1987, Figure 2.1)

\section{E.2 THERMAL LOADS}

The temperature at the midlayer thickness of the lead shield (lead is the material assumed for the reference cask) was selected in the modal study as the appropriate parameter for characterizing thermal load response states. This temperature can be related to three accident parameters: fire duration, fire location, and flame temperature. Fire duration is the duration of the fire during the accident. Flame temperature, which usually ranges from 1,030 to $1,590 \mathrm{~K}$ $\left(1,400\right.$ to $\left.2,400^{\circ} \mathrm{F}\right)$, is dependent on the burning materials and the amount of oxygen present in the flame. Fire location is determined by the relative distance from the fire to the cask. Fire location has been found to be an important factor in determining the thermal load. The heat load

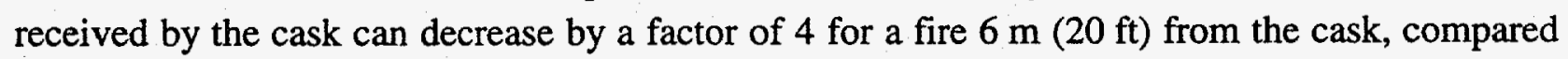
with the heat load for an engulfing fire.

For casks with lead shielding, four discrete temperature response levels $-530,590$, 616 , and $839 \mathrm{~K}\left(500,600,650\right.$, and $\left.1,050^{\circ} \mathrm{F}\right)$ - are used to characterize the ranges of thermal response states and, therefore, the release potentials. The fire durations required to reach these four response states for a $1,200 \mathrm{~K}(1,700 \mathrm{~F})$ engulfing fire were estimated in the modal study (LLNL 1987). Table E.2 shows the results of the required fire durations for the $1,200 \mathrm{~K}$ 
TABLE E.1 Impact Velocities Required to Attain 0.2\%, 2\%, and 30\% Strain Levels for Objects Impacted in Highway and Railway Accidents

\begin{tabular}{|c|c|c|c|c|c|c|c|c|c|}
\hline \multirow{3}{*}{$\begin{array}{l}\text { Accident Type/ } \\
\text { Object Hardness }\end{array}$} & \multicolumn{9}{|c|}{ Impact Velocity $(\mathrm{km} / \mathrm{h})$ at Various Strain Levels and Orientation Angles } \\
\hline & \multicolumn{3}{|c|}{$\begin{array}{r}0.2 \% \text { Strain at } \\
\text { Three Angles }\end{array}$} & \multicolumn{3}{|c|}{$\begin{array}{l}2 \% \text { Strain at } \\
\text { Three Angles }\end{array}$} & \multicolumn{3}{|c|}{$\begin{array}{c}30 \% \text { Strain at } \\
\text { Three Angles }\end{array}$} \\
\hline & $0^{\circ}$ & $45^{\circ}$ & $90^{\circ}$ & $0^{\circ}$ & $45^{\circ}$ & $90^{\circ}$ & $0^{\circ}$ & $45^{\circ}$ & $90^{\circ}$ \\
\hline \multicolumn{10}{|l|}{ Highway } \\
\hline Unyielding & $51.5(32)$ & $56.3(35)$ & $61.1(38)$ & $82.1(51)$ & $78.8(49)$ & $74.0(46)$ & $>241(>150)$ & $182(113)$ & $122(76)$ \\
\hline Median & $51.5(32)$ & $56.3(35)$ & $61.1(38)$ & $82.1(51)$ & $78.8(49)$ & $74.0(46)$ & $241(>150)$ & $241(>150)$ & $241(>150)$ \\
\hline Soft & $51.5(32)$ & $933(58)$ & $135(84)$ & $82.1(51)$ & $163(101)$ & $241(>150)$ & $241(>150)$ & $241(>150)$ & $241(>150)$ \\
\hline Very soft & $67.6(42)$ & $>241(>150)$ & $61.1(38)$ & $94.9(59)$ & $241(>150)$ & $103(64)$ & $241(>150)$ & $241(>150)$ & $241(>150)$ \\
\hline \multicolumn{10}{|l|}{ Railway } \\
\hline Unyielding & $88.5(55)$ & $75.6(47)$ & $61.1(38)$ & $116(72)$ & (96.5) 60 & $77.2(48)$ & $241(>150)$ & $206(128)$ & $169(105)$ \\
\hline Median & $88.5(55)$ & $75.6(47)$ & $61.1(38)$ & $116(72)$ & (96.5) 60 & $77.2(48)$ & $241(>150)$ & $206(128)$ & $169(105)$ \\
\hline Soft & $88.5(55)$ & $75.6(47)$ & $64.4(40)$ & $116(72)$ & $111(69)$ & $105(65)$ & $241(>150)$ & $241(>150)$ & $241(>150)$ \\
\hline Very soft & $88.5(55)$ & $>241(>150)$ & $61.1(38)$ & $116(72)$ & $241(>150)$ & $96.5(60)$ & $241(>150)$ & $241(>150)$ & $241(>150)$ \\
\hline
\end{tabular}

a In the modal study (LLNL 1987), $150 \mathrm{mph}(241 \mathrm{~km} / \mathrm{h})$ is defined as the maximum credible velocity. Numbers in parentheses indicate mph.

Source: LLNL (1987). 
$\left(1,700^{\circ} \mathrm{F}\right)$ engulfing fire to reach the four lead midlayer thickness temperatures. The response states for fires that deviate from the $1,200 \mathrm{~K}$ $\left(1,700^{\circ} \mathrm{F}\right)$ engulfing fire were examined in the modal study; the approach developed in that study to extrapolate the fire duration results estimated for the $1,200 \mathrm{~K}\left(1,700^{\circ} \mathrm{F}\right)$ engulfing fire is presented in the following paragraphs.

For a given fire scenario, the thermal response represented by the lead midlayer thickness temperature can be related to the fire duration, flame temperature, and fire location. The general equation developed in the modal study to extrapolate the thermal response of the $1,200 \mathrm{~K}\left(1,700^{\circ} \mathrm{F}\right)$ engulfing fire to any other fire scenario is expressed as

$$
d_{F}(t, l)=\delta(t) \delta(l) d_{F}\left(1,700^{\circ} \mathrm{F}\right),
$$

where $d_{F}(t, l)$ is the fire duration corresponding to a lead midlayer thickness temperature $\left({ }^{\circ} \mathrm{F}\right)$ for flame temperature $t$ and fire location $l$. The temperature multiplication factor, $\delta(t)$, is used to estimate the relative fire duration required for a flame temperature $t$ to match a $1,200 \mathrm{~K}\left(1,700^{\circ} \mathrm{F}\right)$ fire on the basis of thermal response measured in terms of lead midlayer thickness temperature. Values of $\delta(t)$ provided in the modal study are given in Table E.3. The distance multiplication factor, $\delta(l)$, is used to extrapolate the results of thermal response computed for the engulfing fire (distance $l=0$ ) to the away-from-the-cask fire (distance $=l$ ). For the representative truck cask, $\delta(l)$ is expressed as

$$
\delta(l)=0.78 \exp (0.7732+0.06287 l) \text { for } l>1.5 \mathrm{ft} .
$$

For the representative rail cask, $\delta(l)$ is expressed as

$$
\delta(l)=0.78 \exp (0.62874+0.08471 l) \text { for } l>4 \mathrm{ft} .
$$

\section{E.3 DETERMINATION OF RESPONSE REGIONS}

Cask responses during a transportation accident depend on the containment vessel strain and the lead midlayer thickness temperature. The potential responses have been partitioned into 20 response regions $R(i, j)(i=1,2,3,4 ; j=1,2,3,4,5)$ consisting of the combination of four structural response regions and five thermal response regions, as shown in Table E.4. 
TABLE E.3 Heat Flux Factors

for Flame Temperatures

(engulfing fire)

Flame

Temperature, $t$

\begin{tabular}{cll}
$\mathrm{K}$ & $\left({ }^{\circ} \mathrm{F}\right)$ & $\delta(\mathrm{t})$ \\
\hline & & \\
1,030 & 1,400 & 1.72 \\
1,090 & 1,500 & 1.43 \\
1,140 & 1,600 & 1.21 \\
1,200 & 1,700 & 1.0 \\
1,260 & 1,800 & 0.86 \\
1,310 & 1,900 & 0.73 \\
1,370 & 2,000 & 0.64 \\
1,420 & 2,100 & 0.56 \\
1,480 & 2,200 & 0.49 \\
1,530 & 2,300 & 0.44 \\
1,590 & 2,400 & 0.39 \\
\hline
\end{tabular}

Source: LLNL (1987).

TABLE E.4 Response Regions Categorized by Vessel Strain and Lead Midlayer Thickness Temperature

\begin{tabular}{|c|c|c|c|}
\hline \multicolumn{2}{|c|}{ Structural Response } & \multicolumn{2}{|r|}{ Thermal Response } \\
\hline Region (i) & Condition & Region (j) & Condition \\
\hline 1 & $<0.2 \%$ strain & 1 & $\begin{array}{l}<530 \mathrm{~K}\left(500^{\circ} \mathrm{F}\right) \text { lead midlayer } \\
\text { thickness temperature }\end{array}$ \\
\hline 2 & $0.2 \%$ to $2 \%$ strain & 2 & $\begin{array}{l}530 \text { to } 590 \mathrm{~K}\left(500 \text { to } 600^{\circ} \mathrm{F}\right) \text { lead } \\
\text { midlayer thickness temperature }\end{array}$ \\
\hline 3 & $2 \%$ to $30 \%$ strain & 3 & $\begin{array}{l}590 \text { to } 616 \mathrm{~K}\left(600 \text { to } 650^{\circ} \mathrm{F}\right) \text { lead } \\
\text { midlayer thickness temperature }\end{array}$ \\
\hline \multirow[t]{2}{*}{4} & $>30 \%$ strain & 4 & $\begin{array}{l}616 \text { to } 839 \mathrm{~K}\left(650 \text { to } 1,050^{\circ} \mathrm{F}\right) \\
\text { lead midlayer thickness } \\
\text { temperature }\end{array}$ \\
\hline & & 5 & $\begin{array}{l}>839 \mathrm{~K}\left(1,050^{\circ} \mathrm{F}\right) \text { lead midlayer } \\
\text { thickness temperature }\end{array}$ \\
\hline
\end{tabular}


To determine an appropriate response region $[R(i, j)]$, the user must provide the following input parameters:

- Mechanical load accident parameters:

- Cask velocity,

- Impact angle,

- Cask orientation, and

- Hardness of the impacted object;

- Thermal load accident parameters:

- Fire duration,

- Flame temperature, and

- Fire location with respect to the cask.

The flow diagram to relate the accident parameters to the appropriate response region is given in Figure E.4. All of the threshold or bounding accident parameters used in this algorithm follow those provided in the modal study (LLNL 1987). For accident parameters that are not equal to the threshold values, linear interpolation between the two bounding values is assumed to be appropriate.

\section{APPENDIX E REFERENCE}

Lawrence Livermore National Laboratory, 1987, Shipping Container Response to Severe Highway and Railway Accident Conditions, NUREG/CR-4829, UCID-20733, prepared by Lawrence Livermore National Laboratory, Livermore, Calif., for U.S. Nuclear Regulatory Commission, Washington, D.C., Feb. 


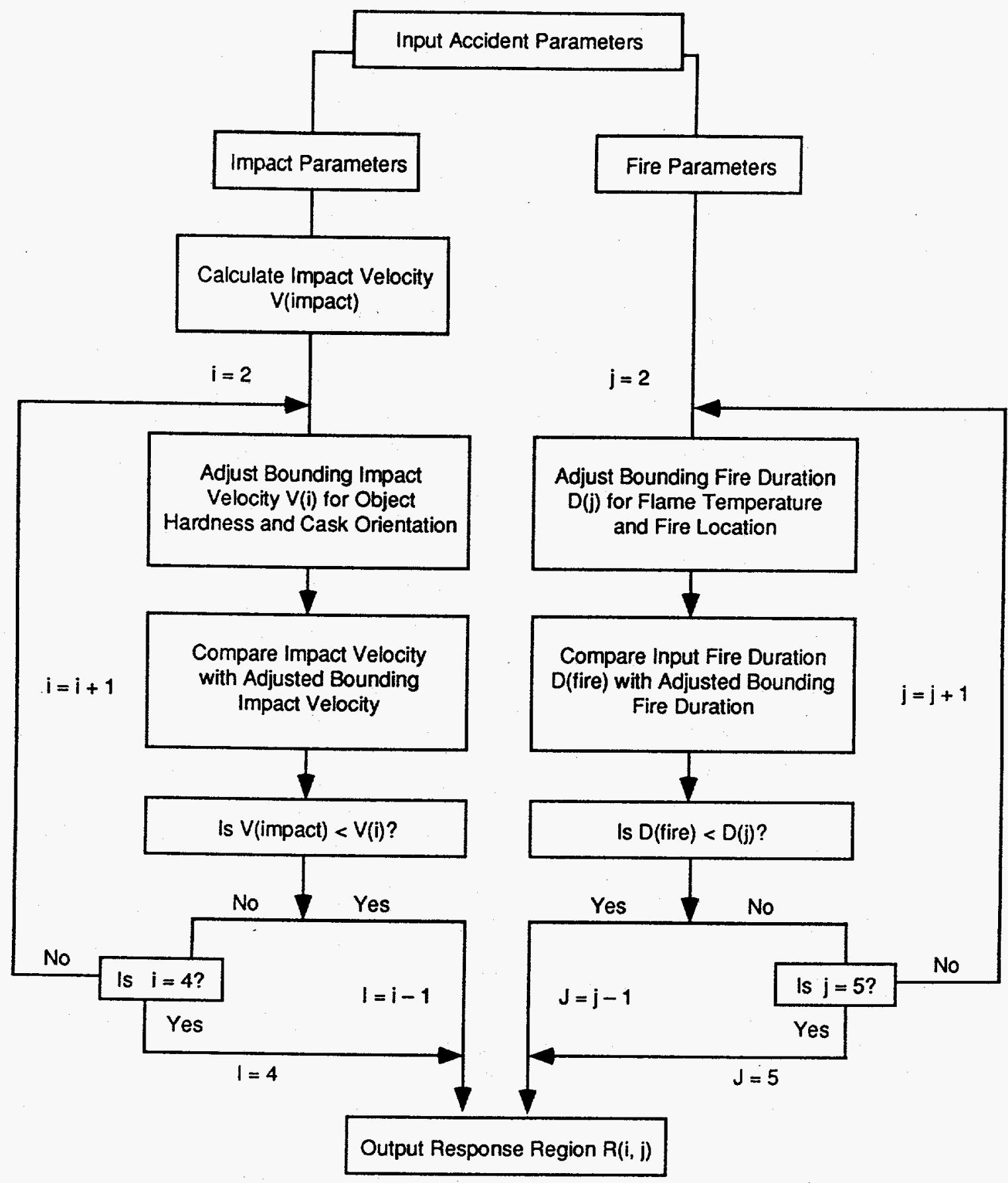

FIGURE E.4 Flow Diagram Used in RISKIND to Determine Cask Response Regions 
E-14 
$F-1$

APPENDIX F:

PROGRAM STRUCTURE 
F-2 


\section{CONTENTS}

APPENDIX F: PROGRAM STRUCTURE …......................................................... F-5

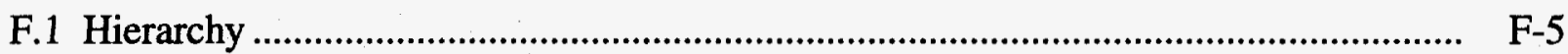

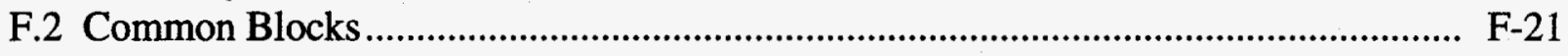

\section{TABLES}

F.1 Descriptions of Major RISKIND Subroutines …….................................................. F-17

F.2 Common Blocks Used in RISKIND .............................................................. F-22

\section{FIGURES}

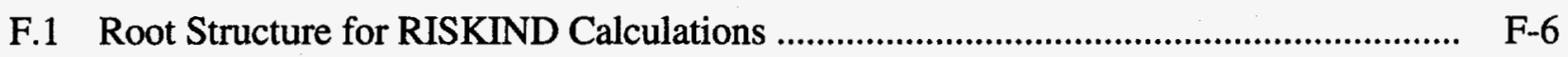

F.2a Individual Accident Scenario Processing ...................................................................... F-7

F.2b Population Accident Scenario Processing.................................................................... F-7

F.3 Structure for the Get_Input Subroutine ......................................................................... F-8

F.4 Structure for the Set_Nuclides Subroutine..................................................................... F-9

F.5 Structure for Routine Calculations........................................................................ F-10

F.6 Structure for Individual Accident Calculations........................................................... F-11

F.7 Structure for Population Accident Calculations............................................................ F-12

F.8 Structure for Puff Dispersion Calculations ......................................................... F-13

F.9 Individual Output Routines............................................................................ F-14

F.10 Population Output Routines ................................................................................... F-15

F.11 Miscellaneous Routines ….......................................................................................... F-16 
$F-4$ 


\section{APPENDIX F:}

\section{PROGRAM STRUCTURE}

This appendix provides information related to the program structure and data transfer used in RISKIND. RISKIND is a Windows ${ }^{\mathrm{TM}}$ application with the user interface written in Microsoft VISUAL BASIC ${ }^{\mathrm{TM}} 3.0^{1}$ The remainder of the RISKIND program, the calculation and output subroutines and utility function modules, is written in Lahey FORTRAN 5.01. ${ }^{2}$ Data transfer is performed through subroutine calls and labeled common blocks.

\section{F.1 HIERARCHY}

The key below and Figures F.1 through F.10 illustrate the structure of the major FORTRAN RISKIND subroutines. These diagrams represent calling sequences and major branching of a RISKIND calculation. Descriptions of the subroutines are given in Table F.1.

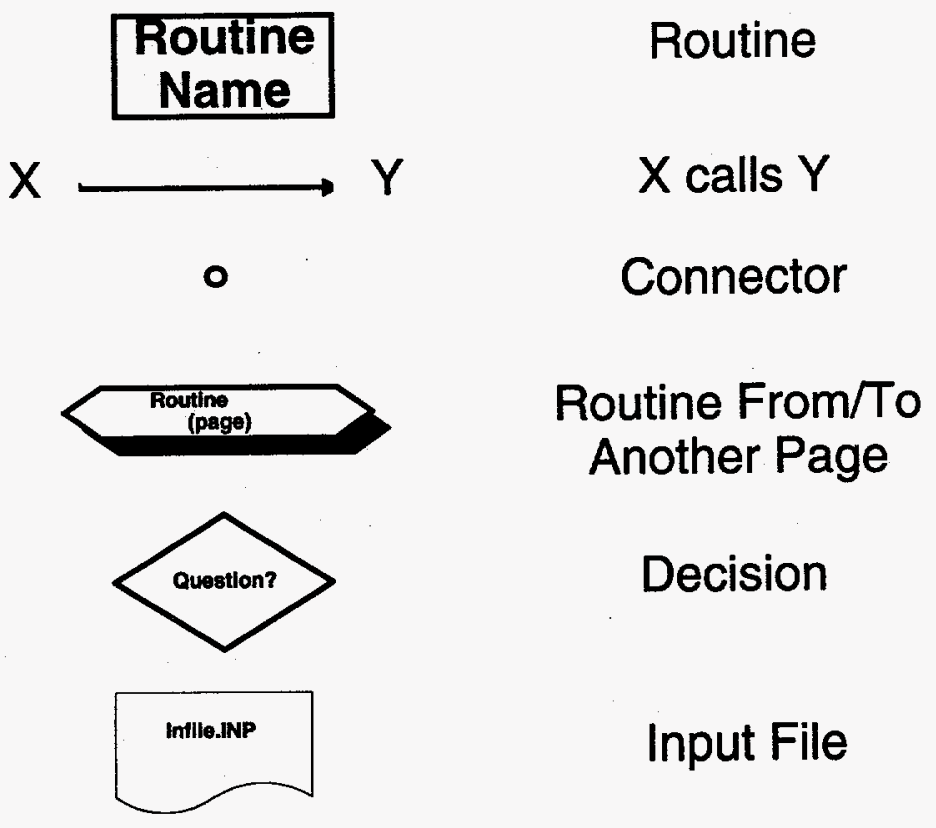

1 Microsoft Corporation, 1993, Microsoft Visual Basic 3.0, Redmond, Wash.

2 Lahey Computer Systems, Inc., Lahey 5.01, Incline Village, Nev. 


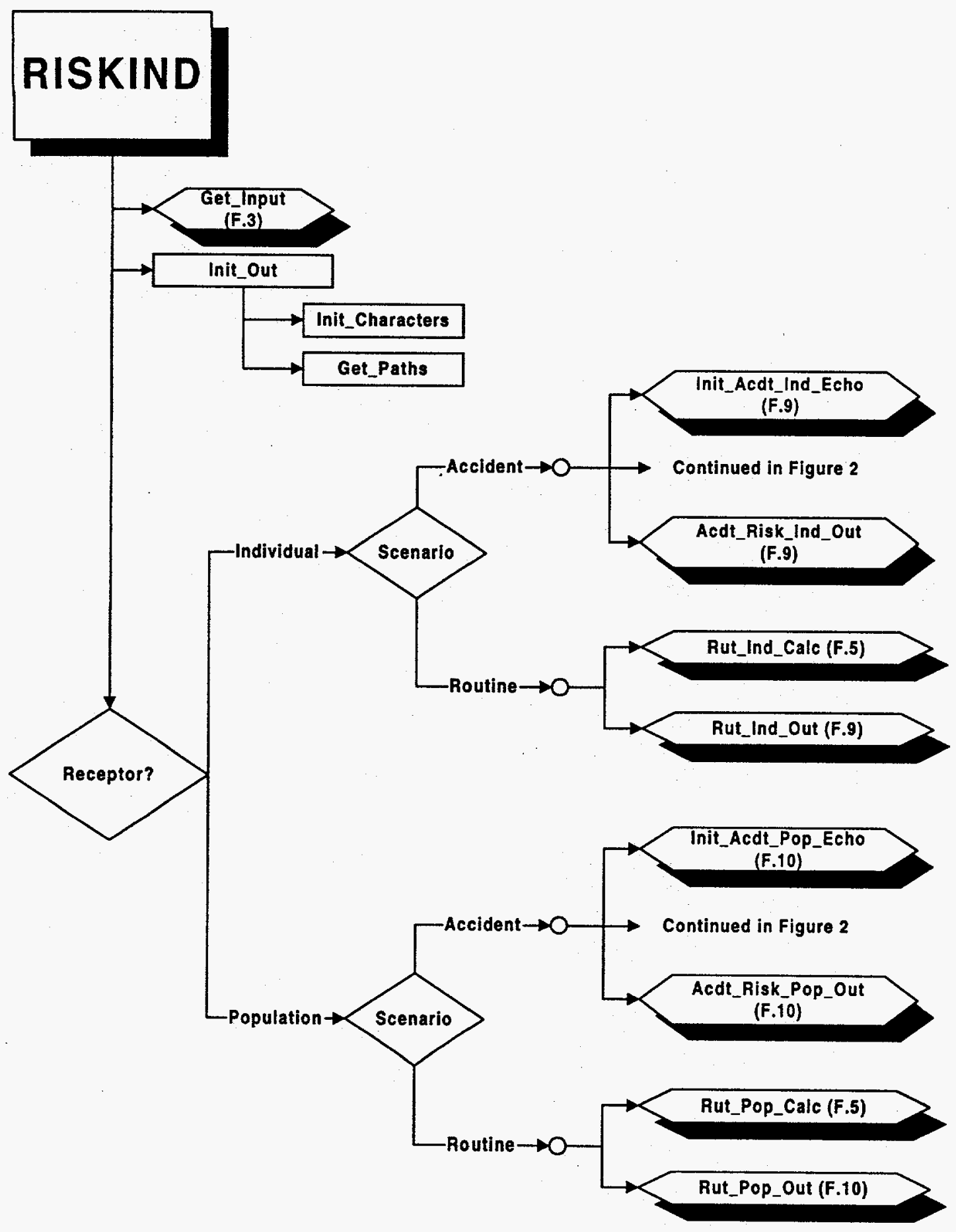

FIGURE F.1 Root Structure for RISKIND Calculations 


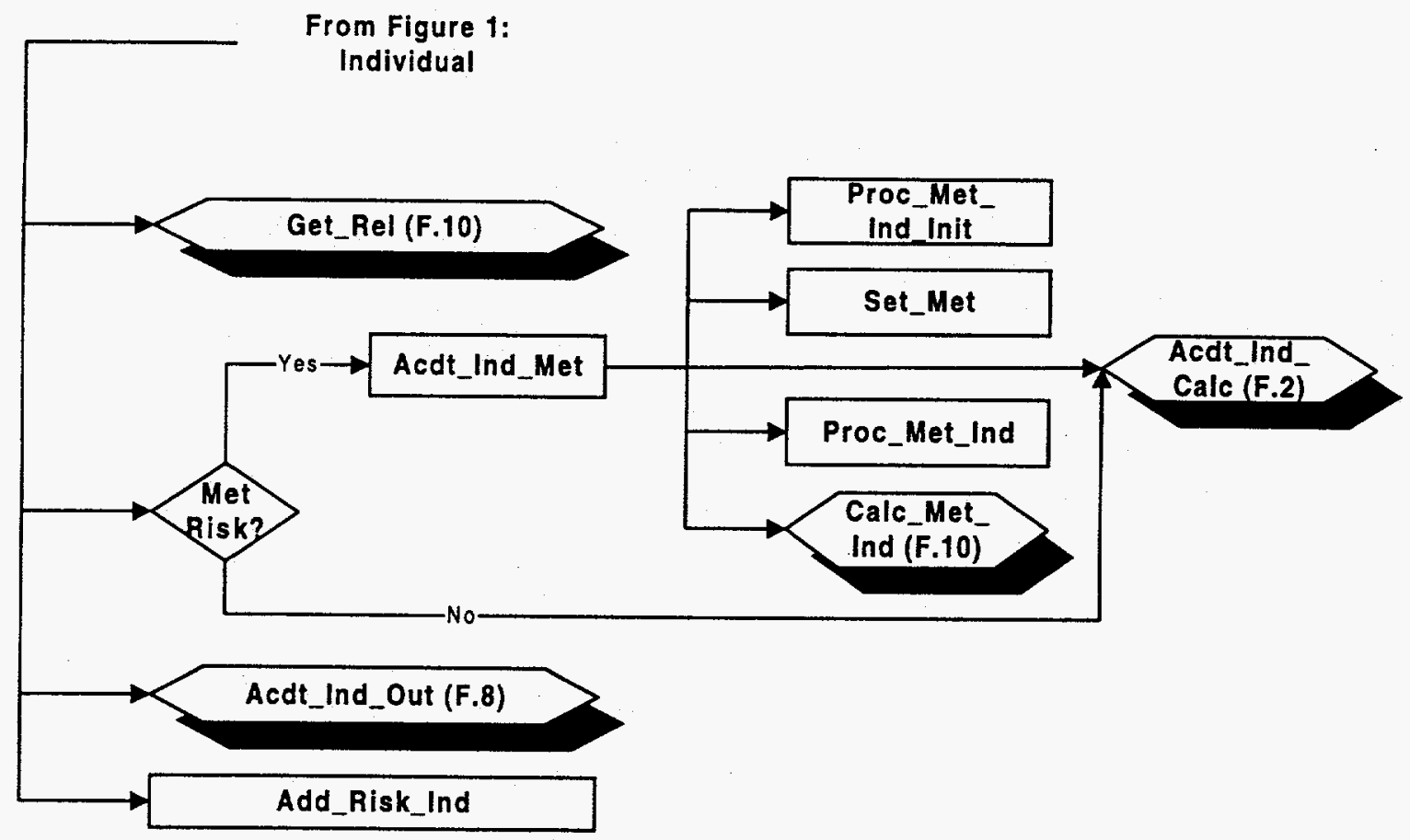

FIGURE F.2a Individual Accident Scenario Processing

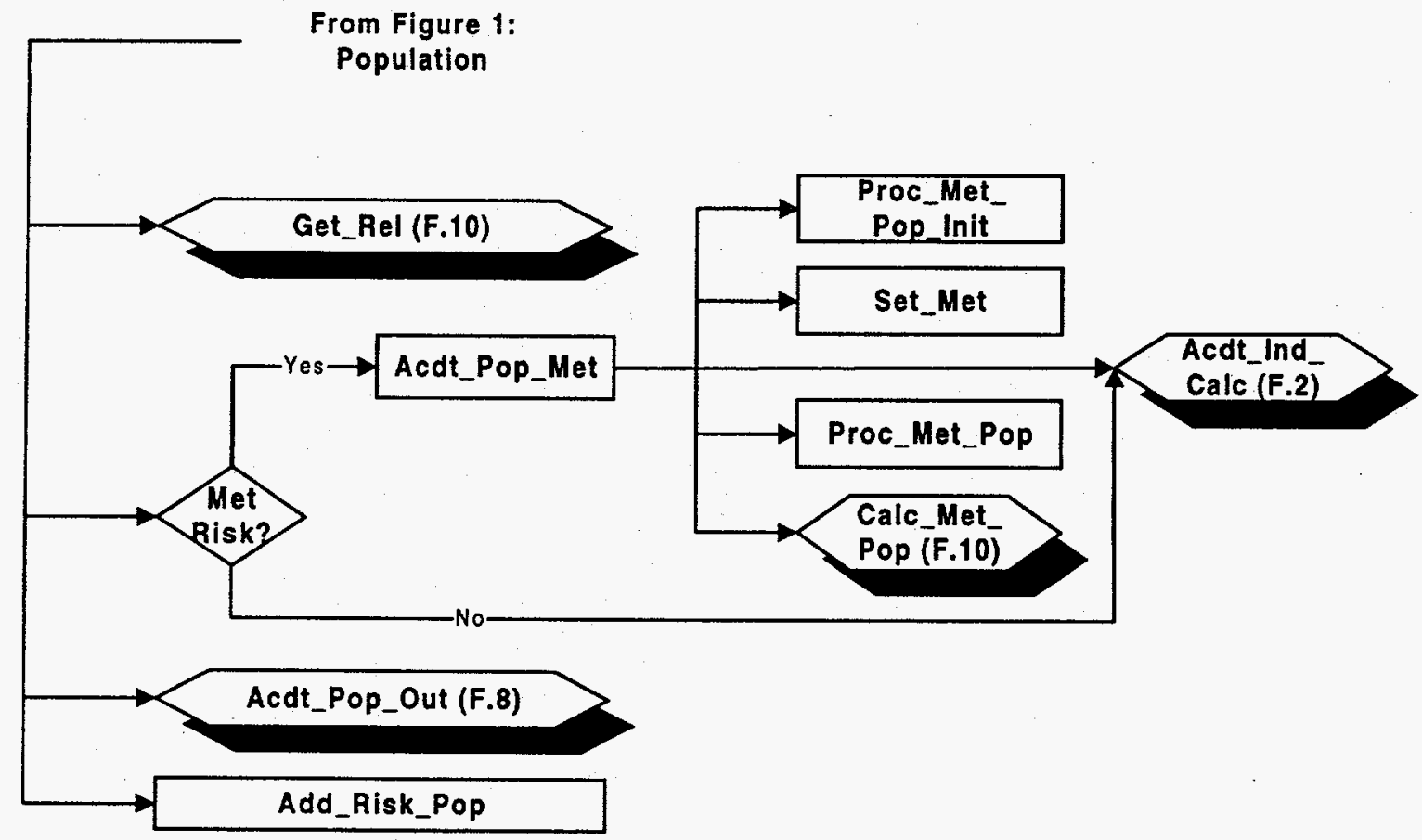

FIGURE F.2b Population Accident Scenario Processing 


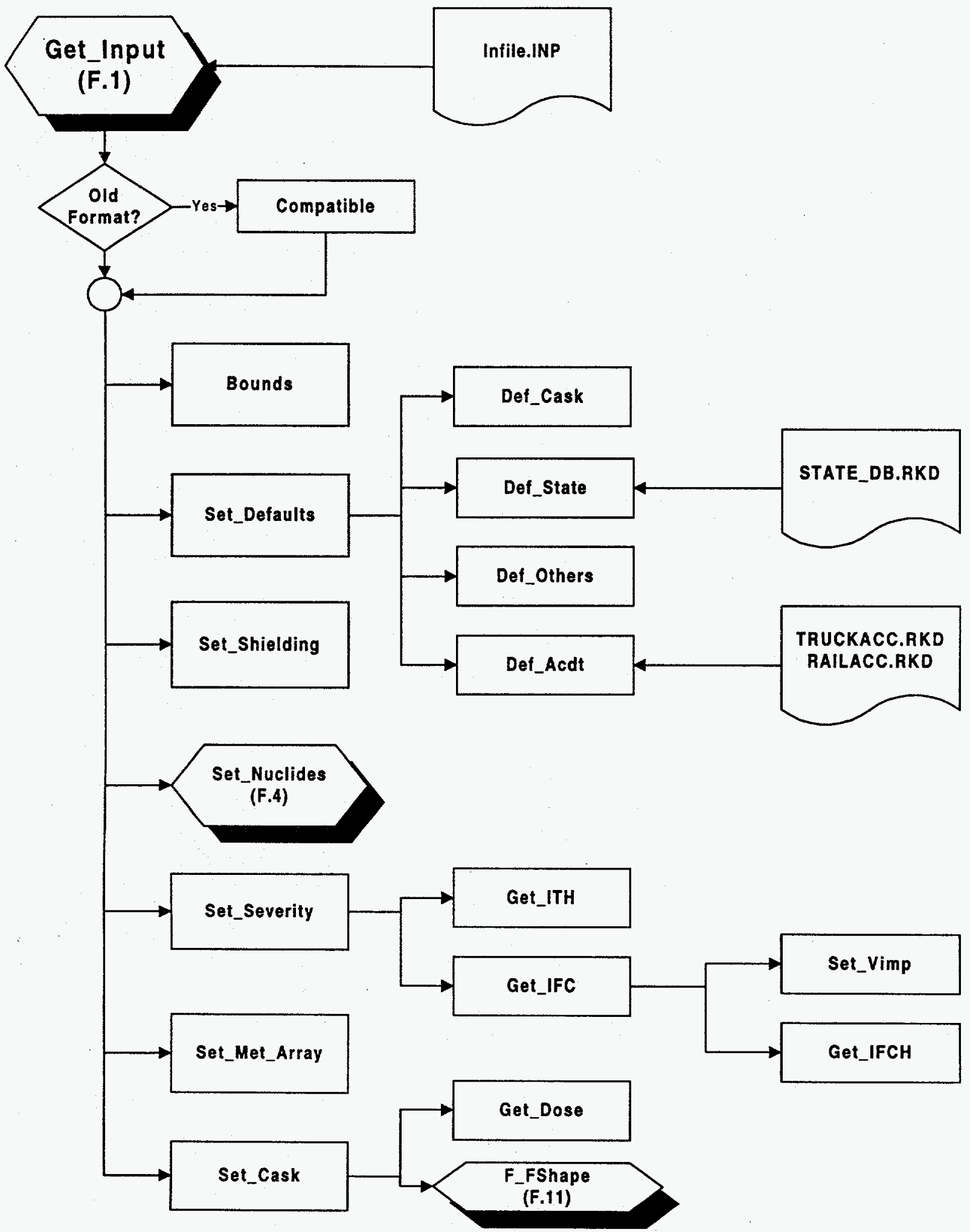

FIGURE F.3 Structure for the Get_Input Subroutine 


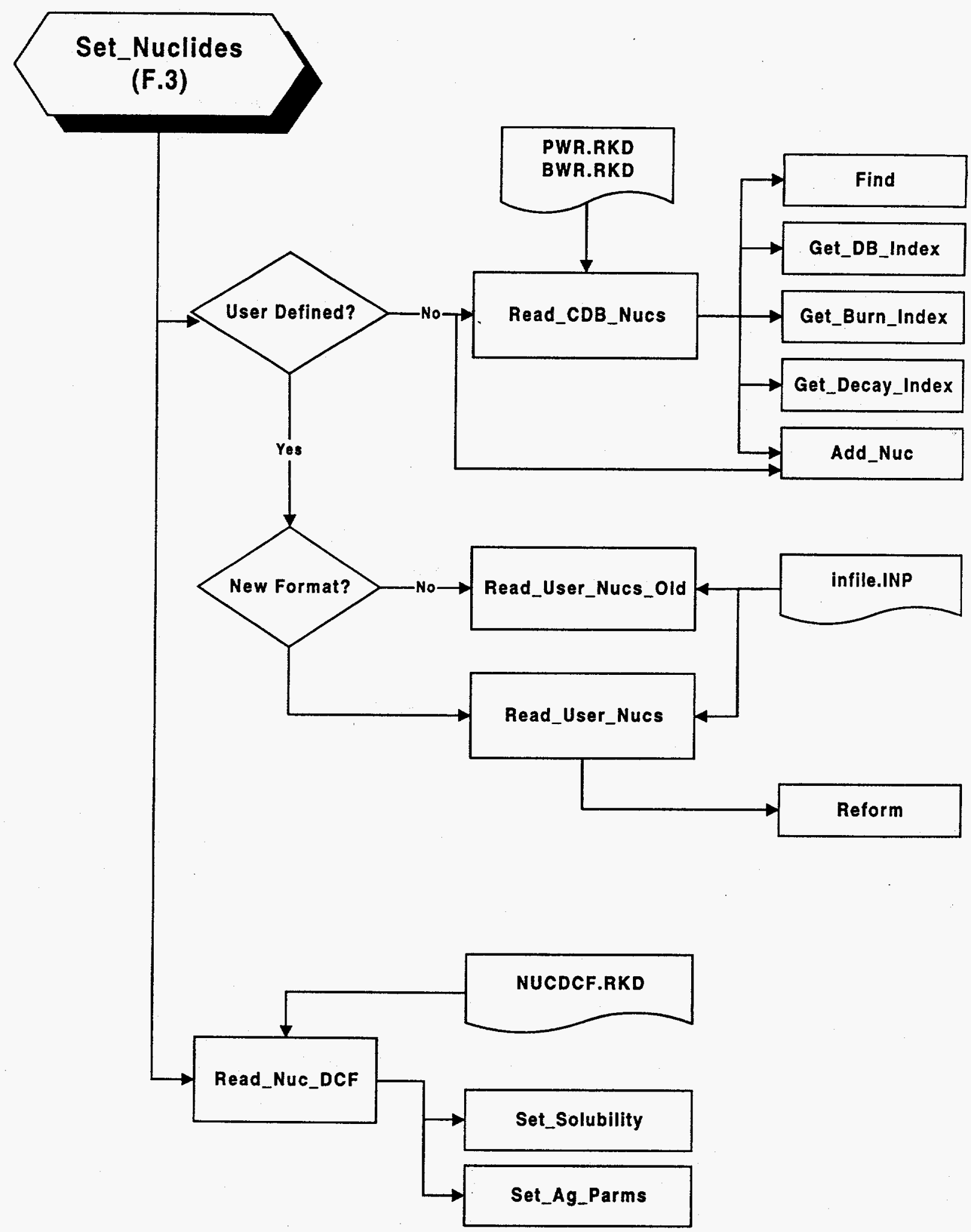

FIGURE F.4 Structure for the Set_Nuclides Subroutine 
Rut_Ind_Calc

(F.1)

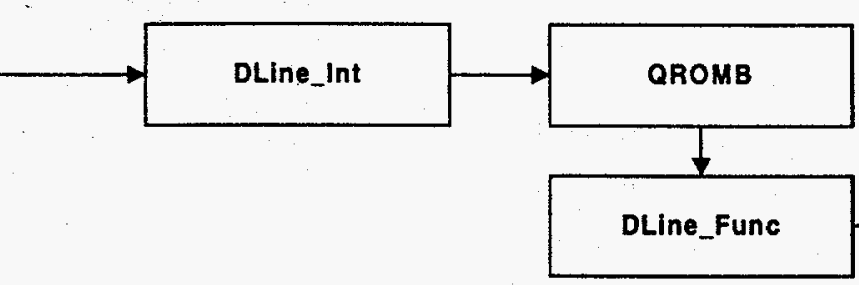

Rut_Pop_Calc

(F.1)

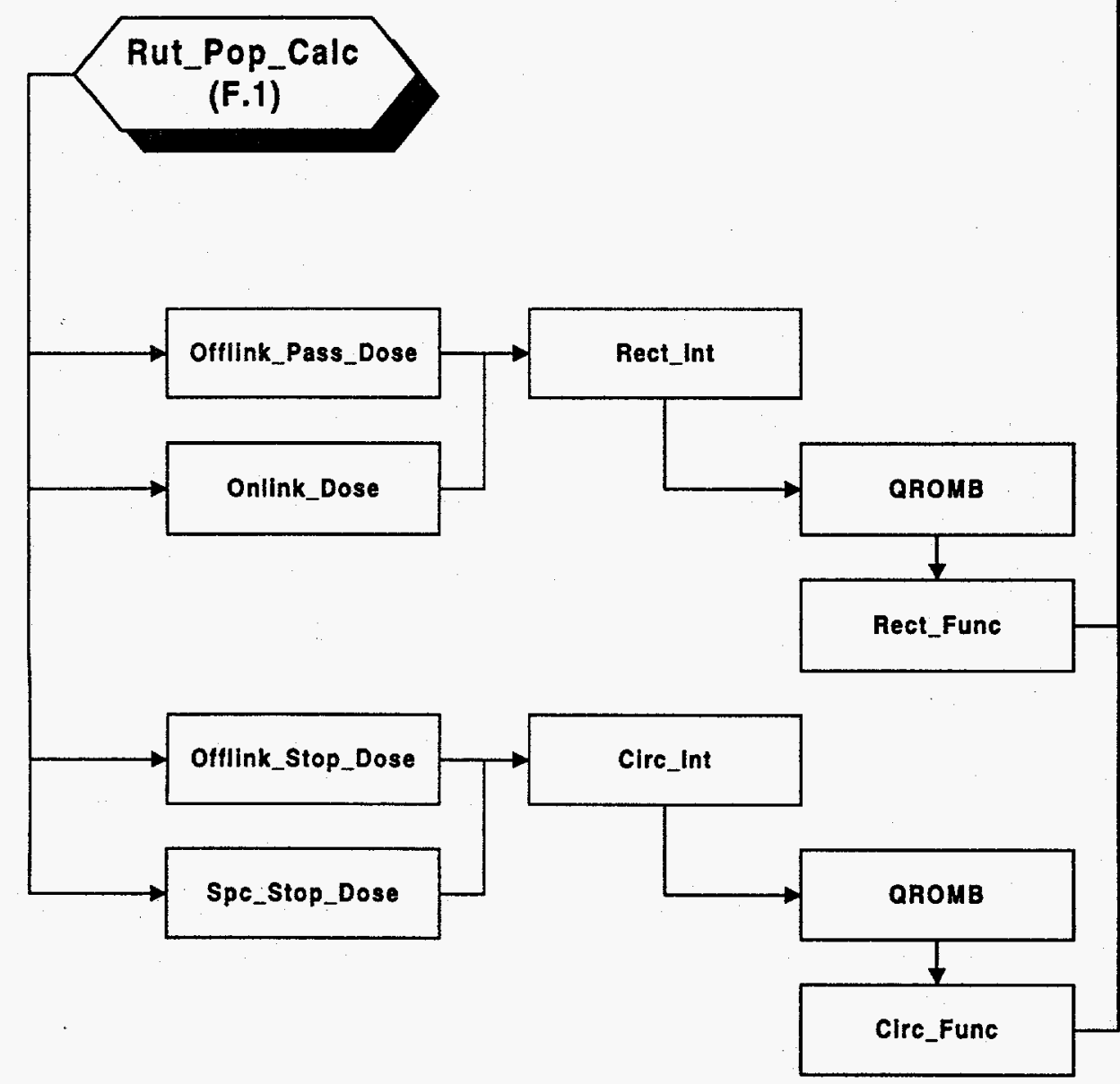

FIGURE F.5 Structure for Routine Calculations 


\section{F-1I}

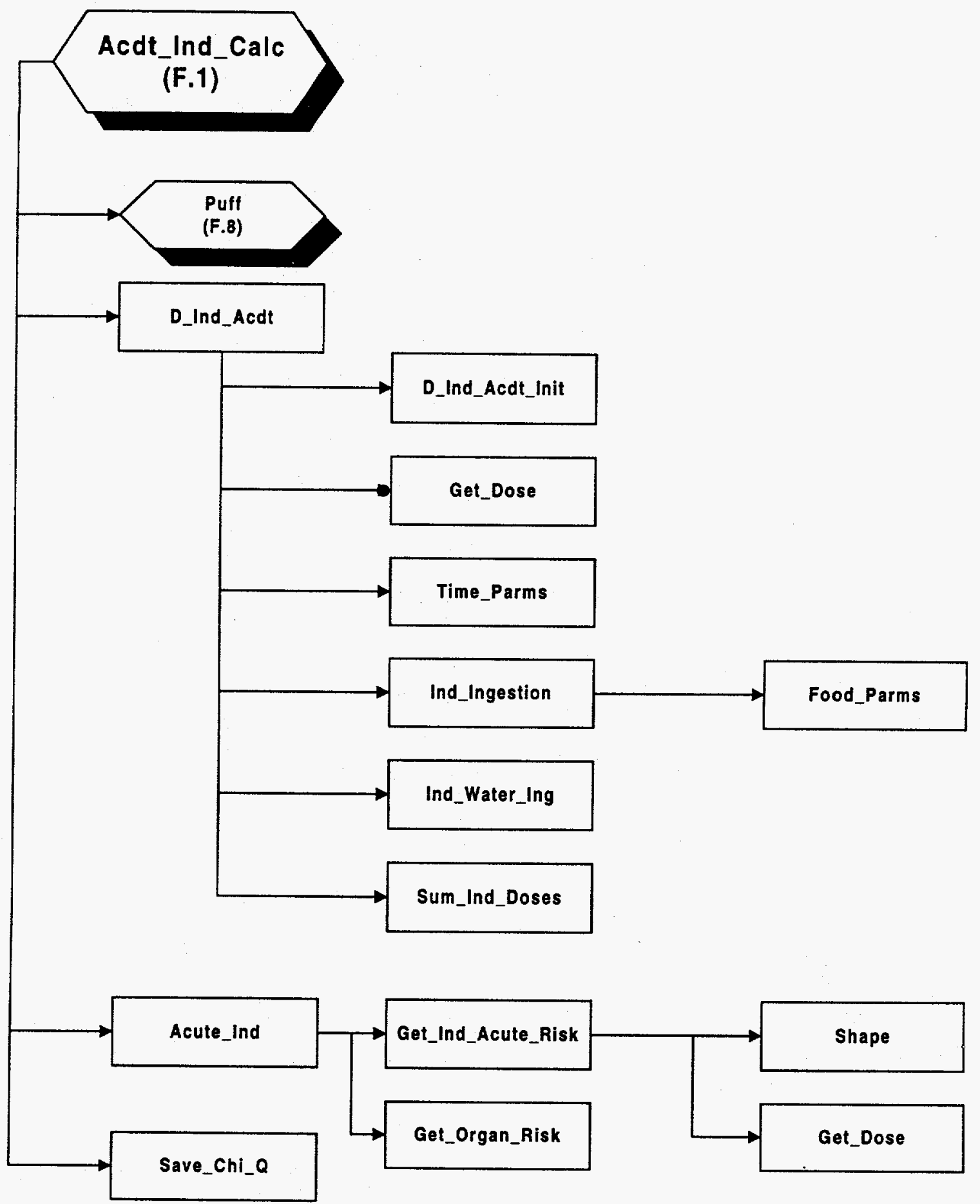

FIGURE F.6 Structure for Individual Accident Calculations 


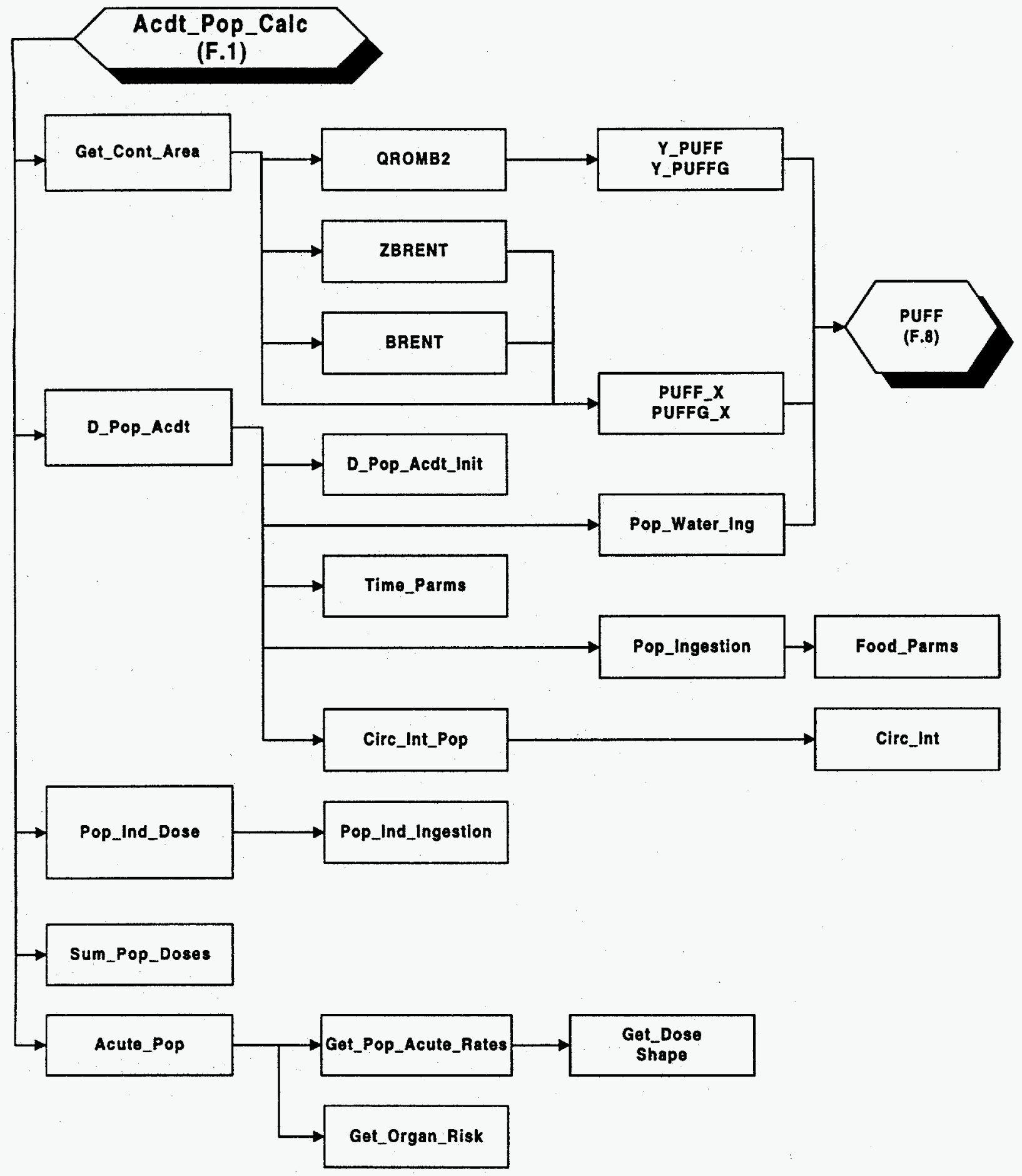

FIGURE F.7 Structure for Population Accident Calculations 
$F-13$

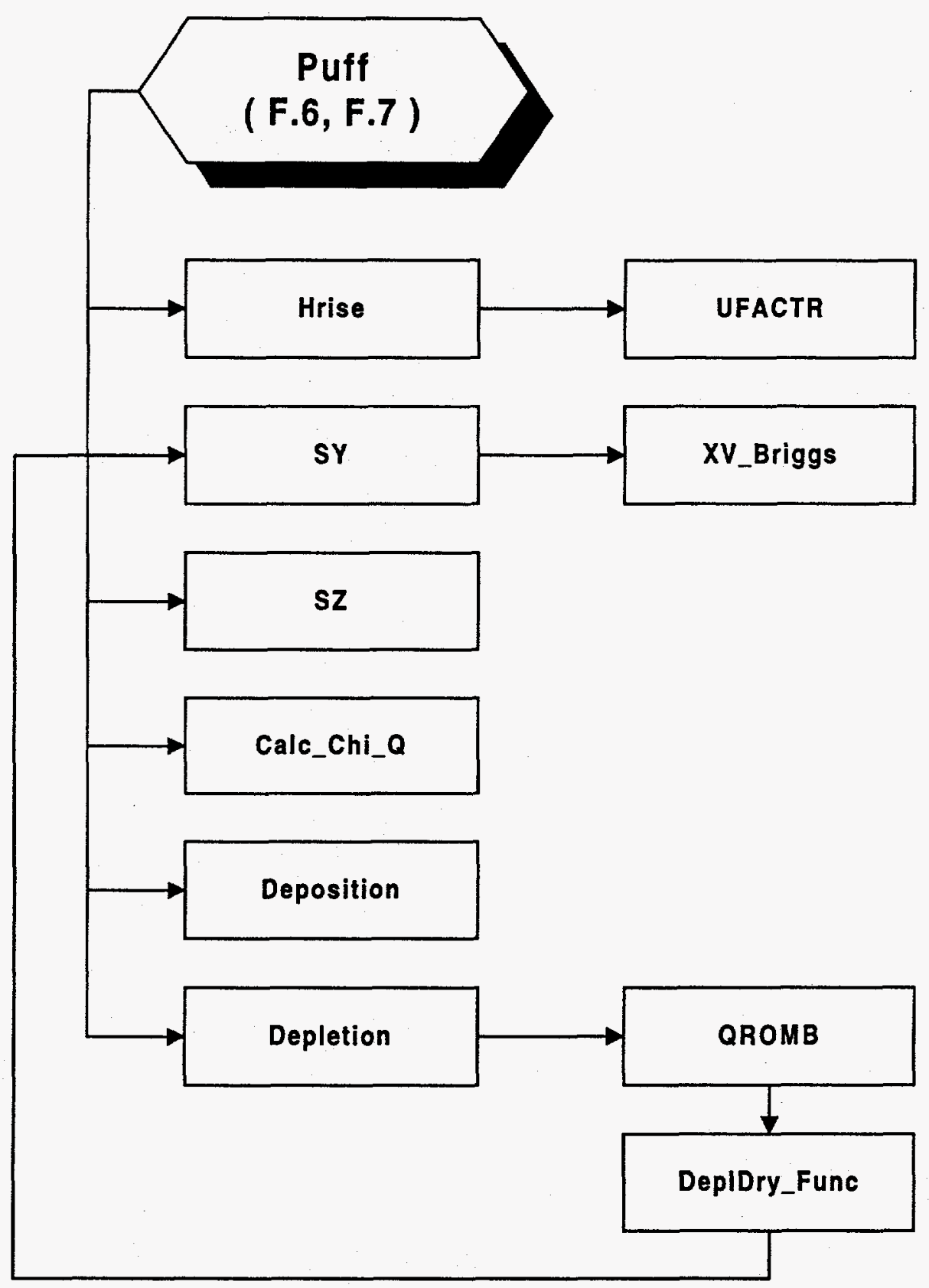

FIGURE F.8 Structure for Puff Dispersion Calculations 


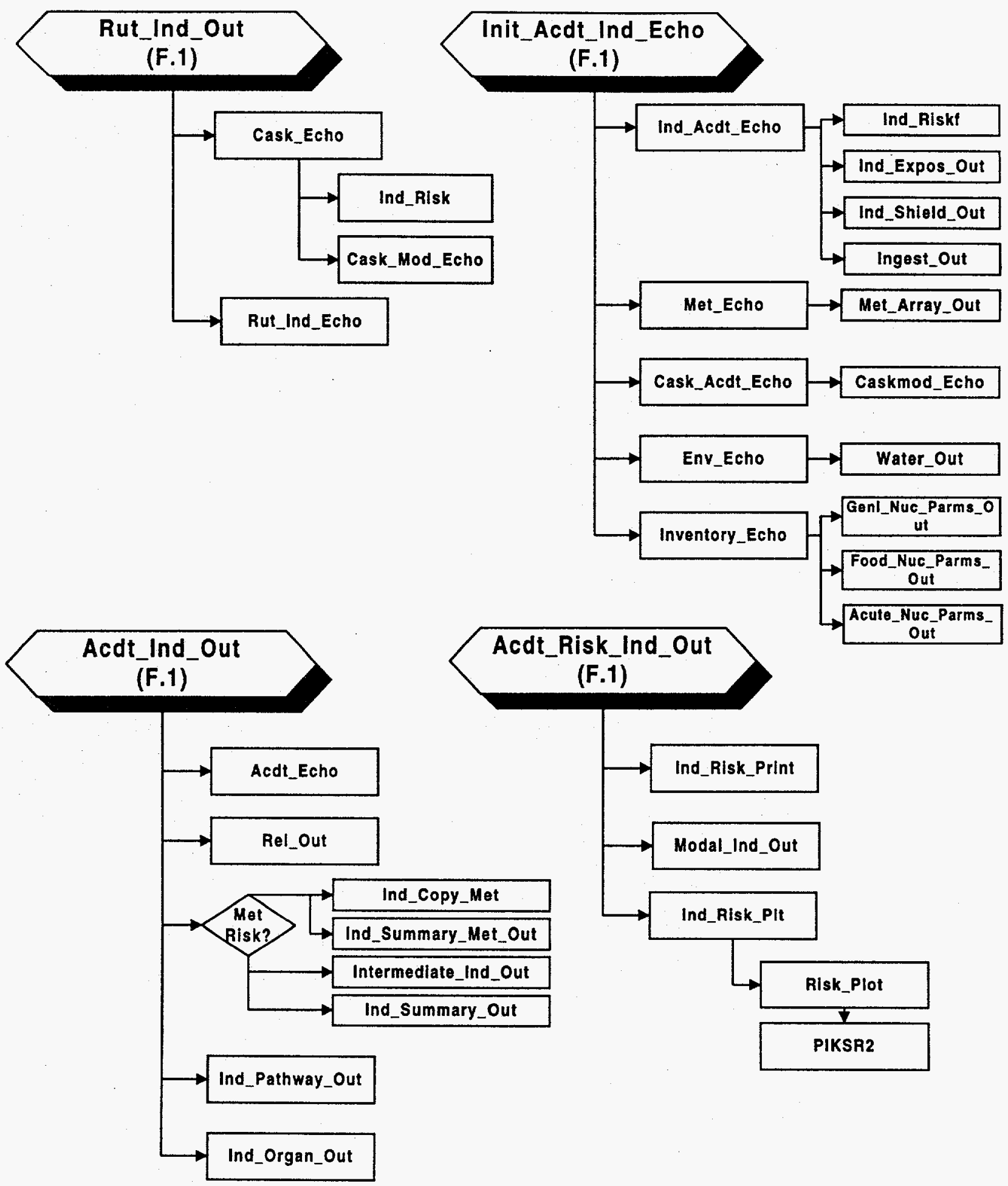

FIGURE F.9 Individual Output Routines 

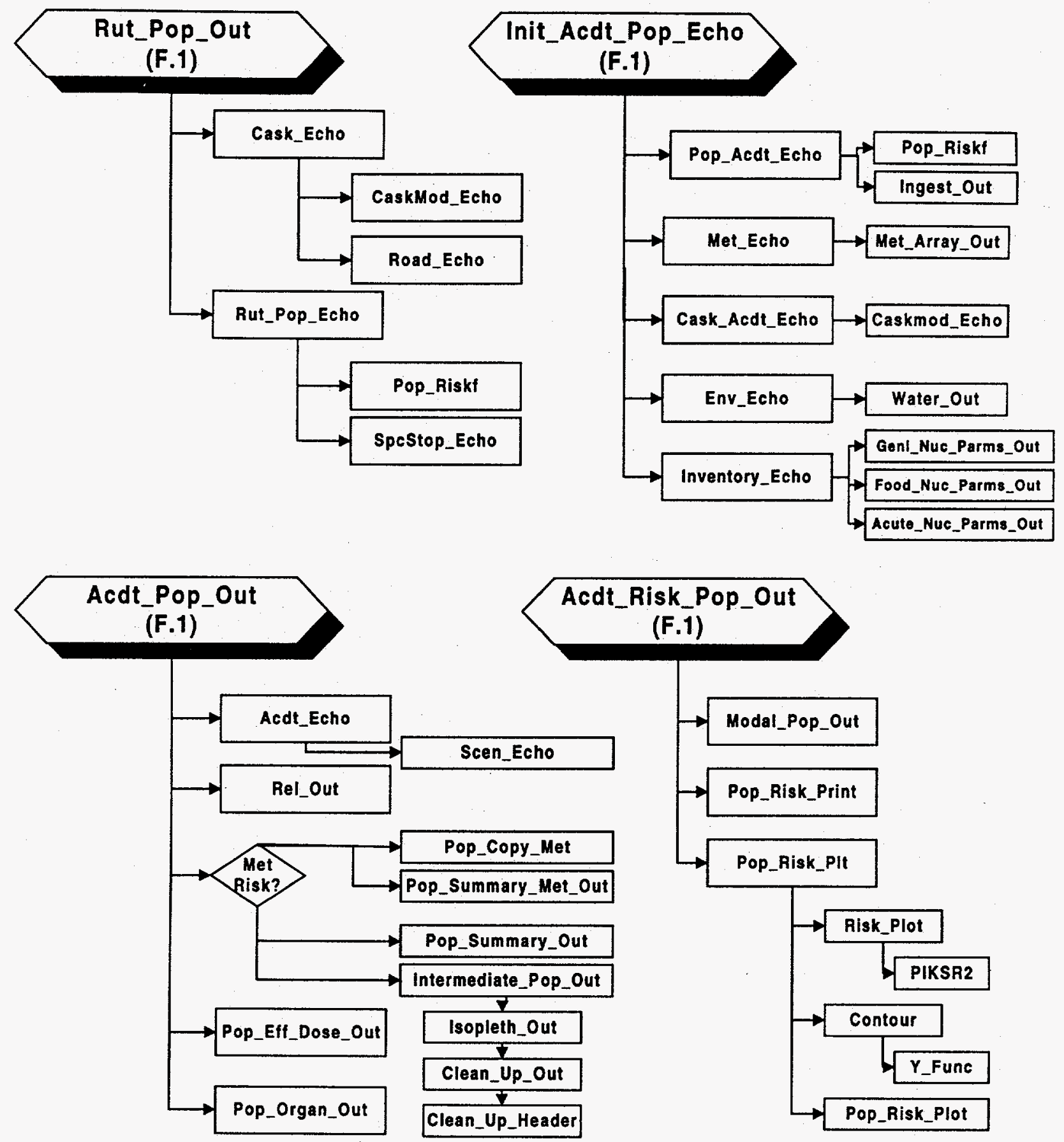

FIGURE F.10 Population Output Routines 

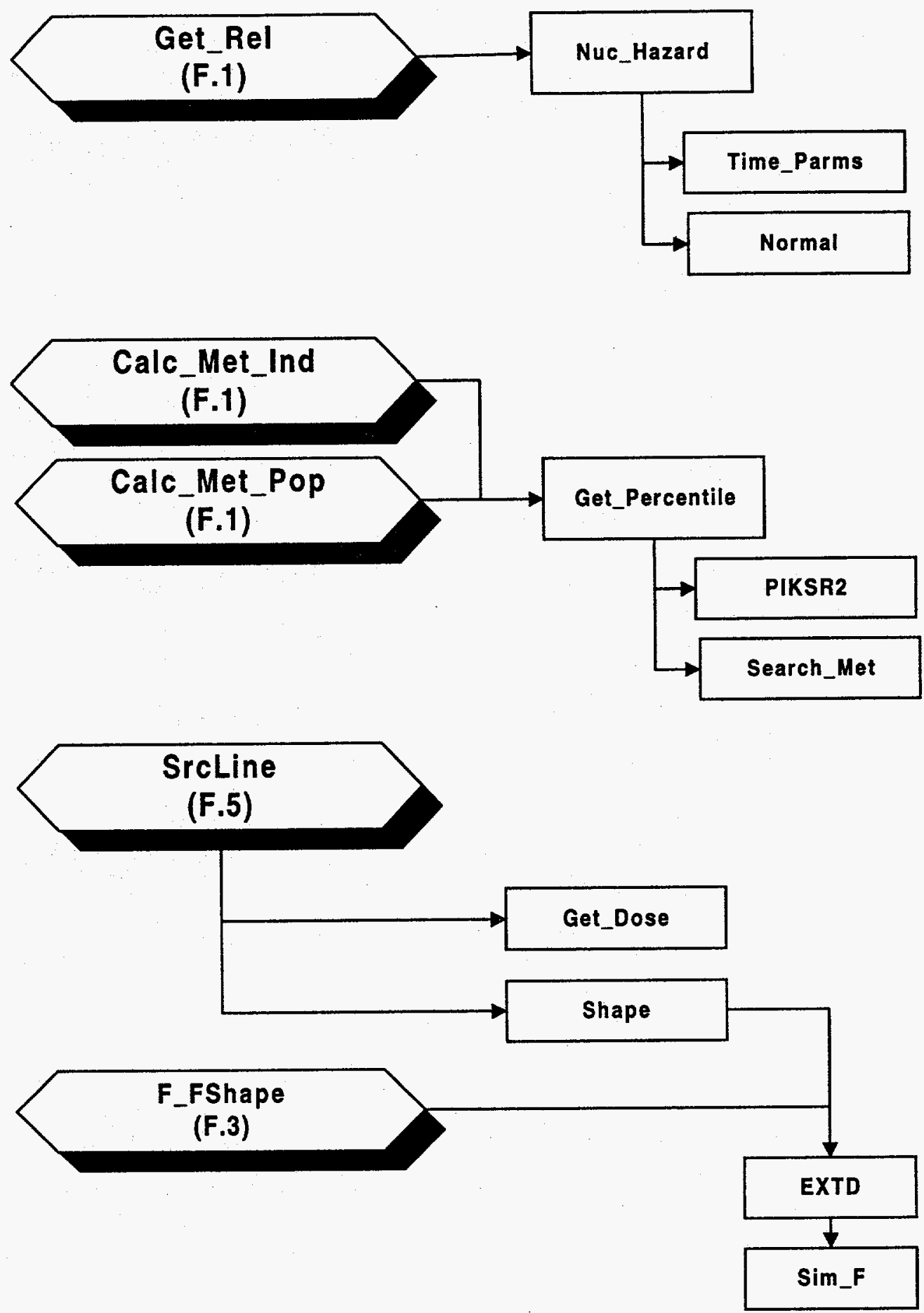

FIGURE F.11 Miscellaneous Routines 
TABLE F.1 Descriptions of Major RISKIND Subroutines

ACDT_ECHO
ACDT_IND_CALC
ACDT_IND_MET
ACDT_IND_OUT
ACDT_POP_CALC
ACDT_POP_OUT
ACDT_POP_MET
ACDT_RISK_IND_OUT
ACDT_RISK_POP_OUT
ACUTE_IND
ACUTE_NUC_PARMS_OUT
ACUTE_POP
ADD_NUC
ADD_RISK_IND
ADD_RISK_POP
BOUNDS
BRENT
CALC_CHI_Q
CALC_MET_IND
CALC_MET_POP
CASK_ACDT_ECHO
CASK_ECHO
CASKMOD_ECHO
CIRC_FUNC
CIRC_INT
CIRC_INT_POP
CLEAN_UP_HEADER
CLEAN_UP_OUT
COMPATIBLE
CONTOUR
D_IND_ACDT
D_IND_ACDT_INIT
D_POP_ACDT

Echoes accident input to the output file after calculations

Performs individual accident calculations for given stability class and wind speed

Performs individual accident calculations over all meteorological conditions

Writes single individual accident results to the output file

Performs population accident calculations for given stability class and wind speed

Writes single population accident results to the output file

Performs population accident calculations over all meteorological conditions

Writes individual accident risks to the output file

Writes population accident risks to the output file

Calculates individual acute doses and effects

Writes radionuclide parameters to the output file

Calculates population acute doses and effects

Adds a radionuclide record to the inventory list

Keeps track of individual risk calculation

Keeps track of population risk calculation

Checks the input data for bounds of application

Search routine from Numerical Methods

Finds the Chi/Q

Determines the meteorological risks for individual calculations

Determines the meteorological risks for population calculations

Echoes cask accident parameters to the output file

Echoes cask input parameters to the output file

Writes cask modification parameters to output file

Circular integral for external cask dose

Circular integral for external cask dose

Circular integral for population external cask dose

Writes header for cleanup of isopleths

Writes cleanup results

Makes previous version input data compatible with current version

Plots isopleth contours

Calculates the pathway doses at a given individual location

Initializes individual accident doses

Calculates population pathway doses 
TABLE F.1 (Cont.)

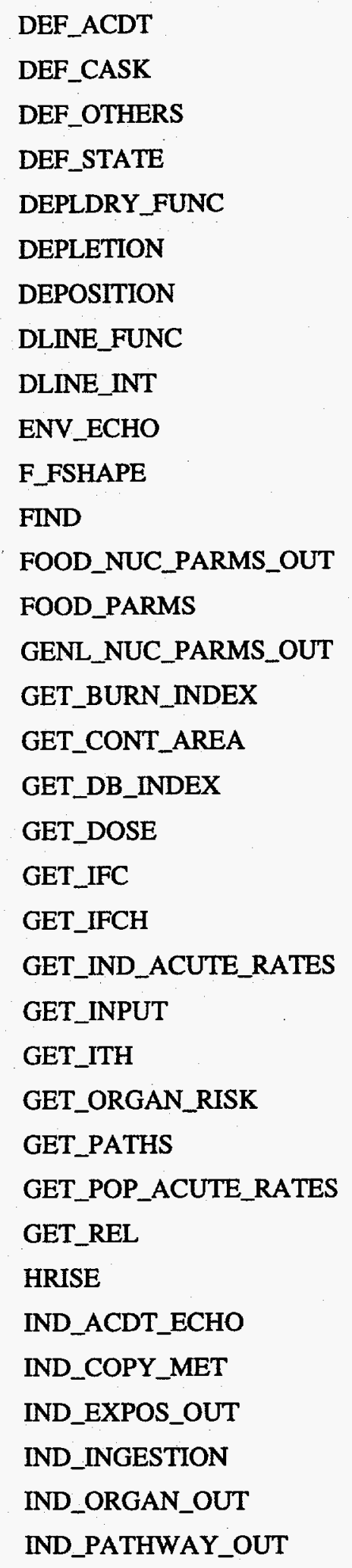

Sets accident data-dependent defaults

Sets cask data-dependent defaults

Sets other data-dependent defaults

Sets state data-dependent defaults

Dry depletion function

Calculates depletion

Calculates deposition

Line integral for external dose

Calculates the dose at a specific point from a passing shipment

Echoes environmental parameters to the output file

Final limiting value of the shape factor at far distances

Finds radionuclide in database

Writes nuclide ingestion parameters

Calculates ingestion parameters

Writes general nuclide parameters

Calculates spent fuel burnup index

Finds isopleths in population accident scenario

Calculates the spent fuel database index

Calculates external dose from cask

Calculates strain response index

Intermediate strain response calculation

Calculates individual acute rate

Reads input data and sets input-dependent defaults

Calculates thermal response index

Calculates organ health effects risks

Sets pathway logical variables

Calculates acute rates for population problem

Gets release parameters

Calculates effective release height from plume rise

Echoes input to output file for individual accident calculations

Stores individual results from specific meteorological condition

Writes individual exposure parameters

Calculates individual dose from food ingestion

Writes organ-specific individual dose and health effects to the output file

Writes individual dose breakdown by pathway 
TABLE F.1 (Cont.)

\begin{tabular}{|c|c|}
\hline IND_RISK_PLT & Plots the individual risk distribution \\
\hline IND_RISK_PRINT & Writes individual risks \\
\hline IND_SHIELD_OUT & Writes individual shielding parameters \\
\hline IND_SUMMARY_MET_OUT & $\begin{array}{l}\text { Writes summary average, } 50 \% \text {, and } 95 \% \text { doses and health effects to the } \\
\text { output file }\end{array}$ \\
\hline IND_SUMMARY_OUT & $\begin{array}{l}\text { Writes summary of the estimated individual dose and health effects to the } \\
\text { output file }\end{array}$ \\
\hline IND_WATER_ING & Calculates individual dose from water ingestion \\
\hline INGEST_OUT & Writes ingestion results \\
\hline INIT_ACDT_IND_ECHO & Echoes input to output file for individual accident calculations \\
\hline INIT_ACDT_POP_ECHO & Echoes input to output file for population accident calculations \\
\hline INIT_CHARACTERS & Initializes output variables \\
\hline INIT_OUT & Initializes the output file \\
\hline INTERMEDIATE_IND_OUT & Writes intermediate individual results \\
\hline INTERMEDIATE_POP_OUT & Writes puff calculations to the output file \\
\hline INVENTORY_ECHO & Echoes the radionuclide inventory to the output file \\
\hline ISOPLETH_OUT & Writes isopleth results \\
\hline MET_ARRAY_OUT & Writes met conditions \\
\hline MET_ECHO & Echoes meteorological input to the output file \\
\hline MODAL_IND_OUT & Writes individual modal study consequence/risk to the output file \\
\hline MODAL_POP_OUT & Writes population modal study consequence/risk to the output file \\
\hline OFF-LINK_PASS_DOSE & Calculates the off-link incident-free population dose for both sides of the route \\
\hline ON-LINK_DOSE & Calculates the on-link incident-free population dose \\
\hline PIKSR2 & Sorts routine from Numerical Recipes \\
\hline POP_ACDT_ECHO & Echoes input to output file for population accident calculations \\
\hline POP_COPY_MET & Stores population results from a specific met condition \\
\hline POP_EFF_DOSE_OUT & Writes detailed pathway dose analysis for the population to the output file \\
\hline POP_IND_DOSE & Estimates the doses to individuals within the isopleths \\
\hline POP_IND_INGESTION & Calculates individual ingestion dose in population problem \\
\hline POP_INGESTION & Calculates population dose from ingestion \\
\hline POP_ORGAN_OUT & Writes organ-specific population dose and health effects to the output file \\
\hline POP_RISK_PLT & Plots the population risk distribution \\
\hline POP_RISK_PRINT & Writes population risk \\
\hline POP_RISKF & Gets the appropriate dose-to-risk conversion factor \\
\hline POP_SUMMARY_MET_OUT & $\begin{array}{l}\text { Writes summary average, } 50 \% \text {, and } 95 \% \text { doses and health effects to the } \\
\text { output file }\end{array}$ \\
\hline
\end{tabular}


TABLE F.1 (Cont.)

\begin{tabular}{|c|c|}
\hline POP_SUMMARY_OUT & $\begin{array}{l}\text { Writes summary of the estimated population dose and health effects to the } \\
\text { output file }\end{array}$ \\
\hline POP_WATER_ING & Calculates the population dose from water ingestion \\
\hline PROC_MET_IND & Processes the results after each set of stability class and wind speed calculations \\
\hline PROC_MET_IND_INIT & Initializes individual problem for meteorological risks \\
\hline PROC_MET_POP & Processes the results after each set of stability class and wind speed calculations \\
\hline PROC_MET_POP_INIT & Initializes population problem for met risks \\
\hline PUFF & Calculates puff parameters at specific location \\
\hline QROMB & Integration routine from Numerical Recipes \\
\hline READ_CDB_NUCS & Reads Characteristic Database nuclide list \\
\hline READ_NUC_DCF & Reads nuclide dose conversion factors \\
\hline READ_USER_NUCS & Reads user-supplied nuclide list \\
\hline READ_USER_NUCS_OLD & Reads old format of user-supplied nuclide list \\
\hline RECT_FUNC & Rectangular function for external dose calculations \\
\hline RECT_INT & Rectangular integral for external population dose calculations \\
\hline REFORM & Reformats nuclide name \\
\hline REL_OUT & Writes release characteristics to the output file \\
\hline RISK_PLOT & Plots the risk \\
\hline ROAD_ECHO & Writes the road parameters \\
\hline RUT_IND_CALC & Performs incident-free individual calculations \\
\hline RUT_IND_ECHO & Writes parameters for individual routine problem \\
\hline RUT_IND_OUT & Echoes input and writes output for incident-free individual calculations \\
\hline RUT_POP_CALC & Performs incident-free population calculations \\
\hline RUT_POP_ECHO & Echoes input and writes output for incident-free population calculations \\
\hline RUT_POP_OUT & Writes output for incident-free population calculations \\
\hline SAVE_CHI_Q & Saves intermediate calculations \\
\hline SCEN_ECHO & Writes the scenario parameters \\
\hline SET_AG_PARMS & Sets the agricultural parameters \\
\hline SET_CASK & Sets the cask normalization factor for $2-\mathrm{m}$ dose rate \\
\hline SET_DEFAULTS & Sets NAMELIST input-dependent defaults \\
\hline SET_MET & Sets meteorological conditions \\
\hline SET_MET_ARRAY & Sets the met array for met risk calculations \\
\hline SET_NUCLIDES & Gets the nuclide information and the dose conversion factors \\
\hline SET_SEVERITY & Calculates the accident severity region \\
\hline SET_SHIELDING & Sets shielding/time factors \\
\hline SET_SOLUBILITY & Sets nuclide solubility \\
\hline
\end{tabular}


TABLE F.1 (Cont.)

SET_VIMP

SHAPE

SPC_STOP_DOSE

SPCSTOP_ECHO

SRCLINE

SUM_IND_DOSES

SUM_POP_DOSES

SY

SZ

TIME_PARMS

UFACTR

WATER_OUT

XV_BRIGGS

ZBRENT
Sets velocity of impact parameters

Calculates the shape factor for the external dose from the cask

Calculates the population incident-free doses at specified stops

Writes population-specified stop doses to the output file

Calculates the external dose rate at a specific distance from the shipment

Sums the individual doses

Sums the population doses

Calculates the horizontal dispersion

Calculates the vertical dispersion

Calculates time-integrated parameters

Adjusts wind velocity as a function of height

Writes doses from water ingestion

Corrects dispersion for initial dispersion

Root-finding routine from Numerical Recipes

\section{F.2 COMMON BLOCKS}

Many of the data transfers among subroutines are handled through labeled common blocks. RISKIND uses 13 common blocks, which are described in Table F.2. 
TABLE F.2 Common Blocks Used in RISKIND

\begin{tabular}{ll}
\hline \multicolumn{1}{c}{ Block } & \multicolumn{1}{c}{ Description } \\
\hline ACUTCOEF & Parameters for acute model \\
BOUNDS & Data for bounds checking \\
EFFECTS & Parameters for health effects \\
IND_ACDT & Storage and passing of individual accident consequence results \\
IND_INTE & Storage of intermediate individual calculations \\
IND_RISK & Storage and passing of individual accident risks \\
IND_RUT & Storage and passing of individual incident-free results \\
INPUT & RISKIND NAMELIST input data \\
NUCLIDES & Storage and passing of radionuclide input data and release calculations \\
OUTCHAR & Maintenance of output character and page number \\
POP_ACDT & Storage and passing of population accident consequence results \\
POP_RISK & Storage and passing of population accident risks \\
POP_RUT & Storage and passing of population incident-free results \\
\hline
\end{tabular}


G-1

APPENDIX G:

\section{DATA INPUT PREPARATION}


G-2 
CONTENTS

APPENDIX G: DATA INPUT PREPARATION......................................................... G-7

G.1 Installation and Operation of RISKIND ……..................................................... G-7

G.2 Input Requirements and Data Entry................................................................... G-8

G.2.1 Scenario Definition ..................................................................................... G-10

G.2.1.1 Input Options ............................................................................. G-10

G.2.2 Main Menu .............................................................................................. G-13

G.2.3 Receptor Data............................................................................................ G-15

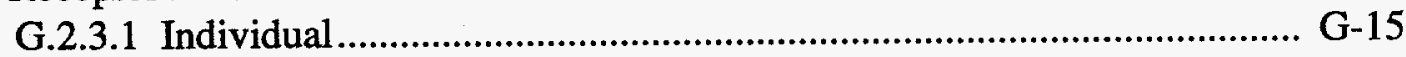

G.2.3.2 Population.................................................................................... G-18

G.2.3.3 Soil and Resuspension Factors ........................................................ G-21

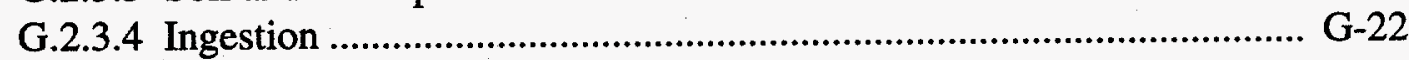

G.2.3.5 Water Consumption....................................................................... G-25

G.2.4 Shipment Parameters...................................................................................... G-28

G.2.4.1 Cask External Dose Parameters.......................................................... G-28

G.2.4.2 Dose Rate Curve Parameters ........................................................... G-30

G.2.4.3 Road Parameters ............................................................................. G-31

G.2.5 Radionuclide Inventory ............................................................................... G-34

G.2.5.1 SNF Inventory.............................................................................. G-34

G.2.5.2 User-Defined Inventory .................................................................... G-36

G.2.6 Accident Parameters................................................................................... G-37

G.2.6.1 One or All Response Region(s) ....................................................... G-38

G.2.6.2 User-Defined Scenario...................................................................... G-42

G.2.7 Meteorological Parameters............................................................................ G-44

G.2.7.1 User-Defined Weather.................................................................... G-44

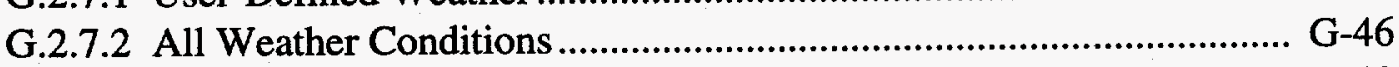

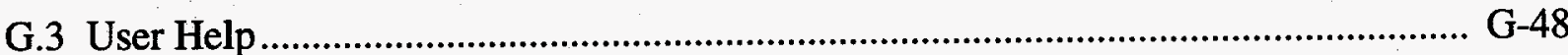

G.3.1 On-Line Help........................................................................................... G-48

G.3.1.1 Input Parameter Definitions.............................................................. G-49

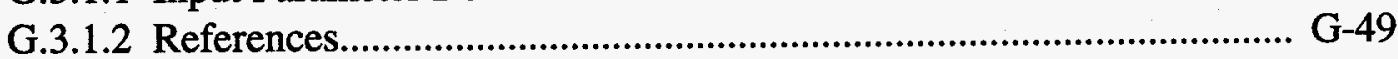

G.3:1.3 Help Diagrams .................................................................................. G-49

G.3.2 Variable List and Definitions ................................................................... G-50

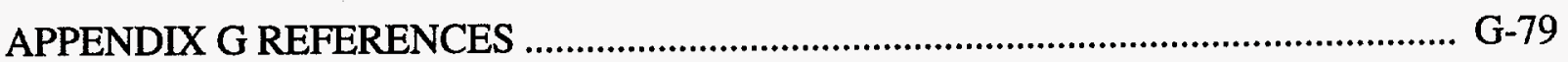




\section{TABLES}

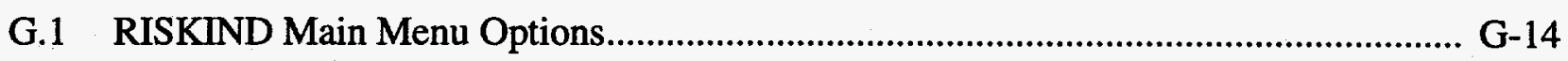

G.2 Estimated Lifetime Cancer Mortalities and Genetic Effects ........................................ G-16

G.3 Default Ingestion Rate Values ............................................................................ G-24

G.4 Comparison of Preliminary Design Characteristics of DOE Initiative I and NRC Modal Study SNF Transportation Casks ..................................................... G-30

G.5 Sample of External Dose Information Based on the DOE Initiative I GA-4 Truck Cask for a PWR ...................................................................................... G-32

G.6 Default Route Values for Truck Transportation ......................................................... G-33

G.7 Default Route Values for Rail Transportation......................................................... G-33

G.8 Default Accident Rates for Truck and Rail Transportation......................................... G-40

G.9 Deposition Velocity Data Summary for Particulate Radionuclides .............................. G-46

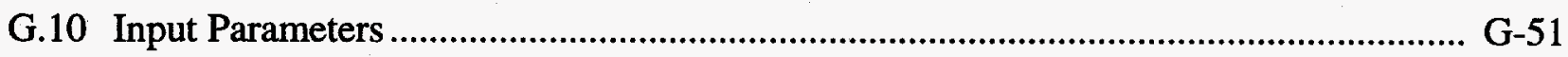

\section{FIGURES}

G.1 RISKIND Window Access Diagram..................................................................... G-9

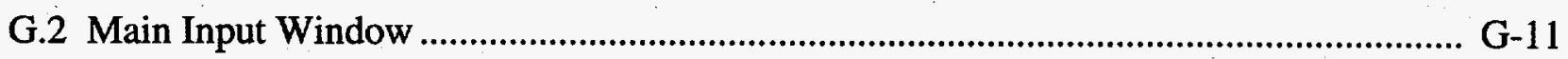

G.3 Individual Parameters Window ................................................................................ G-16

G.4 Population Parameters Window ………….................................................................... G-19

G.5 Routine On-Link/Stops Parameters Window............................................................. G-20

G.6 Soil and Resuspension Factors Window ....................................................................... G-22

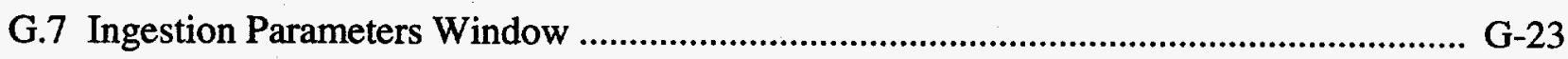

G.8 Ingestion Pathway Details Window ..................................................................... G-24

G.9 Population Ingestion Parameters Window .............................................................. G-26

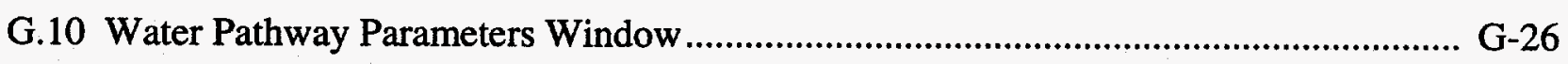

G.11 Water Pathway for Population Window............................................................. G-27

G.12 Shipment Parameters Window for Truck Transportation Mode.................................... G-28 


\section{FIGURES (Cont.)}

G.13 Shipment Parameters Window for Rail Transportation Mode...................................... G-29

G.14 Dose Rate Curve Parameters Window …………...................................................... G-31

G.15 Spent Nuclear Fuel Inventory Window ..................................................................... G-35

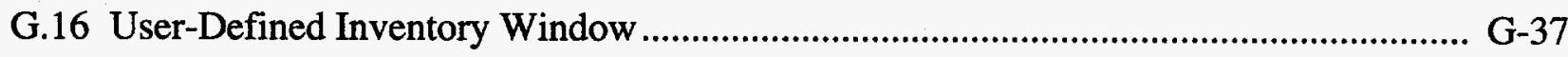

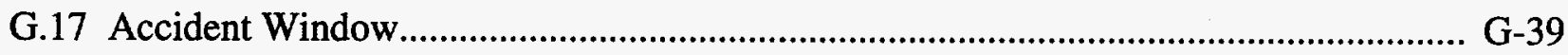

G.18 Defined Accident Scenario Window.......................................................................... G-43

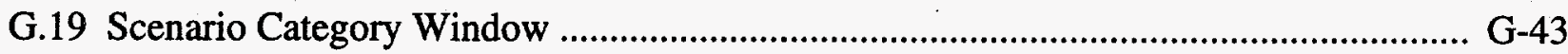

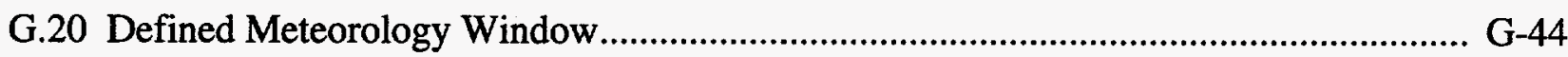

G.21 Nuclide-Dependent Deposition Velocities Window ................................................... G-47

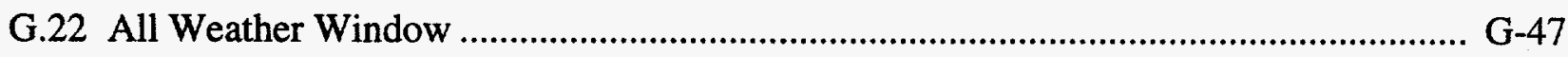

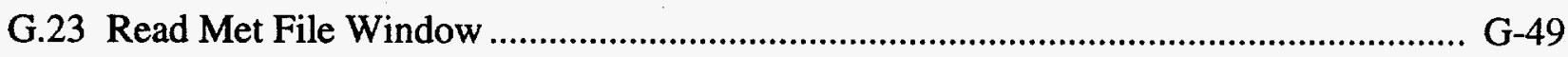

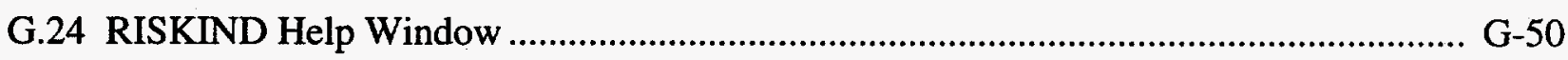

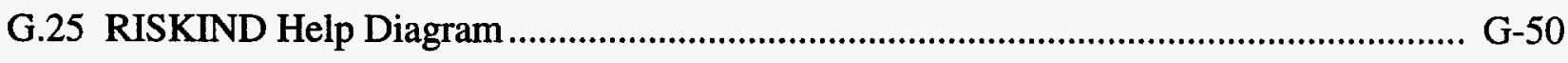


G-6 


\section{APPENDIX G:}

\section{DATA INPUT PREPARATION}

The RISKIND computer code runs on an IBM (or compatible) microcomputer with a Windows ${ }^{\mathrm{TM}} 3.1$ operating system. A hard drive and a math coprocessor (80387 or higher) are required. The RISKIND code consists of two major components:

1. RISKVB.EXE - The Windows ${ }^{\mathrm{TM}}$ interface program that is written in Visual Basic 3.0. ${ }^{1}$ This module handles all user interaction with RISKIND. The user may input and edit the specific parameters necessary for a particular analysis. Input files may be created or retrieved, modified, and saved. The interface program executes RISKIND.EXE (see below) once the user is satisfied with the input selections. The resulting output, both plot graphics and text output, may then be viewed.

2. RISKIND.EXE - A Fortran (Lahey F77L $5.01^{2}$ ) program that performs the radiological calculations on the basis of the input files created with RISKVB.EXE and generates the output files for RISKIND. RISKIND.EXE may be run separately in a DOS 3.1 or higher operating system. This latter mode of operation allows the radiological analysis to be performed in the absence of the Windows ${ }^{\mathrm{TM}}$ operating environment and facilitates the processing of numerous input files in a batch mode (may be executed from a user-developed DOS batch file).

\section{G.1 INSTALLATION AND OPERATION OF RISKIND}

The RISKIND code is available on two 1.44-megabyte (MB) 3.5-in. diskettes. After inserting Disk 1 into the floppy disk drive (A:, or the appropriate drive designation for your machine), installation of RISKIND can be accomplished by double-clicking on A:ISETUP.EXE, while in the File Manager, or by typing "A:ISETUP.EXE" into the command line box under "Run.." in the File menu of either the Program Manager or File Manager. The user will be given a prompt for the directory to be used on the hard drive (default: C:IRISKIND), and installation will continue automatically from that point. The RISKIND code and supporting data files will occupy approximately $5 \mathrm{MB}$ of disk space once expanded and installed. The README.TXT text file in the default directory contains last minute program documentation and a list of the program files that should now reside on the hard drive.

\footnotetext{
' Microsoft Corporation, 1993, Microsoft Visual Basic 3.0, Redmond, Wash.

2 Lahey Computer Systems, Inc., 1991, Lahey 5.01, Incline Village, Nev.
} 
The RISKIND program can be started by double-clicking on the RISKIND icon in the RISKIND group under Windows ${ }^{\mathrm{TM}}$. As mentioned previously, the calculational portion of RISKIND (RISKIND.EXE) can be run separately in DOS by typing RISKIND MYINPUT.INP at the system prompt while in the default RISKIND directory, where MYINPUT.INP is the user input file. This second mode of operation permits batch processing of multiple input files and provides a method for performing the radiological calculations if the Windows ${ }^{\mathrm{TM}}$ operating environment is not available. However, the user-friendly interface and the plot graphics are not available in this second mode.

Available options in the RISKIND windows may be selected by using the mouse or the tab key for moving forward through the selections and Shift-tab for moving backward through selections. The buttons in the various windows available for performing certain actions can be "pressed" (activated) by one of three methods: (1) a mouse click while the mouse arrow is over the button, (2) pressing the Enter key on the keyboard when the button has the input focus (button label is circled), or (3) pressing a hot key (the underlined letters in the different menu items) while the Alt key is depressed. A hot key also corresponds to the underlined letter in the button labels.

\section{G.2 INPUT REQUIREMENTS AND DATA ENTRY}

The user interface to RISKIND consists of a main menu and window and numerous subwindows for problem definition (Figure G.1). The situation to be assessed is defined in terms of input variables that are set through user interaction with the various windows and their options. The input thus generated is collected and stored in an ASCII text file following the FORTRAN NAMELIST format. This file is then used for input to the FORTRAN program RISKIND.EXE, which performs the numerical calculations. The NAMELIST input parameters and their descriptions are discussed in the subsections that follow. Section G.3.2 provides a list of these variables. As an aid to the user who may wish to later edit the input file directly, the variable name used for each input item is listed in parentheses in capital letters next to the corresponding selection in an input window. It is highly recommended that only very experienced users of the code who are aware of the interdependencies of the input parameters edit the input file with a text editor. Input files from the previous release of RISKIND can be run without modification.

Output files retain the name of the input file with a change in the filename extension to "*.OUT." With the user interface, modifications to input files are not automatically saved to disk unless specifically directed through the use of the Save Input item of the File menu discussed in Section G.2.2. However, modified input files may be run without being saved; the input file will be saved to disk with the "*.MOD" file extension and then executed. Input files from the previous release of RISKIND can be run without modification, but the user should check the input parameters first since new parameters have been added to the input. 


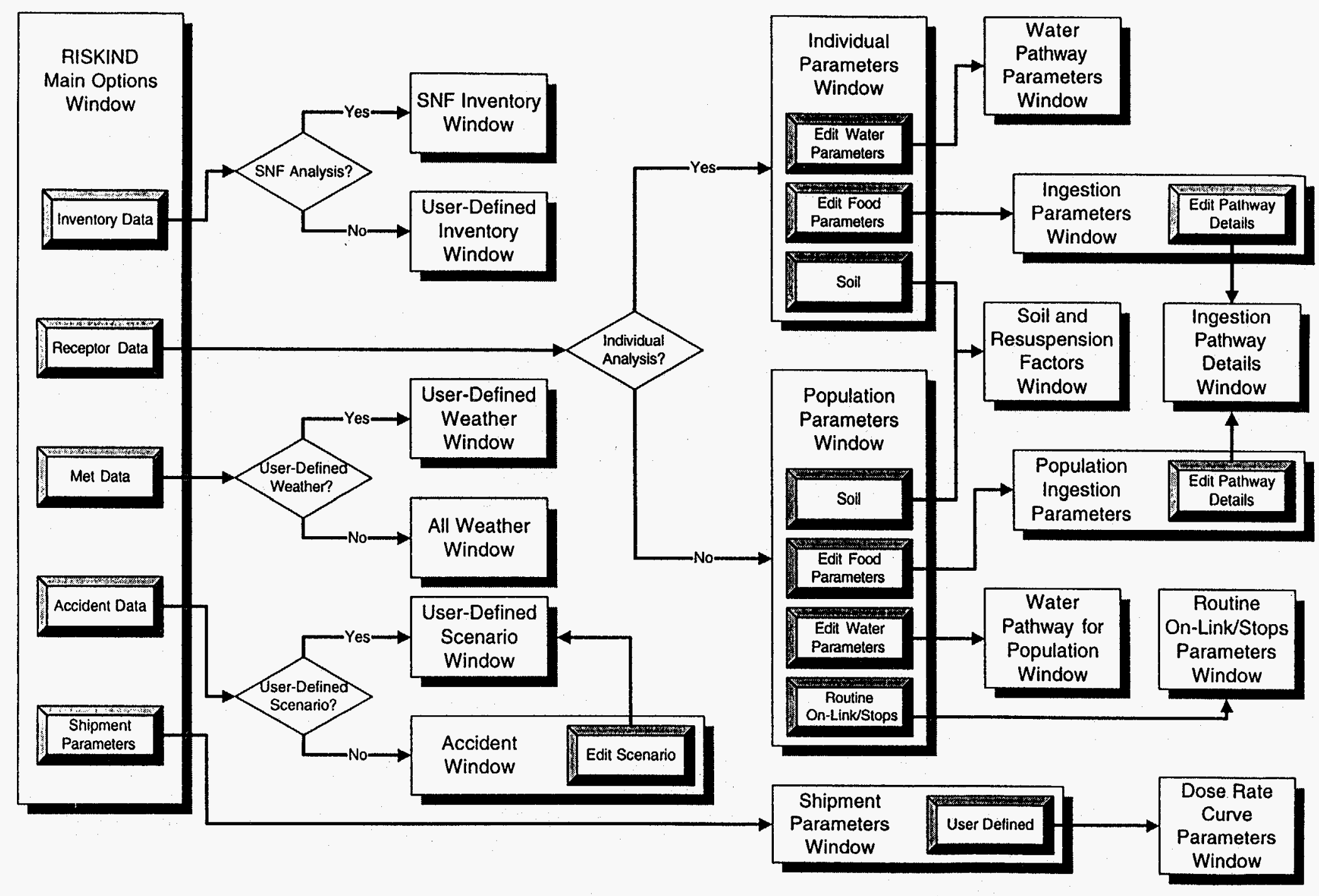

FIGURE G.1 RISKIND Window Access Diagram 
The default problem for RISKIND is loaded automatically from the DEFAULT.RKD input file at the startup of RISKIND. This is a read-only file and should not be removed from the default directory. It may be replaced with a default file more appropriate to the user's needs if desired. Any replacements must be made when the RISKIND program is not running.

RISKIND, Version 1, has bounds checks on the input parameters. Both the user interface and the run-time portions of the program perform the same checks. The user interface checks parameters when an input file is loaded from disk and when entered by the user and will prompt for suitable input if a parameter is found to be out of bounds. The run-time portion of the code will give a warning message and terminate calculations if a parameter is found to be out of bounds.

\section{G.2.1 Scenario Definition}

The situation to be analyzed is defined by the major input options in the main input window (Figure G.2), thus giving the user an overall summary of the problem definition. The window also provides quick access to more detailed problem-specific information for some of the major input options through a button press, which brings up other input windows with parameters grouped by function. The scenario is defined by a series of simple questions reflecting the input options on the main screen. What is being shipped (Inventory Options)? How is it being shipped (Transportation Mode)? Who is affected (Receptor/Population Zone)? How will normal transportation of the material affect the receptor(s) (Scenario)? What happens if there is an accident (Scenario/Accident Scenarios)? To aid the user in setting up an analysis, those input parameters not pertinent to the selected options are not available for input from the user interface.

RISKIND is designed to estimate the impacts associated with the transportation of radioactive materials at the local level. The user is able to model most credible situations involving a truck or rail transport vehicle. This level of detail and versatility requires many location-specific input parameters, some of which may not be readily available. The default data provided with RISKIND help alleviate this problem. However, it is the user's responsibility to ensure that the input data used are the best available and appropriate for the situation to be analyzed. Much of the default data in RISKIND consists of average values that may be unreasonable for a specific location and scenario.

\section{G.2.1.1 Input Options}

Inventory - RISKIND contains an internal spent nuclear fuel (SNF) database for estimating boiling-water reactor (BWR) and pressurized-water reactor (PWR) commercial fuel shipment inventories on the basis of the fuel's history. Appendix A contains a description of the database used. Pressing the Inventory Data button when the Spent Fuel option is selected will 


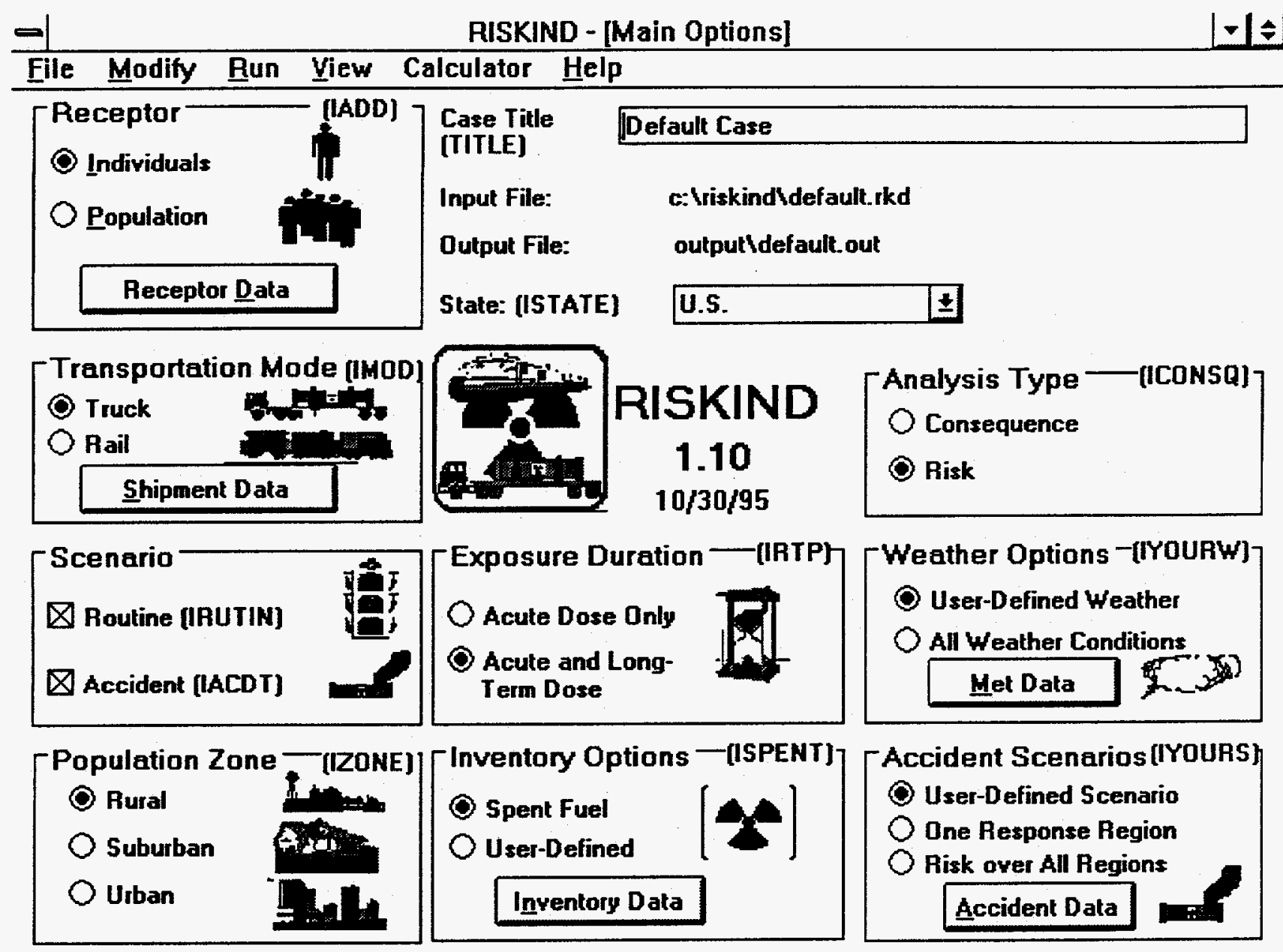

FIGURE G.2 Main Input Window

bring up the SNF Inventory window containing the input parameters required for determining the SNF composition (discussed later in Section G.2.5.1). If the User-Defined option is selected, the Inventory Data button accesses the User Inventory window where the user may select a custom inventory of radionuclides for shipments of nonstandard SNF or other types of radioactive materials.

Transportation Mode - When necessary, most SNF is shipped by truck or rail and sometimes by barge. RISKIND has the option of truck or rail transport. This option affects default values assigned to input parameters such as cask size, accident rates, vehicle speed, and other route characteristics. The Shipment Data button accesses the Shipment Parameters window that contains input for shipping cask and local route characteristics.

Receptor - RISKIND can estimate transportation impacts to specific individual receptors (up to a maximum of 20 ) with unique attributes in a single analysis, or impacts to a population subgroup defined by a specific area relative to the radioactive materials shipment. 
The appropriate selection is made with the radio buttons in the Receptor box. Pressing the Receptor Data button accesses either the Individual Parameters window or the Population Parameters window. These windows contain specific location and receptor attribute input parameters.

Population Zone - RISKIND recognizes three population zones: rural, suburban, and urban. This option affects default values assigned to route parameters such as accident rates, transport vehicle speed, and traffic density. Impacts from ingestion of contaminated foodstuffs following an accidental release can only be selected if the rural population zone is selected. Food is not expected to be grown in suburban and urban areas to any significant extent.

Scenario - Impacts can be analyzed for routine (incident-free) transport of radioactive material, transport under accident conditions, or both. Impacts from routine transport are the result of exposure of the receptors to external radiation emanating from the shipment as it either passes by en route or while it is stopped at a location such as a refueling area. A routine impacts analysis will be conducted if the Routine checkbox is selected. Likewise, an accident analysis will be conducted for the same receptor(s) if the Accident checkbox is selected. Potential accident impacts will be assessed, as discussed below, on the basis of severity of the accident (Accident Scenarios), the weather conditions at the time of accident (Weather Options), and the exposure duration of the receptor(s) (Exposure Duration). Either an accident consequence or risk can be estimated (Analysis Type).

Accident Scenario - The accident scenario ultimately determines how much of the shipment inventory is released to the environment. As discussed in Section 3 and in Appendix E, 20 default response regions constitute the entire range of accident severities possible for a SNF cask given that an accident has occurred. Selection of the User-Defined Scenario option allows the user to input the accident conditions at the time of accident after pressing the Accident Data button. The release characteristics will then be given by the response region determined by the methodology developed in the U.S. Nuclear Regulatory Commission (NRC) modal study (LLNL 1987) as described in Appendix E. As an alternative, the user may directly select the response region after selecting the One Response Region option or may elect to estimate the risk when considering the spectrum of accident severities over all regions (Risk Over All Regions option). This latter option is not available if the Analysis Type is set to Consequence.

Weather Options - After radioactive material is released to the environment from an accident, the material is dispersed to the surrounding receptor locations by atmospheric turbulence. The input for weather conditions at the time of accident can be accessed by using the Met Data button if the User-Defined Weather option is selected. If analyzing the risks for a potential accident and the weather conditions at the time are uncertain, a risk estimate over all weather conditions can be calculated by selecting the All Weather Conditions option. This latter option is not available if the Analysis Type is set to Consequence. 
Exposure Duration - Immediately following an accident, persons in the vicinity may be exposed to the passing radioactive cloud released (inhalation and external radiation) and possibly to increased external radiation levels from the shipment itself, because of containment failure. This short-term exposure generally lasts only a few hours at most, since emergency measures will be taken as soon as possible after the accident to minimize exposure to the general public. Persons exposed might be motorists stopped in traffic at the accident scene, workers in nearby businesses, or persons attempting to rescue accident victims before the arrival of emergency response teams. The Acute Dose Only option directs RISKIND to estimate only this short-term dose. However, other persons living near the accident scene could be exposed to external radiation from the deposited radioactive ground contamination and resuspended contamination, as well as receiving internal exposure from ingesting contaminated foods and inhaling resuspended contamination over the long term (years). The Acute and Long-Term Dose option directs the program to estimate doses from both the short- and long-term exposures.

Analysis Type - What if an accident occurred nearby? is a common question regarding SNF transportation. The impacts following such a postulated accident would be the consequence of the accident as if it had occurred. Selecting the Consequence option sets the program to estimate the effects from a given accident scenario occurring under a single set of defined conditions (i.e., fixed accident severity and weather conditions). On the other hand, many persons are also interested in the risk to themselves or their community rather than the consequence from a potential SNF transportation accident. The risk factors all of the probabilities into the sum of all potential consequences (risk $=$ probability $\times$ consequence). Selecting the Consequence option automatically sets the accident rate and the probabilities for the accident response region and weather condition to 1 . If the total risk is to be estimated, the probability of an accident occurring in conjunction with the probability weighted consequences for every possible combination of accident response region and weather condition is estimated (i.e., 20 response regions $\times 6$ weather stability categories $\times 6$ wind speeds $=720$ consequences combined with their probabilities of occurrence). Selecting the Risk option permits the user to run such an analysis. A constrained risk analysis may also be conducted. Someone may wish to know what the accident risk would be for a given set of weather conditions over all response regions, or the risk over all weather conditions for a given accident severity. Therefore, a full or partial risk analysis is only fully defined once the Risk option is selected and the appropriate choices made in the Weather Options and Accident Scenarios boxes.

\section{G.2.2 Main Menu}

The main menu across the top of the screen is available to the user while the RISKIND main window and many of the subwindows are displayed. Table G.1 lists the options and their functions. As is standard for most Windows ${ }^{\mathrm{TM}}$ programs, the main menu can be accessed either through the use of a mouse or by pressing the Alt key to activate the menu bar. Hot keys or the arrow keys may be used for traversing the menu and making a selection once the menu is activated. 
TABLE G.1 RISKIND Main Menu Options

\begin{tabular}{|c|c|c|}
\hline Menu Item & Sub-Menu Item & Function \\
\hline \multirow[t]{4}{*}{ File } & Read Input & Reads user-specified input file into memory. \\
\hline & Save Input & $\begin{array}{l}\text { Saves the current version of the input data in a file using the } \\
\text { current input file name. }\end{array}$ \\
\hline & Save Input As & $\begin{array}{l}\text { Saves the current version of the input data in a file using a } \\
\text { different input file name. }\end{array}$ \\
\hline & EXIT & Terminates the RISKIND program and returns to Windows ${ }^{\mathrm{TM}}$. \\
\hline \multirow[t]{5}{*}{ Modify } & Receptor & $\begin{array}{l}\text { Duplicates the Receptor Data button in the main window and } \\
\text { accesses the Individual or Population Parameters window. }\end{array}$ \\
\hline & Shipment & $\begin{array}{l}\text { Duplicates the Shipment Data button in the main window and } \\
\text { accesses the Shipment Parameters window. }\end{array}$ \\
\hline & Inventory & $\begin{array}{l}\text { Duplicates the Inventory Data button in the main window and } \\
\text { accesses the SNF Inventory or the User-Defined Inventory } \\
\text { window. }\end{array}$ \\
\hline & Meteorology & $\begin{array}{l}\text { Duplicates the Met Data button in the main window and accesses } \\
\text { the Defined Meteorology or the All Weather window. }\end{array}$ \\
\hline & Accident & $\begin{array}{l}\text { Duplicates the Accident Data button in the main window and } \\
\text { accesses the Accident window. }\end{array}$ \\
\hline Run & & Performs the radiological calculations with the current input data. \\
\hline \multirow[t]{4}{*}{ View } & Last Report & Permits viewing of the last output file generated by RISKIND. \\
\hline & Plots & $\begin{array}{l}\text { Plots data from the last set of calculations performed with } \\
\text { RISKIND. If applicable, the user may select from among risk, } \\
\text { air concentration isopleth, and ground concentration isopleth } \\
\text { plots. }\end{array}$ \\
\hline & Any File & Permits viewing of any ASCII text file. \\
\hline & Images & $\begin{array}{l}\text { Turns images displayed in the main window on or off. Screen } \\
\text { redraws of the main window may be substantially faster on } \\
\text { slower computers with the images turned off. }\end{array}$ \\
\hline Calculator & & $\begin{array}{l}\text { Brings up the Windows }{ }^{\mathrm{TM}} \text { calculator from the Accessories group } \\
\text { for quick calculations. }\end{array}$ \\
\hline \multirow[t]{4}{*}{ Help } & Contents & Lists topics (input parameters) available from user help. \\
\hline & References & Brings up the reference list for the default input parameter values. \\
\hline & Diagrams & $\begin{array}{l}\text { Accesses submenu of available help diagrams for additional } \\
\text { explanation of selected input parameters. }\end{array}$ \\
\hline & About RISKIND & Displays general information about RISKIND. \\
\hline
\end{tabular}




\section{G.2.3 Receptor Data}

\section{G.2.3.1 Individual}

The Individual Parameters window (Figure G.3) is brought up by pushing the Receptor Data button on the main window when individual receptors are selected. Up to 20 individuals may be specified for a single run of the program. Individuals may be added or deleted by using the buttons at the bottom of the window.

General Information - The General Information box has a droplist box for selecting the desired individual. Also present is the user name or label given to that specific individual (XNAME), the individual's breathing rate (BRTIND), and a choice of dose-to-risk conversion factors for use in the health effects calculations (INDTYPE).

The default breathing rate of $8,000 \mathrm{~m}^{3} / \mathrm{yr}$ is that suggested for an average adult in NRC Regulatory Guide 1.109 (NRC 1977a), as recommended by the International Commission on Radiological Protection (ICRP 1975). Regulatory Guide 1.109 also suggests a breathing rate of $3,700 \mathrm{~m}^{3} / \mathrm{yr}$ for children. Unless a receptor is engaged in strenuous activity prior to an accident, the individual's breathing rate is expected to be near the average. A summary of breathing rate information relating to age and physical activity can be found in Snyder et al. (1994).

The Health Risk Factors option allows the user to select among the dose-to-health risk conversion factors for estimating latent health effects. The effects estimated are the number of nonfatal cancer cases per person-rem, the number of fatal cancers per person-rem, and the number of adverse genetic effects per person-rem. Cancer incidence and fatalities are determined over the lifetime of the exposed population. Genetic effects occur in descendants of the exposed population. For individual receptors, these latent health results represent the probability of occurrence for the dose received. The conversion factors used in RISKIND are those recommended by the ICRP (ICRP 1991). Two conversion factor options are available, one for workers and another for the general public. The factors used for workers are slightly lower than those for the general public because the worker population is expected to be in better physical condition. Table 4.4 lists the values used. If a receptor receives more than a 20-rem dose, the risk conversion factors are doubled to account for the better effectiveness of higher dose rates for creating lasting adverse effects (ICRP 1991). Table G.2 compares cancer fatality and genetic effect studies.

Shielding - Exposure is reduced when a receptor is sheltered from radioactive sources such as a passing radioactive materials shipment or ground contamination. RISKIND provides a set of default shielding factors for a variety of shelter types and sources. These shielding factors are listed in Table 3.5 and on-screen and are from the Reactor Safety Study (NRC 1975). These factors are conservative values for a given source and shelter type: 1 represents no shielding, 


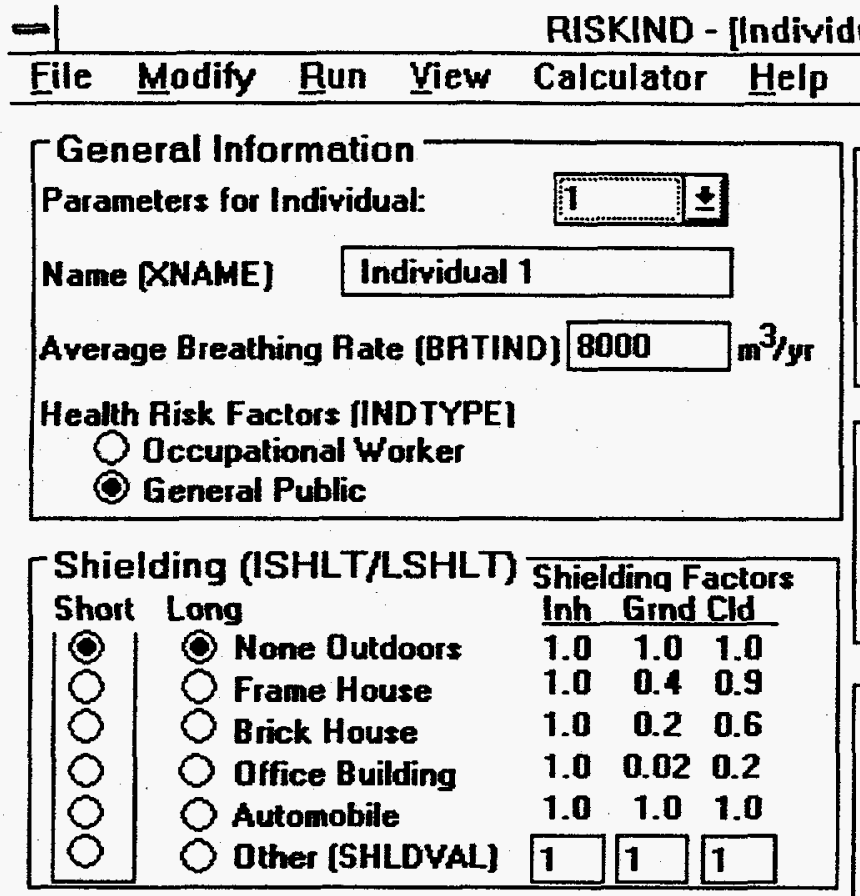

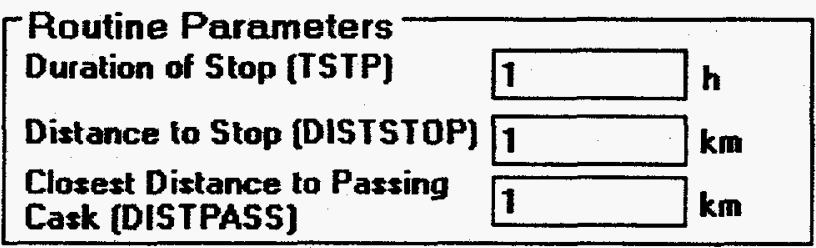

$\left[\begin{array}{ll}\text { Location during Accident } & \text { (XRECEP] } \\ \text { Downwind Distance } & \mathbf{1} \\ \text { Crosswind Distance } & \mathbf{k m} \\ \text { Elevation } & \mathrm{km} \\ & 0\end{array}\right]$

\begin{tabular}{|c|c|c|}
\hline Short-I erm Accident Param & & \\
\hline Short-Term Exposure Time [TEXT] & 2 & $\mathbf{h}$ \\
\hline Medical Treatment (ITREAT) & Minimal & \pm \\
\hline Health Risk Conservatism (IBOUND) & Central & \pm \\
\hline
\end{tabular}

Long-Term Accident Parameters Long-term exposure time (YEVD) Time Fractions (OCUPF): $\left[\begin{array}{ll}\text { Shielded } & .62 \\ \text { Outdoor } & .02\end{array}\right]$ [Food Ingestion Pathway (IDFOOD) $\bigcirc$ off $\mathcal{O}$ 0n Edit Parameters Water Ingestion Pathway [IWATER] $\bigcirc$ off $O$ on Erin Fazameaters

ok Cancel Saye Indiyidual Delete Individual

TABLE G.2 Estimated Lifetime Cancer Mortalities and Genetic Effects

\begin{tabular}{lcc}
\hline \multicolumn{1}{c}{ Source of Estimate } & $\begin{array}{c}\text { Lifetime Cancer } \\
\text { Fatalities per } \\
10^{6} \text { person-rem }\end{array}$ & $\begin{array}{c}\text { Genetic Effects per } \\
\text { Generation per } \\
10^{6} \text { person-rem }\end{array}$ \\
\hline National Research Council (1990) & 790 & $110-200$ \\
UNSCEAR (1986) & $700-1,100$ & 119 \\
ICRP (1991) & 500 & 130 \\
EPA (1989b) & 390 & 260 \\
\hline
\end{tabular}


0 represents complete shielding. For external radiation, the shielding provided by a particular structure depends on its construction materials and thickness, location with respect to the receptor and the radioactive source, and the energy of the radiation. For inhalation doses, open windows and the efficiency of ventilation systems at removing airborne contamination must be considered. Because a number of considerations must be taken into account, the user is provided with an option for entering a custom value for each source type if data are available for a particular situation. The short-term value (ISHLT) is used for routine shipment doses (ground source term factor) and for calculations of short-term accident exposure during plume passage immediately following an accident. The long-term value (LSHLT) is used for the long-term accident exposure calculations and is only available when accident calculations are specified.

Routine Parameters - For each individual routine shipment calculation, two doses are estimated, one for the dose received as the shipment passes by the receptor, and the other for the shipment at a fixed location relative to the receptor. A separate distance input is present for each of the two dose calculations (DISTPASS and DISTSTOP). An exposure time input is also needed for the stop calculation (TSTP).

Location during Accident - This box provides the input for situating the individual receptor with respect to the potential accident location (XRECEP) for the calculation of radioactive contamination levels. Only values greater than or equal to zero are acceptable input, because the elevation of the receptor is used in the adjustment of the plume height when considering elevated terrain downwind of the accident site (Section 3.3.1.1.2). If a receptor is located at a lower elevation than the accident site, the accident can be modeled as an elevated release for situations such as an accident on or near a bridge.

Short-Term Accident Parameters - For short-term accident calculations, the exposure time (TEXT) is needed for determining the dose received from external radiation from loss of cask shielding and deposited ground contamination. To estimate any acute health effects, the user may select the level of medical treatment received and the level of conservatism used in the acute dose model described in Section 4. Medical treatment options (ITREAT) are minimal and supportive. Minimal treatment refers to only the administration of basic first aid for any type of physical trauma. Supportive treatment directly counteracts radiation damage through such measures as hospitalization with state-of-the-art antibiotic therapy, blood transfusions, electrolyte replacement, and intravenous feeding. Because of the scarcity of data and some differences in opinion, the acute health effects model (Abrahamson et al. 1989, 1991) incorporates three sets of fixed parameters (IBOUND) for estimating acute effects; one for estimating upper bound responses, another for central estimates, and a third for lower bound estimates. Generally, the central estimates should be selected, unless the user is thoroughly familiar with the model and has reason to use the lower or upper bound estimates.

Long-Term Accident Parameters - Input is provided for the long-term exposure time (YEVD), which has a default of 50 years. This value is taken from the most restrictive of 
U.S. Environmental Protection Agency (EPA) long-term protective action guidelines (PAGs), which is a maximum of 5 rem in 50 years (EPA 1991). When considering residential receptors, the average residence time at one location could be used. For the United States, the average time a typical homeowner lives in a house is approximately 9 years; $90 \%$ of homeowners live in the same house for 30 years or less (EPA 1989a).

The fractions of the long-term exposure spent indoors (shielded) and outdoors (not shielded) at the individual location are also input (OCUPF). The sum of these two must be less than or equal to 1 , but are not required to equal 1 since a portion of the time may be spent at some other location such as work or home. The default values are based on the average time spent at home (EPA 1989a).

Long-term parameters related to the inhalation of resuspended radioactivity, food ingestion, and water intake can be accessed through their respective buttons in this box. The ingestion and water pathways can be turned on or off by selecting the appropriate radio buttons. The ingestion pathway can only be turned on if the population zone is set to rural in the main program window.

\section{G.2.3.2 Population}

The Population Parameters window (Figure G.4) is brought up by pushing the Receptor Data button on the main window when population receptors are selected. The Routine On-Link/Stops Parameters button is active in this window if routine calculations are selected. This button brings up the input window of the same name (Figure G.5) that contains input for the population on-link (sharing the transportation route with the shipment) and stops doses.

General Information - The area within the nearest distance (XPZ[1]) and maximum distance (XPZ[2]) to the shipment route is used for both routine shipment and accident calculations. In combination with the distance traveled input (SHIPDIST), a rectangular area is defined and is used for the routine off-link dose estimate calculations. For accident calculations, the area under consideration is defined by the radioactive cloud dimensions in addition to the nearest and farthest distances from the route. The number of people exposed under routine and accident conditions is determined by the affected area and population density (POPD). The population density may be input directly by the user or a state average population density (1990 census) may be selected (DOC 1992). The default population density is the average for rural population zones in the United States (NRC 1977b). If the state average option is selected, the state selected in the main program window determines the average value. 


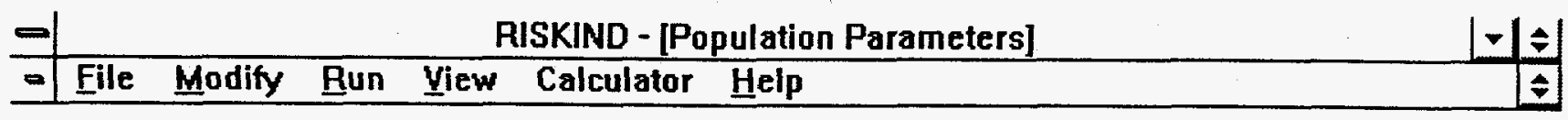

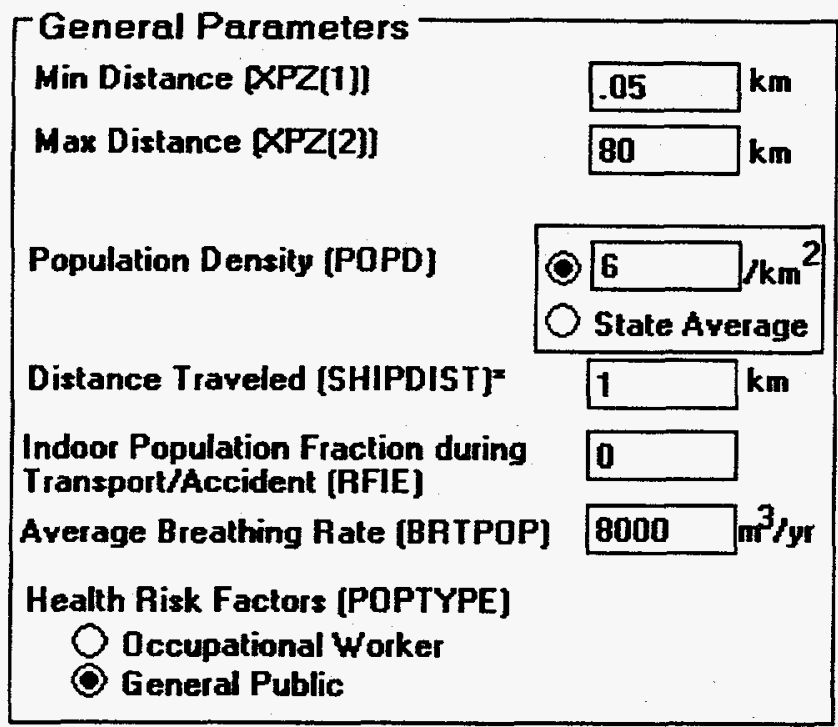

Short-Term Accident Parameters Short-Term Exposure Time (HTEXP) 2 Medical Treatment [ITREAT) Health Risk Conservatism (IBOUND) Central

- Routine only

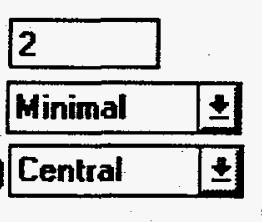

$\underline{\underline{a}}$

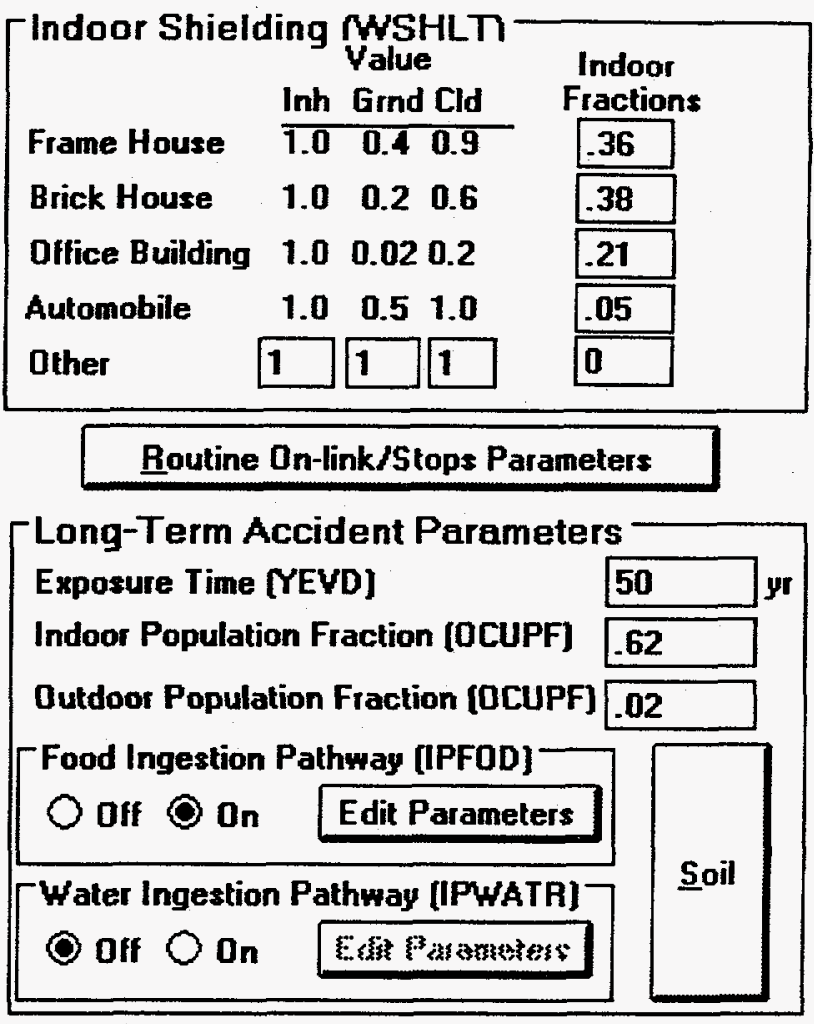

Cancel

FIGURE G.4 Population Parameters Window

Breathing rates (BRTPOP) and health risk factors (POPTYPE) are discussed in Section G.2.3.1. The indoor population fraction input (RFIE) applies to both routine shipment and accident conditions. The fraction of the population indoors at the time of an accident is given by this input; the shielding is determined by the Indoor Shielding box parameters. The remaining fraction of the population is assumed to be outdoors and unshielded.

Indoor Shielding - The same shielding factors discussed in Section G.2.3.1 are available for population calculations. They are applied slightly differently since a group of persons is involved. For the persons assumed to be indoors, the indoor fractions (WSHLT) relate to the distribution of the indoor population among the different shielding types. Thus, the indoor fractions must sum to 1 . This shielding distribution applies to both routine and accident conditions (short- and long-term). 


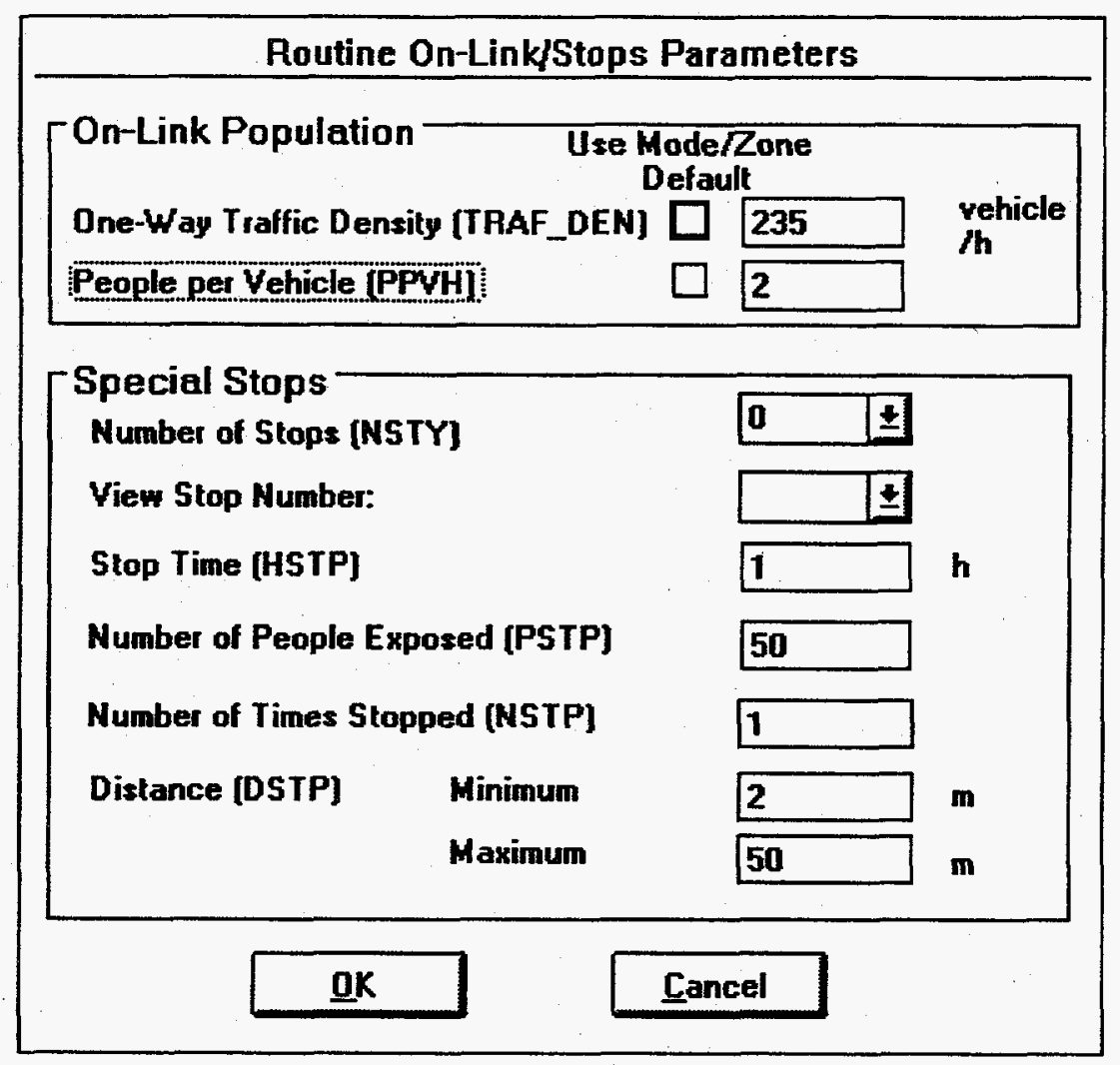

FIGURE G.5 Routine On-Link/Stops Parameters Window

Short-Term Accident Parameters - These input parameters are the same as those discussed in Section G.2.3.1.

Long-Term Accident Parameters - These input parameters are the same as those discussed in Section G.2.3.1.

On-Link Population - Persons sharing the transportation route traveling in the same and opposing directions to a radioactive materials shipment are denoted as the on-link population. Their exposure is dependent on the one-way traffic density (TRAF_DEN) and the number of persons per vehicle (PPVH). The default one-way traffic density of 235 vehicles per hour is per lane for truck transport and is derived from the one-way traffic density in rural zones of 470 vehicles per hour (NRC 1977b), assuming two lanes of travel in each direction. The default value of two persons per vehicle is for truck transport (Neuhauser and Kanipe 1992).

Special Stops - Up to 10 special stops for assessing doses to population subgroups can be input (NSTY). The number of times stopped at such a location (NSTP), the stop time (HSTP), and the number of persons exposed (PSTP) must be input for each of these stop types. The dose calculated for such a stop assumes that the number of persons exposed is distributed 
evenly about an annular ring defined by minimum and maximum distances (DSTP) from the shipment.

\section{G.2.3.3 Soil and Resuspension Factors}

The Soil and Resuspension Factors window (Figure G.6) is accessed by pressing the Soil button in either the Individual Parameters or Population Parameters windows.

Soil - The soil removal half-life (PHALF) is used in the calculation of long-term ground contamination levels, applies to all radionuclides, and accounts for environmental loss mechanisms in that the radionuclide becomes unavailable for ingestion pathways or resuspension into the air. Such mechanisms include chemical reaction with other soil constituents and wind and water erosion. The RISKIND default value of 50 years is that used in the EPA CAP88-PC program (Parks 1992).

The soil cleanup level input (PAG) is the long-term dose value used by RISKIND for determining cleanup levels for population problems (Section 3.4.4). The value specifies the maximum permissible dose to an individual over the long-term exposure period (YEVD) discussed in Section G.2.3.1.

The EPA has published suggested PAGs dealing with exposure to accidental radioactive releases (EPA 1991). These guidelines deal with the early (short-term) and later (long-term) phases following an accidental release. The early phase is defined as "the period beginning at the projected (or actual) initiation of a release and extending to a few days later, when deposition of airborne materials has ceased and enough information has become available to permit reliable decisions about the need for longer term protection" (EPA 1991). Early phase considerations are not considered in RISKIND because forewarning (i.e., time to mitigate potential exposure) of an accidental transport-related release is not likely, and cleanup is not a short-term mitigative action. Short-term mitigative actions include washing exposed skin and changing clothing, seeking shelter, and evacuation, depending on the situation at hand.

The most restrictive of the longer term guidelines suggests a limit of 5 rem to a single individual over a 50-year exposure period. If the exposure to a single individual in a given population isopleth exceeds the PAG value over the specified time (default for YEVD is 50 years), RISKIND will perform an extra set of calculations for that isopleth to determine the approximate ground concentrations necessary after cleanup needed to stay within the PAG limit. This determination "reduces" the dose from inhalation of resuspended material, groundshine, and ingestion. Short-term doses and water ingestion are not considered in the calculations.

Resuspension Factor - Estimates of resuspended air concentrations for the long-term inhalation and external cloudshine exposure pathways are based on the work in NRC (1974) and Anspaugh et al. 1974 (Equation 3.57). The decay time (RSALF) is the half-life used for 


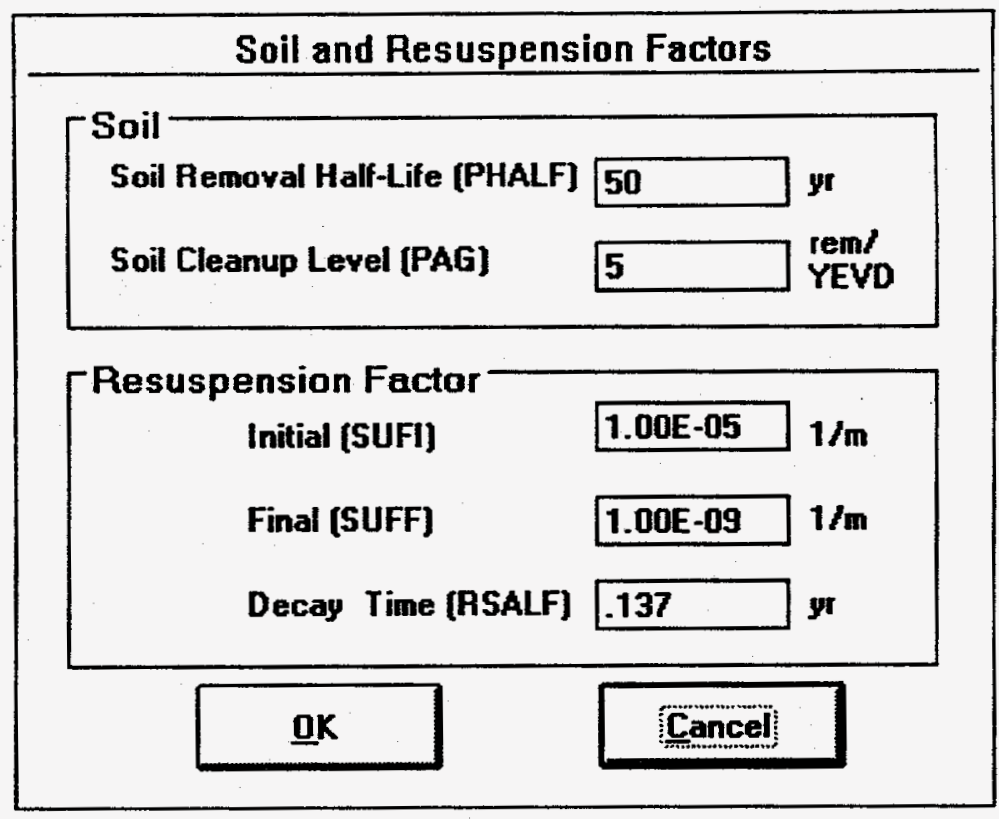

FIGURE G.6 Soil and Resuspension Factors Window

computing the resuspension decay constant (ln 2/RSALF) in the resuspension factor. The resuspension factor has an initial value (SUFD) that decays over a period of time, depending on RSALF (Equation 3.55), and a final value (SUFF) that remains constant over further periods of time. The RISKIND default values used for RSALF, SUFI, and SUFF were taken from NRC (1974).

\section{G.2.3.4 Ingestion}

Individual - The Ingestion Parameters window (Figure G.7) is accessed by pressing the Ingestion button in the Individual Parameters window if the ingestion pathway is activated $(\mathrm{IDFOOD}=1)$.

An option is available for throwing away the initially contaminated foodstuffs (IACFOD). If this option is chosen, deposition of radionuclides directly onto vegetation from the initial plume passage is not considered; only vegetation contamination from the root-uptake mechanism and later deposition from resuspended material are taken into account. If not interdicted, initially contaminated foodstuffs are assumed to be consumed at a constant rate over a one-year period following harvest.

The vegetation decontamination factor (DFACT) accounts for external washing of vegetables before consumption. The default value of 0.5 was taken from Parks (1992). Minimum and maximum values of 0.15 and 0.75 have been suggested in Snyder et al. (1994) for iodine on leafy vegetables and fruits. 


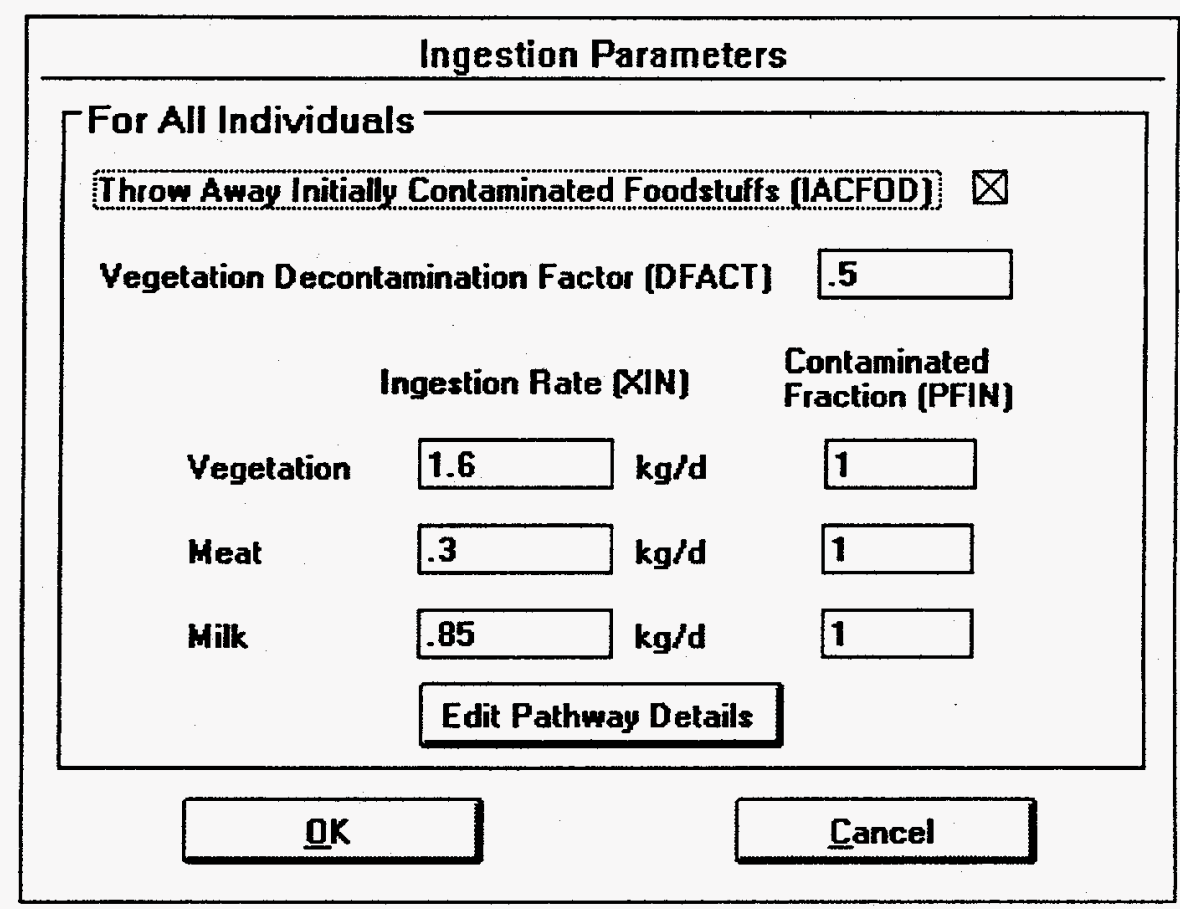

FIGURE G.7 Ingestion Parameters Window

RISKIND considers ingestion of three food types: vegetables, meat, and milk. The default individual ingestion rates (XIN[1 to 3], Table G.3) are taken from NRC Regulatory Guide 1.109 (NRC 1977a). Vegetables includes fruits, vegetables, and grains; meat includes beef and poultry; and milk includes milk and milk by-products. The fraction of contaminated food of each food type eaten (PFIN[1 to 3]) is used to represent that fraction of the food that was grown locally in the contaminated area. The remaining fraction accounts for noncontaminated food that was imported from other regions.

The Ingestion Pathway Details window (Figure G.8) is brought up by pressing the button of the same name in the Ingestion Parameters window. This window contains the input parameters specific to crop contamination. The fraction of contamination that is retained on plants from airborne deposition (F_RETAIN) has a default value of 0.2 (NRC 1977a) for particulates. Activity deposited on plant surfaces decreases over time due to weathering processes. The rate constant used to model these processes (DECAY_WEATHER) has a default value of $0.0495 /$ day, which corresponds to a 14-day half-life (NRC 1977a). Half-lives for weathering processes are typically in the range of 1 to 35 days (Snyder et al. 1994). Radionuclide contaminant concentrations in vegetation result from root uptake from the soil as well as from direct deposition. The effective soil density (EFF_SOIL_DEN) is used in the root uptake calculations. The default value of $240 \mathrm{~kg} / \mathrm{m}^{2}$ is based on a $15-\mathrm{cm}$ plow layer (NRC 1977a). 
TABLE G.3 Default Ingestion Rate Values

\begin{tabular}{lll}
\hline & $\begin{array}{l}\text { Individual } \\
\text { Calculations }\end{array}$ & $\begin{array}{l}\text { Population } \\
\text { Calculation }\end{array}$ \\
\hline Vegetation $(\mathrm{kg} / \mathrm{d})$ & 1.6 & 0.52 \\
Meat $(\mathrm{kg} / \mathrm{d})$ & 0.30 & 0.26 \\
Milk $(\mathrm{kg} / \mathrm{d})$ & 0.85 & 0.30 \\
\hline
\end{tabular}

Source: NRC (1977a).

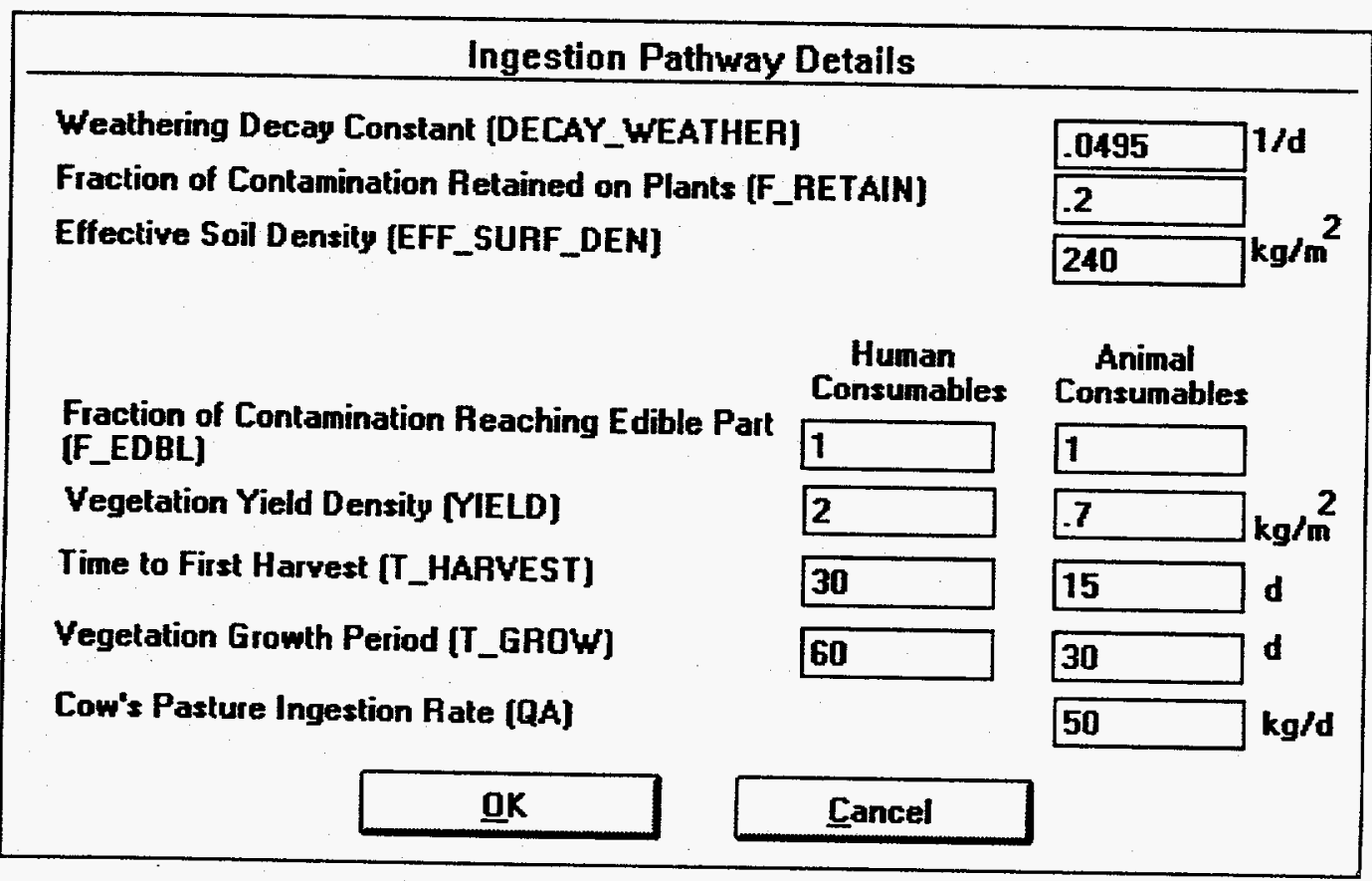

FIGURE G.8 Ingestion Pathway Details Window 
Following the model in NRC Regulatory Guide 1.109 (NRC 1977a), two types of vegetation are considered in RISKIND: one for human consumption (fruits, grains, and vegetables) and the other for animal consumption (pasture grass or hay). The time to first harvest following an accidental release for each type (T_HARVEST_HUM or T_HARVEST_COW) is set to half the value given for the normal growing season (vegetation growth period, T_GROW_HUM or T_GROW_COW), since there is no way of predicting the time of an accident. The default growing periods are 60 and 30 days, respectively, for human-consumed vegetation and animal-consumed vegetation with yield densities (YIELD_HUM and YIELD_COW) of 2 and $0.7 \mathrm{~kg} / \mathrm{m}^{2}$ (NRC 1977a), respectively. Most crops have a minimum growing season of about 90 days or less (Kennedy and Strenge 1992). The animal's pasture ingestion rate (QA) is also taken from NRC (1977a).

Population - The ingestion dose for population calculations is a societal dose based on the assumption that all food grown in the contaminated area is eaten, but not necessarily by those living in the local area. The window for population input (Figure G.9) has added parameters for the fraction of land used for farming (FARM) and land productivity for vegetables (GVEGE), meat (GMEAT), and milk (GMIK). These variables have average state-dependent default values (Saricks et al. 1989) specified by the state selected in the RISKIND main window. Vegetable production values in Saricks et al. (1989) include a variety of vegetables, fruits, and grains. Meat production values include beef, pork, poultry, and eggs. Milk production is for the entire amount of milk produced annually. All production values were calculated by using the percentage of land in farms for each state. Production values will be underestimated if the user employs data based on the entire land area for a state or the region of interest. If all food is not assumed to be consumed by humans, the UF(i) input parameter may be reset from 1 to the fraction of each food type $i$ produced that is consumed by humans.

With the exception of the vegetation yield density for humans (replaced by GVEGE), all other input remains the same for population ingestion input as for individual ingestion input. Individual food consumption rates and contaminated fractions input are retained for a separate individual estimate to be used in the PAG comparison for each ground concentration isopleth.

\section{G.2.3.5 Water Consumption}

The Water Pathway Parameters window (Figure G.10 or G.11 for individual or population, respectively) is accessed by pressing the Edit Parameters button in the Water Ingestion Pathway box in the Individual Parameters or Population Parameters window.

The water pathway option is a simple model intended only for use with relatively small surface water bodies used as drinking water supplies. The water bodies are characterized by their depth and width dimensions (WBDYD and WBDYW) and their exchange rates (WEXCG). The 
Population Ingestion Parameters

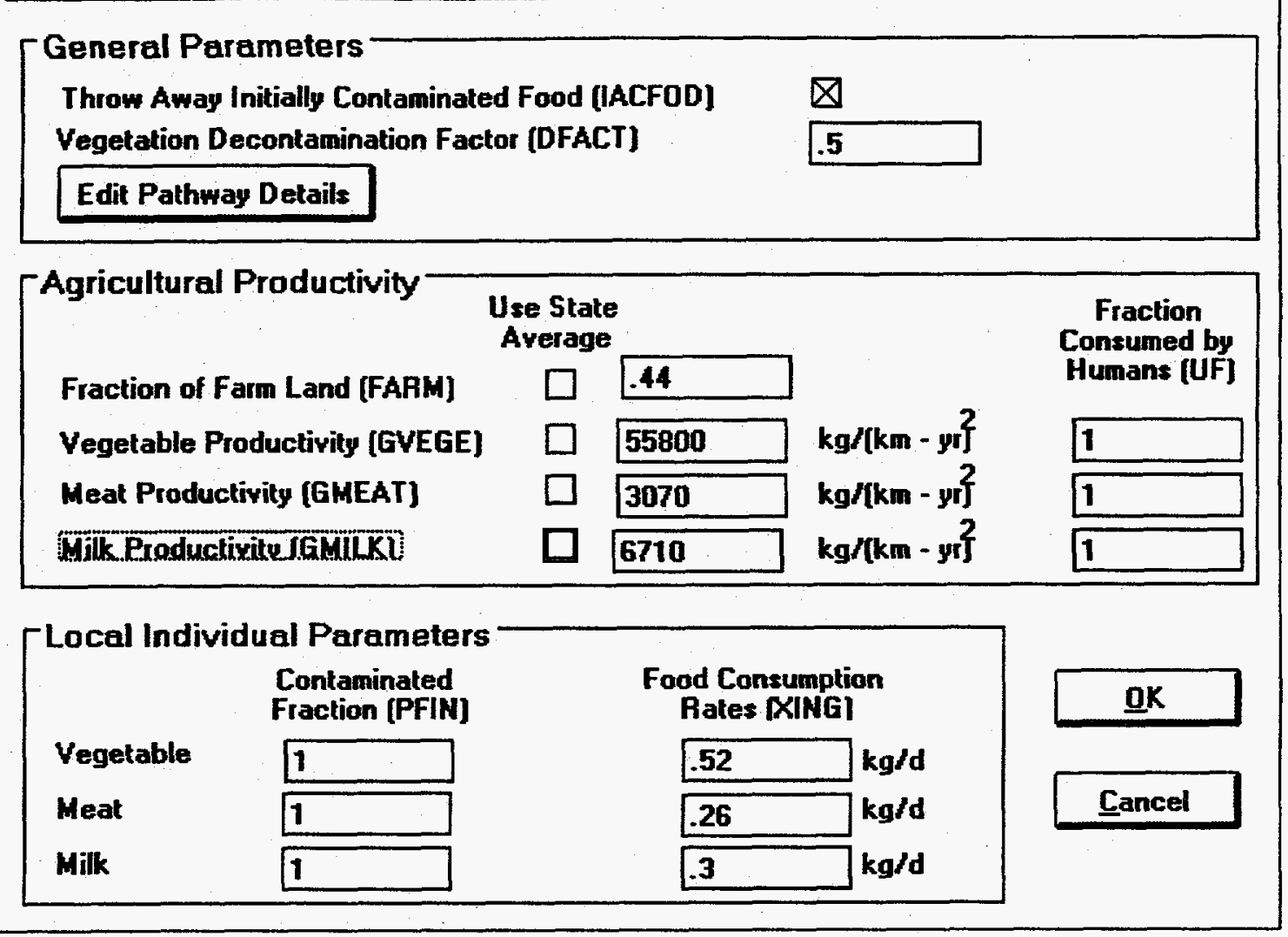

FIGURE G.9 Population Ingestion Parameters Window

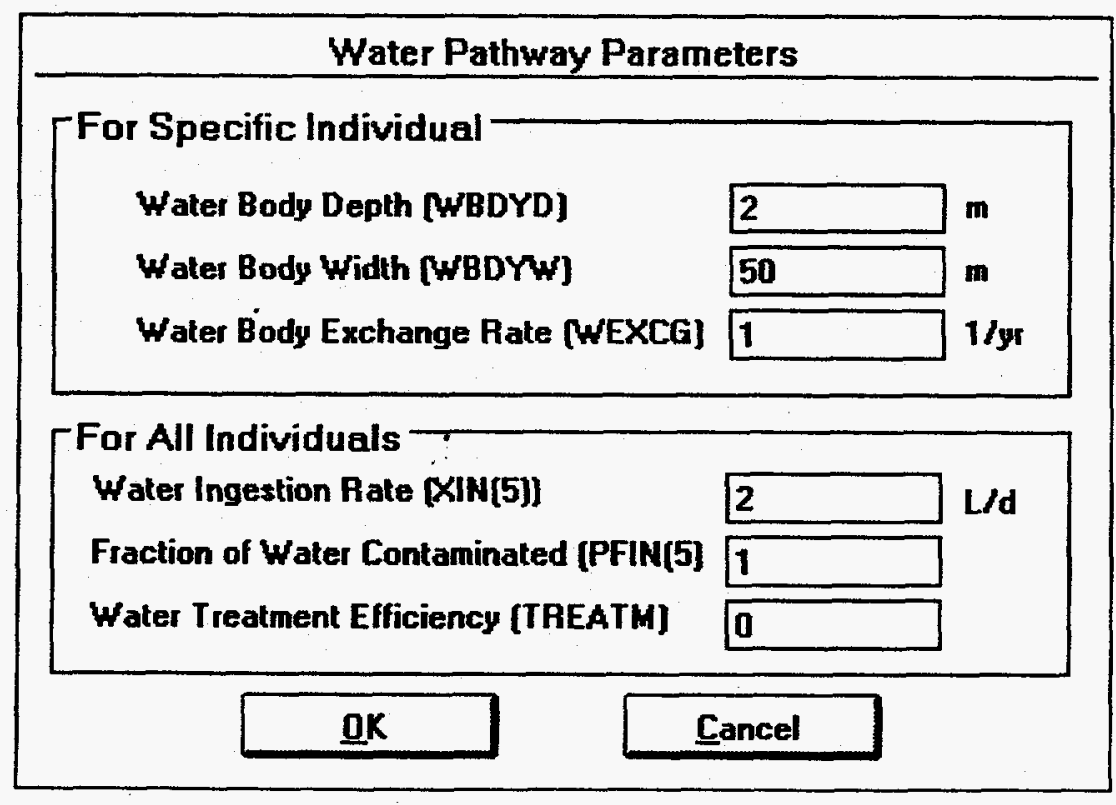

FIGURE G.10 Water Pathway Parameters Window 


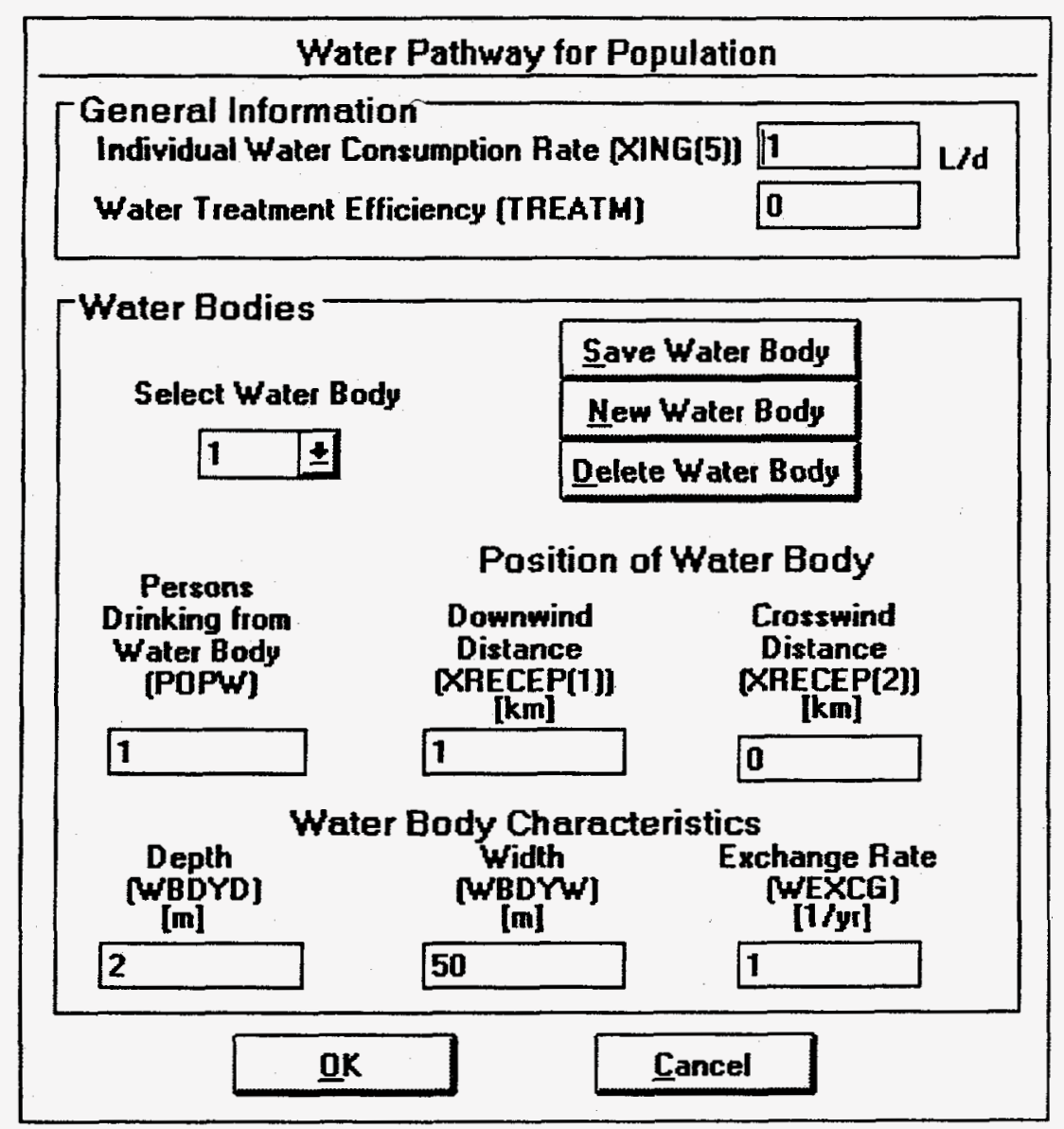

FIGURE G.11 Water Pathway for Population Window

exchange rates should be based on the amount of average water in the system and its replenishment with uncontaminated water from rivers or underground sources. Consumption of the water is characterized by the individual consumption rate (XIN[5] or XING[5]) and the water treatment efficiency (TREATM) of the water delivery system. A treatment efficiency of 0 represents no treatment; an efficiency of 1 represents complete decontamination.

For individual receptor estimates, the drinking water body is assumed to be at the location of each individual; the fraction of water consumed by the individual that is from the local contaminated source (PFIN[5]) is also input. For population estimates, up to 20 water bodies may be specified, each characterized by location (XRECEP[1,j], XRECEP[2,j]) and the number of persons drinking from it. The sole source of drinking water is assumed to be the contaminated water body for population calculations. 


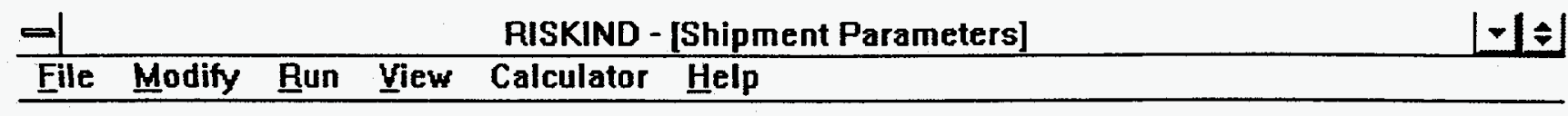
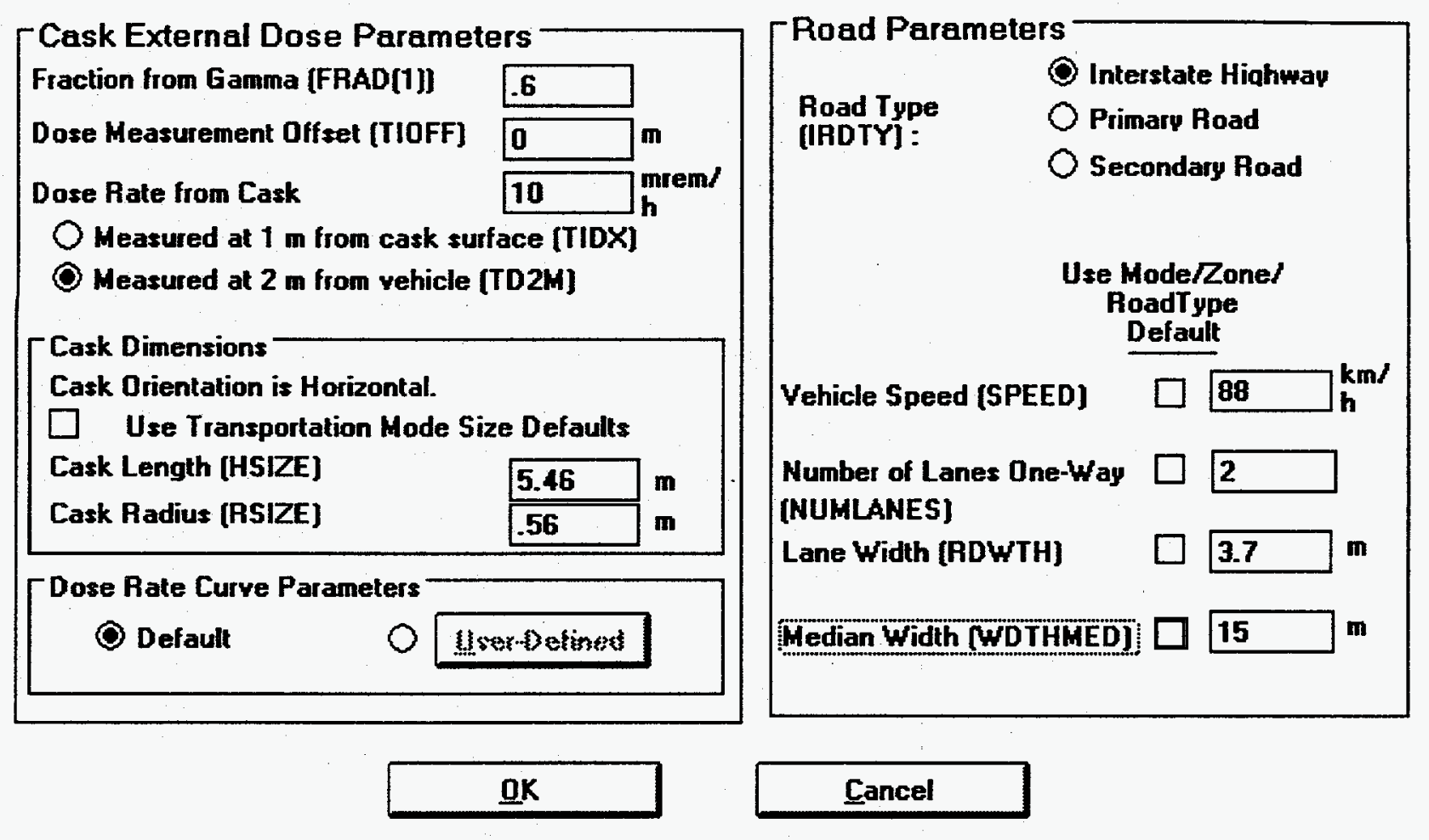

FIGURE G.12 Shipment Parameters Window for Truck Transportation Mode

\section{G.2.4 Shipment Parameters}

User input for the shipping cask external dose rate variables and route data are contained in the Shipping Parameters window (Figures G.12 and G.13), which is accessed by pressing the Shipment Data button in the main RISKIND window.

\section{G.2.4.1 Cask External Dose Parameters}

The shipping cask length (HSIZE) and width (RSIZE) input parameters are used in both routine and accident calculations. For routine calculations, these parameters are used to adjust the dose rate from the cask, according to the cask's size, by using the method in Appendix B if the shape factor option is selected (discussed below). The fraction of the external dose rate due to gamma radiation is specified with FRAD(1); the balance is assumed to come from neutron radiation. For accident calculations, the cask dimensions are used to estimate the initial size of the radioactive cloud at the release (accident) point according to the method described in Section 3.3.1.8. Table G.4 lists a number of cask types and their characteristics. The default dimensions of the cask are taken from the study used to estimate the default dose rate curves 


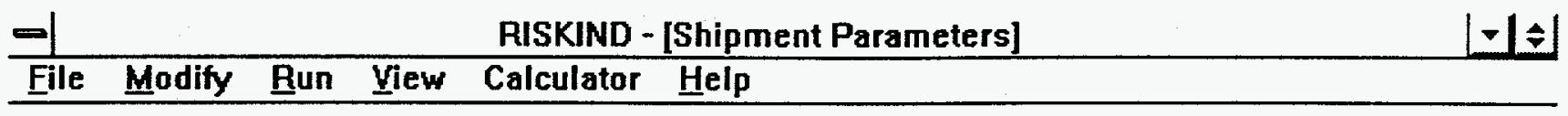
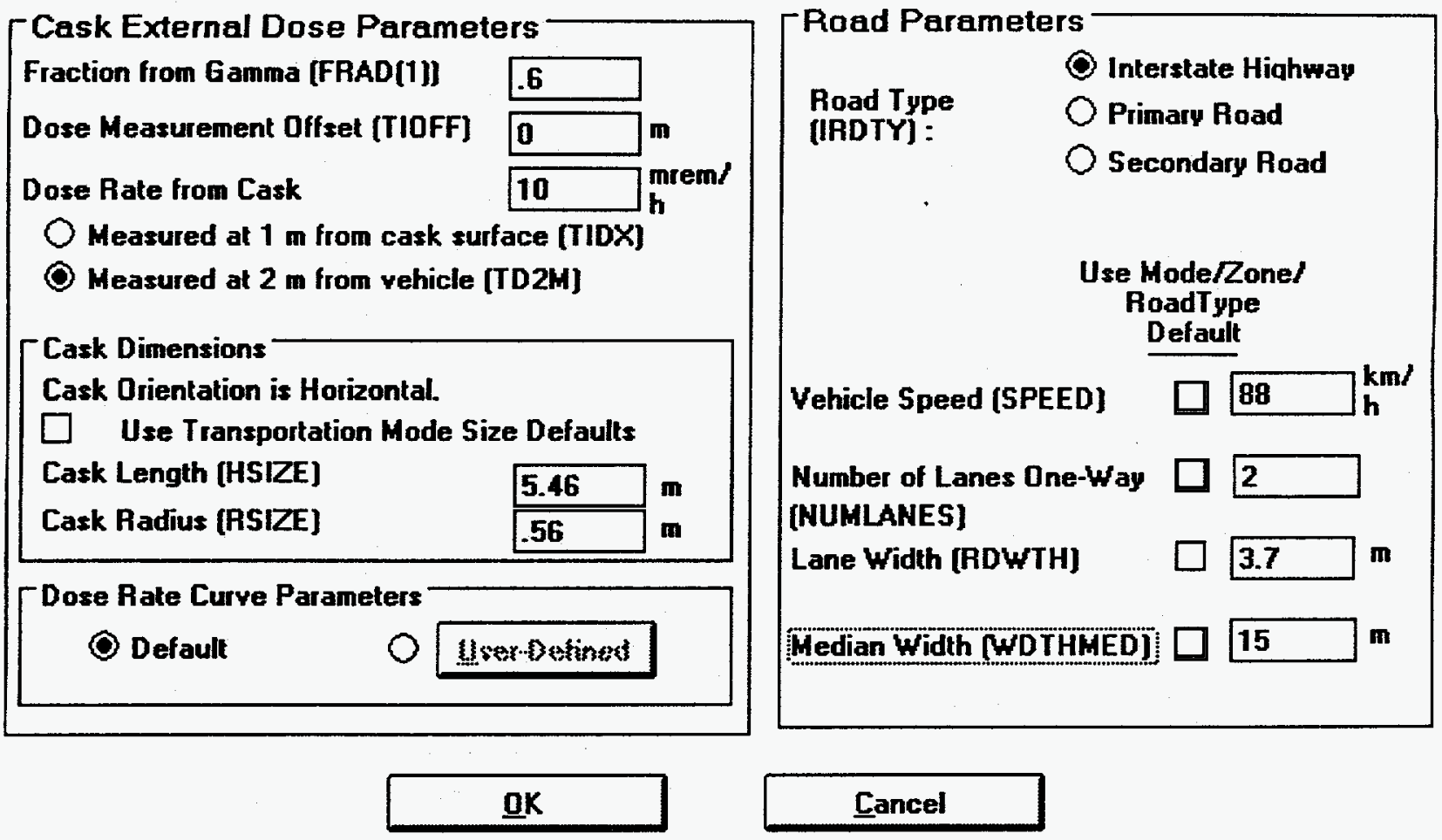

FIGURE G.13 Shipment Parameters Window for Rail Transportation Mode

(Chen and Yuan 1988). If the Use Transportation Mode Size Defaults box is checked, the cask dimensions used in the NRC modal study (LLNL 1987) will be used.

Several improvements have been made since the original release of RISKIND. First, the user input dose rate from the cask can be measured at $1 \mathrm{~m}$ from the cask (the only previous option) or $2 \mathrm{~m}$ from the transport vehicle, the distance for the regulatory check. ${ }^{3}$ Second, another input parameter has been added (TIOFF) to account for the distance from the cask surface to the lateral plane of the transport vehicle from where the regulatory check is made. Previously, the cask surface was assumed to coincide with the outside surface of the transport vehicle. This assumption required that the distance to the cask surface rather than that to the vehicle be used in cases in which the distance from the cask surface to the outside vehicle surface was significant compared to the distance from the receptor to the transport vehicle. All input distances still reference the lateral plane of the vehicle. Old RISKIND input files will run correctly because the default value for the offset distance is set to $0 \mathrm{~m}$. The third improvement to the code is that the

18

3 The $10 \mathrm{mrem} / \mathrm{h}$ limit at $2 \mathrm{~m}$ is according to the specifications of the Code of Federal Regulations, Title 10, Part 71 (NRC 1994b), and Title 49, Part 173, (DOT 1994). 
TABLE G.4 Comparison of Preliminary Design Characteristics of DOE Initiative I and NRC Modal Study SNF Transportation Casks

\begin{tabular}{|c|c|c|c|c|c|c|c|c|}
\hline Cask Type & $\begin{array}{l}\text { GA-4 } \\
\text { Cask } \\
\text { (truck) }\end{array}$ & $\begin{array}{l}\text { GA-9 } \\
\text { Cask } \\
\text { (truck) } \\
\end{array}$ & $\begin{array}{l}\text { BR-100 } \\
\text { Cask } \\
\text { (rail/ } \\
\text { barge) } \\
\end{array}$ & $\begin{array}{l}\text { BR-100 } \\
\text { Cask } \\
\text { (rail/ } \\
\text { barge) } \\
\end{array}$ & $\begin{array}{l}\text { NRC } \\
\text { Modal } \\
\text { Study } \\
\text { (truck) } \\
\end{array}$ & $\begin{array}{l}\text { NRC } \\
\text { Modal } \\
\text { Study } \\
\text { (rail) } \\
\end{array}$ & $\begin{array}{l}\text { MPC } \\
\text { Conceptual } \\
\text { Design } \\
\text { (rail) } \\
\end{array}$ & $\begin{array}{l}\text { MPC } \\
\text { Conceptual } \\
\text { Design } \\
\text { (rail) } \\
\end{array}$ \\
\hline Fuel type & PWR & BWR & PWR & BWR & PWR & PWR & PWR & BWR \\
\hline $\begin{array}{l}\text { Number of fuel } \\
\text { assemblies }\end{array}$ & 4 & 9 & 21 & 52 & 1 & 21 & 21 & 40 \\
\hline $\begin{array}{l}\text { Initial uranium weight } \\
\text { (MTU/cask) }\end{array}$ & 1.69 & 1.59 & 8.89 & 9.19 & 0.46 & 8.89 & 10.3 & 8.0 \\
\hline Length (m) & 4.77 & 5.03 & 5.13 & 5.13 & 6.93 & 6.93 & 5.29 & 5.29 \\
\hline Radius (cm) & 50.48 & 50.48 & 104.1 & 104.1 & 46.4 & 109 & 108.6 & 108.6 \\
\hline $\begin{array}{l}\text { Fuel burnup } \\
\text { (MWd/MTU) }\end{array}$ & 35,000 & 30,000 & 35,000 & 30,000 & 33,000 & 33,000 & 40,000 & 40,000 \\
\hline Cooling time (yr) & 10 & 10 & 10 & 10 & 5 & 5 & $10^{\mathrm{a}}$ & $10^{a}$ \\
\hline $\begin{array}{l}\text { Maximum initial } \\
\text { enrichment (wt\% } \\
\text { uranium-235) }\end{array}$ & 4.5 & 4.5 & 4.5 & 4.5 & $-b$ & - & 3.75 & 3.75 \\
\hline $\begin{array}{l}\text { Fraction of gamma } \\
\text { radiation }\end{array}$ & 0.83 & 0.83 & 0.60 & 0.48 & - & - & - & - \\
\hline $\begin{array}{l}\text { Fraction of neutron } \\
\text { radiation }{ }^{c}\end{array}$ & 0.17 & 0.17 & 0.40 & 0.52 & - & - & - & - \\
\hline
\end{tabular}

a Five years for storage, 10 years for transport.

b A hyphen indicates that data are not available

c Dose rate fractions estimated at $2 \mathrm{~m}$ from the centerline of the casks.

Sources: LLNL (1987), Babcock and Wilcox (1990), General Atomics (1990), and DOE (1994).

default cask external dose rate curves for gamma and neutron radiation now fit empirically to a single equation (Equation 2.2) that can be used to fit any dose rate curve; the curve coefficients may be specified by the user if pertinent dose rate data are available.

\section{G.2.4.2 Dose Rate Curve Parameters}

The User-Defined button in the Dose Rate Curve Parameters box accesses the window (Figure G.14) for changing the dose rate curve coefficients (ACOEFU) if the user wishes to use dose rate curves specific to the shipping package and contents. The dose rate curves were developed by using the energy spectrum from a "typical" commercial SNF cask (Chen and Yuan 1988). Nonstandard types of SNF or other radioactive materials can have a much different energy spectrum. The user may also wish to turn off the shape factor correction, that is, the 


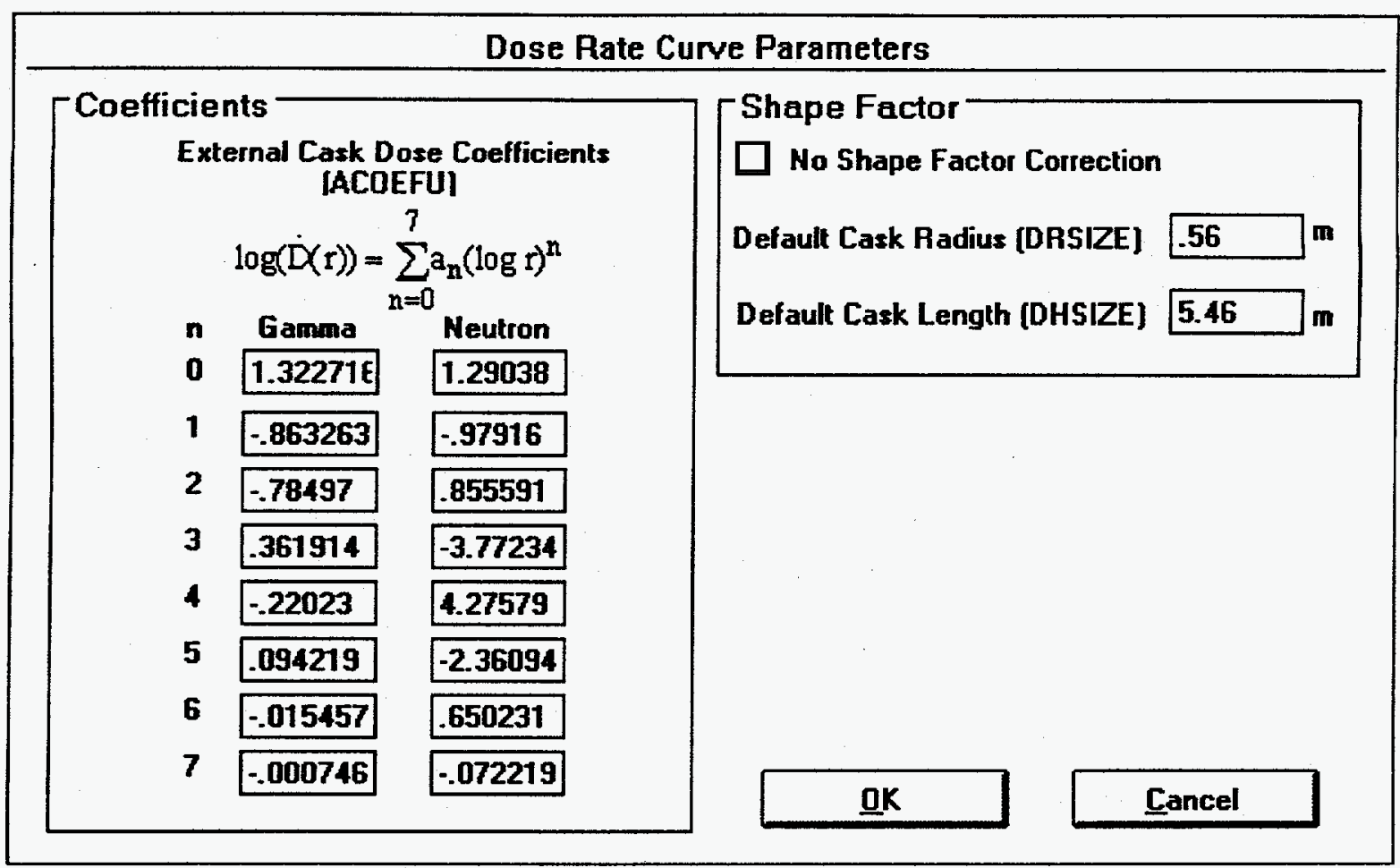

FIGURE G.14 Dose Rate Curve Parameters Window

check box in the Shape Factor box, if using a custom dose rate curve, or change the dimensions of the default cask length (DHSIZE) and radius (DRSIZE) to coincide with the new curve(s). The shape factor correction in RISKIND adjusts the dose rate for the user cask on the basis of a cylindrical surface source configuration, which has the dimensions of the default cask. See Appendix B for details. Table G.5 lists example dose rates and doses received from a GA-4 truck cask.

\section{G.2.4.3 Road Parameters}

The road type (IRDTY) input parameter is used in determining a number of datadependent defaults that include accident rate (ACTA), vehicle speed (SPEED), number of lanes one-way for truck transport or the number of parallel tracks for rail transport (NUMLANES), lane width (RDWTH), and median width for truck transport or track spacing for rail transport (WDTHMED). Tables G.6 and G.7 give the data-dependent values.

The SPEED default is used for estimating routine passing doses to individual and population receptors for both truck and rail transport. It is not available for input when only accident calculations have been specified. The NUMLANES, RDWTH, and WDTHMED parameters are only used for routine population on-link calculations (Section 2.3). For truck 
TABLE G.5 Sample of External Dose Information Based on the DOE Initiative I GA-4 Truck Cask ${ }^{\mathrm{a}, \mathrm{b}}$ for a PWR

\begin{tabular}{|c|c|c|c|c|c|}
\hline Interval & $\begin{array}{c}\text { Distance } \\
(\mathrm{m})\end{array}$ & $\begin{array}{c}\text { Dose Rate, } \dot{\mathrm{D}} \\
(\mathrm{mrem} / \mathrm{h})\end{array}$ & $\begin{array}{l}\text { Dose from } \\
\text { Passing } \\
\text { Shipment, D } \\
\text { (mrem) }\end{array}$ & $\begin{array}{c}\text { Population } \\
\text { Dose at Stops } \\
\mathrm{D}_{\mathrm{ps}} \text { (person- } \\
\text { mrem } / \mathrm{h} \text { ) }\end{array}$ & $\begin{array}{c}\text { Off-Link } \\
\text { Population Dose, } \\
\text { Doff (person- } \\
\text { mrem } / \mathbf{k m})\end{array}$ \\
\hline 1 & 1 & $2.16 \mathrm{E}+01$ & $1.15 \mathrm{E}-01$ & $0.00 \mathrm{E}+00$ & $0.00 \mathrm{E}+00$ \\
\hline 2 & 2 & $1.00 \mathrm{E}+01$ & 8.25E-02 & $1.33 \mathrm{E}-04$ & $1.01 \mathrm{E}-04$ \\
\hline 3 & 3 & $5.68 \mathrm{E}+00$ & 6.33E-02 & $2.49 \mathrm{E}-04$ & $1.69 \mathrm{E}-04$ \\
\hline 4 & 4 & $3.64 \mathrm{E}+00$ & $5.08 \mathrm{E}-02$ & $3.48 \mathrm{E}-04$ & $2.26 \mathrm{E}-04$ \\
\hline 5 & 5 & $2.52 \mathrm{E}+00$ & $4.22 \mathrm{E}-02$ & 4.33E-04 & $2.70 \mathrm{E}-04$ \\
\hline 6 & 6 & $1.84 \mathrm{E}+00$ & $3.60 \mathrm{E}-02$ & $5.07 \mathrm{E}-04$ & $3.12 \mathrm{E}-04$ \\
\hline 7 & 7 & $1.41 \mathrm{E}+00$ & $3.12 \mathrm{E}-02$ & 5.73E-04 & $3.46 \mathrm{E}-04$ \\
\hline 8 & 8 & $1.10 \mathrm{E}+00$ & $2.75 \mathrm{E}-02$ & $6.32 \mathrm{E}-04$ & $3.76 \mathrm{E}-04$ \\
\hline 9 & 9 & $8.89 \mathrm{E}-01$ & $2.45 \mathrm{E}-02$ & $6.84 \mathrm{E}-04$ & $3.95 \mathrm{E}-04$ \\
\hline 10 & 10 & $7.31 \mathrm{E}-01$ & $2.21 \mathrm{E}-02$ & 7.32E-04 & 4.21E-04 \\
\hline 11 & 12 & $5.17 \mathrm{E}-01$ & $1.83 \mathrm{E}-02$ & 8.17E-04 & $4.59 \mathrm{E}-04$ \\
\hline 12 & 14 & $3.83 \mathrm{E}-01$ & $1.56 \mathrm{E}-02$ & 8.89E-04 & $4.92 \mathrm{E}-04$ \\
\hline 13 & 16 & $2.95 \mathrm{E}-01$ & $1.34 \mathrm{E}-02$ & $9.52 \mathrm{E}-04$ & $5.22 \mathrm{E}-04$ \\
\hline 14 & 18 & $2.33 \mathrm{E}-01$ & $1.18 \mathrm{E}-02$ & $1.01 \mathrm{E}-03$ & $5.47 \mathrm{E}-04$ \\
\hline 15 & 20 & $1.88 \mathrm{E}-01$ & $1.05 \mathrm{E}-02$ & $1.06 \mathrm{E}-03$ & $5.70 \mathrm{E}-04$ \\
\hline 16 & 25 & $1.19 \mathrm{E}-01$ & 8.04E-03 & $1.16 \mathrm{E}-03$ & $6.15 \mathrm{E}-04$ \\
\hline 17 & 30 & $8.15 \mathrm{E}-02$ & $6.44 \mathrm{E}-03$ & $1.25 \mathrm{E}-03$ & $6.50 \mathrm{E}-04$ \\
\hline 18 & 35 & $5.87 \mathrm{E}-02$ & 5.31E-03 & $1.31 \mathrm{E}-03$ & $6.79 \mathrm{E}-04$ \\
\hline 19 & 40 & 4.41E-02 & $4.46 \mathrm{E}-03$ & $1.37 \mathrm{E}-03$ & $7.04 \mathrm{E}-04$ \\
\hline 20 & 45 & $3.41 \mathrm{E}-02$ & 3.81E-03 & $1.42 \mathrm{E}-03$ & $7.25 \mathrm{E}-04$ \\
\hline 21 & 50 & $2.70 \mathrm{E}-02$ & $3.30 \mathrm{E}-03$ & $1.47 \mathrm{E}-03$ & $7.43 \mathrm{E}-04$ \\
\hline 22 & 60 & $1.80 \mathrm{E}-02$ & $2.55 \mathrm{E}-03$ & $1.54 \mathrm{E}-03$ & $7.71 \mathrm{E}-04$ \\
\hline 23 & 70 & $1.26 \mathrm{E}-02$ & $2.04 \mathrm{E}-03$ & $1.60 \mathrm{E}-03$ & 7.94E-04 \\
\hline 24 & 80 & $9.23 \mathrm{E}-03$ & $1.66 \mathrm{E}-03$ & $1.65 \mathrm{E}-03$ & $8.12 \mathrm{E}-04$ \\
\hline 25 & 90 & $6.97 \mathrm{E}-03$ & $1.37 \mathrm{E}-03$ & $1.69 \mathrm{E}-03$ & 8.28E-04 \\
\hline 26 & 100 & $5.40 \mathrm{E}-03$ & $1.15 \mathrm{E}-03$ & $1.72 \mathrm{E}-03$ & 8.40E-04 \\
\hline 27 & 200 & 8.39E-04 & $2.95 \mathrm{E}-04$ & $1.92 \mathrm{E}-03$ & $9.00 \mathrm{E}-04$ \\
\hline 28 & 300 & $2.23 \mathrm{E}-04$ & $1.02 \mathrm{E}-04$ & $1.99 \mathrm{E}-03$ & 9.17E-04 \\
\hline 29 & 400 & $7.23 \mathrm{E}-05$ & $3.96 \mathrm{E}-05$ & $2.01 \mathrm{E}-03$ & $9.25 \mathrm{E}-04$ \\
\hline 30 & 500 & $2.59 \mathrm{E}-05$ & $1.65 \mathrm{E}-05$ & 2.03E-03 & $9.27 \mathrm{E}-04$ \\
\hline 31 & 600 & $9.88 \mathrm{E}-06$ & $7.32 \mathrm{E}-06$ & 2.03E-03 & $9.28 \mathrm{E}-04$ \\
\hline 32 & 700 & $3.95 \mathrm{E}-06$ & $3.54 \mathrm{E}-06$ & $2.03 \mathrm{E}-03$ & $9.29 \mathrm{E}-04$ \\
\hline 33 & 800 & $1.64 \mathrm{E}-06$ & $1.94 \mathrm{E}-06$ & $2.03 E-03$ & $9.29 \mathrm{E}-04$ \\
\hline 34 & 900 & $7.06 \mathrm{E}-07$ & $1.25 \mathrm{E}-06$ & $2.04 \mathrm{E}-03$ & $9.29 \mathrm{E}-04$ \\
\hline 35 & 1000 & $3.14 \mathrm{E}-07$ & $9.78 \mathrm{E}-07$ & $2.04 \mathrm{E}-03$ & $9.29 \mathrm{E}-04$ \\
\hline
\end{tabular}

a It is assumed that the fraction of the gamma dose $\left(f_{g}\right)$ is equal to 0.83 , that the fraction of the neutron dose $\left(f_{n}\right)$ is equal to 0.17 , and that the shielding factor is equal to 1 . The dose rate is assumed to be the regulatory limit, that is, $10 \mathrm{mrem} / \mathrm{h}$ at $2 \mathrm{~m}$ from the surface of a GA-4 truck cask.

b The dose information contains $\dot{\mathrm{D}}=$ dose rate (Equation 2.1 ), $\mathrm{D}=$ dose from passing vehicle (Equation 2.8), $D_{p s}=$ population dose at stops (Equation 2.6) for population density of 1 person $/ \mathrm{km}^{2}$, and $D_{\text {off }}=$ off-link population dose (Equation 2.12) for population density of 1 person $/ \mathrm{km}^{2}$ for a distance of $1 \mathrm{~km}$ from 30 to $1,000 \mathrm{~m}$ on one side of the route. The vehicle speed (V) is assumed to be $1 \mathrm{~km} / \mathrm{h}$. 
TABLE G.6 Default Route Values for Truck Transportation

\begin{tabular}{|c|c|c|c|c|c|c|}
\hline Road Type & $\begin{array}{c}\text { Population } \\
\text { Zone }\end{array}$ & $\begin{array}{c}\text { Vehicle Speed } \\
\text { [SPEED] } \\
(\mathrm{km} / \mathrm{h}) \\
\end{array}$ & $\begin{array}{c}\text { Lane Width } \\
\text { [RDWTH] } \\
\text { (m) }\end{array}$ & $\begin{array}{c}\text { Number of } \\
\text { Lanes in One } \\
\text { Direction } \\
\text { [NUMLANES] }\end{array}$ & $\begin{array}{c}\text { Median Width } \\
\text { [WDTHMED] } \\
\text { (m) }\end{array}$ & $\begin{array}{c}\text { One-Way } \\
\text { Traffic Density } \\
\text { [TRAF_DEN] } \\
\text { (Vehicles/h) }\end{array}$ \\
\hline \multirow[t]{3}{*}{ Interstate } & Rural & 88 & 3.7 & 2 & 15 & 235 \\
\hline & Suburban & 88 & 3.7 & 2 & 5 & 390 \\
\hline & Urban & 88 & 3.7 & 3 & 3 & 930 \\
\hline \multirow[t]{3}{*}{ Primary } & Rural & 80 & 3.7 & 1 & 0 & 235 \\
\hline & Suburban & 64 & 3.7 & 1 & 0 & 390 \\
\hline & Urban & 48 & 3.7 & 2 & 0 & 930 \\
\hline \multirow[t]{3}{*}{ Secondary } & Rural & 72 & 3.4 & 1 & 0 & 235 \\
\hline & Suburban & 48 & 3.7 & 1 & 0 & 390 \\
\hline & Urban & 40 & 3.7 & 1 & 0 & 930 \\
\hline
\end{tabular}

TABLE G.7 Default Route Values for Rail Transportation

\begin{tabular}{|c|c|c|c|}
\hline $\begin{array}{c}\text { Population } \\
\text { Zone } \\
\end{array}$ & $\begin{array}{c}\text { Vehicle Speed } \\
\text { [SPEED] } \\
(\mathrm{km} / \mathrm{h})\end{array}$ & $\begin{array}{c}\text { Number of } \\
\text { Parallel Tracks } \\
\text { [NUMLANES] }\end{array}$ & $\begin{array}{c}\text { One-Way } \\
\text { Traffic Density } \\
\text { [TRAF_DEN] } \\
\text { (Vehicles/h) }\end{array}$ \\
\hline Rural & 64 & 1 & 1 \\
\hline Suburban & 40 & 1 & 5 \\
\hline Urban & 24 & 1 & 5 \\
\hline
\end{tabular}


transport, SNF shipments are required to use the interstate highway system as much as possible, with some restrictions. Over $90 \%$ of the interstate highway system consists of four-lane highways (FHWA 1991) two lanes in each direction (NUMLANES default). The majority of all roads in the United States have lanes that are $12 \mathrm{ft}(3.7 \mathrm{~m})$ wide; a few have widths of 9,10 , or $11 \mathrm{ft}(2.7,3.0$, or $3.4 \mathrm{~m})$. Median widths vary with population zone and road type and are typically smaller in urban areas where space is at a premium; also, speeds in urban areas may be lower than in rural areas. For rail transport, the route type designations of Total Rail and Mainline Only are used solely for determining default accident rates (Section G.2.6.1). Total Rail includes accidents that occur in rail yards, while Mainline Only excludes rail yard accidents. Track width is not useful for determining the potential location of receptors in a passing railcar for rail transport. A typical railcar width of $3 \mathrm{~m}$ (AAR 1974) is used as the rail analogue to the lane width in on-link dose calculations.

\section{G.2.5 Radionuclide Inventory}

Depending on the selection in the Inventory Options box in the RISKIND main window, the Inventory Data button on the RISKIND main screen brings up spent fuel parameters (Figure G.15) or a user list of radionuclides and amounts (Figure G.16). The old version of RISKIND had inventories available for commercial BWR or PWR spent fuel. RISKIND, Version 1, maintains this option and also provides for a user-defined inventory.

\section{G.2.5.1 SNF Inventory}

The SNF Inventory window (Figure G.15) provides the input parameters used in RISKIND for characterizing the radionuclide inventory for a SNF shipment. Appendix A contains the SNF database description.

Spent Fuel Specifications - Spent fuel is characterized according to its type (RTYPE), BWR or PWR; the burnup (BURNUP), which is a measure of the amount of energy obtained from the fuel; its cooling time (TFUEL), which is the length of time since the fuel has been removed from the reactor; and the amount of uranium initially present (UMT). The majority of SNF assemblies discharged annually from reactors have a burnup near the default value of 35,000 MWd/MTIHM (EIA 1995). Burnups greater than 40,000 and 60,000 MWd/MTIHM for BWR and PWR fuel, respectively, are rare. For cooling times, as of the end of 1993, approximately $40 \%$ of BWR spent fuel and $50 \%$ of PWR spent fuel in storage were discharged prior to 1986 [EIA 1995]. Shipping casks are licensed by the NRC with restrictions on fuel burnup and cooling time. Most casks are not licensed to ship fuel that has a cooling time less than one year (NRC 1994a). 


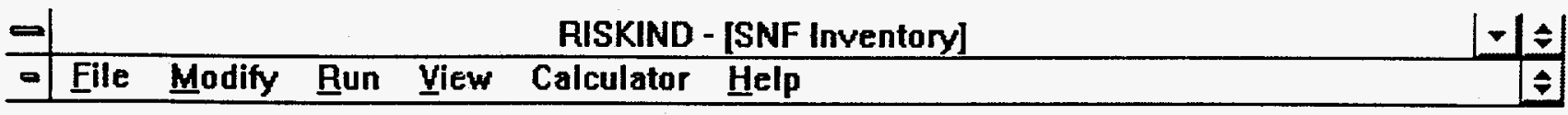

$\left[\begin{array}{ll|}\text { Spent Fuel Specification } & \text { O BWR } \\ \text { Reactor Type (RTYPE) } & \text { O PWR } \\ \text { Reactor Fuel Burnup (BURNUP) } & 35000 \\ \text { Spent Fuel Cooling Time (TFUEL] } & 10 \\ \text { Total Uranium in Cask (UMT) } & \text { yr } \\ 8.89 & \begin{array}{l}\text { Metric } \\ \text { Ton Use Transport Hode Hodal Study }\end{array} \\ \hline\end{array}\right.$

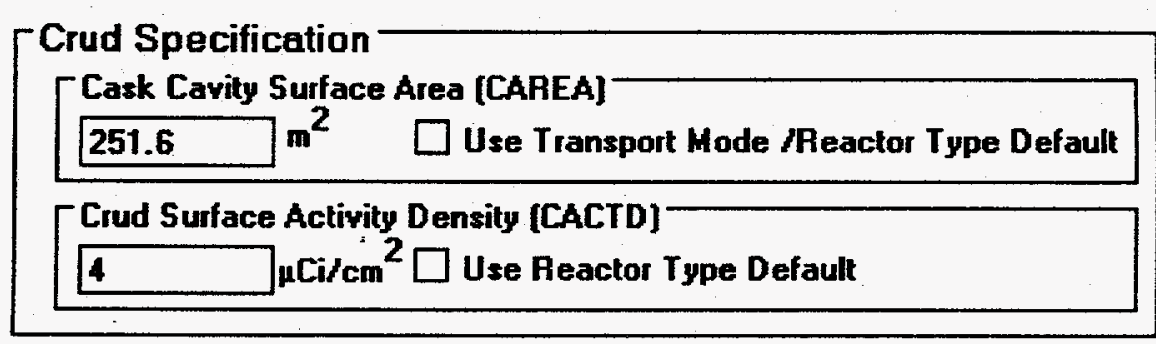

\begin{tabular}{ll|}
$\begin{array}{l}\text { Other } \\
\text { Cask Label (TYPCSK) } \\
\text { Hazard Limit (HZLM) }\end{array}$ & Modal Rail \\
\hline
\end{tabular}

DaK

Cancel

FIGURE G.15 Spent Nuclear Fuel Inventory Window

A typical fuel assembly contains approximately 0.45 (PWR) or 0.20 (BWR) metric tons of uranium (MTU) [EIA 1995]. The total amount of uranium in the shipping cask is the amount per assembly multiplied by the number of assemblies in the cask. Table G.4 contains information on the amount of uranium in a number of different cask types. The default value for UMT is taken from the NRC modal study (LLNL 1987) for the given transportation mode if the default box is checked.

Crud Specifications - In RISKIND, the amount of radioactive material available for release from a SNF shipping cask is considered to be from two sources. The first is the SNF itself, as discussed above, and the second is the crud material, which primarily consists of reactor coolant corrosion products that have deposited on the fuel rods and assemblies. Crud contains mostly neutron-activated nuclides and may also contain fissile materials and fission products. During shipment, crud may spall (break away) from the rods, become airborne in the cask cavity, and be released to the environment should a leak path develop in the cask containment system. The spalling can be caused by impact, vibration, abrasion, or thermal changes. The amount of spalled crud that may be released depends on the crud's adhesion to the fuel rods and assemblies 
and its particle size distribution. The amount of crud plated on the spent fuel varies considerably and depends on plant operating conditions and the water chemistry of the reactor and storage pool. The amount of crud material in a cask and the fraction that could be spalled from the rods and assemblies during an accident are estimated on the basis of the method described in a recent Sandia National Laboratories report (Sandoval et al. 1991). The approach used is discussed further in Appendix D, which also contains representative internal cask surface areas and bounding case activity densities. The activity estimated to be in the crud is assumed to be from cobalt- 60 and is incorporated in the estimated SNF inventory listed in the RISKIND output.

Other - Other input parameters for SNF inventories are the user-defined label (TYPCSK) and the hazard limit (HZLM). The hazard limit is a radionuclide selection criterion applied to three pathways to reduce the number of radionuclides being considered. Its application is discussed in Appendix C. The radionuclides that are estimated to cause approximately $99 \%$ of the potential risk are selected when HZLM $=0.01$, the default value. Setting the hazard limit to 0 selects all radionuclides.

\section{G.2.5.2 User-Defined Inventory}

The User-Defined Inventory window (Figure G.16) provides the necessary input for defining a custom radionuclide inventory, that is, an inventory for a nonstandard SNF shipment or other type of radioactive material shipment. As was the case for the SNF inventory window discussed above, inputs are provided for a user-defined label and the hazard limit.

RISKIND currently contains a database of 211 radionuclides. Up to 100 radionuclides may be selected for a single analysis. The radionuclides presently selected for an analysis appear with their specified inventory amount and their radionuclide type (category) in the Inventory box. RISKIND recognizes five radionuclide types, which are described in Section G.2.6.

The addition of a radionuclide from the list is accomplished by selecting the desired radionuclide in the Radionuclide droplist box, specifying the appropriate inventory amount in the Amount box, and selecting the radionuclide's type in the Nuclide Type box if the default category is not appropriate for the current application. By pressing the Enter button, the radionuclide is added to the inventory list.

The amount or type of a radionuclide already entered can be edited by selecting the radionuclide in the Inventory list. The radionuclide will be removed from the list and placed in the Edit Inventory box. The radionuclide is then returned to the list, after the appropriate corrections have been made, by pressing the Enter button in the Edit Inventory box. Removal of the item from the list is accomplished according to the same procedure used to get the radionuclide into the Edit Inventory box. A radionuclide's removal from the list is permanent unless it is re-entered from the Edit Inventory box by using the Enter button. 
User Defined Inventory

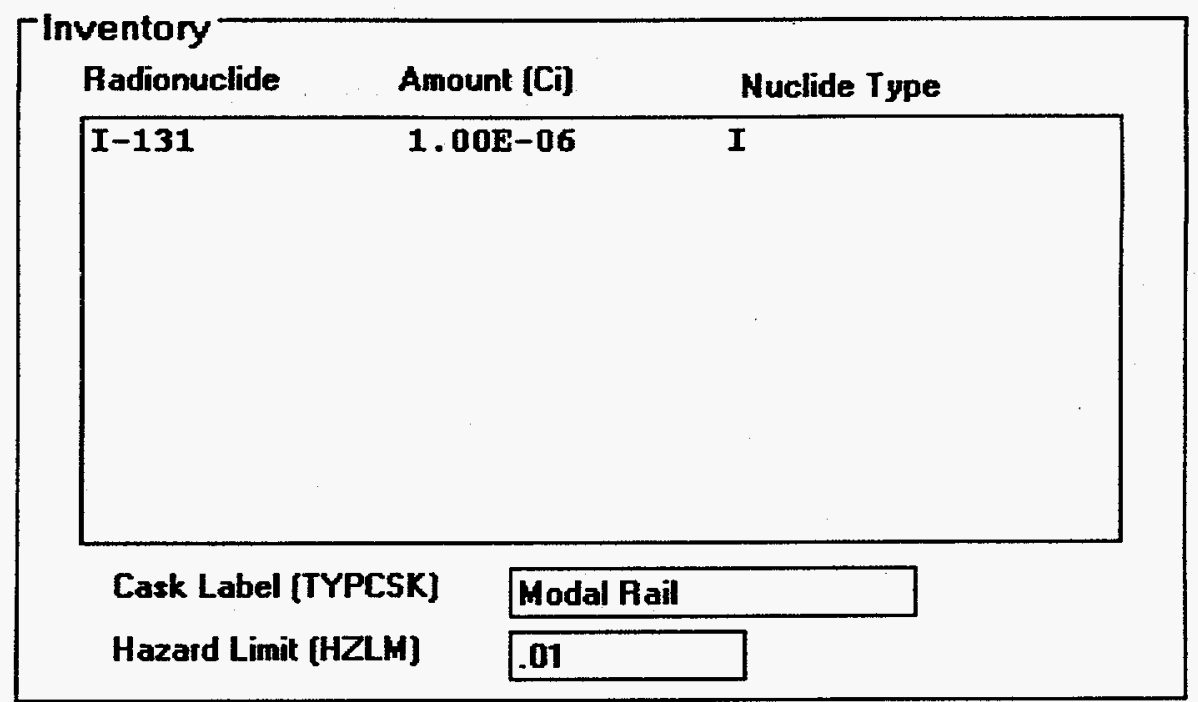

\begin{tabular}{|c|c|c|c|}
$\begin{array}{c}\text { Edit Inventory } \\
\text { Radionuclide }\end{array}$ & \multicolumn{2}{c|}{ Amount (Ci) } \\
\hline AC-225 & Nuclide Type \\
\hline & Enter \\
\hline
\end{tabular}

ㅁK

Cancel

FIGURE G.16 User-Defined Inventory Window

\section{G.2.6 Accident Parameters}

Twenty accident response regions constitute the default in RISKIND and correspond to the regions defined in the NRC modal study (LLNL 1987). Stammer et al. (1990) have characterized accident events on the basis of actual or potential situations that result in levels of structural and thermal response, such that at least one event is defined for each of the 20 response regions. The NRC (Lahs 1987) has also provided the predicted cask response to a number of selected historical accident events.

In RISKIND, Version 1, the user is also able to define a custom set of regions (maximum of 20) and the associated input parameters to suit the analysis at hand. The Accident Scenarios box in the main RISKIND window allows the user to choose among defining the accident parameters necessary for estimating the region to use; selecting a particular region to use for the analysis, such as for a consequence analysis; or selecting all regions for a risk analysis. 


\section{G.2.6.1 One or All Response Region(s)}

The Accident Data button in the main RISKIND window brings up the Accident window (Figure G.17) if one or all response regions is (are) selected.

Accident Specification - If risk calculations are to be performed, the accident rate input (ACTA) for the region under study is provided. The user should use the appropriate sitespecific value if it is available or may choose to use a default value based on the state, population zone, and road type for truck transport. For the rail transport mode, the default accident rates are dependent on state and route type. These accident rates are taken from Saricks and Kvitek (1994) and listed in Table G.8. The truck accident rates are for commercial inter-state carriers using heavy combination tractor-trailer rigs. The rail accident rates are for commercial freight trains.

The release height (HS) is the physical release height of escaped material above the ground from an accident. This value could be the cask height or road height, unless other information is available. The default value of $1 \mathrm{~m}$ is the approximate height above ground of a cask on a tractor-truck trailer or railcar.

RISKIND, Version 1, makes the dispersion coefficients and the number of concentration isopleths available to the user. The Pasquill-Gifford coefficients were developed from data on ground level releases (Eimutis and Konicek 1972); the Briggs coefficients are based on data from elevated releases. However, Briggs suggests that his coefficients are not appropriate for (effective) release heights much higher than $100 \mathrm{~m}$ (Briggs 1974). The original release of RISKIND automatically used the Pasquill-Gifford coefficients for releases less than $30 \mathrm{~m}$ in height and Briggs coefficients for releases greater than $30 \mathrm{~m}$ in height. Users can now select the original implementation on the basis of the effective release height or choose the desired coefficients to be used on the basis of the situation being analyzed.

Air and ground radionuclide concentration isopleths are calculated for population analyses. For individual analyses, air and ground concentrations are estimated at the actual location of each receptor. The number of isopleths droplist input (NISOPL) appears only for population runs. The difference in concentration between isopleths is maintained as the $\sqrt{10}$, starting at the location of maximum concentration. Thus, the estimated concentration drops by an order of magnitude every second isopleth while moving outward from the area of maximum concentration. A minimum of 4 and a maximum of 20 isopleths may be specified. Ten isopleths (five orders of magnitude) generally cover enough area to include any significant impact. A warning message will appear if isopleth NISOPL+1 would increase the impacts by more than $1 \%$. 


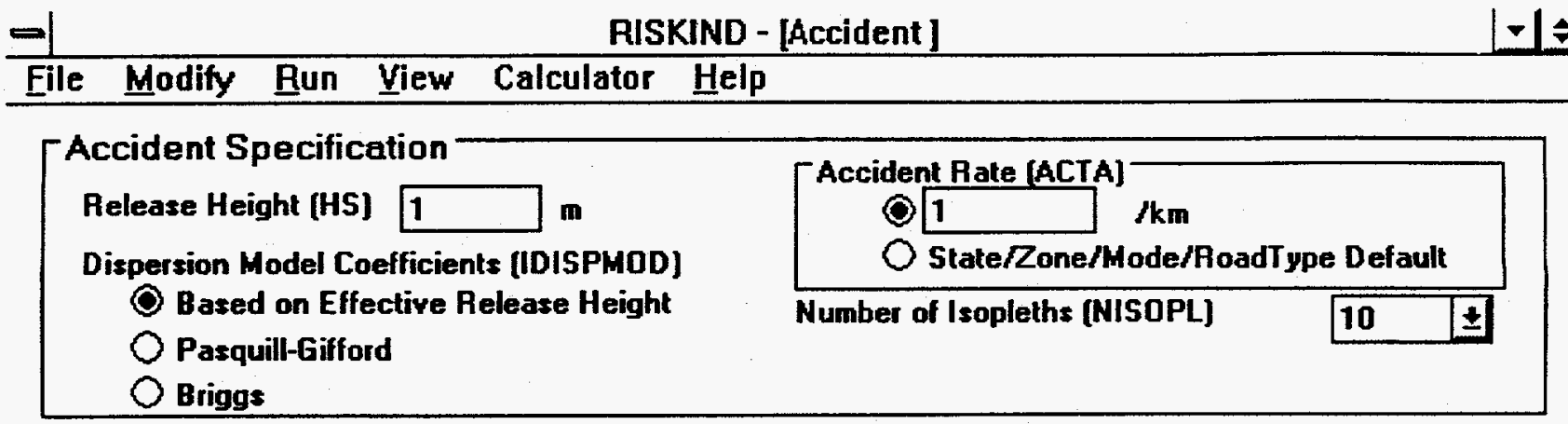

\begin{tabular}{|c|c|c|c|c|c|}
\hline \multicolumn{4}{|c|}{ - Release Parameters } & 20 & \\
\hline \multicolumn{3}{|c|}{$\begin{array}{c}\text { Nuclide Type } \\
\text { Dependent Parameters }\end{array}$} & $\begin{array}{l}\text { Region } \\
\text { Region Probability (FSEV) }\end{array}$ & 6 & \\
\hline \multirow{2}{*}{$\begin{array}{l}\text { Nuclide } \\
\text { Type } \\
\text { INUTYPEI }\end{array}$} & \multirow{2}{*}{$\begin{array}{l}\text { Fraction } \\
\text { Released } \\
\text { (FRELS) }\end{array}$} & \multirow{2}{*}{$\begin{array}{c}\text { Fraction } \\
\text { Dispersed } \\
\text { [FDISP] }\end{array}$} & Heat Release [HEATF] & 2000000 & \multirow[t]{7}{*}{ cal /s } \\
\hline & & & \multirow{2}{*}{$\begin{array}{c}\text { Shielding Factor [SEXT] } \\
\text { Gamma }\end{array}$} & & \\
\hline Particulate & 2.00E-06 & 1 & & 1 & \\
\hline Bu & $2.70 \mathrm{E}-05$ & 1 & \multirow{2}{*}{$\begin{array}{l}\text { Neutron } \\
\text { Fraction of Shipment Content } \\
\text { Failed (FAlLS) }\end{array}$} & $\mathbf{1}$ & \\
\hline Cs & $2.00 E-04$ & 1 & & .1 & \\
\hline 1 & $2.50 \mathrm{E}-03$ & 1 & \multirow{2}{*}{$\begin{array}{l}\text { Spallation Fraction (FSPAL) } \\
\text { Crud Release (FRCRUD) }\end{array}$} & 1 & \\
\hline Gas & 3.30E-01 & 1 & & 1 & \\
\hline & & $\underline{\mathbf{O K}}$ & Cancel & & \\
\hline
\end{tabular}

FIGURE G.17 Accident Window

Release Parameters - The Release Parameters box contains the relevant input for defining an accident response region, that is, the conditional probability and the released and dispersed fractions of the SNF and crud inventories. The fraction released (FRELS) and dispersed (FDISP) of the SNF inventory are given for five radionuclide types with different physical characteristics: particulates, vapors (ruthenium, cesium, and iodine), and gases (LLNL 1987). Because this categorization may not be appropriate for a shipment inventory other than SNF, RISKIND, Version 1, allows the user to redefine the radionuclide type labels (NUTYPE) as well as the values for release and dispersion. A maximum of five radionuclide types is allowed. The user may also switch the type for a particular radionuclide in the User-Defined Inventory window (Section G.2.5.2), and, therefore, account for different speciations of the same radionuclide under different conditions. The radionuclide categorization also affects the deposition velocity for individual calculations (Section G.2.7.1). 
TABLE G.8 Default Accident Rates for Truck and Rail Transportation

\begin{tabular}{|c|c|c|c|c|c|c|}
\hline \multirow[b]{3}{*}{ State } & \multicolumn{4}{|c|}{ Truck (accidents/shipment-km) } & \multirow{2}{*}{\multicolumn{2}{|c|}{ Rail (accidents/railcar-km) }} \\
\hline & \multicolumn{2}{|c|}{ Interstate } & \multirow[b]{2}{*}{ Primary } & \multirow[b]{2}{*}{ Secondary } & & \\
\hline & Rural & Suburb/Urban & & & Total & Mainline Only \\
\hline AL & $1.26 \mathrm{E}-07$ & $4.68 \mathrm{E}-07$ & $5.16 \mathrm{E}-07$ & $3.96 \mathrm{E}-07$ & $4.80 \mathrm{E}-08$ & 2.75E-08 \\
\hline $\mathbf{A Z}$ & $1.60 \mathrm{E}-07$ & 2.71E-07 & 2.12E-07 & $1.45 \mathrm{E}-07$ & $1.75 \mathrm{E}-08$ & $1.30 \mathrm{E}-08$ \\
\hline $\mathrm{AR}$ & $1.73 \mathrm{E}-07$ & 4.82E-07 & 4.69E-07 & $6.84 \mathrm{E}-07$ & $6.78 \mathrm{E}-08$ & 3.54E-08 \\
\hline $\mathrm{CA}$ & $1.64 \mathrm{E}-07$ & $1.92 \mathrm{E}-07$ & $1.15 \mathrm{E}-07$ & $2.22 \mathrm{E}-07$ & $5.10 \mathrm{E}-08$ & 2.51E-08 \\
\hline $\mathrm{CO}$ & $2.76 \mathrm{E}-07$ & $6.28 \mathrm{E}-07$ & 4.11E-07 & 4.42E-07 & $1.73 \mathrm{E}-08$ & $1.02 \mathrm{E}-08$ \\
\hline CT & $4.60 \mathrm{E}-07$ & $2.67 \mathrm{E}-07$ & $2.56 \mathrm{E}-07$ & $9.09 \mathrm{E}-07$ & 2.83E-07 & $1.01 \mathrm{E}-07$ \\
\hline $\mathrm{DE}$ & $0.00 \mathrm{E}+00$ & $2.56 \mathrm{E}-07$ & 7.35E-07 & $4.81 \mathrm{E}-07$ & $1.77 \mathrm{E}-07$ & $1.11 \mathrm{E}-07$ \\
\hline FL & 1.21E-07 & $2.25 \mathrm{E}-07$ & 3.73E-07 & $6.33 \mathrm{E}-07$ & $4.02 \mathrm{E}-08$ & 2.21E-08 \\
\hline GA & $1.65 \mathrm{E}-07$ & $4.87 \mathrm{E}-07$ & $6.15 \mathrm{E}-07$ & $4.04 \mathrm{E}-07$ & $6.44 \mathrm{E}-08$ & $2.84 \mathrm{E}-08$ \\
\hline ID & $2.30 \mathrm{E}-07$ & $1.73 \mathrm{E}-07$ & 4.93E-07 & $2.29 \mathrm{E}-07$ & 7.01E-08 & 4.14E-08 \\
\hline IL & $1.76 \mathrm{E}-07$ & $8.75 \mathrm{E}-07$ & $6.40 \mathrm{E}-07$ & $1.78 \mathrm{E}-07$ & $1.07 \mathrm{E}-07$ & $2.97 \mathrm{E}-08$ \\
\hline IN & $1.92 \mathrm{E}-07$ & $4.58 \mathrm{E}-07$ & 4.72E-07 & 2.80E-07 & $4.64 \mathrm{E}-08$ & $1.93 \mathrm{E}-08$ \\
\hline IA & $1.78 \mathrm{E}-07$ & $3.54 \mathrm{E}-07$ & 4.03E-07 & $1.24 \mathrm{E}-07$ & $1.47 \mathrm{E}-07$ & $7.16 \mathrm{E}-08$ \\
\hline KS & 2.04E-07 & $4.48 \mathrm{E}-07$ & 5.11E-07 & $1.38 \mathrm{E}-07$ & $3.61 \mathrm{E}-08$ & $1.75 \mathrm{E}-08$ \\
\hline $\mathrm{KY}$ & $1.46 \mathrm{E}-07$ & $5.13 \mathrm{E}-07$ & 5.74E-07 & $8.80 \mathrm{E}-07$ & $4.48 \mathrm{E}-08$ & $2.44 \mathrm{E}-08$ \\
\hline LA & $1.30 \mathrm{E}-07$ & $3.54 \mathrm{E}-07$ & $3.53 \mathrm{E}-07$ & $2.39 \mathrm{E}-07$ & $1.24 \mathrm{E}-07$ & 4.28E-08 \\
\hline ME & $2.44 \mathrm{E}-07$ & $9.03 \mathrm{E}-07$ & 5.44E-07 & $2.28 \mathrm{E}-07$ & $3.78 \mathrm{E}-07$ & $1.85 \mathrm{E}-07$ \\
\hline $\mathrm{MD}$ & $3.95 E-07$ & $3.08 \mathrm{E}-07$ & $3.56 \mathrm{E}-07$ & $1.24 \mathrm{E}-06$ & $5.62 \mathrm{E}-08$ & $2.58 \mathrm{E}-08$ \\
\hline MA & $6.47 \mathrm{E}-07$ & $1.42 \mathrm{E}-07$ & $3.43 \mathrm{E}-07$ & $4.61 \mathrm{E}-06$ & $1.16 \mathrm{E}-07$ & $4.97 \mathrm{E}-08$ \\
\hline MI & $1.59 \mathrm{E}-07$ & $3.16 \mathrm{E}-07$ & 2.68E-07 & $8.10 \mathrm{E}-08$ & $1.65 \mathrm{E}-07$ & $7.19 \mathrm{E}-08$ \\
\hline $\mathrm{MN}$ & $2.06 \mathrm{E}-07$ & $2.66 \mathrm{E}-07$ & 4.19E-07 & $2.16 \mathrm{E}-07$ & $8.48 \mathrm{E}-08$ & $3.16 \mathrm{E}-08$ \\
\hline MS & 1.19E-07 & $2.01 \mathrm{E}-07$ & $4.48 \mathrm{E}-07$ & $6.50 \mathrm{E}-08$ & $1.15 \mathrm{E}-07$ & 8.51E-08 \\
\hline $\mathrm{MO}$ & $1.78 \mathrm{E}-07$ & $5.18 \mathrm{E}-07$ & $5.36 \mathrm{E}-07$ & $2.49 \mathrm{E}-07$ & $5.28 \mathrm{E}-08$ & $2.56 \mathrm{E}-08$ \\
\hline MT & 2.52E-07 & $1.00 \mathrm{E}-06$ & 5.38E-07 & $1.02 \mathrm{E}-07$ & $1.73 \mathrm{E}-08$ & $1.10 \mathrm{E}-08$ \\
\hline NE & $1.77 \mathrm{E}-07$ & $6.97 \mathrm{E}-07$ & $3.62 \mathrm{E}-07$ & $9.90 \mathrm{E}-08$ & 4.63E-08 & $2.56 \mathrm{E}-08$ \\
\hline NV & $1.57 \mathrm{E}-07$ & $6.33 E-07$ & 4.35E-07 & 3.17E-07 & $3.23 \mathrm{E}-08$ & 2.19E-08 \\
\hline NH & $1.39 \mathrm{E}-07$ & $2.20 \mathrm{E}-08$ & $4.36 \mathrm{E}-07$ & 3.33E-07 & $2.15 \mathrm{E}-07$ & $1.72 \mathrm{E}-07$ \\
\hline NJ & $7.65 \mathrm{E}-07$ & 2.77E-07 & $6.80 \mathrm{E}-07$ & $9.69 \mathrm{E}-07$ & $1.24 \mathrm{E}-07$ & $4.82 \mathrm{E}-08$ \\
\hline $\mathrm{NM}$ & $1.92 \mathrm{E}-07$ & $9.64 \mathrm{E}-07$ & 4.77E-07 & $1.22 \mathrm{E}-06$ & $9.40 \mathrm{E}-09$ & $6.60 \mathrm{E}-09$ \\
\hline NY & 2.93E-07 & $5.69 \mathrm{E}-07$ & $3.16 \mathrm{E}-07$ & $9.48 \mathrm{E}-07$ & 8.32E-08 & 4.30E-08 \\
\hline $\mathrm{NC}$ & $2.28 \mathrm{E}-07$ & $5.92 \mathrm{E}-07$ & 5.17E-07 & 6.37E-07 & $5.70 \mathrm{E}-08$ & 2.27E-08 \\
\hline ND & $9.90 \mathrm{E}-08$ & $4.40 \mathrm{E}-07$ & $1.99 \mathrm{E}-07$ & $4.00 \mathrm{E}-08$ & $2.41 \mathrm{E}-08$ & $1.80 \mathrm{E}-08$ \\
\hline $\mathrm{OH}$ & $2.27 \mathrm{E}-07$ & $3.16 \mathrm{E}-07$ & $4.42 \mathrm{E}-07$ & $1.10 \mathrm{E}-06$ & 4.73E-08 & 2.12E-08 \\
\hline OK & $1.47 \mathrm{E}-07$ & $3.76 \mathrm{E}-07$ & $3.61 \mathrm{E}-07$ & $1.73 \mathrm{E}-07$ & $4.66 \mathrm{E}-08$ & 2.72E-08 \\
\hline OR & $2.20 \mathrm{E}-07$ & $3.99 \mathrm{E}-07$ & 4.17E-07 & 1.63E-07 & $1.25 \mathrm{E}-07$ & $5.77 \mathrm{E}-08$ \\
\hline PA & $3.60 \mathrm{E}-07$ & $3.02 \mathrm{E}-07$ & $7.21 \mathrm{E}-07$ & 7.92E-07 & $4.38 \mathrm{E}-08$ & 2.69E-08 \\
\hline RI & $1.98 \mathrm{E}-07$ & $2.27 \mathrm{E}-07$ & $1.37 \mathrm{E}-07$ & $1.67 \mathrm{E}-06$ & $1.05 \mathrm{E}-06$ & $0.00 \mathrm{E}+00$ \\
\hline SC & $1.83 \mathrm{E}-07$ & $3.13 \mathrm{E}-07$ & $6.27 \mathrm{E}-07$ & $2.27 \mathrm{E}-07$ & 5.11E-08 & $3.31 \mathrm{E}-08$ \\
\hline $\mathrm{SD}$ & $2.09 \mathrm{E}-07$ & 8.57E-07 & $3.94 \mathrm{E}-07$ & $1.49 \mathrm{E}-07$ & $1.02 \mathrm{E}-07$ & $9.09 \mathrm{E}-08$ \\
\hline TN & $1.48 \mathrm{E}-07$ & 7.97E-07 & $5.56 \mathrm{E}-07$ & $6.26 \mathrm{E}-07$ & 5.59E-08 & $1.88 \mathrm{E}-08$ \\
\hline TX & $1.56 \mathrm{E}-07$ & 2.74E-07 & 2.78E-07 & $1.09 \mathrm{E}-07$ & $7.12 \mathrm{E}-08$ & $3.16 \mathrm{E}-08$ \\
\hline UT & $2.41 \mathrm{E}-07$ & $2.52 \mathrm{E}-07$ & $3.70 \mathrm{E}-07$ & $5.00 \mathrm{E}-07$ & $5.78 \mathrm{E}-08$ & 2.31E-08 \\
\hline VT & $1.38 \mathrm{E}-07$ & $0.00 \mathrm{E}+00$ & $6.30 \mathrm{E}-07$ & $6.80 \mathrm{E}-07$ & $1.52 \mathrm{E}-07$ & $1.16 \mathrm{E}-07$ \\
\hline VA & $2.54 \mathrm{E}-07$ & 2.63E-07 & 4.67E-07 & 5.03E-07 & $4.35 \mathrm{E}-08$ & $1.91 \mathrm{E}-08$ \\
\hline
\end{tabular}




\section{TABLE G.8 (Cont.)}

\begin{tabular}{|c|c|c|c|c|c|c|}
\hline \multirow[b]{3}{*}{ State } & \multicolumn{4}{|c|}{ Truck (accidents/shipment-km) } & & \\
\hline & \multicolumn{2}{|c|}{ Interstate } & \multirow[b]{2}{*}{ Primary } & \multirow[b]{2}{*}{ Secondary } & \multicolumn{2}{|c|}{ Rail (accidents/railcar-km) } \\
\hline & Rural & Suburb/Urban & & & Total & Mainline Only \\
\hline WA & $2.50 \mathrm{E}-07$ & 1.61E-07 & $2.62 \mathrm{E}-07$ & $7.30 \mathrm{E}-08$ & $3.49 \mathrm{E}-08$ & $1.44 \mathrm{E}-08$ \\
\hline WV & 3.10E-07 & 2.95E-07 & $1.17 \mathrm{E}-06$ & $7.87 \mathrm{E}-07$ & $9.61 \mathrm{E}-08$ & 7.42E-08 \\
\hline WI & $1.74 \mathrm{E}-07$ & $5.29 \mathrm{E}-07$ & $2.80 \mathrm{E}-07$ & $3.24 \mathrm{E}-07$ & $1.65 \mathrm{E}-07$ & $7.66 \mathrm{E}-08$ \\
\hline WY & $3.42 \mathrm{E}-07$ & $2.98 \mathrm{E}-07$ & $3.41 \mathrm{E}-07$ & $3.70 \mathrm{E}-07$ & $3.10 \mathrm{E}-08$ & 1.97E-08 \\
\hline US & 2.03E-07 & $3.58 \mathrm{E}-07$ & $3.94 \mathrm{E}-07$ & $3.48 \mathrm{E}-07$ & $5.57 \mathrm{E}-08$ & $2.66 \mathrm{E}-08$ \\
\hline
\end{tabular}

Source: Saricks and Kvitek (1994).

The amount of inventory released to the atmosphere is characterized by how many rods fail; how much of the inventory in the failed rods is released to the cask cavity; and finally, how much of the released material in the cask cavity is dispersed to the environment through a compromised cask containment system. The fraction of the shipment content failed (FAIIS) is the fraction of failed spent fuel rods in a SNF cask. It can be used for the fraction of failed packages in a multiple package shipment of other radioactive materials. The default values are from the NRC modal study (LLNL 1987). The fraction released (FRELS) is the fraction of the SNF inventory released from failed rods to the cask cavity. However, it can be used as the fraction released from the shipping package for other radioactive material shipments. Default values are from the NRC modal study (LLNL 1987). The dispersed fraction (FDISP) is the fraction of the released SNF inventory dispersed to the atmosphere as a respirable aerosol for the given accident response region. Default values are based on the NRC modal study (LLNL 1987).

The number of accident regions input (NSV) is only available if the risk over all regions was selected in the Accident Scenarios box in the main window. The default value taken from the NRC modal study is 20 . Up to 20 accident regions may be defined for a custom set of accident severity categories, such as the 8 defined in NUREG-0170 (NRC 1977b). The conditional probability for a given accident response region (FSEV) is only available if a risk analysis was specified in the main RISKIND window. These default values were also taken from the NRC modal study (LLNL 1987).

The heat flux generated for an accident response region (HEATF) is used to determine the effective release height of the radioactive cloud from buoyant plume rise (Section 3.3.1.1.1). The default values are somewhat subjective and will vary with the particular aspects of an accident; especially on wind speed, the amount of diesel fuel or other combustible available for combustion, and whether or not fuel tanks were ruptured. Accidents not involving fire were given a small default heat flux $(500 \mathrm{cal} / \mathrm{s})$ to account for the thermal properties of the SNF 
assemblies. For perspective, a $2 \times 10^{6} \mathrm{cal} / \mathrm{s}$ heat flux corresponds to a burn rate of approximately $1 \mathrm{gal} / \mathrm{min}$ on the basis of a heat content of $1.07 \times 10^{-4} \mathrm{cal} / \mathrm{g}$ and a density of $11.3 \mathrm{~kg} / \mathrm{gal}$ (CRC 1970) for diesel fuel.

If a SNF inventory was specified, input for the shielding factor (SEXT), spallation fraction (FSPAL), and crud release (FRCRUD) are provided. The shielding factor is the multiple increase of the original cask external dose rate due to loss of shielding in an accident such as lead slump in some casks as a result of fire. The default values are set to 1 for lack of data. This input option is made available for situations in which some information is available on the external dose rate following an accident. The spallation fraction and crud release input are discussed in Appendix. D. The default values are taken from Sandoval et al. (1991).

\section{G.2.6.2 User-Defined Scenario}

The Defined Accident Scenario window (Figure G.18) is accessed through the Accident Data button on the main window, if a user-defined scenario is selected. This window provides the necessary input for determining the accident response region to which an accident scenario belongs. The rationale used in RISKIND for this determination is taken from the NRC modal study (LLNL 1987) and is provided in Appendix E.

Impact Parameters - The input variables required are the cask impact velocity (VCASK), impact angle (ALPHA), orientation angle (BETA), and impact object hardness (IHARD) for the impact parameters. The default cask velocity is set to $65 \mathrm{~km} / \mathrm{h}$ because approximately half of all truck accidents occur in the $51-84 \mathrm{~km} / \mathrm{h}$ range, and $32 \%$ occur within approximately the same range for rail (NRC 1974). The NRC modal study also limited this value to a maximum of $241 \mathrm{~km} / \mathrm{h}(150 \mathrm{mph})$, since it was argued that greater speeds for SNF shipments are not credible. Default values of $90^{\circ}$ for the impact and orientation angles (head-on collision) and an unyielding value for impact object hardness were chosen to provide the most conservative results. The impact object hardness values are representative of water (very soft), tillable soil (soft), hard soil/soft rock (medium), and hard rock (unyielding) (LLNL 1987).

Fire Parameters - Fire-related parameters include the flame temperature (TFLAME), fire duration (DFIRE), and fire location relative to the shipping cask (FLOCA). The default flame temperature was given a value of $1,350 \mathrm{~K}$, since approximately $70 \%$ of fires expected in transportation accidents will not achieve temperatures more than 1,350 K (LLNL 1987). Approximately $75-80 \%$ of expected truck/truck and truck/train accident fires and $75 \%$ of rail accident fires are expected to last 0.75 hours (the RISKIND default) or less (LLNL 1987). The default fire location is set to that for an engulfing fire $(0 \mathrm{~m})$.

When data input to the Defined Accident Scenario window is completed, clicking on the OK button will save this data internally and bring up the Scenario Category window (Figure G.19), which will display the accident response region selected on the basis of the above 


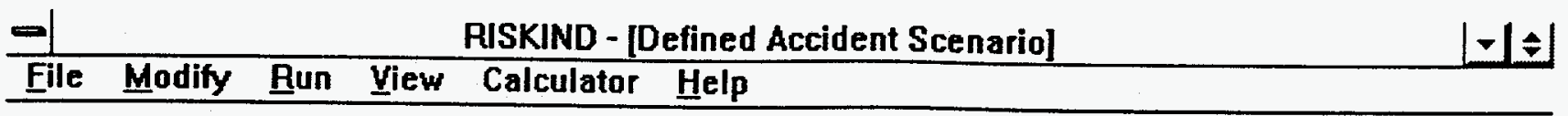

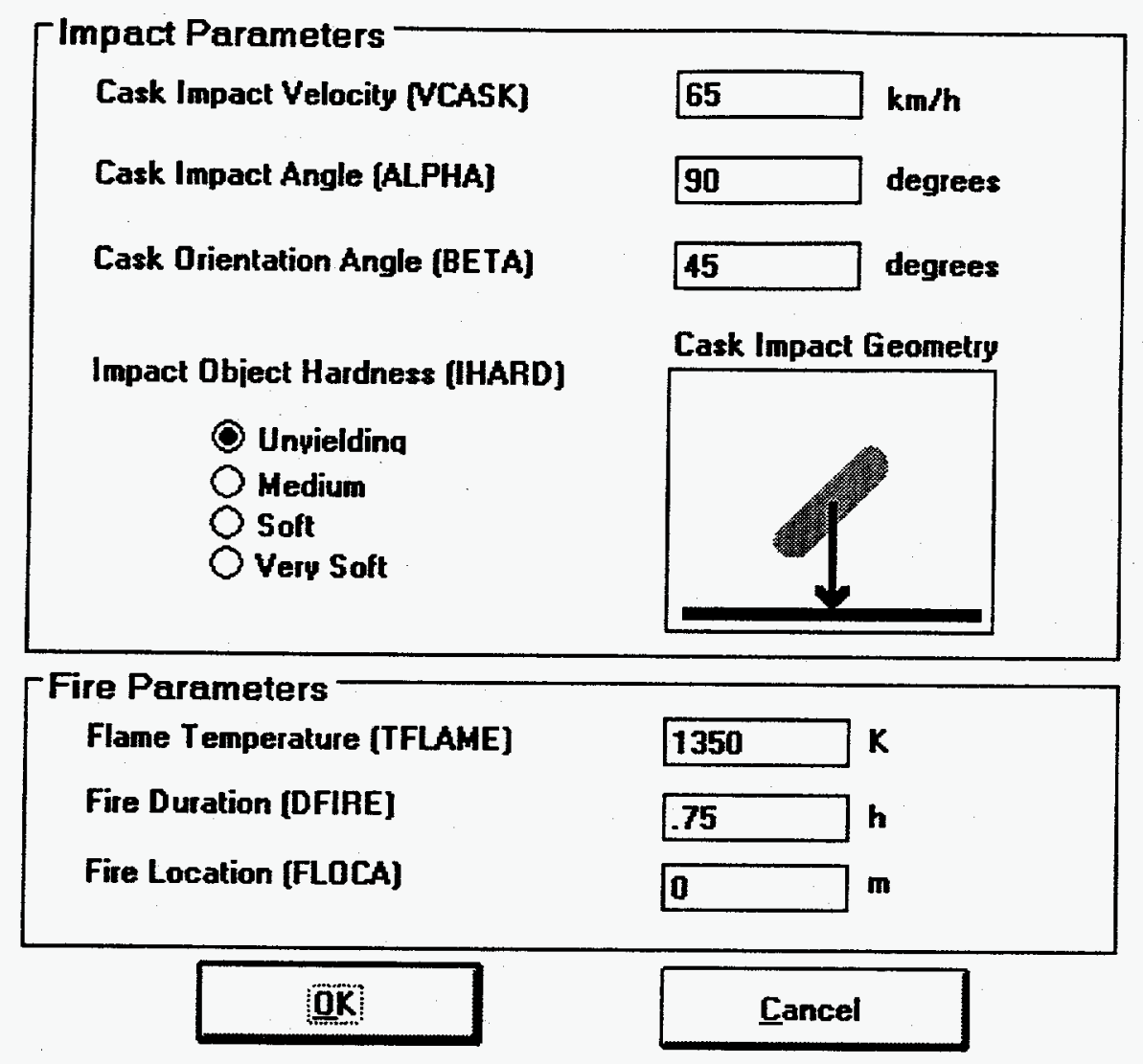

FIGURE G.18 Defined Accident Scenario Window

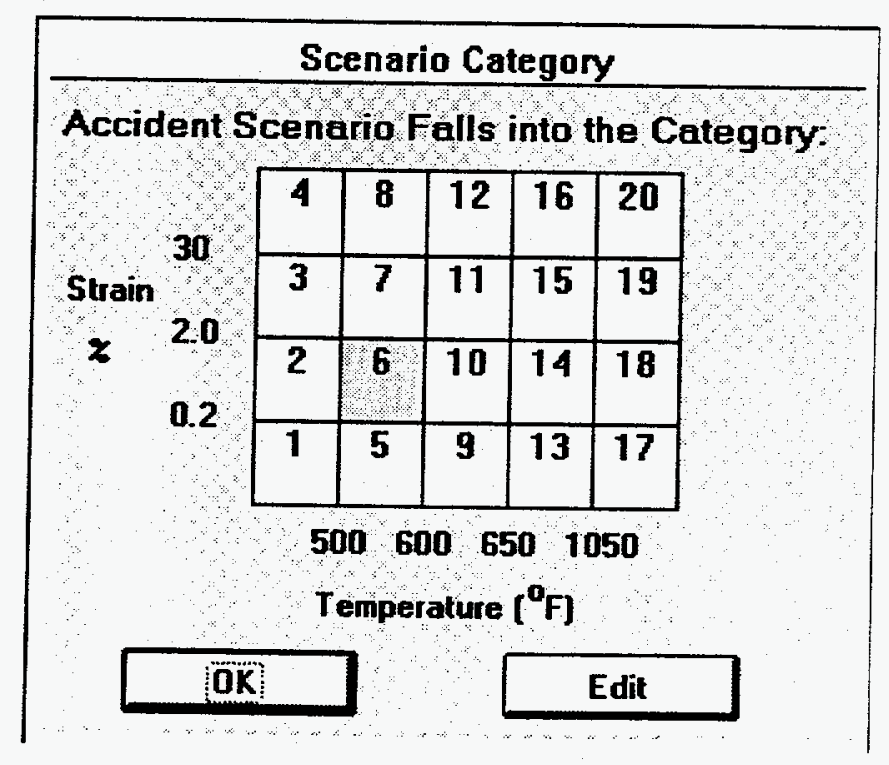

FIGURE G.19 Scenario Category Window 
user input. Pressing the OK button on the Scenario Category window puts the user in the Accident window, which has a button (Edit Accident Scenario) for returning to the Defined Accident Scenario window; the Edit button puts the user back into the Defined Accident Scenario window.

\section{G.2.7 Meteorological Parameters}

Calculations may be performed by using one set of weather conditions (i.e., one stability class and wind speed) for a consequence assessment, or calculations may be performed over all possible combinations of stability classes and wind speeds $(6 \times 6=36)$ for a probabilistic risk assessment.

\section{G.2.7.1 User-Defined Weather}

In the main RISKIND window, the User-Defined Weather selection in the Weather options box displays the Defined Meteorology window (Figure G.20), when the Met Data button is pressed.

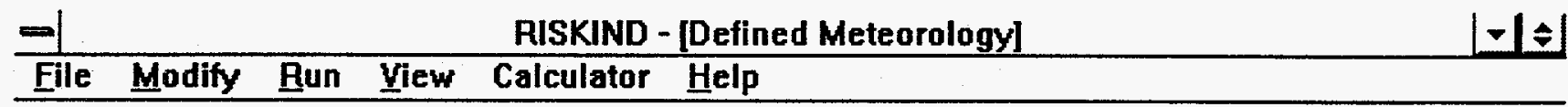

\begin{tabular}{|c|c|c|}
\hline \multicolumn{3}{|c|}{ Weather Parameters } \\
\hline Pasquill Stability Category (ITYPE) & $\mathbf{D}$ & \\
\hline Wind Speed at Anemometer [W/SM] & 4 & $\mathrm{~m} / \mathrm{s}$ \\
\hline Anemometer Height (ANH) & 10 & $\mathbf{m}$ \\
\hline Ambient Temperature [TABK] & 283 & $\mathbf{K}$ \\
\hline Atmospheric Mixing Height (DMIX) & 1000 & $\mathbf{m}$ \\
\hline Weather Condition Probability [METFREQ] & 1 & \\
\hline
\end{tabular}

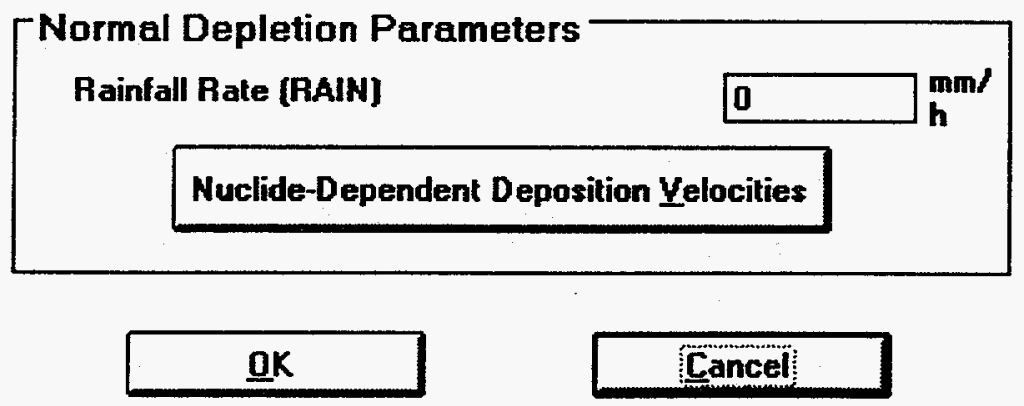

FIGURE G.20 Defined Meteorology Window 
Weather Parameters - The primary weather parameters required by the Gaussian puff dispersion model used in RISKIND are the Pasquill weather stability category (ITYPE) and the wind speed at the effective release height. The wind speed at the effective release height is estimated on the basis of wind speed (WSM) measured at a given anemometer height (ANH). The D stability category is the default in RISKIND since neutral stability classes are, on average, prevalent about $50 \%$ of the time across the United States (Doty et al. 1976). A default wind speed of $4 \mathrm{~m} / \mathrm{s}$ was selected because the $4.47 \mathrm{~m} / \mathrm{s}$ wind speed category in most STability ARray (STAR) data has the highest frequency of occurrence. A standard height for wind speed measurements is $10 \mathrm{~m}$ (NRC 1972).

The ambient outside temperature (TABK) is used for plume rise estimates and has a default value of $283 \mathrm{~K}$ (Parks 1992). The atmospheric mixing height (DMIX) is assumed to reflect the rising radioactive puff, if the puff reaches that height, causing a total vertical mixing condition of the puff between the ground and mixing height. The default value of $1,000 \mathrm{~m}$ is taken from Parks (1992). Depending on the time of day, season of the year, and location in the United States, the mixing height can range from tens of meters to greater than $4,000 \mathrm{~m}$ above ground level (Holzworth 1972). The probability of the weather condition occurring (METFREQ) as defined with the above parameters is only available when a risk analysis is selected in the main RISKIND window.

Normal Depletion Parameters - The radioactive cloud released during an accident is gradually depleted due to dry and wet deposition (Section 3.3.1.5.3). For dry deposition, the deposition velocity of each radionuclide determines how fast the radionuclide settles out of the passing radioactive cloud in depletion calculations and how much contamination is deposited on the ground. Many measurements of dry deposition velocity have been reported by McMahon and Dennison (1979) and Sehmel (1980). Values for particulates range over several orders of magnitude and depend on meteorological conditions, surface conditions, particle size, and nuclide types. Values will tend to be higher over some areas of farmland with taller crops, wooded areas, and suburban/urban areas. Table G.9 presents the deposition velocity range for various particulate radionuclides. Separate deposition velocities for the cesium, iodine, ruthenium, and particulate radionuclide types may be used in RISKIND for estimating individual receptor impacts.

Pressing the Nuclide-Dependent Deposition Velocities button brings up the window with the same name (Figure G.21), where the deposition velocities (VDEPNUC) may be input. For population impact calculations, only one deposition velocity is used; the input (VDEP) replaces the Nuclide-Dependent Deposition Velocities button on the Defined Meteorology window. The default for all deposition velocities, except for inert gases $(=0)$, is a conservative value of $0.01 \mathrm{~m} / \mathrm{s}$. As with all other input parameters in RISKIND, whenever possible, the user should use the best available data for the specific situation being analyzed and not rely on the default values provided with the program. 
TABLE G.9 Deposition Velocity Data Summary for Particulate Radionuclides

\begin{tabular}{lll}
\hline Depositing Material & $\begin{array}{c}\text { Deposition Velocity } \\
(\mathrm{cm} / \mathrm{s})\end{array}$ & Deposition Surface \\
\hline Barium & $0.001-0.006$ & Grass \\
Strontium & $0.002-0.01$ & Grass \\
Radium & $0.05-0.5$ & Tank \\
Plutonium & $3.2-7.3$ & Tray \\
Cesium-137 & $0.09 \pm 0.06$ & Water \\
& $0.04 \pm 0.05$ & Soil \\
& $0.2-0.05$ & Grass \\
Ruthenium-103 & $2.3 \pm 1.0$ & Water \\
& $0.1 \pm 0.2-0.6 \pm 0.4$ & Soil \\
& $0.02-0.8$ & Grass \\
Zirconium-95, & $5.7 \pm 3.4$ & Water \\
Niobium-95 & $2.9 \pm 2.7$ & Soil \\
& $0.6-5.3$ & Ocean with rain \\
Beryllium-7 & $0.7 \pm 1.3$ & Sticky paper \\
Tellurium-127, & & \\
Tellurium-129 & & \\
\hline
\end{tabular}

Source: Sehmel (1980).

The rainfall rate (RAIN) is used to estimate depletion due to wet deposition. The default value of $0 \mathrm{~mm} / \mathrm{h}$ assumes no rainfall during the accident. The wet deposition model in RISKIND is only appropriate for rainfall rates on the order of a few $\mathrm{mm} / \mathrm{h}$. Higher rainfall rates lead to water runoff, which is not considered. Runoff occurs in urban areas during rainfall rates approximately greater than $3 \mathrm{~mm} / \mathrm{h}$; extremely heavy rains such as those at $25 \mathrm{~mm} / \mathrm{h}$ may not produce runoff in agricultural areas that were not previously saturated with water to some extent (Ritchie et al. 1978).

\section{G.2.7.2 All Weather Conditions}

The All Weather window (Figure G.22) replaces the Defined Meteorology window discussed above, when the risk over all weather conditions is selected in the main window. The 


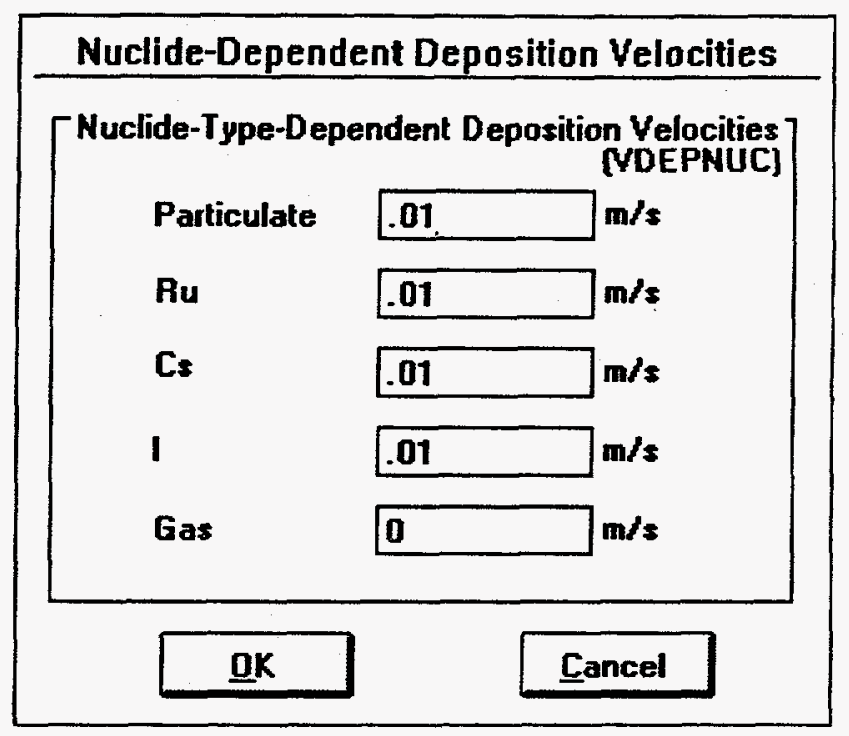

FIGURE G.21 Nuclide-Dependent Deposition Velocities Window

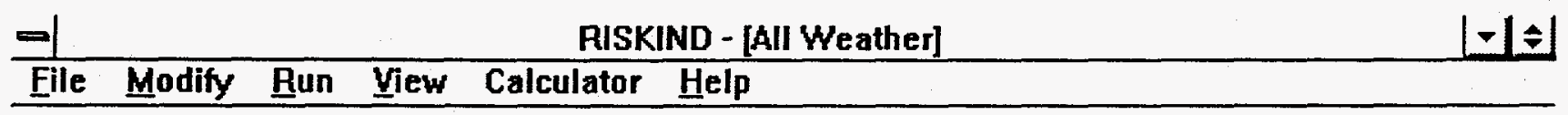

\begin{tabular}{|c|c|c|c|c|}
\hline \multicolumn{5}{|l|}{ Dispersion Parameters - } \\
\hline Morning Mixing Height $[A M \mid X]$ & 400 & $\mathbf{m}$ & Anemometer Height [ANH] & 10 \\
\hline PM Mixing Height [PMIX] & 1600 & $\mathbf{m}$ & Ambient Temperature [TABK] & 283 \\
\hline \multicolumn{5}{|l|}{-Depletion Parameters } \\
\hline Rainfall Rate [RAIN] & $\mathbf{0}$ & $\begin{array}{l}\mathrm{mm} / \\
\mathrm{h}\end{array}$ & Nuclide-Dependent Depositior & Yelocities \\
\hline
\end{tabular}

\begin{tabular}{|c|c|c|c|c|c|c|}
\hline \multirow{4}{*}{$\begin{array}{c}\text { Stability } \\
\text { Class }\end{array}$} & \multirow{2}{*}{\multicolumn{4}{|c|}{ Wind Speed [W/S] }} & & \multirow[t]{2}{*}{ Read Met File } \\
\hline & & & & & & \\
\hline & .89 & 246 & 4.47 & 6.93 & 9.61 & 12.52 \\
\hline & \multicolumn{6}{|c|}{ [DFREQ] } \\
\hline A & .0278 & .0278 & .0278 & .0278 & .0278 & .0278 \\
\hline $\mathbf{B}$ & .0278 & .0278 & .0278 & .0278 & .0278 & .0278 \\
\hline C & .0278 & .0278 & .0278 & .0278 & .0278 & .0278 \\
\hline $\mathbf{D}$ & .0278 & .0278 & .0278 & .0278 & .0278 & .0278 \\
\hline $\mathbf{E}$ & .0278 & .0278 & .0278 & .0278 & .0278 & .0278 \\
\hline $\mathbf{F}$ & .0278 & .0278 & .0278 & .0278 & .0278 & .0278 \\
\hline
\end{tabular}

FIGURE G.22 All Weather Window 
weather input selections discussed above are present except that input for the AM (AMDX) and PM (PMIX) mixing heights, rather than one mixing height, is requested. Daily, annual, and seasonal averages of mixing heights for different regions of the United States can be found in Holzworth (1972).

The major addition in this window is the Joint Frequency Distribution box. RISKIND recognizes the six Pasquill stability categories (A through F) and has provisions for up to six wind speed categories. The user may enter the fraction (not percentage) of time the wind is blowing in each stability category for each wind speed directly or may read a STAR data file to obtain the information.

An added feature in RISKIND, Version 1, is the ability to import STAR weather data. To give the user initial data for an assessment, over 200 weather data files in STAR format from the National Oceanic and Atmospheric Administration are provided for the 48 contiguous states. These data are a superset of those currently used by the CAP88-PC code (Parks 1992). The EPA developed the code for demonstrating compliance with radionuclide emission standards (EPA 1989b) that DOE facilities are required to use. STAR files may be added to RISKIND by placing the appropriate file in the METFILES subdirectory and adding the file name to the list in the STARSET2.TXT file in the METFILES subdirectory. The STAR file must have a *.STR file name extension because this extension is appended to the name in the STARSET2.TXT file when RISKIND goes to find the STAR file. Because of local variations in the weather, it is strongly recommended that site-specific weather data, if available, be used for any final risk analysis.

The risk calculation for a specific compass direction may be chosen, or the data for the 16 directions can be collapsed to a $6 \times 6$ joint frequency array for a nondirectional risk estimate. The Read Met File button brings up the corresponding window (Figure G.23) where the user may make the appropriate selection. The user may choose a specific direction for the weather data if a consequence assessment is being performed, or may choose to do a nondirectional assessment. The program will check the summation of the joint frequency input and warn the user if a total summation of $1.0 \pm 0.01$ is not achieved.

\section{G.3 USER HELP}

Help on RISKIND input parameters is available on-line and in this appendix.

\section{G.3.1 On-Line Help}

Access to on-line help is available through the Help submenu at the right of the main menu bar. 


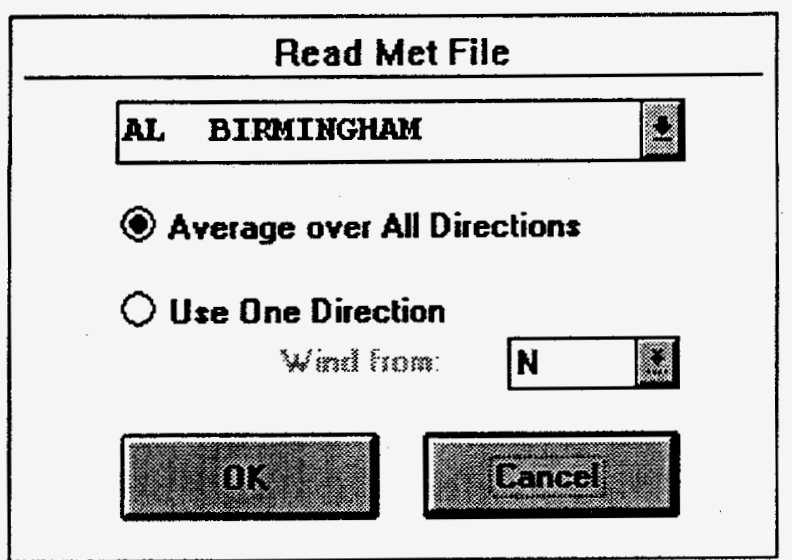

\section{FIGURE G.23 Read Met File Window}

\section{G.3.1.1 Input Parameter Definitions}

Access to on-line help for parameter definitions is available through the Contents item under the Help submenu at the right of the main menu bar, or by pressing the F1 function key while the parameter of interest has the input focus and is the one being edited. In either case, the RISKIND Help window (Figure G.24) is displayed. Five text boxes provide (1) a definition or explanation for the parameter and any default dependencies on other input, (2) the name of the input window where the user may modify the parameter, (3) the valid input range for the parameter recognized by RISKIND, (4) the RISKIND default value for the parameter, and (5) the equation(s) listed in the main text of the manual where the parameter is used.

Both the user interface and run-time portions of the program perform the same validity checks on the input parameters to make certain that all parameters are within the acceptable ranges for the program. Calculations are not performed, and an error message is issued if a parameter is found to be out of bounds.

\section{G.3.1.2 References}

References to information contained in the input parameter definitions can be listed through the References item under the Help submenu or by pressing the References button on the RISKIND Help window.

\section{G.3.1.3 Help Diagrams}

A number of diagrams can be accessed that depict various input parameters so that the user can better understand their use. Figure G.25 shows an example of the help diagrams available to the user. Help diagrams are brought up through the Diagrams submenu under the Help submenu. 


\section{G.3.2 Variable List and Definitions}

Table G.10 contains a list of all RISKIND input variables and their definitions. These definitions may also be found in on-line help.

\begin{tabular}{|c|c|c|}
\hline \multicolumn{3}{|c|}{ RISKIND Help } \\
\hline \multicolumn{2}{|c|}{ Available Topics } & Close \\
\hline BRTIND & 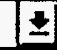 & References \\
\hline \multicolumn{3}{|c|}{ BRTIND(i) - Breathing rate for individual receptor $i$} \\
\hline \multicolumn{3}{|c|}{ Location: Individual Parameters window } \\
\hline \multicolumn{3}{|c|}{$\begin{array}{l}\text { Yalid Input }>=180 \text { and }\langle=24100 \text { [see Snyder et al. } 1994 \text { for a summary } \\
\text { of breathing rate information relating to age and physical activity) }\end{array}$} \\
\hline \multicolumn{3}{|c|}{ Default: 8000 [m3/yr] (average adult breathing rate, NRC 1977a) } \\
\hline Equation & & \\
\hline
\end{tabular}

FIGURE G.24 RISKIND Help Window

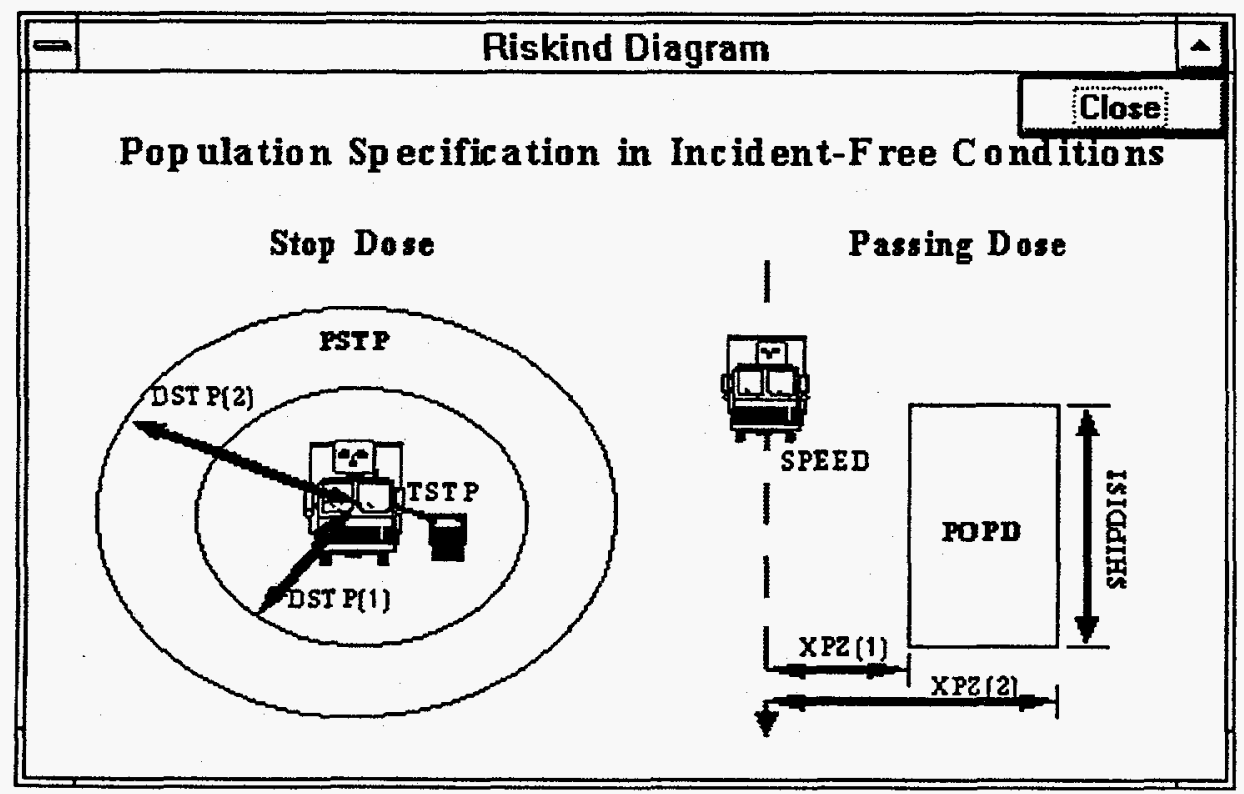

FIGURE G.25 RISKIND Help Diagram 
TABLE G.10 Input Parameters

Input

Parameter

Description

\&INDATA FORTRAN NAMELIST data delimiter input string for RISKIND. The NAMELIST format is used in FORTRAN programs as a method for data input.

ACOEFU(j,k) User-defined coefficients for estimating the external dose from the shipping package. These values used only if Cask Coefficients are enabled by check box (LACOEF $=1$ ) in the Shipment Parameters window. The dose is calculated according to

$\log ($ Dose rate $)=\Sigma A C O E F(j, k) \times(\log [r])^{\wedge}(\mathrm{j}-1)$, where $k$ is the type of dose (1: gamma; 2 : neutron), and $j$ is the index for summation (1 through 8 ).

Location: Dose Rate Curves Parameters window.

Valid Input: Any double precision real number.

Defaults: See Table 2.1 in the RISKIND manual.

Equation: 2.2 .

ACTA Accident probability per kilometer traveled for risk calculation.

Location: Accident window.

Data-Dependent Defaults: If the default checkbox is checked (ACTA is set to -1), the value corresponding to the currently selected state, transportation mode, route type, and population zone is used (ISTATE, IMOD, IRDTY, IZONE, respectively). These values are maintained in the TRUCKACC.RKD and RAILACC.RKD data files for truck and rail accident rates, respectively, as taken from Saricks and Kvitek (1994).

Valid input: $>0$ and $\leqq 1,-1$ for data-dependent default.

Default: $1[/ \mathrm{km}]$ (set for a consequence calculation).

Equation:

ALPHA Cask impact angle (degrees) for user-defined accident scenario. The impact angle is the angle between the cask velocity (the direction along which the cask is traveling) and the plane of the surface struck.

Location: Defined Accident Scenario window.

Valid Input: 0 to 90 .

Default: 90 [degrees] (head-on collision).

Equation: E.1.

AMIX Annual average morning mixing height. The average of AMIX and PMIX (annual afternoon mixing height) is used to determine the mixing height for calculations involving Pasquill stability class D weather.

Location: All Weather window.

Valid Input: $>0$ and $\leqq 5,000$ (mixing heights can range from a few tens of meters to $>4,000 \mathrm{~m}$ [Holzworth 1972]).

Default: 400 [m] (annual average morning mixing heights range from approximately 300 to $800 \mathrm{~m}$, the majority of the areas in the United States have values in the 300 to $500 \mathrm{~m}$ range [Holzworth 1972]).

Equation: 3.15 to $3.18,3.30 .3 .31$. 
TABLE G.10 (Cont.)

Input

Parameter
Description

Anemometer height. The height at which the value for wind speed (WSM) is measured.
Location: All Weather or Defined Meteorology window, depending on the weather option
selected.
Valid Input: $>0$ and $\leqq 200(>200 \mathrm{~m}$ is approximately where the wind speed power law, used in the
effective wind speed and release height calculations, starts to breakdown Hanna et al. [1982]).
Default: 10.0 [m] (standard meteorological instrumentation height [e.g., see NRC 1972].
Equation: 3.10 .

BETA Cask orientation angle (degrees). The orientation angle is the angle between the cask's longitudinal axis and the impact surface.

Location: Defined Accident Scenario window.

Valid Input: 0 to 90.

Default: 90 [degrees] (end-on collision).

Equation: Determines impact velocity using lookup Table E.1.

BRTIND(i) Breathing rate for individual receptor $i$.

Location: Individual Parameters window.

Valid Input: $\geqq 180$ and $\leqq 24,100$ (see Snyder et al. [1994] for a summary of breathing rate information relating to age and physical activity).

Default: $8,000\left[\mathrm{~m}^{3} / \mathrm{yr}\right]$ (average adult breathing rate [NRC 1977a]).

Equation: $3.50,3.72$.

BRTPOP Average individual breathing rate for population risk estimates.

Location: Population Parameters window.

Valid Input: $\geqq 180$ and $\leqq 24,100$ (see Snyder et al. [1994] for a summary of breathing rate information relating to age and physical activity).

Default: $8,000\left[\mathrm{~m}^{3} / \mathrm{yr}\right]$ (average adult breathing rate [NRC 1977a]).

Equation: $3.95,3.106$.

BURNUP Reactor fuel burnup.

Location: SNF Inventory window.

Valid Input: 0 to 60,000 (no commercial PWR or BWR assemblies discharged to date have a burnup greater than 60,000 [EIA 1995]).

Default: 35,000 [MWd/MTIHM] (the majority of assemblies discharged annually have a burnup near this value [EIA 1995]).

Equation: Used with lookup table of DOE SNF database described in Appendix A.

CACTD Crud surface activity density of cask for spent fuel inventories.

Location: SNF Inventory window.

Data-Dependent Default: Defaults are dependent on fuel type (RTYPE).

Valid Input: $>0$ and $\leq 1,500$ (the maximum observed has been 1,250 for BWR fuel [Sandoval et al. 1991])

Default: 4 or $350\left[\mu \mathrm{Ci} / \mathrm{cm}^{2}\right]$ (average maximum values for PWR and BWR fuels, respectively [Sandoval et al. 1991])

Equation: Multiplied by CAREA, FSPAL, FRCRUD, and crud inventory to get cobalt- 60 source term to add to SNF inventory releases. 
TABLE G.10 (Cont.)

Input

Parameter

CAREA

DECAY WEATHER

DFACT

DFIRE

DFREQ(i,j)
Total surface area of cask cavity, including fuel for spent fuel inventories.

Location: SNF Inventory window.

Data-Dependent Default: Defaults dependent on fuel type and transportation mode (RTYPE, IMOD).

Valid Input: $>0$ and $\leq 500$ (the larger licensed rail casks have surface areas $<400$ [Sandoval et al. 1991])

Default: $\left[\mathrm{m}^{2}\right.$ ] Truck - 39.0 (PWR), 26.7 (BWR); Rail - 251.6 (PWR), 209.5 (BWR). (Values are for the NLI-1/2 truck and IF-300 rail casks [Sandoval et al. 1991]).

Equation: Multiplied by CACTD, FSPAL, FRCRUD, and crud inventory to get cobalt-60 source term to add to SNF inventory releases.

Weathering decay constant for loss of contamination from vegetation due to weathering processes.

Location: Ingestion Pathway Details window.

Valid Input: 0.693 to 0.0198 ( $\ln 2 / 1$ to $\ln 2 / 35$, based on information in Snyder et al. [1994]).

Default: 0.0495 [1/d] (ln 2/14 d NRC [1977a]).

Equation: $3.58,3.59,3.60$.

Decontamination factor. Fraction of initially deposited contamination remaining on humanconsumed vegetation after washing.

Location: Ingestion Parameters or Population Ingestion Parameters window, depending on receptor option selected.

Valid Input: 0 to 1.

Default: 0.5 (Parks 1992).

Equation: $3.74,3.110$.

Fire duration for user-defined accident scenario.

Location: Defined Accident Scenario window.

Valid Input: 0 to 100 (a portion of a train not involving spent fuel derailed and burned for over four days near Livingston, Louisiana in 1982; modal study [LLNL 1987]).

Default: 0.75 [h] (approximately 75 to $80 \%$ of expected truck/truck and truck/train accident fires and $75 \%$ of rail accident fires will last $0.75 \mathrm{~h}$ or less, NRC modal study [LLNL 1987]).

Equation: E.2.

Fractional frequency of occurrence for each of the $j(1$ to 6$)$ average wind-speed classes for each of the $i$ ( 1 to 6$)$ atmospheric stability classes. Used when estimating risk over meteorological conditions.

Location: All Weather window.

Valid Input: 0 to 1 for each entry (the sum of all entries should total 1 , unless only one direction was specified).

Default: $36 * 0.0278$ (uniform distribution).

Equation: Multiplied by impact estimated by using atmospheric stability $i$ and wind speed $j$ to estimate the risk for that weather condition. 
TABLE G.10 (Cont.)

Input

Parameter

DHSIZE

User-defined reference cask length for shape factor correction when Dose Rate Curve Parameters are enabled (IACOEF $=1$ ) and Shape Factor Correction is still used (ISHPF $=0$ ).

Location: Dose Rate Curves Parameters window.

Valid Input: $>0$ and $\leqq 25$ (a limiting value would be a railcar loaded with waste packages and treated as a single source for routine risk calculations; the useful length of some railcars exceeds $20 \mathrm{~m}$ [AAR 1974).

Default: 5.46 [m] (cask size used for developing the routine dose rate curves [Chen and Yuan 1988]).

Equation: B.8, B.14.

DISTPASS(i) Nearest distance of individual receptor $i$ to the passing shipment.

Location: Individual Parameters window.

Valid Input: 0.001 to 80.0 (routine doses beyond $1 \mathrm{~km}$ are generally insignificant; the maximum input distance used here is to maintain consistency with accident calculations).

Default: $1.0[\mathrm{~km}]$ (unit distance).

Equation: 2.7 to 2.11 .

DISTSTOP(i) Distance of individual receptor $i$ from the stopped shipment.

Location: Individual Parameters window.

Valid Input: 0.001 to 80.0 (routine doses beyond $1 \mathrm{~km}$ are generally insignificant; the maximum input distance used here is to maintain consistency with accident calculations).

Default: $1.0[\mathrm{~km}]$ (unit distance).

Equation: 2.5 .

DMIX

Mixing height for user-defined weather.

Location: Defined Meteorology window.

Valid Input: $>0$ and $\leqq 5,000$ (mixing heights can range from a few tens of meters to $>4,000 \mathrm{~m}$

[Holzworth 1972]).

Default: 1,000 [m] (Parks 1992).

Equation: 3.15 to $3.18,3.30,3.80,3.82$.

DRSIZE User-defined reference cask radius for shape factor correction when Dose Rate Curve Parameters are enabled (IACOEF = 1) and Shape Factor Correction is still used (ISHPF = 0 ).

Location: Dose Rate Curves Parameters window.

Valid Input: $>0$ and $\leqq 5$ (a limiting value would be a railcar loaded with waste packages and treated as a single source for routine risk calculations; the useful height of some railcars exceeds $3 \mathrm{~m}$ [AAR 1974]).

Default: $0.56[\mathrm{~m}]$ (cask size used for developing the routine dose rate curves [Chen and Yuan 1988]).

Equation: B.6, B.10, B.12, B.16, B.18, B.19. 
TABLE G.10 (Cont.)

Input

Parameter

Description

DSTP( $i, j) \quad$ Annular exposure region radii of each population stop type $j$ for routine population calculations. A maximum of 10 independent stop types may be defined (NSTY = 10 maximum); each type is defined by the area bounded by a minimum and maximum radii.

( $i=1$ : minimum radius; $i=2$ : maximum radius).

Location: Routine On-Link/Stops Parameters window.

Valid Input: 1 to 80,000 (routine doses beyond $1,000 \mathrm{~m}$ are generally insignificant; the maximum input distance used here is to maintain consistency with accident calculations).

Default: $(1, j)=2,(2, j)=90[\mathrm{~m}]$ (based on a study by Madsen and Wilmot [1982] for truck transport for an average truck stop; values for rail transport will depend on the size of the rail yard and surrounding countryside).

Equation: 2.6 .

EFF_SURF_DEN Effective surface density of the soil.

Location: Ingestion Pathway Details window.

Valid Input: $\geqq 0$.

Default: $240\left[\mathrm{~kg} / \mathrm{m}^{2}\right]$ (assumes a 15-cm plow layer [NRC 1977a]).

Equation: $3.59,3.60$.

F_EDBL_COW Fraction of plant contamination reaching edible portion of animal-consumed vegetation.

Location: Ingestion Pathway Details window.

Valid Input: 0 to 1 .

Default: 1 (NRC 1977a).

Equation: 3.58 to 3.60 .

F_EDBL_HUM Fraction of plant contamination reaching edible portion of human-consumed vegetation.

Location: Ingestion Pathway Details window.

Valid Input: 0 to 1 .

Default: 1 (NRC 1977a).

Equation: 3.58 to 3.60 .

F_RETAIN Fraction of air-deposited contamination retained on vegetation.

Location: Ingestion Pathway Details window.

Valid Input: 0 to 1 .

Default: 0.2 (NRC 1977a).

Equation: 3.58 to 3.60 .

FAILS(i) Fraction of failed rods in spent fuel cask $i$ can be used for fraction of failed packages in a multiple package shipment for other radioactive materials; $i$ is the accident response region (accident severity category) index, maximum of 20.

Location: Accident window.

Valid Input: 0 to 1 .

Default: $0.03,0.1,2 * 1,0.03,0.1,2 * 1,0.03,0.1,10 * 1$ (NRC modal study [LLNL 1987]).

Equation: 3.1. 
TABLE G.10 (Cont.)

\section{Input \\ Parameter}

FARM

FDISP(i,j)

FLOCA

FRAD(i)

FRCRUD(i)
Fraction of land that is farmland within the zone bounded by the nearest [XPZ(1)] and farthest $[\mathrm{XPZ}(2)]$ distances from an accident.

Location: Population Ingestion Parameters window.

Data-Dependent Default: Dependent on the currently selected state (ISTATE) if the default checkbox is checked (FARM is set to -1 ). The values used for calculations are from Saricks et al. (1989).

Valid Input: $>0$ and $\leqq 1,-1$ for data-dependent default.

Default: 0.44 (U.S. average, Saricks et al. [1989]).

Equation: 3.109 .

Fraction of released inventory dispersed to the atmosphere as a respirable aerosol for accident response region $i$ (maximum of 20) for radionuclide type $j(1$ to 5 ).

Location: Accident window.

Valid Input: 0 to 1 .

Default: $0,19 * 1,0,19 * 1,0,19 * 1,0,19 * 1,0,19 * 1$ (NRC modal study [LLNL 1987]).

Equation: 3.1 .

Fire location for user-defined accident scenario. The distance of the cask from the fire.

Location: Defined Accident Scenario window.

Valid Input: 0 to 10 (modal study [LLNL 1987]).

Default: 0 [m] (engulfing fire).

Equation: Ė.3, E.4.

Fraction of dose rate at user-defined distance from the waste package contributed by gamma (1) and neutron (2) radiation.

Location: Shipment Parameters window.

Valid Input: 0 to 1 for FRAD(1); FRAD(2) $=1$ - FRAD(1).

Default: $0.60,0.40$ (intermediate values for existing PWR and BWR casks, see Table G.4).

Equation: 2.4 .

Fraction of spalled crud released in each accident response region (accident severity category) (i) for SNF inventory.

Location: Accident window.

Valid Input: 0 to 1 .

Default: $20^{*} 1$ (all spalled crud [the crud that has flaked or broken off the fuel rods] is assumed to be released if a leak path is available; a number of mechanisms could be operable that would mitigate some or all of the release; these mechanisms include deposition and gravitational settling of the crud within the cask, as well as the possibility of the crud blocking the leak path itself.).

Equation: Multiplied by CAREA, CACTD, FSPAL, and crud inventory to get cobalt- 60 source term to add to SNF inventory releases. 
TABLE G.10 (Cont.)

Input
Parameter

Fraction of inventory released from failed rods to the cask cavity in accident response region $i$ for each of the five radionuclide types $(j)$; can be used for the fraction released from the shipping package for shipments other than SNF.

Location: Accident window.

Valid Input: 0 to 1 .

Default: NRC modal study (LLNL 1987).

Equation: 3.1 .

FSEV(i,j) Conditional probability of each accident response region $i$ (accident severity category) for the two transportation modes $(j)$ ( 1 - truck, 2 - rail).

Location: Accident window.

Valid Input: 0 to 1 .

Default: NRC modal study (LLNL 1987).

Equation: Multiplied by ACTA and by impact estimated using accident region $i$ parameters to estimate the risk for that accident severity under a given set of weather conditions.

FSPAL(i) Crud spallation fraction in each accident response region $i$.

Location: Accident window.

Valid Input: 0 to 1.

Default: $0.0,3 * 1 ., 0.15,3 * 1 ., 0.15,3 * 1 ., 0.15,3 * 1 ., 0.15,3 * 1$ (based on Sandoval et al. [1991] and the NRC modal study [LLNL 1987]).

Equation: Multiplied by CAREA, CACTD, FRCRUD, and crud inventory to get cobalt-60 source term to add to SNF inventory releases.

GMEAT Farmland meat productivity.

Location: Population Ingestion Parameters window.

Data-Dependent Default: dependent on the currently selected state (ISTATE) if the default checkbox is checked (GMEAT set to -1 ). The values used for calculations are from Saricks et al. (1989).

Valid Input: 0 to 50,000 (the maximum for 1982 was 17,000 in Iowa [Saricks et al. 1989]); -1 for the data-dependent default.

Default: $3,070\left[\mathrm{~kg} / \mathrm{km}^{2}\right.$-yr] (U.S. average).

Equation: 3.109.

GMILK Farmland milk productivity.

Location: Population Ingestion Parameters window.

Data-Dependent Default: dependent on the currently selected state (ISTATE) if the default checkbox is checked (GMILK is set to -1 ). The values used for calculations are from Saricks et al. (1989).

Valid Input: 0 to 100,000 (the maximum for 1982 was 75,000 in Wisconsin [Saricks et al. 1989]); -1 for the data-dependent default.

Default: $6,710\left[\mathrm{~kg}^{\mathrm{km}}{ }^{2}\right.$-yr] (U.S. average).

Equation: 3.109 . 
TABLE G.10 (Cont.)

Input Description

GVEGE Farmland vegetation productivity.

Location: Population Ingestion Parameters window.

Data-Dependent Default: Dependent on the currently selected state (ISTATE) if the default checkbox is checked (GVEGE is set to -1 ). The values used for calculations are from Saricks et al. (1989).

Valid Input: 0 to 400,000 (the maximum for 1982 was 330,000 in Illinois [Saricks et al. 1989]);

-1 for the data-dependent default.

Default: $55,800\left[\mathrm{~kg} / \mathrm{km}^{2}\right.$-yr] (U.S. average).

Equation: 3.109 .

HEATF(i) Heat flux generated for each accident response region $i$ (accident severity category). Used to determine the effective release height from buoyant plume rise.

Location: Accident window.

Valid Input: $\geqq 0$.

Default: $4 * 500,16 * 2.0 \mathrm{E} 6$ [cal/s] (based on a heat content of $1.07 \mathrm{E}-4 \mathrm{cal} / \mathrm{g}$ and a density of $11.3 \mathrm{~kg} / \mathrm{gal}$ [CRC 1970] for diesel fuel; a $2.0 \mathrm{E} 6 \mathrm{cal} / \mathrm{s}$ heat flux corresponds to a burn rate of approximately $1 \mathrm{gal} / \mathrm{min}$ ).

Equation: 3.3 to 3.9 .

HS

Physical release height of escaped material. This value could be the cask height or road height unless other information is available.

Location: Accident window.

Valid Input: 0 to 200 ( $>200 \mathrm{~m}$ is approximately where the wind speed power law, used in the effective wind speed and release height calculations, starts to break down [Hanna et al. 1982]).

Default: $1.0[\mathrm{~m}]$ (approximate height above ground of cask on a tractor-truck trailer or railcar). Equation: 3.2 to 3.4 .

HSIZE Cask length. Used for shape factor corrections of external dose from cask and initial dispersion of plume.

Location: Shipment Parameters window.

Data-Dependent Default: Dependent on the transportation mode selected if the default box is checked (IMOD).

Valid Input: $>0$ and $\leqq 25$ (a limiting value would be a railcar loaded with waste packages being treated as a single source for routine risk calculations; the useful length of some railcars exceeds $20 \mathrm{~m}$ [AAR 1974]).

Default: $5.46[\mathrm{~m}]$ (cask size used for developing the routine dose rate curves [Chen and Yuan 1988]; if the default box is checked, the NRC modal study [LLNL 1987] value for a truck or rail cask will be used ).

Equation: 3.37, B.9, B.15. 
TABLE G.10 (Cont.)

Input

Parameter

HSTP(i)

HTEXP

HZLM

IACDT

\section{Description}

Exposure duration for each population stop type $i$ for routine population calculations. A maximum of 10 independent stop types may be defined (NSTY = 10 maximum; each type is defined with an independent stop time.

Location: Routine On-Link/Stops Parameters window.

Valid Input: 0 to 100 (Commercial shipments rarely remain in one place for more than a few hours; allowance is given for severe weather or mechanical problems.).

Default: $\left.10^{*} 1 \mathrm{~h}\right]$ (Unit time duration).

Equation: 2.6.

Short-term exposure duration immediately after an accident; used in population calculations.

Location: Population Parameters window.

Valid Input: $>0$ to 100; based on EPA protective action guidelines' (EPA 1991) loose definition of the early phase of an accident, which is defined to extend up to a few days after the initiation of a release when all airborne material is assumed to have deposited; however, emergency response procedures in most cases would limit such exposure to hours, if not minutes. In addition, most of the short-term dose is dominated by inhalation of the passing plume, which generally passes by within minutes of an accident but can take longer due to a prolonged release, slower wind speeds, and/or farther distances from the release point. External exposure from ground contamination can be accounted for with the long-term exposure option for any prolonged exposure period.

Default: 2.0 [h] (evacuation could be expected to be completed in most cases within this time frame in the aftermath of an accidental release, see e.g., Sprung et al. [1990]).

Equation: $3.92,3.98$.

Radionuclide selection criterion applied to three pathways to reduce the number of radionuclides being considered. Setting to 0 selects all radionuclides. The radionuclides that are estimated to cause approximately $99 \%$ of the potential risk are selected when HZLM $=0.01$. The estimated risk in the screening process using HZLM is only a rough estimate, and HZLM should be set to a smaller value than required.

Location: SNF Inventory or User-Defined Inventory window.

Valid Input: 0 to 1 .

Default: $0.01(1 \%)$ (generally selects less than 10 out of possibly hundreds of radionuclides from a SNF shipment).

Equation: C.15.

Determines whether accident calculations are performed. Accident calculations include shortterm effects: external dose from the cask with possible loss of shielding, external dose from material deposited on the ground from the plume passage, inhalation of material as the plume passes, and external cloudshine from the material as it passes. The long-term doses may also be calculated: long-term groundshine, inhalation and cloudshine from resuspended material, and ingestion through food and water pathways.

Location: Main Options window.

Valid Input: 0 - do not perform accident calculations; 1 - perform accident calculations.

Default: 1 (perform accident calculations).

Equation: Controls program option. 
TABLE G.10 (Cont.)

Input

Parameter

Description

IACFOD Determines whether the food being grown at the time of the accident is discarded or distributed for ingestion. This food is contaminated by the direct deposition of radionuclides during the plume passage.

Location: Ingestion Parameters or Population Ingestion Parameters window.

Valid Input: 0 - discard initially contaminated food; 1 - do not discard initially contaminated food.

Default: 0 (discard initially contaminated food).

Equation: Controls program option.

IACOEF Determines whether the default or user external cask dose coefficients are to be used.

Location: Shipment Parameters window.

Valid Input: 0 - default dose coefficients, 1 - user-defined dose coefficients.

Default: 0 (use default gamma and neutron dose curves).

Equation: Controls program option.

IADD Number of individual receptor locations.

Location: Individual/Population option selected in the Main Options window; increased or decreased with the Save and Delete Individual buttons in the Individual Parameters window.

Valid Input: 1 to 20,0 for population calculations.

Default: 1 (individual problem with one receptor).

Equation: Controls program option.

IBOUND Determines level of conservatism in the acute health risk calculations.

Location: Individual Parameters or Population Parameters window.

Valid Input: $1=$ lower bounds, $2=$ central estimates, $3=$ upper bounds.

Default: 2 (central estimates).

Equation: Controls program option.

ICONSQ Determines whether a risk or consequence problem is being specified. If consequence is chosen, the accident rate (ACTA) is not used, the relative probability of the accident severity category (FSEV) is set to 1 , and the probability of the user-defined weather condition (METFREQ), one wind speed for one stability class, is 1.

Location: Main Options window.

Valid Input: $0=$ risk problem, $1=$ consequence problem.

Default: 0 (risk problem).

Equation: Controls program option.

IDFOOD(i) Determines whether or not the food pathway (ingestion) is calculated for individual receptor $i$ (maximum of 20 receptors, number of receptors set by IADD).

Location: Individual Parameters window.

Valid input: $0=$ do not calculate food pathway, $1=$ calculate food pathway.

Default: $20 * 1$ (calculate food pathway).

Equation: Controls program option. 
TABLE G.10 (Cont.)

Input

Parameter

IDISPMOD

IDPG(100)

IHARD

IMOD
Controls which dispersion coefficients are used for the plume dispersion calculations. A 0 specifies Pasquill-Gifford coefficients to be used for effective release heights $<30 \mathrm{~m}$ and Briggs coefficients to be used for higher releases. Alternately, Pasquill-Gifford coefficients (1) or Briggs coefficients (2) may be specifically selected. Pasquill-Gifford coefficients should be used for releases at or near ground level. Briggs coefficients were derived from elevated release studies but are not recommended for elevated releases much greater than $100 \mathrm{~m}$.

Location: Accident window.

Valid Input: $0=$ dependent on effective release height, $1=$ Pasquill-Gifford coefficients, 2 = Briggs coefficients.

Default: 0 (dependent on effective release height).

Equation: Controls program option.

Radionuclide type for each element:

(1: particulate; 2: ruthenium; 3: cesium; 4: iodine; 5: inert gas).

Location: User-Defined Inventory window.

Valid Input: 1 to 5 .

Default:

$1,1,1,5,5,1,1,1,1,1,1,1,1,1,1,1,1,1,1,1,1,5,5,1,1,1,1,1,1,2,2,2$,

$1,1,1,1,1,1,1,4,5,3,1,1,1,1,1,1,1,1,1,1,1,1,1,1,1,1,1,1,1,1,1,1$,

$1,1,1,1,1,1,1,1,5,1,1,1,1,1,1,1,1,1,1,1,1,1,1$,

respectively, for

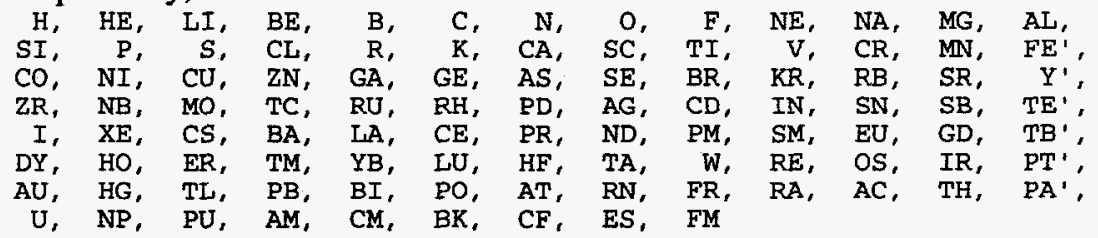

Impact object hardness index for a user-defined accident scenario.

Location: Defined Accident Scenario window.

Valid Input: 1 = unyielding, 2 = medium, $3=$ soft, $4=$ very soft.

Default: 1 (Unyielding).

Equation: Determines impact velocity using lookup Table E.1.

Transportation mode option flag. Used for determining some data-dependent defaults [ACTA, CAREA, UMT, HSIZE, RSIZE, SPEED, RDWTH, PPVH, XPZ(1)].

Location: Main Options window.

Valid Input: $1=$ truck, 2 = rail.

Default: 1 (truck)

Equation: Controls program option. 
TABLE G.10 (Cont.)

Input
Parameter $\quad$ Description

INDTYPE(i) Selects the individual type (member of the general public or an occupational worker) of receptor $i$. Selection determines the health risk factors for potential cancer incidence, cancer fatality, and genetic effects to be used for routine and long-term health risk calculations.

Location: Individual Parameters window.

Valid Input: 0 - occupational worker, 1 - member of the general public.

Default: $20 * 1$ (member of the general public).

Equation: Controls program option.

IPFOD

Population food pathway option flag. The ingestion dose to the population is a societal dose. That is, the dose is independent of the number of people in the affected area and is based on the assumption that all of the food grown in the affected area will be consumed, either locally or in other areas.

Location: Population Parameters window.

Valid Input: $0=$ population food pathway off, $1=$ population food pathway on.

Default: 1 (include population food pathway).

Equation: Controls program option.

IPWATR Number of water body locations for population drinking water dose calculations. The user sets XRECEP (1) and XRECEP (2) to input the coordinates of each location.

Location: Set by enabling water ingestion in the Population Parameters window and incremented or decremented by the New and Delete Water Bodies buttons, respectively, in the Water Pathway for Population window.

Valid Input: 1 to 20,0 if drinking water not considered.

Default: 0 (drinking water not considered).

Equation: Controls program option.

IRDTY Road type option flag. Used in determining some data-dependent defaults [ACTA, NUMLANES, RDWTH, WDTHMED, XPZ(1)].

Location: Shipment Parameters window.

Valid Input: Truck:1 = interstate highway, 2 = primary road, 3 = secondary road;

Rail: $1=$ total, 2 = mainline only.

Default: 1 (interstate highway/total rail).

Equation: Controls program option.

IRTP(i) Long-term pathway option flag for individual receptor $i$ (maximum of 20 receptors, number of receptors set by IADD). IRTP(1) is used for population calculations.

Location: Main Options window.

Valid Input: 1 = calculate short- and long-term exposures; $0=$ calculate short-term exposures only.

Default: $20 * 1$ (short-term and long-term pathways).

Equation: Controls program option. 
TABLE G.10 (Cont.)

Input

Parameter
Description
IRUTIN

ISHLT(i)

ISHPF

ISPENT

ISTATE
Routine dose calculation option flag.

Location: Main Options window.

Valid Input: $0=$ no routine calculations, $1=$ do routine calculations.

Default: 1 (do routine calculations).

Equation: Controls program option.

Shelter type for individual receptor $i$ for routine and short-term accident calculations (maximum of 20 receptors, number of receptors set by IADD). See Table 3.5 in the RISKIND manual or the Individual Parameters input window for the shielding values used for each selection. The shielding values are taken from NRC (1975).

Location: Individual Parameters window.

Valid Input: $0=$ outdoors (no shielding), $1=$ frame house, $2=$ brick house, $3=$ office building, $4=$ automobiles on road, $5=$ user-specified shielding factor (defined in SHLDVAL).

Default: $20 * 0$ (outdoors, no shielding).

Equations: $2.5,2.7,2.8,3.47$ to 3.50 .

Shape factor correction option when user-defined Dose Rate Curve coefficients are specified.

Location: Checkbox in Shape Factor box in Dose Rate Curve Parameters window.

Valid Input: $0=$ shape factor correction active, $1=$ shape factor correction not used.

Default: 0 (include shape factor).

Equation: Controls program option.

Option flag for selecting the type of radioactive inventory.

Location: Main Options window.

Valid Input: 1 = spent fuel, radionuclide inventory is estimated as defined by the RTYPE, BURNUP, and TFUEL variables as in the original code; $0=$ user radionuclide inventory.

Default: 1 (spent fuel inventory).

Equation: Controls program option.

Index of state to use in determining data-dependent defaults (ACTA, FARM, GVEGE, GMEAT, GMILK, POPD).

1. AL

2. AZ

3. AR

4. CA

5. $\mathrm{CO}$

6. CT

7. $\mathrm{DE}$

8. FL

9. GA

10. ID

11. IL

12. IN 13. IA

14. $\mathrm{KS}$ 15. KY

16. LA

17. $\mathrm{ME}$

18. MD

19. MA

20. $\mathrm{M}$

21. MN

22. MS 23. MO

24. MT

25. NE

26. NV

27. $\mathrm{NH}$

28. NJ

29. NM

30. NY 31. NC

32. ND

33. $\mathrm{OH}$

34 . OK

35. OR

36. PA 37. RI

38. SC 39. SD

40. TN

41. TX

42. UT

43. VT

44. VA 45. WA

46. WV 47. WI

48. WY

Location: Main Options window.

Valid Input: 1 to 49 .

Default: 49 (U.S.).

Equation: Array index. Determines data-dependent defaults. 
TABLE G.10 (Cont.)

Input

Parameter
Description

ITREAT Option flag for level of medical treatment for acute health risk effects.

Location: Individual Parameters or Population Parameters window.

Valid Input: 1 = minimal treatment, 2 = supportive treatment.

Default: 1 (minimal treatment).

Equation: Controls program option.

ITYPE

Pasquill atmospheric stability categories.

Location: Defined Meteorology window.

Valid Input: 1 to 6 corresponds to Pasquill stability categories A to F.

Default: 4, Pasquill stability class D (neutral stability classes are prevalent about $50 \%$ of the time on average across the United States [Doty et al. 1976]).

Equation: Array index. Determines the dispersion coefficients used in Equations 3.32 to 3.34 .

IWATER(i) Individual $i$ water consumption pathway option flag (maximum of 20 receptors, number of receptors set by IADD).

Location: Individual Parameters window.

Valid Input: $0=$ water consumption not included, $1=$ water consumption included.

Default: $20 * 0$ (water ingestion exposure pathway not included).

Equation: Controls program option.

IYOURS Accident problem type option flag.

Location: Radio buttons in Accident Scenarios box in Main Options window; if the third option is selected, $i$ is determined by the Region Considered field in the Accident window.

Valid Input: $-1=$ input your own accident scenario; $0=$ risk over all accident severity categories; $i=$ use $i$ th accident response region, 1 to NSV (number of regions considered).

Default: -1 (user-defined accident scenario).

Equation: Controls program option.

IYOURW Meteorological data input option flag.

Location: Main Options window.

Valid Input: $1=$ input user-provided wind speed and stability, $0=$ risk over all weather types (all combinations of wind speed and stability category).

Default: 1 (user-defined single weather type).

Equation: Controls program option.

IZONE Population zone index used for determining some data-dependent defaults and dispersion coefficients (ACTA, SPEED, XPZ(1),TRAF_DEN).

Location: Main Options window.

Valid Input: 1 = rural, 2 = suburban, 3 = urban.

Default: 1 (rural, the majority of most transportation routes are in rural population zones).

Equation: Controls program option. 
TABLE G.10 (Cont.)

Input

Parameter

LSHLT(i)

METFREQ

NISOPL

$\operatorname{NSTP}(10)$

NSTY

NSV
Description

Shelter type for long-term accident calculations for individual receptor $i$. Fraction of time spent over the long-term in the specified shelter type is input with the OCUPF(i,j) parameter. See Table 3.5 in the RISKIND manual or the Individual Parameters input window for the shielding values used for each selection. The shielding values are taken from NRC (1975).

Location: Individual Parameters window.

Valid Input: $0=$ outdoors (no shielding), $1=$ frame house, $2=$ brick house, $3=$ office building, 4 = automobiles on road, 5 = user-defined (values in SHLDVAL).

Default: $20 * 0$ (outdoors, no shielding).

Equation: $3.69,3.71 .3 .73$.

Probability of a given weather condition ( 1 weather stability category and 1 wind speed). Used in risk calculations with user-defined weather selected (IYOURW $=1$ ).

Location: Defined Meteorology window.

Valid Input: 0 to 1 .

Default: 1 (consequence calculation).

Equation: Multiplied by the impacts from a defined set of weather conditions (single stability class and wind speed) to obtain the risk for that set of weather conditions.

Number of concentration isopleths used in a population accident problem. Starting at the area of highest radionuclide concentration, the average concentration in each surrounding isopleth is reduced by a factor of $3.162\left(10^{\wedge} 1 / 2\right)$.

Location: Accident window.

Valid Input: 4 to 20 .

Default: 10 (covers five orders of magnitude difference in contaminant concentrations between the innermost isopleth (the area of highest concentration) and the outermost isopleth (the area of lowest concentration considered).

Equation: Controls program loop.

Number of stops occurring for each population problem stop type. A maximum of 10 independent stop types may be defined (NSTY $=10$ maximum); each type is defined with an independent number of stops.

Location: Routine On-Link/Stops Parameters window.

Valid Input: 1 to 100.

Default: $10^{*} 1$ ( 1 stop for each stop type).

Equation: 2.6 .

Number of population problem stop types for routine calculations.

Location: Routine On-Link/Stops Parameters window.

Valid Input: 0 to 10 .

Default: $\mathbf{0}$ (no special stops considered for routine calculations).

Equation: Controls program option.

Number of accident response regions (accident severity categories) considered.

Location: Accident window when risk over all regions is calculated.

Valid Input: 1 to 20.

Default: 20 (NRC modal study [LLNL 1987]).

Equation: Controls program option. 
TABLE G.10 (Cont.)

Input

Parameter

Description

NUMLANES Number of lanes going in each direction for the truck route of interest or the number of neighboring parallel tracks for the rail transport mode. Used for routine on-link population calculations.

Data-Dependent Default: Dependent on the road type (IRDTY) and population zone (IZONE), if the default box is checked.

Location: Shipment Parameters window when population calculations are to be performed (IADD = 0).

Valid Input: 1 to 10 .

Default: 2 for truck, 1 for rail (over $90 \%$ of the U.S. interstate highway system consists of fourlane roads, two in each direction [FHWA 1991]).

Equation: 2.15 .

NUTYPE(i) Label for radionuclide type $i$.

Location: Accident window.

Valid Input: Alphanumeric text, limited to 12 characters.

Default: "Particulates," "Ru," "Cs," "I," "Gas" for $i=1$ to 5, respectively (NRC modal study [LLNL 1977]).

Equation: Program display option.

$\operatorname{OCUPF}(\mathrm{i}, \mathrm{j}) \quad$ Indoor and outdoor occupancy factors $(j=1$ and 2 , respectively) for calculating long-term doses. Remaining fraction assumed to be off-site. $\operatorname{OCUPF}(1, \mathrm{j})$ used for population calculation. Location: Individual Parameters or Population Parameters window.

Valid Input: 0 to 1.

Default: $20 * 0.62$ (indoors), $20 * 0.02$ (outdoors) (EPA [1989a]; average based on time spent at home).

Equation: $3.69,3.71,3.73 .3 .101,3.104,3.107$.

PAG

Long-term dose value for determining cleanup levels for population problems. The EPA has published suggested PAGs dealing with exposure to accidental radioactive releases (EPA 1991). These guidelines deal with the early (short-term) and later phases (long-term) following an accidental release. Early phase considerations are discussed in the RISKIND manual but are not implemented in the program because forewarning (i.e., time to mitigate potential exposure) of an accidental transport-related release is not likely, and cleanup is not a short-term mitigative action. The most restrictive of the longer term guidelines suggests a limit of 5 rem to a single individual over a 50-year exposure period. If the exposure to a single individual in a given population isopleth exceeds the PAG value over the exposure time set (default for YEVD is $50 \mathrm{yr}$ ), RISKIND will perform an extra set of calculations for that isopleth to determine the approximate ground concentrations needed after cleanup to stay within the PAG limit. This determination "reduces" the dose from inhalation of resuspended material, groundshine, and ingestion. Short-term doses and water ingestion are not considered.

Location: Soil and Resuspension Factors window when performing population calculations $(\mathrm{IADD}=0$ ).

Valid Input: 0.1 to 27, less restrictive PAGs from the EPA suggest a limit of 2 rem in the first year following an accident and $0.5 \mathrm{rem} / \mathrm{yr}$ for each subsequent year, $2+0.5 \times 49=27$.

Default: 5.0 [rem/YEVD yr] (see description of parameter above).

Equation: Used to scale contaminant ground concentrations on an isopleth-by-isopleth basis if an average individual receptor were to receive a dose greater than the PAG value. 
TABLE G.10 (Cont.)

Input

Parameter

Description

PFIN(i) Contaminated fractions of each food type $i$ ( $i=1$ meat, 2 milk, 3 vegetation, 4 reserved for future use, 5 water) consumed by individuals.

Location: Ingestion Parameters or Population Parameters window for meat, milk, and vegetation; Water Pathways Parameters window for water for individuals; if water intake is selected for population calculations, all water ingested by the persons at each water body location is assumed to be contaminated.

Valid Input: 0 to 1 .

Default: $5 * 1.0$ (all food ingested is contaminated).

Equation: 3.74 to 3.77 .

PHALF Radionuclide removal half-life from soil. The rate constant for radionuclide removal from soil is 0.693/PHALF.

Location: Soil and Resuspension Factors window.

Valid Input: $>0$ to 135 (Sprung et al. 1990).

Default: 50 [yr] (Parks 1992).

Equation: $3.51,3.52,3.57$.

PMIX

Annual afternoon mixing height. For calculations involving Pasquill stability class A (unstable) weather, the mixing height is taken to be $1.5^{*} \mathrm{PMIX}$. The mixing height is set equal to PMIX for other unstable conditions (classes B and C), and the average of AMIX (annual morning mixing height) and PMIX is used to determine the mixing height for calculations involving Pasquill stability class D weather (neutral conditions).

Location: All Weather window.

Valid Input: $>0$ and $\leqq 5,000$ (mixing heights can range from a few tens of meters to $>4,000 \mathrm{~m}$ [Holzworth 1972]).

Default: $1,600[\mathrm{~m}]$ (typical values for the annual average afternoon mixing height in the United States range from 1,200 to $>2,600 \mathrm{~m}$, more than two-thirds of the country has mixing heights $<2,000 \mathrm{~m}$ [Holzworth 1972]).

Equation: 3.15 to $3.18,3.30,3.31$.

POPD Average population density between distances, XPZ(1) and XPZ(2), for population calculations, accident and off-link routine.

Location: Population Parameters window.

Data-Dependent Default: Average population density for the selected state (ISTATE), if the default box is checked.

Valid Input: $>0$ to $1.0 \mathrm{E} 6$ (This is an arbitrary maximum density corresponding to 1 person $/ \mathrm{m}^{2}$. Densities such as this could be exceeded at public functions such as outdoor concerts or ball games. However, shielding from the surrounding persons would become a factor at higher densities for routine calculations and is not accounted for.).

Default: 6.0 [persons $/ \mathrm{km}^{2}$ ] (average rural population density [NRC 1977b]).

Equation: 2.12, 3.88, 3.98. 
TABLE G.10 (Cont.)

\begin{tabular}{cc}
\hline Input \\
Parameter & Description \\
\hline
\end{tabular}

POPTYPE Selects the population type (members of the general public or occupational workers). Selection determines the health risk factors for potential cancer incidence, cancer fatality, and genetic effects to be used for routine and long-term health risk calculations.

Location: Population Parameters window.

Valid Input: $0=$ occupational workers, $1=$ members of the general public.

Default: 1 (members of the general public).

Equation: Controls program option.

POPW(i) Number of persons consuming water from each water body $i$ (maximum of 20) in a population accident calculation.

Location: Water Pathway for Population window.

Valid Input: 1 to 100 (the drinking water model in RISKIND is only intended for small, local water distribution systems).

Default: $20 * 1,(1$ person drinking from each water body).

Equation: 3.113 .

PPVH Number of people per vehicle sharing the transport route.

Location: Routine On-Link/Stops Parameters window.

Valid Input: 0 to 1,000 (allowance is made for passenger trains).

Default: 2 (for truck transportation; a value of 5 is often used for rail transportation [Neuhauser and Kanipe 1992]).

Equation: 2.16 .

PSTP(i) Number of persons exposed at each stop type $i$ for routine population calculations. A maximum of 10 independent stop types may be defined (NSTY $=10$ maximum).

Location: Routine On-Link/Stops Parameters window.

Valid Input: 1 to 1,000 .

Default: $10 * 50$ (Neuhauser and Kanipe 1992).

Equation: 2.6.

QA Feed (wet weight) ingestion rate for beef cattle and milk cows.

Location: Ingestion Pathway Details window.

Valid Input: $\geqq 0$ to 100 .

Default: 50 [kg/d] (NRC 1977a).

Equation: $3.61,3.62$.

RAIN

Rainfall rate. The wet deposition model in RISKIND is only appropriate for rainfall rates on the order of a few $\mathrm{mm} / \mathrm{h}$. Higher rainfall rates lead to water runoff, which is not considered.

Location: Defined Meteorology or All Weather window.

Valid Input: 1 to 25 (Runoff occurs in urban areas during rainfall rates approximately greater than $3 \mathrm{~mm} / \mathrm{h}$; extremely heavy rains such as $25 \mathrm{~mm} / \mathrm{h}$ may not produce runoff in agricultural areas not previously saturated with water to some extent [Ritchie et al. 1978]).

Default: $0.0[\mathrm{~mm} / \mathrm{h}]$ (no rainfall).

Equation: 3.24 . 
TABLE G.10 (Cont.)

Input

Parameter

RDWTH

RFIE

RSALF

RSIZE

RTYPE
Width of one lane for truck transportation. Used in routine on-link population calculations.

Location: Shipment Parameters window when setting up routine population calculations.

Data-Dependent Default: Dependent on the road type (IRDTY) and population zone (IZONE)

if the default box is checked.

Valid Input: 2 to 10.

Default: 3.7 [m] (The majority of roads in the United States have a lane width of $12 \mathrm{ft}$ [FHWA 1991].).

Equation: $2.15,2.16$.

Fraction of population indoor during routine transit and/or accident.

Location: Population Parameters window.

Valid Input: 0 to 1 .

Default: 0.0 (everyone outdoors, no credit for shielding).

Equation: $2.12,3.90,3.93,3.96$.

Resuspension factor decay half-life. The resuspension decay constant is given by 0.693/RSALF.

Location: Soil and Resuspension Factors window.

Valid Input: $>0$ and $\leqq 100$ (based on Sprung et al. [1990]).

Default: 0.137 [yr] (NRC 1974).

Equation: 3.53 to $3.55,3.57$.

Radius of cask. Used for shape factor corrections of external dose from cask and initial dispersion of plume.

Location: Shipment Parameters window.

Data-Dependent Default: Dependent on the transportation mode selected if the default box is checked (IMOD).

Valid Input: $>0$ and $\leqq 5$ (a limiting value would be a railcar loaded with waste packages being treated as a single source for routine risk calculations; the useful height of some railcars exceeds 3 m [AAR 1974]).

Default: $0.56[\mathrm{~m}]$ (size of truck cask from Chen and Yuan [1988] used for developing the routine dose rate curves; if the default box is checked, the NRC Modal study [LLNL 1987] value for a truck or rail cask will be used.).

Equation: 3.38 , B.7, B.11, B.13, B.17 to B.19.

Reactor type for spent fuels.

Location: SNF Inventory window.

Valid Input: "BWR" or "PWR."

Default: "PWR."

Equation: Controls program option. 
TABLE G.10 (Cont.)

Input

Parameter

$\operatorname{SEXT}(\mathbf{i}, \mathrm{j})$

SHIPDIST

SHLDVAL

SPEED

STARNAME

SUFF
Description

External dose multiplication factor due to loss of shielding in an accident; expressed in multiples of TIDX (dose rate at $1 \mathrm{~m}$ ) for each accident response region $i(\mathrm{j}=1$ gamma, 2 neutron).

Location: Accident window.

Valid Input: $\geqq 1$.

Default: $40^{*} 1$ (no loss of shielding in accident).

Equation: 3.49 .

Distance traveled next to off-link population of interest for routine transport calculations.

Location: Population Parameters window.

Valid Input: $\geqq 0.1$ and $\leqq 5,000$.

Default: $1.0[\mathrm{~km}]$ (unit distance).

Equation: 2.12 .

User input shielding factor for exposure pathway $i$ ( $i=1$ inhalation, 2 cloudshine, 3 groundshine).

Location: Individual Parameters or Population Parameters window.

Valid Input: 0 to $1 ; 0=$ full shielding, $1=$ no shielding.

Default: 1.0 (no shielding).

Equation: User-specified value for ISHLT, LSHLT, and WSHLT arrays.

Vehicle travel speed during routine transport.

Location: Shipment Parameters window.

Data-Dependent default: Dependent on the selected transportation mode, population zone, and route type if the default box is checked (IMOD, IZONE, IRDTY).

Valid Input: $>0$ and $\leqq 240$ (the maximum credible speed was determined to be $240 \mathrm{~km} / \mathrm{h}$ in the NRC modal study [LLNL 1987].

Default: 88 or $64[\mathrm{~km} / \mathrm{h}]$ (truck on interstate in rural zone or rail in rural zone).

Equation: $2.8,2.10,2.12,2.15,2.16$.

Identifier of meteorological site chosen (filename of actual STAR file used).

Location: All Weather window, selected indirectly in the Read Met File window when choosing STAR file by site location.

Valid Input: Alphanumeric text (valid filename).

Default: “" (No STAR file selected).

Equation: Program display option.

Final resuspension factor for determining resuspended air concentrations.

Location: Soil and Resuspension Factors window.

Valid Input: $\geqq 1 E-11$ and $\leqq 1 E-4$ (based on [Kennedy and Strenge 1992]).

Default: 1E-9 [1/m] (NRC 1974; Anspaugh et al. 1974).

Equation: 3.53 to $3.55,3.57$. 
TABLE G.10 (Cont.)

Input

Parameter

Description

SUFI

Initial resuspension factor for determining resuspended air concentrations.

Location: Soil and Resuspension Factors window.

Valid Input: $\geqq 1 E-11$ and $\leq E-4$ (based on [Kennedy and Strenge 1992]).

Default: $1 \mathrm{E}-5[1 / \mathrm{m}]$ (NRC 1974).

Equation: 3.53 to $3.55,3.57$.

T_GROW_COW Time of exposure to contamination for animal-consumed vegetation during the growing season.

Location: Ingestion Pathway Details window.

Valid Input: 0 to $\leqq 180$ (most crops have minimum growing periods of 90 days or less

[Kennedy and Strenge 1992]).

Default: 30 [days] (NRC 1977a).

Equation: $3.59,3.60$.

T_GROW_HUM Time of exposure to contamination for human-consumed vegetation during the growing season.

Location: Ingestion Pathway Details window.

Valid Input: 0 to $\leqq 180$ (most crops have minimum growing periods of 90 days or less

[Kennedy and Strenge 1992]).

Default: 60 [days] (NRC 1977a).

Equation: $3.59,3.60$.

T_HARVEST_ Time to first harvest of animal-consumed vegetation since an accidental release of radioactive COW

material.

Location: Ingestion Pathway Details window.

Valid Input: 0 to $\leqq 180$ (most crops have minimum growing periods of 90 days or less [Kennedy and Strenge 1992]).

Default: 15 [days] (The probability of the accident during a specific portion of the growing season is unknown; therefore, the time to first harvest is taken to be half the growing season.)

Equation: $3.58,3.60$.

T_HARVEST _ Time to first harvest of human-consumed vegetation since an accidental release of radioactive HUM

material.

Location: Ingestion Pathway Details window.

Valid Input: 0 to $\leqq 180$ (most crops have minimum growing periods of 90 days or less [Kennedy and Strenge 1992]).

Default: 30 [days] (The probability of the accident during a specific portion of the growing season is unknown; therefore, the time to first harvest is taken to be half the growing season.).

Equation: $3.58,3.60$.

TABK Ambient temperature. Used in the plume rise calculations for accidental releases.

Location: Defined Meteorology or All Weather window.

Valid Input: 211 to 330 (minimum and maximum recorded temperatures in the United States

[National Climatic Data Center]).

Default: 283 [K] (Parks 1992).

Equation: 3.8 . 
TABLE G.10 (Cont.)

Input

Parameter

Description

TD2M

External dose rate at $2 \mathrm{~m}$ from the cask.

Location: Shipment Parameters window.

Valid Input: $>0$ and $\leq$ MAX (where MAX corresponds to a dose rate that would produce $10 \mathrm{mrem} / \mathrm{h}$ at $2 \mathrm{~m}$ from the lateral side of the transport vehicle, the maximum allowable rate [49 CFR 173 (DOT 1994) and 10 CFR 71 (NRC 1994b)]).

Default: $10[\mathrm{mrem} / \mathrm{h}]$ (maximum allowable external dose rate with cask at vehicle edge, TIOFF $=0$ ).

Equation: Converted to dose rate at $1 \mathrm{~m}$ for calculations as TIDX.

TEXT(i) Individual receptor $i$ short-term exposure duration immediately after accident.

Location: Individual Parameters window.

Valid Input: $>0$ to 100, based on EPA protective action guidelines' (EPA 1991) loose definition of the early phase of an accident, which is defined to extend up to a few days after the initiation of a release when all airborne material is assumed to have deposited. However, emergency response procedures in most cases would limit such exposure to hours if not minutes. In addition, most of the short-term dose is dominated by inhalation of the passing plume, which generally passes by within minutes of an accident but can take longer due to a prolonged release, slower wind speeds, and/or farther distances from the release point. External exposure from ground contamination can be accounted for with the long-term exposure option for any prolonged exposure period.).

Default: 2.0 [h] (evacuation could be expected to be completed in most cases within this time frame in the aftermath of an accidental release, see e.g., Sprung et al. [1990]).

Equation: $3.48,3.49$.

TFLAME Flame temperature used for determining the accident response region (accident severity category) for a user-defined accident scenario.

Location: Defined Accident Scenario window.

Valid Input: $\geqq 1,000$ and $\leqq 1,600$ (NRC modal study [LLNL 1987]).

Default: $1,350[\mathrm{~K}]$ (approximately $70 \%$ of fires expected in transportation accidents will not achieve temperatures more than 1,350 K, NRC modal study [LLNL 1987]).

Equation: Used to look up value in Table E.3 for Equation E.2.

TFUEL Spent fuel cooling time.

Location: SNF Inventory window.

Valid Input: 1 to 100 .

Default: 10 [yr] (As of the end of 1993, approximately $40 \%$ of BWR spent fuel and 50\% of PWR spent fuel in storage were discharged prior to 1986 [EIA 1995].)

Equation: Used with lookup table of DOE SNF database described in Appendix A. 
TABLE G.10 (Cont.)

Input

Parameter

Description

TIDX

External dose rate at $1 \mathrm{~m}$ from cask surface.

Location: Shipment Parameters window.

Valid Input: $>0$ and $\leq$ MAX (where MAX corresponds to a dose rate that would produce $10 \mathrm{mrem} / \mathrm{h}$ at $2 \mathrm{~m}$ from the lateral side of the transport vehicle, the maximum allowable rate [49 CFR 173 (DOT 1994) and 10 CFR 71 (NRC 1994b)]).

Default: $21[\mathrm{mrem} / \mathrm{h}$ ] (maximum allowable external dose rate of $10 \mathrm{mrem} / \mathrm{h}$ at $2 \mathrm{~m}$, using the default dose curve coefficients to obtain the dose rate at $1 \mathrm{~m}$ with cask at vehicle edge TIOFF $=0$ ).

Equation: 2.4 .

TIOFF Offset of cask surface from the lateral edge of the transport vehicle.

Location: Shipment Parameters window.

Valid Input: 0.0 to 5.0 (a limiting value would be the width of a railcar [AAR 1974].

Default: $0.0[\mathrm{~m}]$ (outside edge of cask surface coincides with edge of the transport vehicle).

Equation: 2.5 to 2.15 .

TITLE Case identifier to be printed in header of output file. User-defined label.

Location: Main Options window.

Valid Input: Alphanumeric text, limited to 48 characters.

Default: "Default Case."

Equation: Program display option.

TRAF_DEN Traffic density (the one-way vehicle count per lane).

Location: Routine On-Link/Stops Parameters window.

Valid Input: 0 to 2,200 (2,200 passenger cars per hour per lane is about the maximum flow rate attainable under ideal conditions. Any more cars leads to congestion and stop-and-go traffic.

[AASHTO 1994].

Default: 235 (based on 470 vehicles per hour in a rural zone (NRC 1977b), with the assumption that traffic was evenly distributed between two lanes).

Equation: 2.16.

TREATM Contaminated water treatment efficiency. A treatment efficiency of 0.7 would mean that $70 \%$ of the contamination was removed from the water consumed.

Location: Water Pathway or Water Pathway for Population window.

Valid Input: 0 to 1.

Default: 0.0 (no treatment).

Equation: $3.66,3.67$.

TSTP(i) Stop duration by individual receptor $i$ for routine calculations.

Location: Individual Parameters window.

Valid Input: 0 to 100 (commercial shipments rarely remain in one place for more than a few hours; allowance is given for severe weather or mechanical problems).

Default: $20^{*} 1.0$ [h] (unit time duration).

Equation: 2.5 . 
TABLE G.10 (Cont.)

Input

Parameter

TYPCSK

UF(i)

UMT

VCASK
User label for cask/shipping package description.

Location: SNF Inventory or User-Defined Inventory window.

Valid Input: Alphanumeric text, limited to 20 characters.

Default: "Modal Truck" or "Modal Rail," depending on the transportation mode selected.

Equation: Program display option.

Fraction of contaminated foodstuffs for each food type $i$ ( $i=1$ meat, 2 milk, 3 vegetation) produced that is used for human consumption. For population accident calculations involving ingestion.

Location: Population Ingestion Parameters window.

Valid Input: 0 to 1 .

Default: $3 * 1$ (All contaminated food produced is consumed by humans.).

Equation: 3.109 .

Total uranium in cask. A typical fuel assembly contains approximately 0.45 (PWR) or 0.20 (BWR) MTU (EIA 1995). The total amount of uranium in the shipping cask is the amount per assembly multiplied by the number of assemblies in the cask.

Location: SNF Inventory window.

Data-Dependent Default: The amount of uranium in PWR fuel in the cask studied in the NRC modal study (LLNL 1987) is used if the default box is checked. Depending on the transportation mode selected (IMOD), the amount in 1 assembly (truck) or 21 assemblies (rail) per cask will be used.

Valid Input: $>0$ and $\leqq 30$ (Most railcars have a weight limit near 70 tons, with higher values for specially designed cars [AAR 1974]). However, the largest certified railcar shipping cask, the NAC-STC, can only carry 26 PWR assemblies (about $12 \mathrm{MTU}$ ) and has a maximum gross weight of 114 metric tons [NRC 1994a]).

Default: 0.46 (Truck) or 8.89 (Rail) [MTU] (LLNL 1987).

Equation: Used with lookup table of DOE SNF database described in Appendix A.

Accident cask velocity. Input is the speed of the cask at the time of impact for accident calculations.

Location: Defined Accident Scenario.

Valid Input: $>0$ and $\leqq 240$ (the maximum credible speed was determined to be $240 \mathrm{~km} / \mathrm{h}$ in the NRC modal study [LLNL 1987]).

Default: $65[\mathrm{~km} / \mathrm{h}$ ] (Approximately half of all truck accidents occur in the 51 to $84 \mathrm{~km} / \mathrm{h}$ range, and 32\% occur within approximately the same range for rail (NRC 1974).

Equation: E.1. 
TABLE G.10 (Cont)

Input

Parameter

VDEP

VDEPNUC(5)

VERSION

WBDYD(i)
Ground deposition velocity of radionuclides for population accident calculations. Typical deposition velocities are generally less than $0.01 \mathrm{~m} / \mathrm{s}$ (Sehmel 1980; McMahon and Dennison 1979). However, the deposition velocity is dependent on such variables as particle size and type, surface roughness, and atmospheric stability. Values will tend to be higher over some areas of farmland with taller crops, wooded areas, and suburban/urban areas.

Location: Defined Meteorology or All Weather window, depending on the selected weather option.

Valid Input: 0 to 0.07 (based on references in Sehmel [1980] and McMahon and Dennison [1979]).

Default: $0.01[\mathrm{~m} / \mathrm{s}]$ (see discussion above in the input parameter description).

Equation: 3.81, 3.82. Used in place of VDEPNUC in Equations 3.19, 3.20, 3.27, 3.29, and 3.30 for population calculations.

Deposition velocity of each nuclide type for individual receptor problems. Typical deposition velocities are generally less than $0.01 \mathrm{~m} / \mathrm{s}$ (Sehmel 1980; McMahon and Dennison 1979). However, the deposition velocity is dependent on such variables as particle size and type, surface roughness, and atmospheric stability. Values will tend to be higher over some areas of farmland with taller crops, wooded areas, and suburban/urban areas.

Location: Nuclide-Dependent Deposition Velocities window.

Valid Input: 0 to 0.07 (based on references in Sehmel [1980] and McMahon and Dennison [1979]).

Default: $0.01,0.01,0.01,0.01,0.00[\mathrm{~m} / \mathrm{s}]$ (See discussion above in the input parameter description.).

Equation: $3.19,3.20,3.27,3.29,3.30$.

Version of RISKIND used to set up problem.

Location: Not accessible from screen interface, not intended for modification by users.

Valid Input: Not applicable.

Default: Current version.

Equation: Not applicable.

Depth of water body at each receptor $i$ (20 maximum) for individual accident calculations involving water consumption. For population calculations, depth of water body $i$ (20 maximum) if water consumption is considered.

Location: Water Pathways Parameters or Water Pathway for Population window.

Valid Input: $>0$ and $\leqq 10$ (the drinking water model in RISKIND is only intended for small local water distribution systems).

Default: $20 * 2.0$. [m].

Equation: $3.63,3.66,3.67$. 
TABLE G.10 (Cont.)

Input

Parameter
Description

WBDYW(i) Cross-wind width of water body at each receptor $i$ (20 maximum) for individual accident calculations involving water consumption. For population calculations, cross-wind width of water body $i$ ( 20 maximum) if water consumption is considered.

Location: Water Pathways Parameters or Water Pathway for Population window.

Valid Input: $>0$ and $\leqq 1,000$ (the drinking water model in RISKIND is only intended for small local water distribution systems).

Default: $20 * 50[\mathrm{~m}]$.

Equation: 3.65 .

WDTHMED Width of median between opposing lanes of traffic for truck transport or distance between adjacent track centerlines for rail transport. Used in routine on-link population calculations.

Location: Shipment Parameters window when routine population calculations are specified $($ IADD $=0$, IRUTIN $=1$ ).

Data-Dependent Default: Dependent on the road type (IRDTY) and population zone (IZONE), if the default box is checked.

Valid Input: 0 to 50 .

Default: 15 for truck, 6 for rail [m] (median widths of 15 to $30 \mathrm{~m}$ are common on rural freeways [AASHTO 1994]).

Equation: 2.15 .

WEXCG(i) Exchange rate of water body at each receptor $i$ (20 maximum) for individual accident calculations involving water consumption. For population calculations, exchange rate of water body $i$ (20 maximum) if water consumption is considered.

Location: Water Pathways Parameters or Water Pathway for Population window.

Valid Input: 0 to 100.

Default: $20 * 1$. [/yr] (unit exchange rate).

Equation: $3.66,3.67$.

WS(i) Average wind speed $i$ for one of the six wind-speed classes of the wind frequency data when using the all weather option.

Location: All Weather window.

Valid Input: 0.1 to 25 (The dispersion model in RISKIND was not developed for the higher wind speeds encountered in stormy weather such as hurricanes.).

Default: $0.89,2.46,4.47,6.93,9.61$, and 12.52 [m/s] (STAR file wind speed categories).

Equation: Used in place of WSM in Equation 3.10 when calculating risks over all weather conditions.

WSHLT(i) Fraction of population with each shielding type $i$ for population calculations $(1=$ frame house, $2=$ brick house, $3=$ office building, $4=$ cars on road, $5=$ user-defined [SHLDVAL]). These values are heavily dependent on location and time of day.

Location: Population Parameters window.

Valid Input: 0 to 1 , summation over $i$ should $=1$.

Default: $0.36,0.38,0.21,0.05,0.0$ (based on information in [NRC 1975]).

Equation: $2.12,3.91,3.94,3.97$. 
TABLE G.10 (Cont.)

Input Parameter Description

WSM

Wind speed measured at anemometer height (ANH) with the user-specified weather option.

Location: Defined Meteorology window.

Valid Input: 0.1 to 25 (The dispersion model in RISKIND was not developed for the higher wind speeds encountered in stormy weather such as hurricanes.).

Default: $4.0 .[\mathrm{m} / \mathrm{s}]$ (Wind speeds in this range are the most common. The $4.47 \mathrm{~m} / \mathrm{s}$ wind speed category in most STAR files has the highest frequency of occurrence.).

Equation: 3.10.

XIN(i) Individual food consumption rate of food type $i$ for individual problems ( $i=1$ meat, 2 milk, 3 vegetation, 5 water).

Location: Ingestion Parameters and Water Pathway Parameters.

Valid Input: 0 to 5 .

Defaults: 1-meat: 0.30; 2-milk: 0.85; 3-vegetation: 1.6; 5-water: 2.0 [kg/d] (NRC 1977a).

Equation: 3.74 to 3.77 .

XING(i) Average individual food consumption rate of food type $i$ ( $i=1$ meat, 2 milk, 3 vegetation, 5 water) for population problems.

Location: Population Ingestion Parameters window for meat, milk, and vegetation; Water Pathway for Population window for water.

Valid Input: 0 to 5 .

Defaults: 1-meat: 0.26; 2-milk: 0.30; 3-vegetation: 0.52; 5-water: 1.0 [kg/d] (NRC 1977a). Equation: 3.113, used in place of XIN in Equations 3.74 to 3.77 for local individual calculations for PAG determination.

XNAME(i) User label for individual receptor $i$ (maximum of 20 individuals).

Location: Individual Parameters window.

Valid Input: Alphanumeric text, maximum of 20 characters.

Default: "Individual 1."

Equation: Program display option.

XPZ(i) Population zone downwind distances ( $i=1$ minimum, 2 maximum) for accident calculations and nearest and farthest distances to shipment route for off-link population routine calculations.

Location: Population Parameters window.

Valid Input: 0.001 to 80.0 (NRC 1977c).

Defaults: $0.05,80.0[\mathrm{~km}](\mathrm{NRC} 1977 \mathrm{c})$.

Equation: $2.12,3.83,3.98$. 
TABLE G.10 (Cont.)

Input

Parameter

$\operatorname{XRECEP}(\mathrm{i}, \mathrm{j}) \quad$ Individual Problem:

Accident Problem: Individual receptor $j$ location coordinates:

$i=1$, downwind distance $(\mathrm{km}) ; i=2$, crosswind distance $(\mathrm{km}) ; i=3$, elevation of receptor $(\mathrm{m})$.

Population Problem:

Accident Problem: Water body $j$ location coordinates: $i=1$, downwind distance $(\mathrm{km}) ; i=2$, crosswind distance $(\mathrm{km})$.

Location: Individual Parameters window for individual calculations or Water Pathway for Population window for population calculations.

Valid Input: 0.001 to 80.0, XRECEP(1) (NRC 1977c).

0 to 80.0, XRECEP(2)

0 to $1,000.0$, XRECEP(3).

Default: $20 *(1.0,0 ., 0$.) (unit distance downwind on the plume centerline).

Equation: 3.4 to $3.6,3.11$ to $3.15,3.20,3.25$ to $3.30,3.35,3.36$.

YEVD Long-term exposure time following a potential accident.

Location: Individual Parameters window for individual calculations or Population Parameters window for population calculations.

Valid Input: 0 to 70 .

Default: 50.0 [yr] (EPA 1988).

Equation: $3.52,3.53,3.57,3.59,3.60,3.66,3.67$.

YIELD_COW Yield density of animal-consumed vegetation on farmland.

Location: Ingestion Pathway Details window.

Valid Input: 0 to 5 .

Default: $0.7\left[\mathrm{~kg} / \mathrm{m}^{2}\right]$ (NRC 1977a).

Equation: 3.58 to 3.60 .

YIELD_HUM Yield density of human-consumed vegetation on farmland.

Location: Ingestion Pathway Details window.

Valid Input: 0 to 5 .

Default: $2.0\left[\mathrm{~kg} / \mathrm{m}^{2}\right]$ (NRC 1977a).

Equation: 3.58 to 3.60 . 


\section{APPENDIX G REFERENCES}

Abrahamson, S., et al., 1989, Health Effects Model for Nuclear Power Accident Consequence Analysis, Low LET Radiation, rev. 1, NUREG/CR-4214, U.S. Nuclear Regulatory Commission, Washington, D.C.

Abrahamson, S., et al., 1991, Health Effects Model for Nuclear Power Plant Accident Consequence Analysis, Modifications of Models Resulting from Recent Reports on Health Effects of Ionizing Radiation, rev. 1, Part II, Addendum 1, NUREG/CR-4214, U.S. Nuclear Regulatory Commission, Washington, D.C.

American Association of State Highway and Transportation Officials (AASHTO), 1994, A Policy on Geometric Design of Highways and Streets, AASHTO, Washington, D.C.

Anspaugh, L.R., et al., 1974, "Resuspension Element Status Report," in The Dynamics of Plutonium in Desert Environments, NVO-142, U.S. Department of Energy, Nevada Operations Office, Las Vegas, Nev.

Association of American Railroads (AAR), 1974, Car and Locomotive Cyclopedia of American Practices, Simmons-Boardman Publishing Corporation, New York, N.Y.

Babcock and Wilcox, 1990, BR-100 100-Ton Rail/Barge Spent Fuel Shipping Casks: Preliminary Design Report, February 1990, B\&W Document 51-1177082-02, Lynchburg, Va.

Briggs, G.A., 1974, Diffusion Estimation for Small Emissions, Environmental Research Laboratories Atmospheric Turbulence and Diffusion Laboratory 1973 Annual Report, Report No. ATDL-106, National Oceanic and Atmospheric Administration, Washington, D.C.

Chen, S.Y., and Y.C. Yuan, 1988, "Calculation of Radiation Dose Rates from a Spent Nuclear Fuel Shipping Cask," Transactions of American Nuclear Society 56:110-112.

Chemical Rubber Company (CRC) 1970, Handbook of Tables for Applied Engineering Science, Cleveland, Ohio.

Doty, S.R., et al., 1976, A Climatological Analysis of Pasquill Stability Categories Based on STAR Summaries, National Climatic Center, National Oceanic and Atmospheric Administration, Asheville, N.C., April.

Eimutis, E.C., and M.G. Konicek, 1972, "Derivation of Continuous Functions for the Lateral and Vertical Dispersion Coefficients," Atmospheric Environment 6:859-863.

Energy Information Administration (EIA), 1995, Spent Nuclear Fuel Discharges from U.S. Reactors 1993, SR/CNEAF/95-01, U.S. Department of Energy, Washington, D.C., Feb. 
Federal Highway Administration (FHWA), 1991, Highway Statistics 1990, U.S. Department of Transportation, Washington, D.C.

General Atomics, 1990, GA-4/GA-9 Legal Weight Truck from Reactor Shipping Casks: Preliminary Design Report, April 1990, GA-A19862, San Diego, Calif.

Hanna, S.R., et al., 1982, Handbook on Atmospheric Diffusion, DOE/TIC-11223, Technical Information Center, U.S. Department of Energy, Washington, D.C.

Holzworth, G., 1972, Mixing Heights, Wind Speeds, and Potential for Urban and Air Pollution throughout the Contiguous United States, AP-101, U.S. Environmental Protection Agency, Washington, D.C.

International Commission on Radiological Protection, 1975, Report of the Task Group on Reference Man: A Report, Pergamon Press, New York, N.Y.

International Commission on Radiological Protection, 1991, 1990 Recommendations of the International Commission on Radiological Protection, ICRP Publication 60, Pergamon Press, New York, N.Y.

Kennedy, Jr., W.E., and D.L. Strenge, 1992, Residual Radioactive Contamination from Decommissioning: Volume 1, Technical Basis for Translating Contamination Levels to Annual Total Effective Dose Equivalent, NUREG/CR-5512, Pacific Northwest Laboratory, Richland, Wash., Sept.

Lahs, W.R., 1987, Transporting Spent Fuel - Protection Provided Against Severe Highway and Railroad Accidents, NUREG/BR-0111, U.S. Nuclear Regulatory Commission, Washington, D.C.

Lawrence Livermore National Laboratory, 1987, Shipping Container Response to Severe Highway and Railway Accident Conditions, NUREG/CR-4829, UCID-20733, prepared by Lawrence Livermore National Laboratory, Livermore, Calif., for U.S. Nuclear Regulatory Commission, Washington, D.C., Feb.

Madsen, M.M., and E.L. Wilmot, 1982, Truck Transportation of Radioactive Materials, SAND82-1952C, Sandia National Laboratories, Albuquerque, N.M.

McMahon, T.A., and P.J. Dennison, 1979, "Empirical Atmospheric Deposition Parameters - A Survey," Atmospheric Environment 13:571-585.

National Research Council, 1990, Health Effects of Exposure to Low Levels of Ionizing Radiation, BEIR V Report, Committee on the Biological Effects of Ionizing Radiation, National Academy Press, Washington, D.C.

Neuhauser, K.S., and F.L. Kanipe, 1992, RADTRAN 4: Volume 3, User Guide, SAND-89-2370, Sandia National Laboratories, Albuquerque, N.M. 
Parks, B.S., 1992, User's Guide for CAP88-PC, EPA 402-B-92-001, U.S. Environmental Protection Agency, Washington, D.C.

Ritchie, L.T., et al., 1978, "Effects of Rainstorms and Runoff on Consequences of Atmospheric Releases from Nuclear Reactor Accidents," Nuclear Safety, 19:220-238.

Sandoval, R.P., et al., 1991, Estimate of CRUD Contribution to Shipping Cask Containment Requirements, SAND-88-1358, Sandia National Laboratories, Albuquerque, N.M., Jan.

Saricks, C., and T. Kvitek, 1994, Longitudinal Review of State-Level Accident Statistics for Carriers of Interstate Freight, ANL/ESD/TM-68, Argonne National Laboratory, Argonne, Ill., March.

Saricks, C.L., et al., 1989, Data Base of Accident and Agricultural Statistics for Transportation Risk Assessment, ANL/EAIS/TM-2, Argonne National Laboratory, Argonne, Ill., Nov.

Sehmel, G.A., 1980, "Particles and Gas Dry Deposition: A Review," Atmospheric Environment 14:983-1011.

Snyder, S.F., et al., 1994, Parameters Used in the Environmental Pathways and Radiological Dose Modules (DESCARTES, CIDER, and CRD Codes) of the Hanford Environmental Dose Reconstruction Integrated Codes (HEDRIC), PNWD-2023 HEDR rev. 1, Pacific Northwest Laboratories, Richland, Wash., May.

Sprung, J.L., et al., 1990, Evaluation of Severe Accident Risks: Quantification of Major Input Parameters, NUREG/CR-4551, vol.2, rev. 1, Part 7, prepared by Sandia National Laboratories, Albuquerque, N.M., for U.S. Nuclear Regulatory Commission, Washington, D.C., Dec.

Stammer, R.E., et al., 1990, Model Study Transportation Accident Characterization, Vanderbilt University, Nashville, Tenn.

United Nations Scientific Committee on the Effects of Ionizing Radiation, 1986, Ionizing Radiation: Sources and Biological Effects, Report A/41/16, Forty First Session, Supplement No. 16, United Nations, New York, N.Y.

U.S. Department of Commerce (DOC), 1992, 1990 Census of Population and Housing: Summary Population and Housing Characteristics-United States, 1990, CPH-1-1, Washington, D.C.

U.S. Department of Energy, 1994, Multi-Purpose Canister System Evaluation: A System Engineering Approach, DOE/RW-0445, Office of Civilian Radioactive Waste Management, Washington, D.C.

U.S. Department of Transportation (DOT), 1994, "Shippers - General Requirements for Shippings and Packagings," Code of Federal Regulations, title 49, part 173, pp. 603-635. 
U.S. Environmental Protection Agency, 1988, Limiting Values of Radionuclide Intake and Air Concentration and Dose Conversion Factors for Inhalation, Submersion, and Ingestion, EPA-520/1-88-020, Washington, D.C.

U.S. Environmental Protection Agency, 1989a, Exposure Factors Handbook, EPA 600 8-89 043, Washington, D.C., July.

U.S. Environmental Protection Agency, 1989b, Risk Assessment Methodology, Environmental Impact Statement for Proposed NESHAPS for Radionuclides, EPA/520/1-89-005, vol. 1, Washington, D.C.

U.S. Environmental Protection Agency, 1991, Manual of Protective Action Guides and Protective Actions for Nuclear Incidents, EPA 400-R-92-001, Washington, D.C., Oct.

U.S. Nuclear Regulatory Commission, 1972, Onsite Meteorological Programs, Regulatory Guide 1.23 , originally published as Safety Guide 23 by the U.S. Atomic Energy Commission, Washington, D.C.

U.S. Nuclear Regulatory Commission, 1974, Liquid Metal Fast Breeder Reactor Program, WASH-1535, Washington, D.C.

U.S. Nuclear Regulatory Commission, 1975, Reactor Safety Study; An Assessment of Accident Risks in U.S. Commercial Nuclear Power Plants, Appendix VI: Calculation of Reactor Accident Consequences, WASH-1400 (NUREG 75/014), Washington, D.C.

U.S. Nuclear Regulatory Commission, 1977a, Calculation of Annual Dose to Man from Routine Releases of Reactor Effluents for the Purpose of Evaluating Compliance with 10 CFR Part 50, Appendix I, Rev. I, Regulatory Guide 1.109, Washington, D.C.

U.S. Nuclear Regulatory Commission, 1977b, Final Environmental Statement on the Transportation of Radioactive Material by Air and Other Modes, NUREG-0170, Washington, D.C.

U.S. Nuclear Regulatory Commission, 1977c, Methods for Estimating Atmospheric Transport and Dispersion of Gaseous Effluents in Routine Releases from Light-Water-Cooled Reactors, Regulatory Guide 1.111, Washington, D.C.

U.S. Nuclear Regulatory Commission, 1994a, Directory of Certificates of Compliance for Radioactive Materials Packages, NUREG-0383, vol. 2, rev. 17, Washington, D.C., Oct.

U.S. Nuclear Regulatory Commission, 1994b, "Packaging and Transportation of Radioactive Material," Code of Federal Regulations, title 10, part 71, p. 203. 
H-I

APPENDIX H:

SAMPLE PROBLEMS 


$$
\text { H-2 }
$$




\section{CONTENTS}

APPENDIX H: SAMPLE PROBLEMS

H.1 Sample Problem One: Incident-Free Conditions

H-5

H.2 Input Data File for Sample Problem One: Incident-Free Conditions

H.3 Output Data File for Sample Problem One: Incident-Free Conditions

H.4 Sample Problem Two: Accident Conditions $\mathrm{H}-12$

H.5 Input Data File for Sample Problem Two: Accident Conditions $\mathrm{H}-15$

H.6 Ouput Data File for Sample Problem Two: Accident Conditions. H-18

APPENDIX H REFERENCE

\section{FIGURES}

H.1 Population Cancer Fatality Probability for Sample Problem 2. H-13

H.1 Radionuclide Concentration Isopleths for Sample Problem 2 H-14 


$$
\text { H-4 }
$$




\section{APPENDIX H:}

\section{SAMPLE PROBLEMS}

This appendix illustrates the use of RISKIND through two sample problems. A sample problem for incident-free dose calculations is presented in Sections H.1 through H.3. A sample problem for dose calculations under accident conditions is presented in Sections H.4 through H.6. In the first problem, the impacts to four receptors encountered along the shipment route are estimated. The second problem considers the consequence to a population subgroup located 200 to $400 \mathrm{~m}$ away from a potential accident. Descriptions of the input parameters used in RISKIND are provided in Appendix G.

\section{H.1 SAMPLE PROBLEM ONE: INCIDENT-FREE CONDITIONS}

The first sample problem considers incident-free transportation of spent nuclear fuel (SNF) along a local interstate highway. The four receptors are the nearest resident to the interstate $(75 \mathrm{~m})$, a customer at a gas station by the local interstate on-ramp $(40 \mathrm{~m})$, a child playing in a nearby school yard $(200 \mathrm{~m})$, and a motorist traveling behind the shipment for $15 \mathrm{~min}$ $(20 \mathrm{~m})$. The sample problem input file, as generated by the user interface and used by the FORTRAN calculational portion of the program, is given in Section H.2. The shipping cask is assumed to be a GA-4 truck cask, and the spent fuel is assumed to be 10 years old with a dose rate of $10 \mathrm{mrem} / \mathrm{h}$ at $2 \mathrm{~m}$. The radiation field is $83 \%$ gamma and $17 \%$ neutron in dose. Two modes of exposure are evaluated: one is for a stop with an exposure time of one hour, and the other is for a passing truck. For the motorist, the stop time is set to $0.25 \mathrm{~h}$ to model the time spent following the shipment.

The sample problem output file is given in Section H.3. The output reflects the input parameters and represents the calculated doses for the four receptors for the two modes of exposure. 


\section{H.2 INPUT DATA FILE FOR SAMPLE PROBLEM ONE: INCIDENT-FREE CONDITIONS}

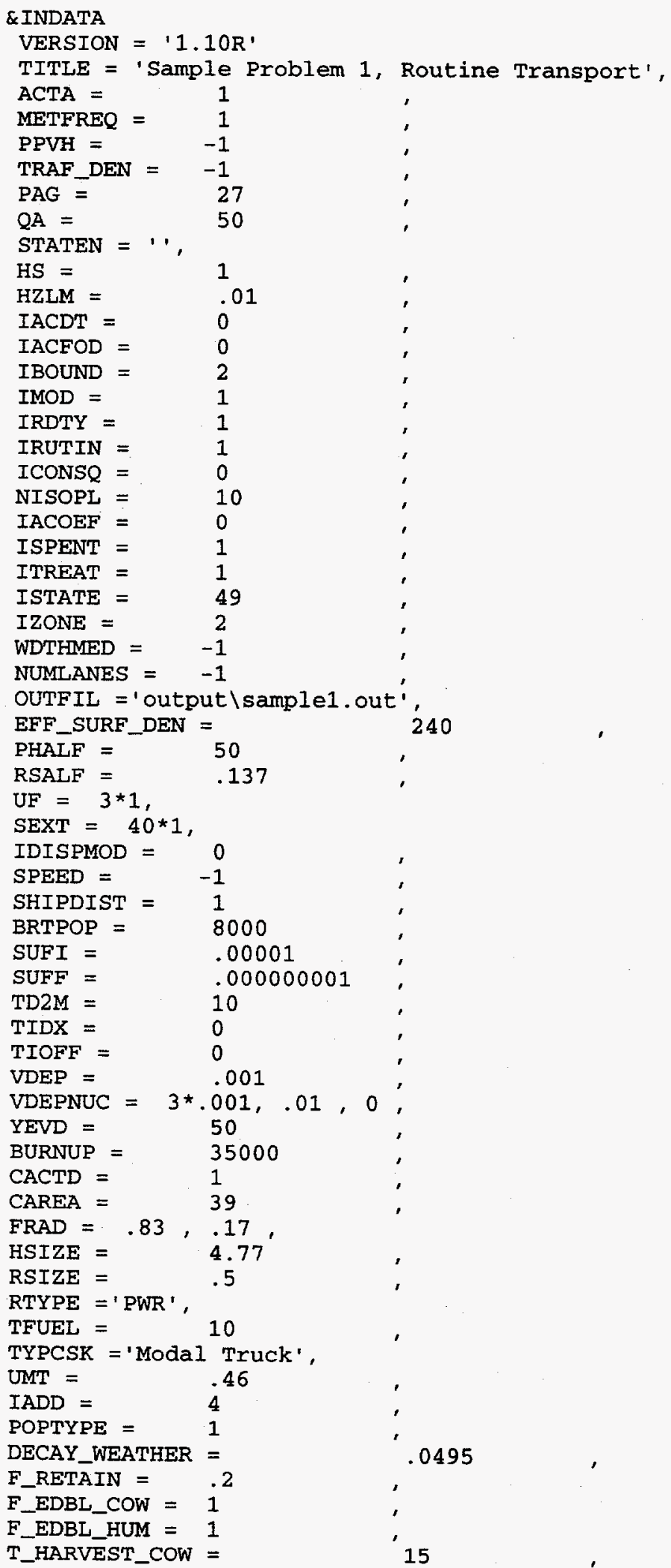




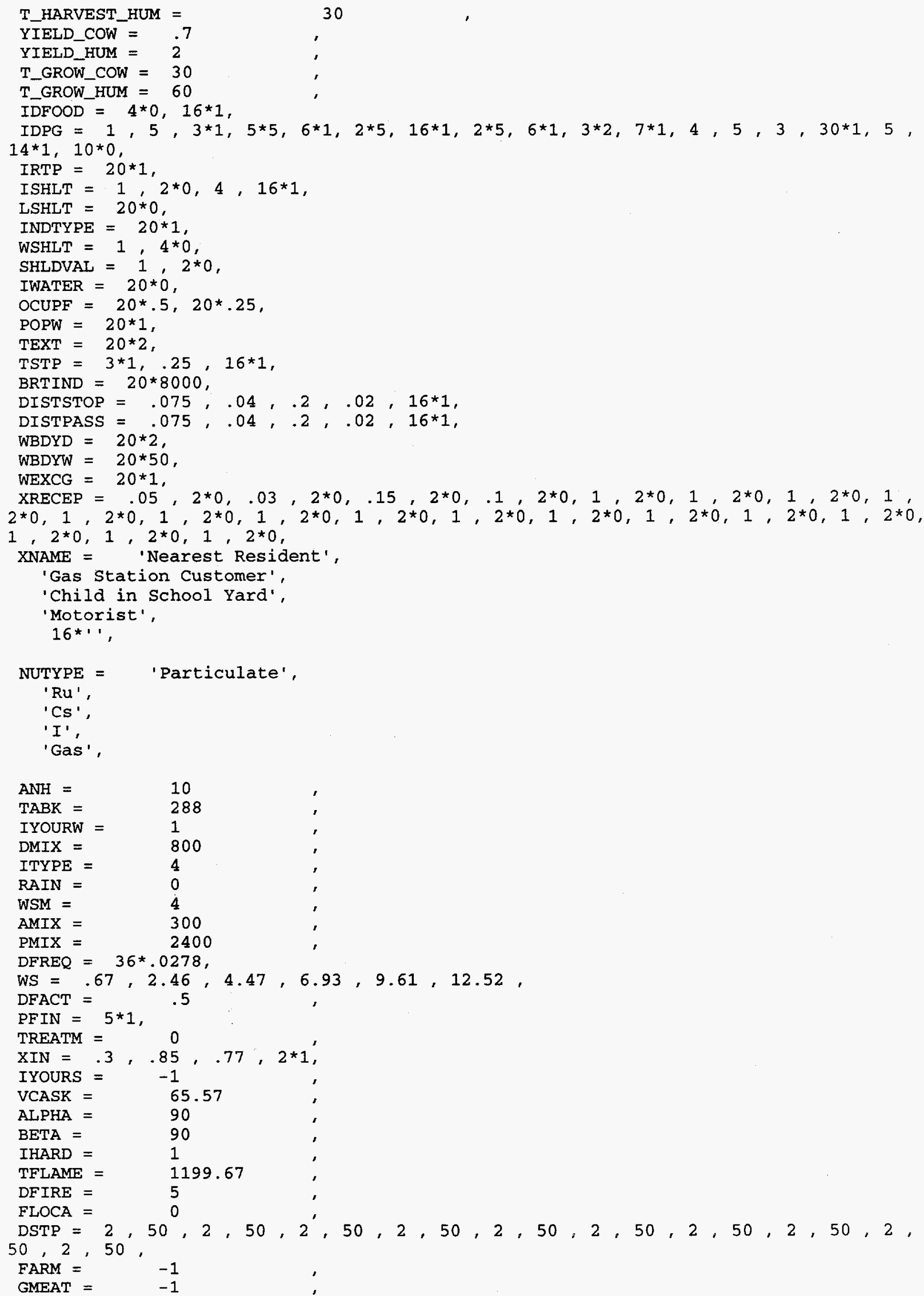




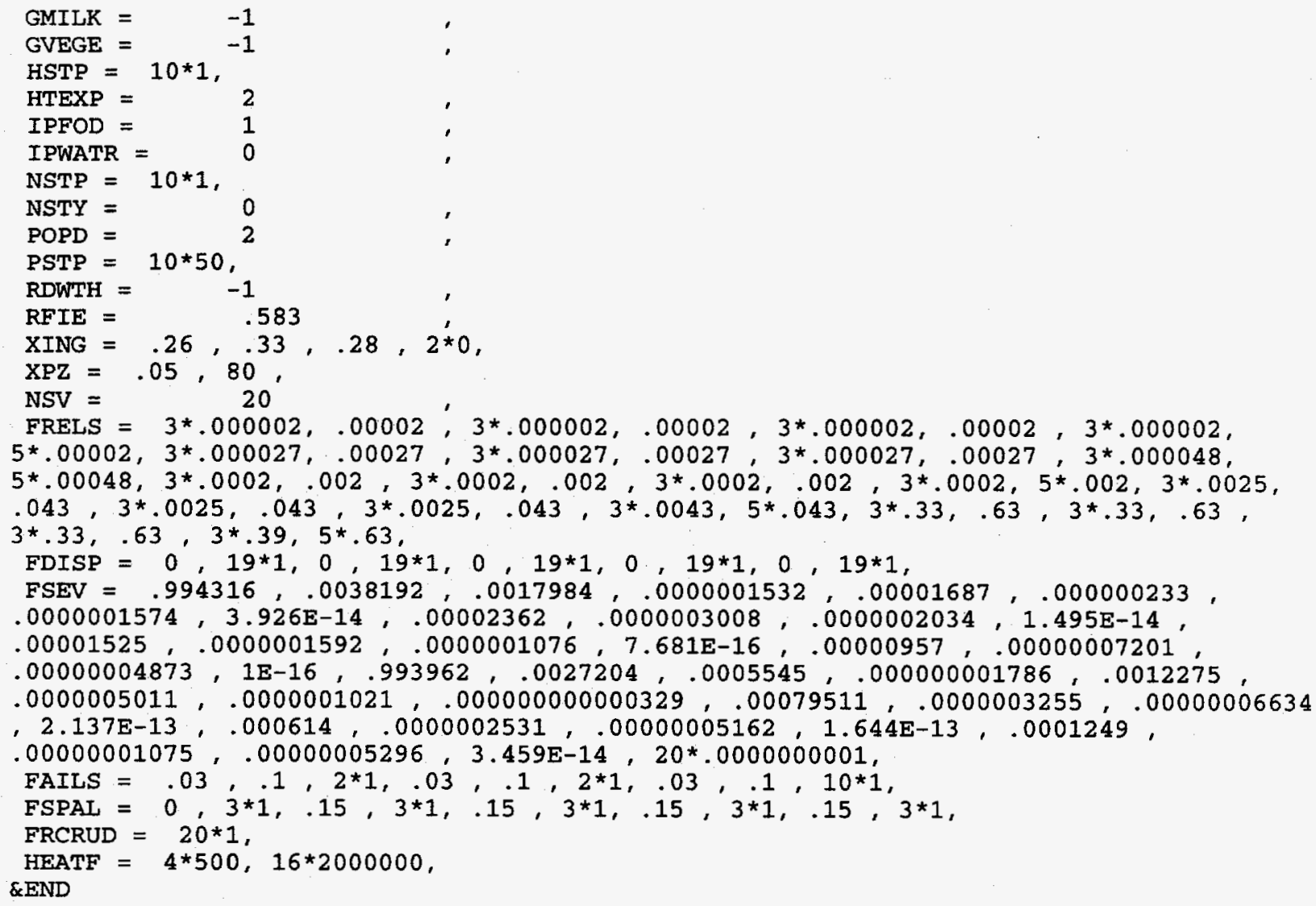




\section{H.3 OUTPUT DATA FILE FOR SAMPLE PROBLEM ONE: INCIDENT-FREE CONDITIONS}

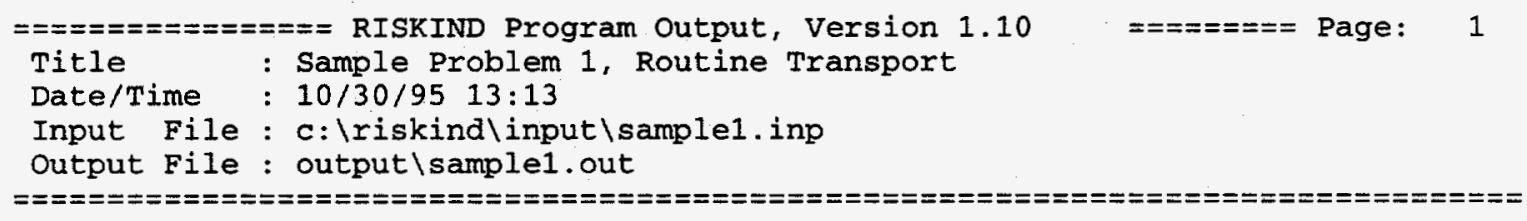

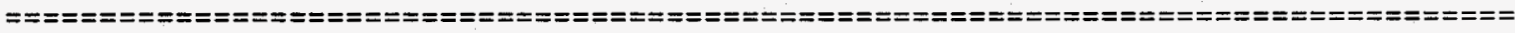

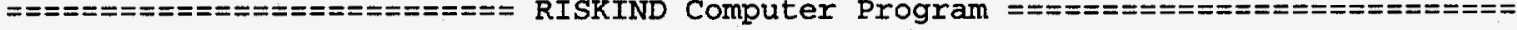

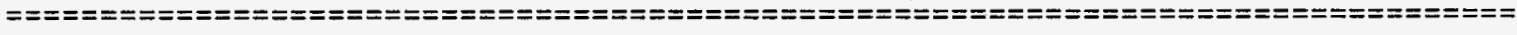

Problem Description

Individual Receptors

Routine Calculations

Note: * next to input description signifies

a data dependent default value 


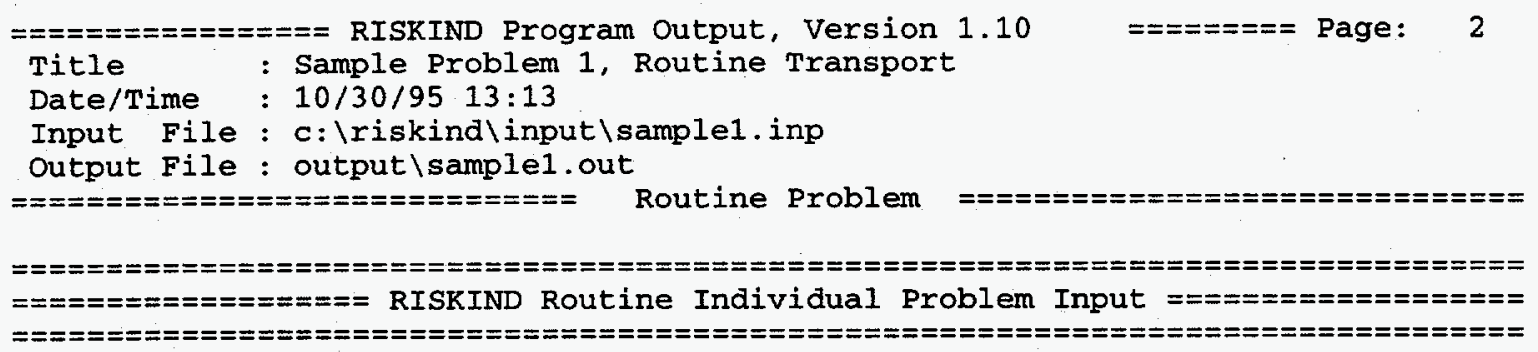

Transport Mode [IMOD]: Truck

Population Zone [IZONE] : Suburban

Dose at $2 \mathrm{~m} \mathrm{[TD2M]:} 10.00 \mathrm{mrem} / \mathrm{hr}$

Measurement offset [TIOFF]: $0.00 \mathrm{~m}$

Gamma Fraction [FRAD(1)]: 0.83

Neutron Fraction [FRAD (2)]: 0.17

Cask Length [HSIZE] : 4.77 m

Cask Radius [RSIZE] : $\quad 0.50 \mathrm{~m}$

Traveling speed [SPEED] ${ }^{*}: 88.00 \mathrm{~km} / \mathrm{hr}$

Individual type [INDTYPE]: Public

Risk Conversion Factors

Non-Fatal Cancers/rem: 1.0E-04

Fatal Cancers/rem: 5.0E-04

Genetic Effects/rem: 1.3E-04

\begin{tabular}{llccc}
\hline & $\begin{array}{c}\text { Stop } \\
\text { Distance } \\
\text { [DISTSTOP] } \\
\text { [km] }\end{array}$ & $\begin{array}{c}\text { Stop } \\
\text { Time } \\
\text { [TSTP] } \\
\text { [hr] }\end{array}$ & $\begin{array}{c}\text { Passing } \\
\text { Distance } \\
\text { [DISTPASS] } \\
\text { [km] }\end{array}$ \\
\hline 1 Nearest Resident & $7.5 \mathrm{E}-02$ & 1.00 & $7.5 \mathrm{E}-02$ \\
2 Gas Station Customer & $4.0 \mathrm{E}-02$ & 1.00 & $4.0 \mathrm{E}-02$ \\
3 Child in School Yard $2.0 \mathrm{E}-01$ & 1.00 & $2.0 \mathrm{E}-01$ \\
4 Motorist & $2.0 \mathrm{E}-02$ & 0.25 & $2.0 \mathrm{E}-02$ \\
\hline
\end{tabular}




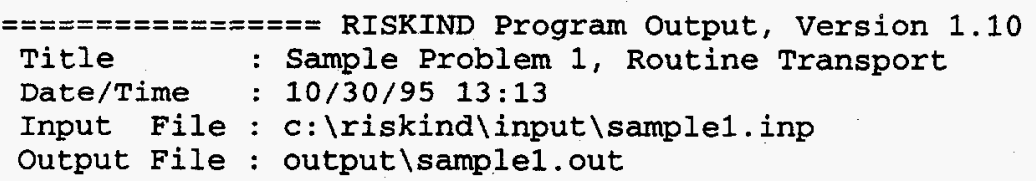

\begin{tabular}{lllll} 
\# Individual Name & $\begin{array}{c}\text { Dose } \\
\text { (rem) }\end{array}$ & $\begin{array}{c}\text { Expected } \\
\text { Non-Fatal } \\
\text { Cancers }\end{array}$ & $\begin{array}{c}\text { Expected } \\
\text { Cancex } \\
\text { Fatalities Effects }\end{array}$ & $\begin{array}{c}\text { Expected } \\
\text { Genetic }\end{array}$ \\
\hline 1 Nearest Resident & $8.3 \mathrm{E}-09$ & $8.3 \mathrm{E}-13$ & $4.2 \mathrm{E}-12$ & $1.1 \mathrm{E}-12$ \\
2 Gas Station Customer & $5.1 \mathrm{E}-08$ & $5.1 \mathrm{E}-12$ & $2.5 \mathrm{E}-11$ & $6.6 \mathrm{E}-12$ \\
3 Child in School Yard & $3.3 \mathrm{E}-09$ & $3.3 \mathrm{E}-13$ & $1.7 \mathrm{E}-12$ & $4.4 \mathrm{E}-13$ \\
4 Motorist & $1.2 \mathrm{E}-07$ & $1.2 \mathrm{E}-11$ & $5.9 \mathrm{E}-11$ & $1.5 \mathrm{E}-11$ \\
\hline
\end{tabular}




\section{H.4 SAMPLE PROBLEM TWO: ACCIDENT CONDITIONS}

The second sample problem considers accident conditions during transport. The input file, as generated by the user interface and used by the FORTRAN calculational portion of the program, is given in Section H.5. In this problem, a collective population dose (consequence) to a specific population subgroup is estimated from accident conditions. This population subgroup extends from 200 to $400 \mathrm{~m}$ from the potential accident site and has an average population density of 600 persons $/ \mathrm{km}^{2}$. The spent fuel is assumed to be pressurized-water reactor fuel, with a burnup of 33,000 megawatt-days per metric ton of initial heavy metal (MWd/MTIHM) and a 10 -year cooling period. Only short-term exposure from the plume passage is assumed. Weather conditions at the time of the potential accident are assumed to be stability category $\mathrm{D}$ and a wind of $4 \mathrm{~m} / \mathrm{s}$ blowing toward the receptor group. The consequence from an accident in the second accident response region, $R(2,1)$, as defined in the modal study (Lawrence Livermore National Laboratory [LLNL] 1987), is estimated.

The sample problem output file is given in Section H.6. The first page of the report gives a brief scenario summary. An input echo is then given starting on page 2; the input parameters are grouped into categories according to their function. Population data tables are followed by the meteorological input data and a table with the shipment parameters, including cask information. Two tables with radionuclide input data are next (pages 4-6), which include the radionuclide inventory retrieved from the SNF database. The inventory is determined on the basis of the cask information given in the preceding table. The radionuclide inventory is accompanied by the dose conversion factors for each radionuclide. This inventory is input to the screening routine described in Appendix $\mathrm{C}$ for determining the radionuclides that dominate the risk estimates for each accident response region of interest.

The input data conclude with a list of general accident parameters that include the release height and the type of dispersion coefficients used. These data are followed by input data, specific to the accident response region under consideration, that contains information such as the radionuclide release fractions and the screened list of radionuclides to be used for risk estimates.

For the population consequence scenario, intermediate calculations are given that present isopleth-specific data such as the number of persons affected, the contaminated area, radionuclide concentrations, and the estimated dose (page 9). Overall collective dose and health risk estimates for the response region are then given in conjunction with a breakdown by exposure pathway. A summary dose table concludes the report output. 
Graphical presentation of the data for a better perspective on the results is available in two formats for population consequences. A breakdown of the population fatality risk is displayed in Figure H.1. Figure H.2 presents a plot of the radionuclide air concentration isopleths estimated for sample problem 2, which shows the extent of the contaminated area under consideration. Both plots are available at the conclusion of a calculation run for display on the user screen with an option to print.

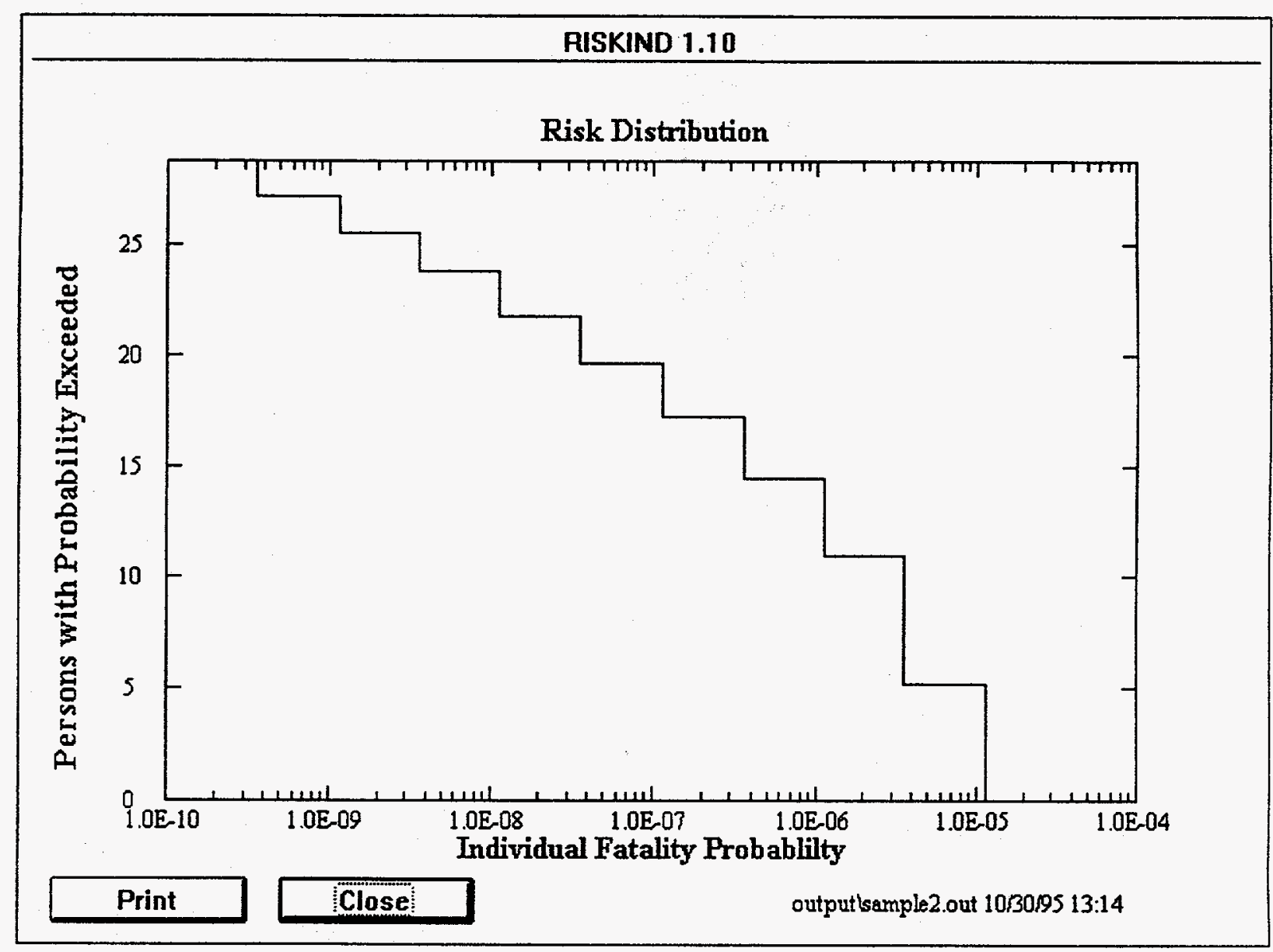

FIGURE H.1 Population Cancer Fatality Probability for Sample Problem 2 


\section{RISKIND 1.10}

Air Isopleths for Population Accident Consequence

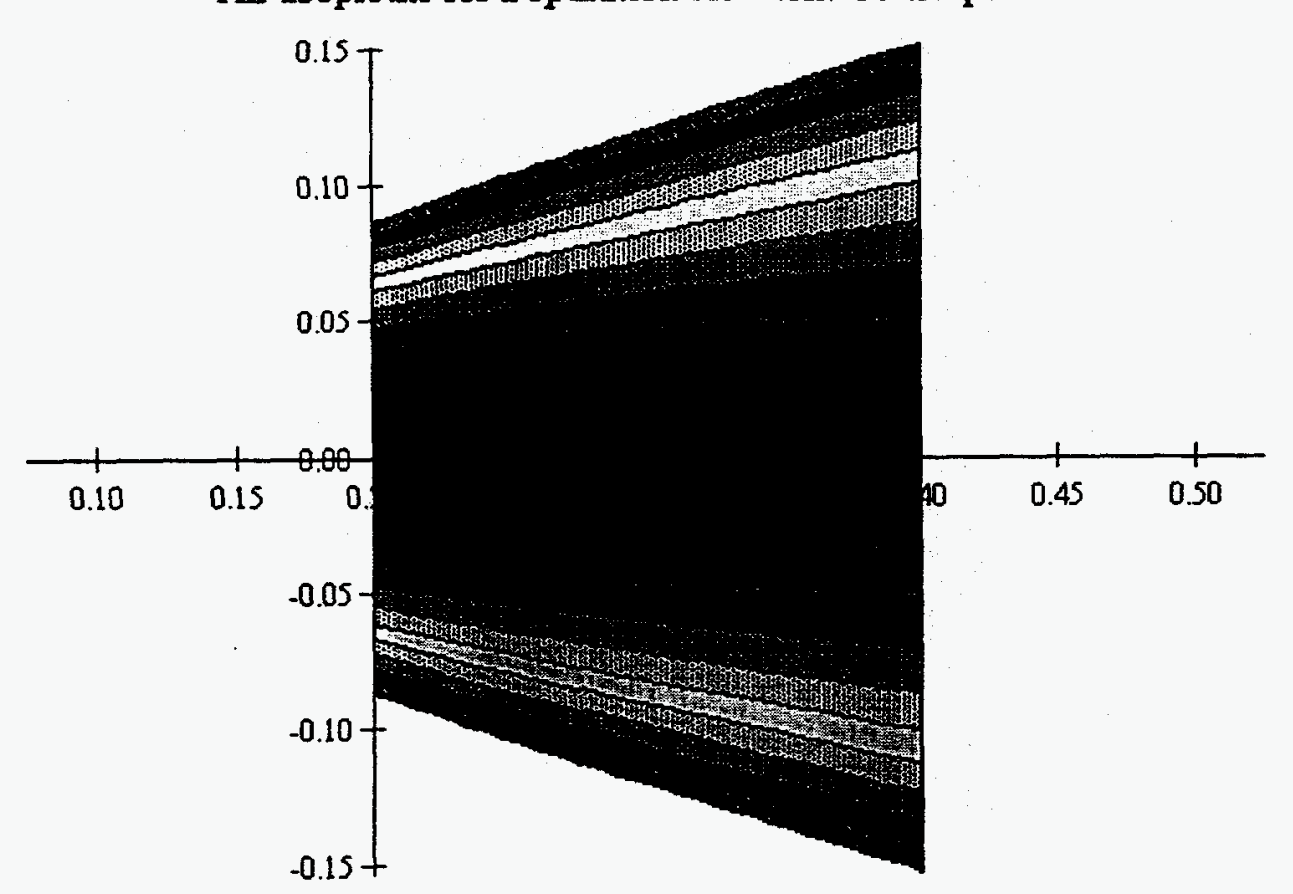

\section{Chis}

$\left(\mathrm{s} / \mathrm{m}^{3}\right)$

2.49E-04

7.88E-05

$2.49 \mathrm{E}-05$

$7.88 \mathrm{E}-06$

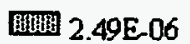

$\square 3.88 \mathrm{E}-07$

2. $2.49 \mathrm{E}-0 ?$

7... 3.88 -08

2.49E-08

7.88E-09

Distance (km)

Print

Close:

output lsample2.out 10/30195 13:14 (D $4.00 \mathrm{~m} / \mathrm{s}$ )

FIGURE H.2 Radionuclide Concentration Isopleths for Sample Problem 2 


\section{H.5 INPUT DATA FILE FOR SAMPLE PROBLEM TWO: ACCIDENT CONDITIONS}

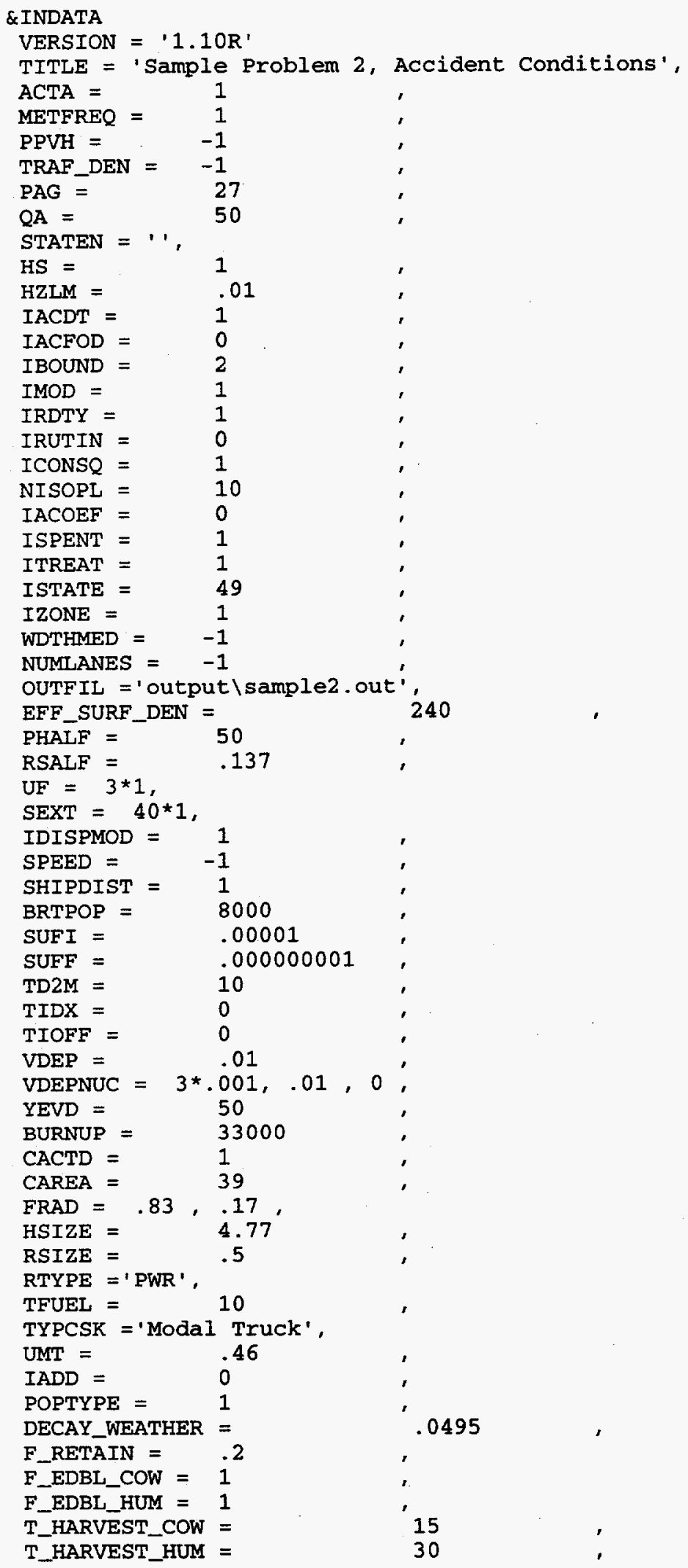




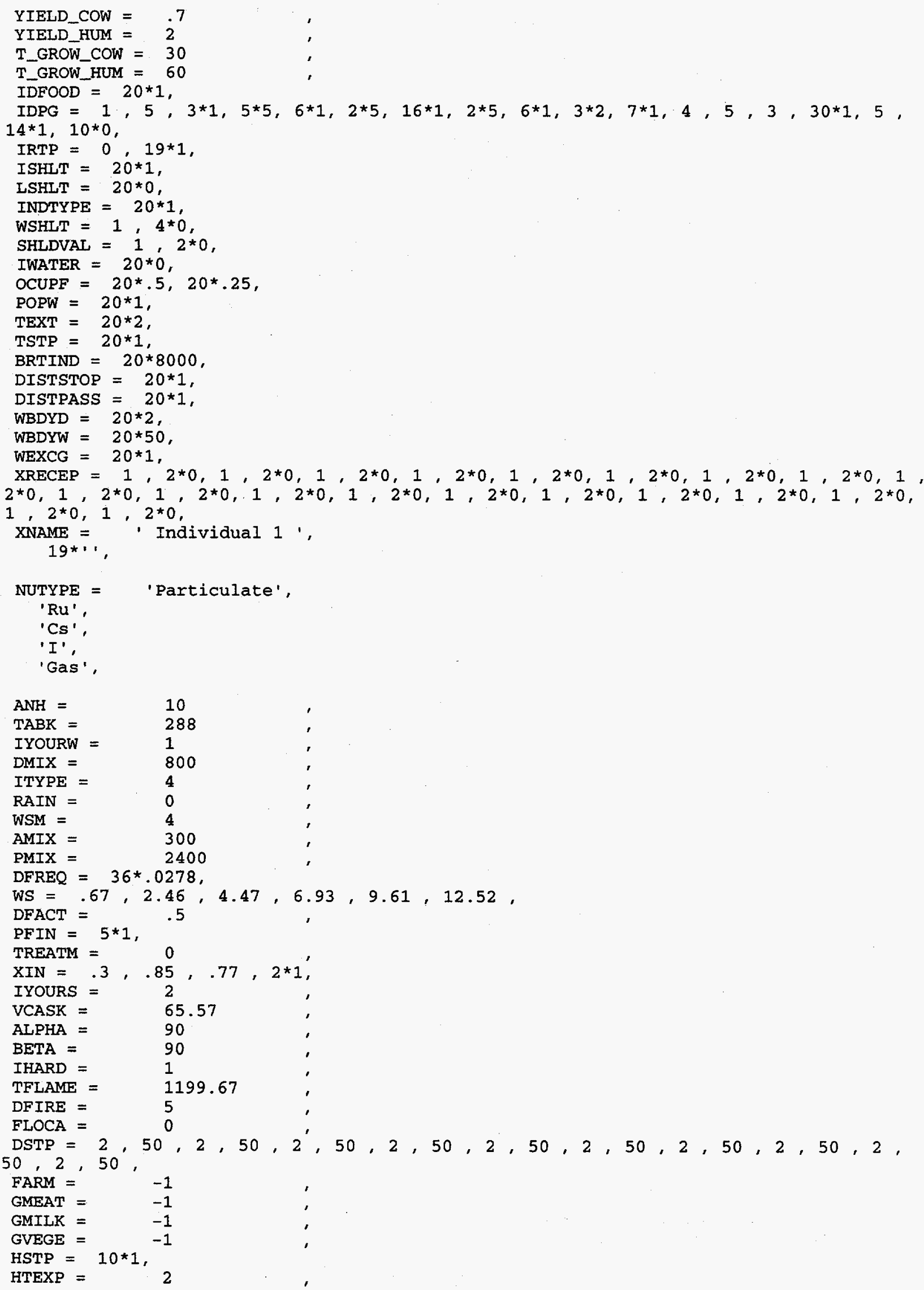




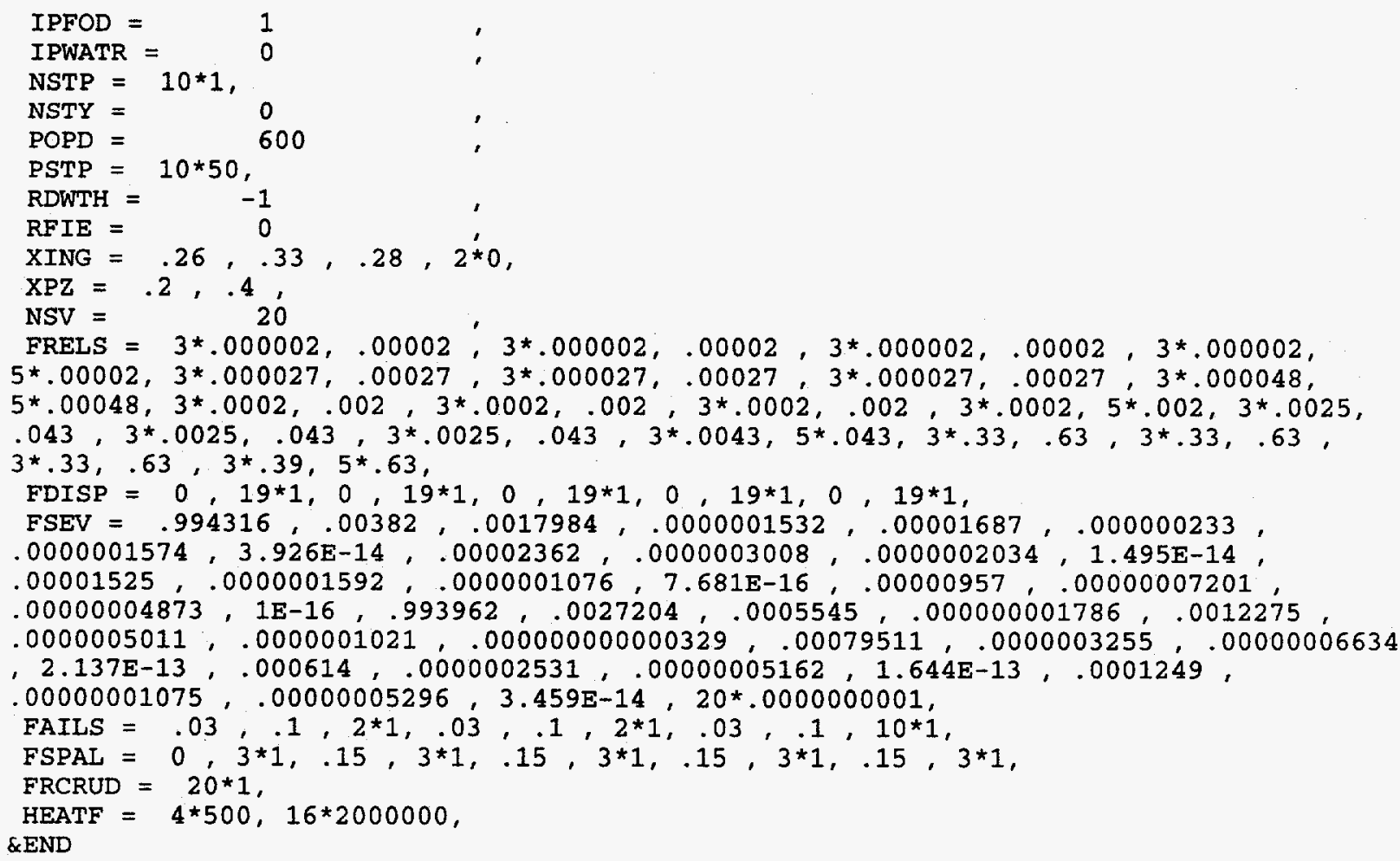




\title{
H.6 OUPUT DATA FILE FOR SAMPLE PROBLEM TWO: ACCIDENT CONDITIONS
}

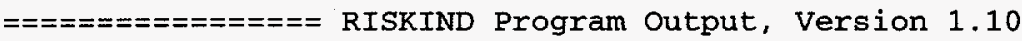 \\ $=ニ=ニ=ニ=$ Page : \\ 1 \\ - Sample Problem 2, Accident Conditions \\ Date/Time : 10/30/95 13:14 \\ Input File: c: \riskind \input\sample2.inp \\ Output File : output \sample2.out

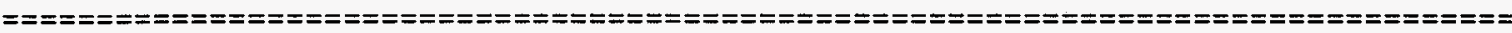

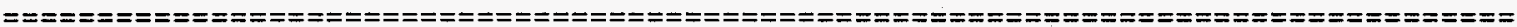

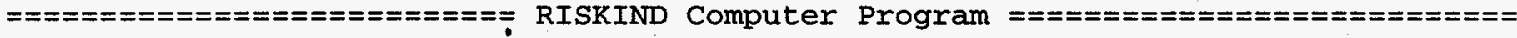

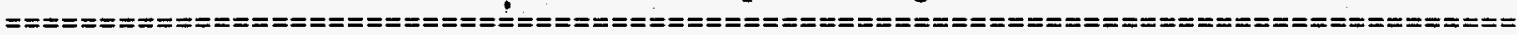

Problem Description

\author{
Population Dose \\ Accident Calculations \\ Single Accident Analysis \\ single Weather Analysis \\ Acute Exposure \\ Plume Inhalation \\ Plume Immersion \\ Early Ground Exposure \\ Exposure to Cask
}

Note: * next to input description signifies

a data dependent default value 
$====== \pm=========$ RISKIND Program Output, Version 1.10

Date/Time: $10 / 30 / 9513: 14$

Input File: c: Iriskind \input \sample2.inp

output File : output $\backslash$ sample2, out

$======== \pm==+=== \pm========== \pm=0$ Input Parameters

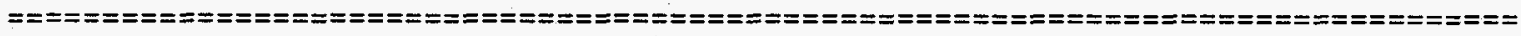

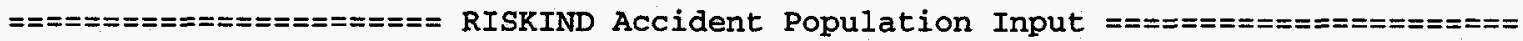

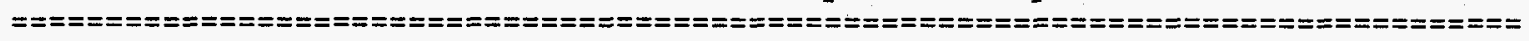

Population Accident Parameters

$\begin{array}{rrr}\text { Minimum Distance [XPZ(1)] : } & 0.20 & \mathrm{~km} \\ \text { Maximum Distance [XPZ(2)] : } & 0.40 & \mathrm{~km} \\ \text { Population Density [POPD] : } & 600.00 \mathrm{person} / \mathrm{km} 2 \\ \text { Average Breathing Rate [BRTPOP] : } & 8000.00 & \mathrm{~m} 3 / \mathrm{yr} \\ \text { Accident Exposure Duration [HTEXP] : } & 2.00 & \mathrm{hr} \\ \text { Accident Indoor Fraction [RFIE] : } & 0.00 \\ \text { Population type [POPTYPE] : } & \text { Public } \\ \text { Risk Conversion Factors } & \\ \text { Non-Fatal Cancers/person-rem: } & 1.0 \mathrm{E}-04 \\ \text { Fatal Cancers/person-rem: } & 5.0 \mathrm{E}-04 \\ \text { Genetic Effects/person-rem: } & 1.3 \mathrm{E}-04 \\ \text { Fraction } & \\ \text { Indoor Shelter [WSHLT] } & \\ \text { Frame House: } & 1.00 \\ \text { Brick House: } & 0.00 \\ \text { Office Bldg: } & 0.00 \\ \text { Automobile : } & 0.00 \\ \text { Other } & 0.00\end{array}$

Derived Shielding Factors

Acute Inhalation: Acute Cloud Shine:

1.00

Acute External:

1.00

1.00 
$\begin{array}{ll}=============\text { RISKIND Program Output, Version } 1.10 \\ \text { Title } & : \text { Sample Problem 2, Accident Conditions } \\ \text { Date/Time } & : 10 / 30 / 9513: 14 \\ \text { Input File : c: } 1 \text { riskind } 1 \text { input } \backslash \text { sample2.inp } \\ \text { Output File : output } \backslash \text { sample2. out } \\ =========================\text { Input Parameters }===\end{array}$

Meteorological Parameters

Dry deposition rate [VDEP] : $1.00 E-02$

Rain fall rate [RAIN] : $0.00 E+00$

Anemometer height [ANH] :

Ambient Temperature [TABK] :

Mixing height [DMIX] :

wind at anemometer [WSM] :

Pasquill stability cat. [ITYPE] :
10.00

288.00

800.00

4.00

D $\mathrm{m} / \mathrm{s}$
$\mathrm{mm} / \mathrm{h}$
$\mathrm{m}$
$\mathrm{K}$
$\mathrm{m}$
$\mathrm{m} / \mathrm{s}$

Shipment Parameters

$\begin{array}{rrr}\text { Transportation Mode [IMOD] : } & \text { Truck } \\ \text { Dose at 2 m [TD2M]: } & 10.00 & \text { mrem/hr } \\ \text { Measurement offset [TIOFF]: } & 0.00 & \mathrm{~m} \\ \text { Gamma Fraction [FRAD(I)] : } & 0.83 & \\ \text { Neutron Fraction [FRAD(2)] : } & 0.17 & \\ \text { Cask Length [HSIZE]: } & 4.77 & \mathrm{~m} \\ \text { Cask Radius [RSIZE] : } & 0.50 & \mathrm{~m} \\ \text { Amount of Uranium [UMT]: } & 0.46 & \mathrm{MTU} \\ \text { Reactor Type [RTYPE] : } & \text { PWR } & \\ \text { Reactor Burnup [BURNUP]: } & 3.30 \mathrm{E}+04 & \mathrm{MWD} \\ \text { Fuel Cooling Time [TFUEL]: } & 10.00 & \mathrm{yr} \\ \text { Surface Area of Cask [CAREA]: } & 39.00 & \mathrm{~m} 2 \\ \text { ace Activity Density [CACTD]: } & 1.00 \mathrm{uCi/cm2}\end{array}$




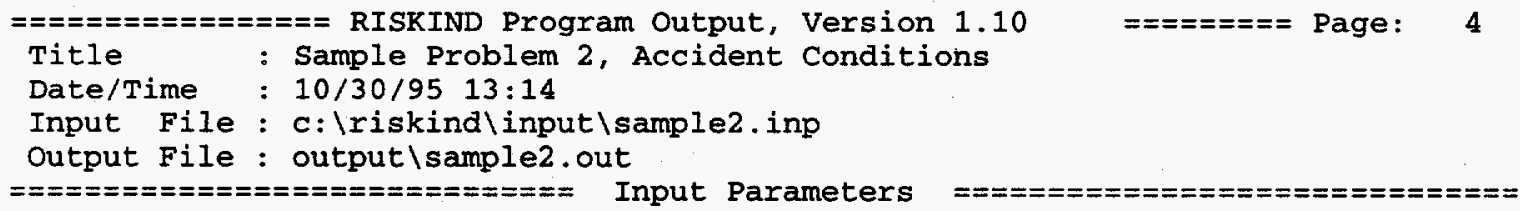

Nuclide Parameters

\begin{tabular}{|c|c|c|c|c|c|c|c|}
\hline $\begin{array}{l}\text { Nuclide } \\
\text { Name }\end{array}$ & $\begin{array}{c}\text { Inventory } \\
\text { Amount } \\
\text { [Ci] }\end{array}$ & $\begin{array}{l}\text { Nucl } \\
=======D 0 \\
\begin{array}{c}\text { Inhalation } \\
{[\mathrm{Sv} / \mathrm{Bq}]}\end{array}\end{array}$ & $\begin{array}{l}\text { lide Invent } \\
\text { ose Convers } \\
\text { Ingestion } \\
\text { [Sv/Bq] }\end{array}$ & $\begin{array}{l}\text { tory and } \\
\text { sion Fact } \\
\text { Cloud } \\
{[\mathrm{Sv} / \mathrm{s}]} \\
{[\mathrm{Bq} / \mathrm{m} 3]}\end{array}$ & $\begin{array}{c}\text { rs }====== \\
\text { Ground } \\
{[\mathrm{Sv} / \mathrm{s}]} \\
{[\mathrm{Bg} / \mathrm{m} 2]}\end{array}$ & $\begin{array}{l}\text { Nucl. } \\
\text { class }\end{array}$ & $\begin{array}{l}\text { Decay } \\
\text { Const. } \\
{[1 / y r]}\end{array}$ \\
\hline $\begin{array}{cr}\text { H } & 3 \\
\text { FE } & 55 \\
\text { CO } & 60 \\
\text { NI } & 63 \\
\text { KR } & 85 \\
\text { SR } & 90 \\
Y & 90 \\
\text { RU106 } \\
\text { RH106 } \\
\text { SB125 } \\
\text { TE125M } \\
\text { CS134 } \\
\text { CS137 } \\
\text { BA137M } \\
\text { CE144 } \\
\text { PR144 } \\
\text { PM147 } \\
\text { SM151 } \\
\text { EU154 } \\
\text { EU155 } \\
\text { PU238 } \\
\text { PU239 } \\
\text { PU240 } \\
\text { PU241 } \\
\text { AM241 } \\
\text { CM244 }\end{array}$ & $\begin{array}{l}2.08 \mathrm{E}+02 \\
1.06 \mathrm{E}+02 \\
1.07 \mathrm{E}+03 \\
1.84 \mathrm{E}+02 \\
2.23 \mathrm{E}+03 \\
2.64 \mathrm{E}+04 \\
2.64 \mathrm{E}+04 \\
2.36 \mathrm{E}+02 \\
2.36 \mathrm{E}+02 \\
5.73 \mathrm{E}+02 \\
1.40 \mathrm{E}+02 \\
2.50 \mathrm{E}+03 \\
3.76 \mathrm{E}+04 \\
3.56 \mathrm{E}+04 \\
6.41 \mathrm{E}+01 \\
6.41 \mathrm{E}+01 \\
4.21 \mathrm{E}+03 \\
1.70 \mathrm{E}+02 \\
1.88 \mathrm{E}+03 \\
6.87 \mathrm{E}+02 \\
1.21 \mathrm{E}+03 \\
1.58 \mathrm{E}+02 \\
2.24 \mathrm{E}+02 \\
3.68 \mathrm{E}+04 \\
8.17 \mathrm{E}+02 \\
7.22 \mathrm{E}+02\end{array}$ & $\begin{array}{l}1.73 \mathrm{E}-11 \\
7.26 \mathrm{E}-10 \\
5.91 \mathrm{E}-08 \\
1.70 \mathrm{E}-09 \\
1.03 \mathrm{E}-11 \\
3.53 \mathrm{E}-07 \\
2.28 \mathrm{E}-09 \\
1.30 \mathrm{E}-07 \\
8.95 \mathrm{E}-10 \\
3.75 \mathrm{E}-09 \\
1.97 \mathrm{E}-09 \\
1.25 \mathrm{E}-08 \\
1.10 \mathrm{E}-08 \\
2.49 \mathrm{E}-09 \\
1.01 \mathrm{E}-07 \\
1.17 \mathrm{E}-11 \\
1.06 \mathrm{E}-08 \\
8.10 \mathrm{E}-09 \\
7.73 \mathrm{E}-08 \\
1.12 \mathrm{E}-08 \\
1.06 \mathrm{E}-04 \\
1.16 \mathrm{E}-04 \\
1.16 \mathrm{E}-04 \\
2.23 \mathrm{E}-06 \\
1.20 \mathrm{E}-04 \\
6.70 \mathrm{E}-05\end{array}$ & $\begin{array}{l}1.73 \mathrm{E}-11 \\
1.64 \mathrm{E}-10 \\
7.28 \mathrm{E}-09 \\
1.56 \mathrm{E}-10 \\
1.03 \mathrm{E}-11 \\
4.14 \mathrm{E}-08 \\
2.91 \mathrm{E}-09 \\
8.30 \mathrm{E}-09 \\
8.95 \mathrm{E}-10 \\
9.85 \mathrm{E}-10 \\
9.92 \mathrm{E}-10 \\
1.98 \mathrm{E}-08 \\
1.59 \mathrm{E}-08 \\
2.49 \mathrm{E}-09 \\
5.71 \mathrm{E}-09 \\
3.15 \mathrm{E}-11 \\
2.83 \mathrm{E}-10 \\
1.05 \mathrm{E}-10 \\
2.58 \mathrm{E}-09 \\
4.13 \mathrm{E}-10 \\
8.65 \mathrm{E}-07 \\
9.56 \mathrm{E}-07 \\
9.56 \mathrm{E}-07 \\
1.85 \mathrm{E}-08 \\
9.84 \mathrm{E}-07 \\
5.45 \mathrm{E}-07\end{array}$ & $\begin{array}{l}0.00 \mathrm{E}+00 \\
0.00 \mathrm{E}+00 \\
1.26 \mathrm{E}-13 \\
0.00 \mathrm{E}+00 \\
1.19 \mathrm{E}-16 \\
1.97 \mathrm{E}-16 \\
1.90 \mathrm{E}-16 \\
1.04 \mathrm{E}-14 \\
1.04 \mathrm{E}-14 \\
2.02 \mathrm{E}-14 \\
4.53 \mathrm{E}-16 \\
7.56 \mathrm{E}-14 \\
2.73 \mathrm{E}-14 \\
2.88 \mathrm{E}-14 \\
2.80 \mathrm{E}-15 \\
1.94 \mathrm{E}-15 \\
6.92 \mathrm{E}-19 \\
3.61 \mathrm{E}-20 \\
6.14 \mathrm{E}-14 \\
2.49 \mathrm{E}-15 \\
4.87 \mathrm{E}-18 \\
4.24 \mathrm{E}-18 \\
4.75 \mathrm{E}-18 \\
2.19 \mathrm{E}-19 \\
8.18 \mathrm{E}-16 \\
4.91 \mathrm{E}-18\end{array}$ & $\begin{array}{l}0.00 \mathrm{E}+00 \\
0.00 \mathrm{E}+00 \\
2.35 \mathrm{E}-15 \\
0.00 \mathrm{E}+00 \\
2.64 \mathrm{E}-18 \\
5.61 \mathrm{E}-18 \\
5.33 \mathrm{E}-18 \\
2.12 \mathrm{E}-16 \\
2.12 \mathrm{E}-16 \\
4.33 \mathrm{E}-16 \\
3.61 \mathrm{E}-17 \\
1.52 \mathrm{E}-15 \\
5.54 \mathrm{E}-16 \\
5.86 \mathrm{E}-16 \\
5.83 \mathrm{E}-17 \\
3.79 \mathrm{E}-17 \\
3.40 \mathrm{E}-20 \\
5.02 \mathrm{E}-21 \\
1.18 \mathrm{E}-15 \\
5.90 \mathrm{E}-17 \\
8.37 \mathrm{E}-19 \\
3.67 \mathrm{E}-19 \\
8.02 \mathrm{E}-19 \\
5.20 \mathrm{E}-21 \\
2.74 \mathrm{E}-17 \\
8.78 \mathrm{E}-19\end{array}$ & $\begin{array}{l}\text { Particul } \\
\text { Particul } \\
\text { Particul } \\
\text { Particul } \\
\text { Gas } \\
\text { Particul } \\
\text { Particul } \\
\text { Ru } \\
\text { Ru } \\
\text { Particul } \\
\text { Particul } \\
\text { Cs } \\
\text { Cs } \\
\text { Particul } \\
\text { Particul } \\
\text { Particul } \\
\text { Particul } \\
\text { Particul } \\
\text { Particul } \\
\text { Particul } \\
\text { Particul } \\
\text { Particul } \\
\text { Particul } \\
\text { Particul } \\
\text { Particul } \\
\text { Particul }\end{array}$ & $\begin{array}{l}5.60 \mathrm{E}-02 \\
2.60 \mathrm{E}-01 \\
1.30 \mathrm{E}-01 \\
6.90 \mathrm{E}-03 \\
6.50 \mathrm{E}-02 \\
2.40 \mathrm{E}-02 \\
9.50 \mathrm{E}+01 \\
6.90 \mathrm{E}-01 \\
7.30 \mathrm{E}+05 \\
2.50 \mathrm{E}-01 \\
4.40 \mathrm{E}+00 \\
3.40 \mathrm{E}-01 \\
2.30 \mathrm{E}-02 \\
1.40 \mathrm{E}+05 \\
8.90 \mathrm{E}-01 \\
2.10 \mathrm{E}+04 \\
2.60 \mathrm{E}-01 \\
7.70 \mathrm{E}-03 \\
7.90 \mathrm{E}-02 \\
1.40 \mathrm{E}-01 \\
7.90 \mathrm{E}-03 \\
2.90 \mathrm{E}-05 \\
1.10 \mathrm{E}-04 \\
4.80 \mathrm{E}-02 \\
1.60 \mathrm{E}-03 \\
3.80 \mathrm{E}-02\end{array}$ \\
\hline
\end{tabular}




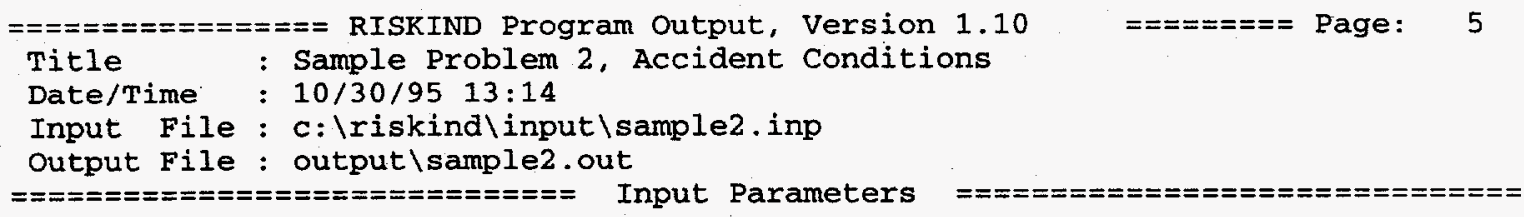

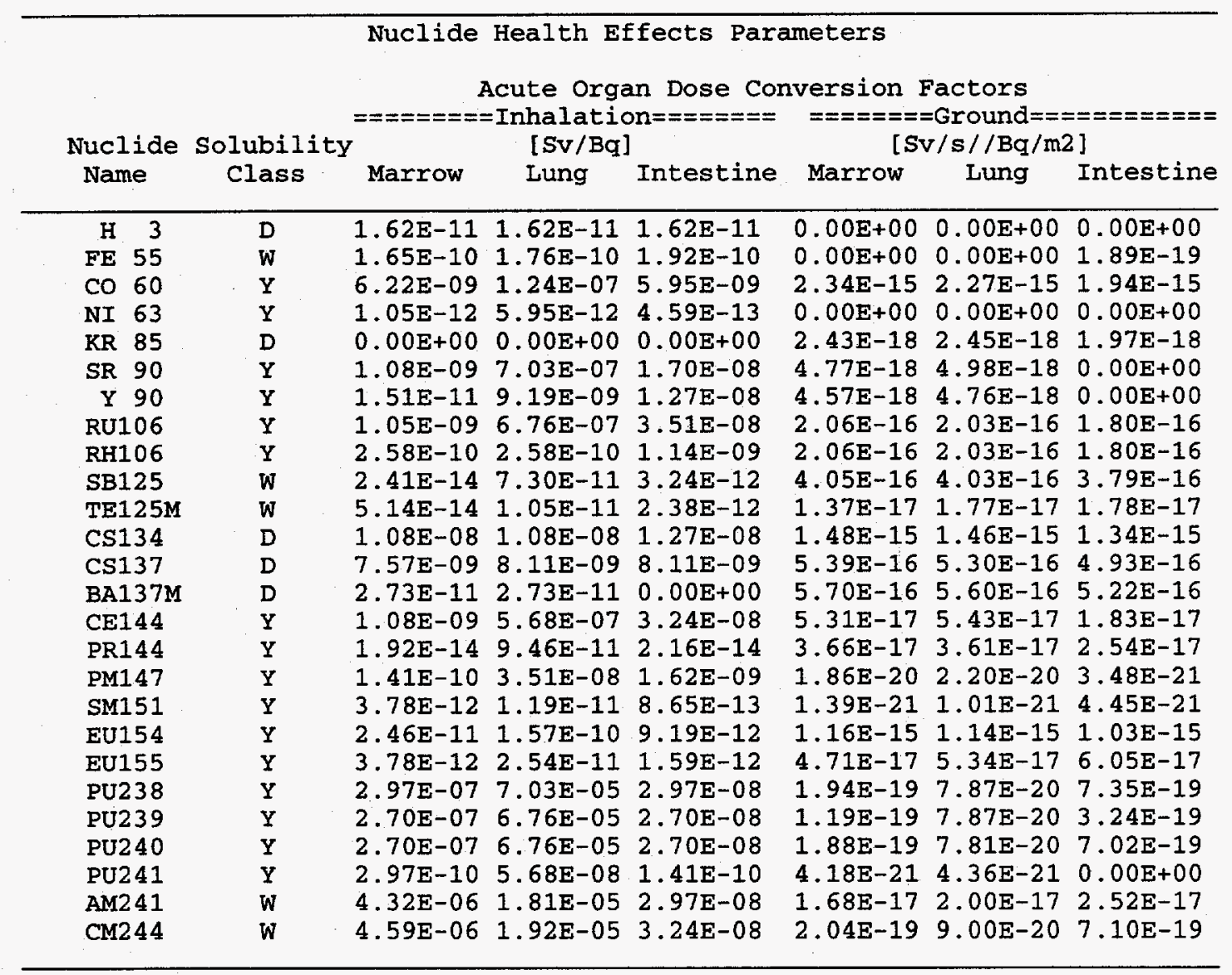




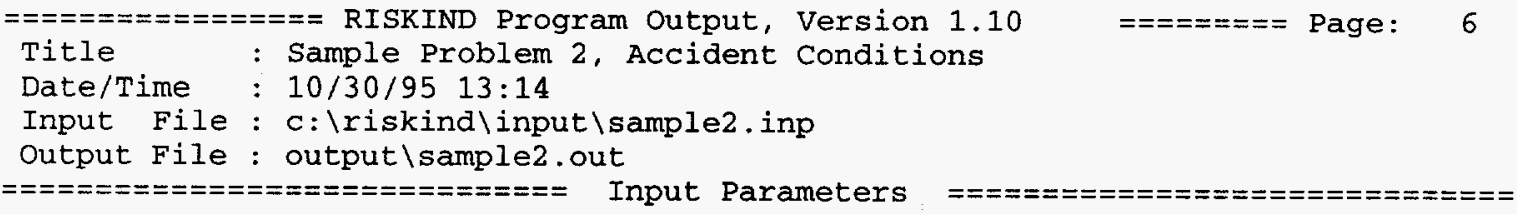

Nuclide Health Effects Parameters

Acute Organ Dose Conversion Factors

$=========$ Cloudshine $========$

Name Marrow [S Lung Intestine

\begin{tabular}{|c|c|c|c|}
\hline $\mathrm{H} 3$ & $0.00 \mathrm{E}+00$ & $0.00 \mathrm{E}+00$ & $0.00 \mathrm{E}+00$ \\
\hline FE 55 & $0.00 E+00$ & $0.00 \mathrm{E}+00$ & $9.85 E-19$ \\
\hline CO 60 & $1.23 E-13$ & $1.24 \mathrm{E}-13$ & $1.11 \mathrm{E}-13$ \\
\hline NI 63 & $0.00 E+00$ & $0.00 \mathrm{E}+00$ & $0.00 \mathrm{E}+00$ \\
\hline KR 85 & $1.09 \mathrm{E}-16$ & 1. $14 \mathrm{E}-16$ & $9.59 \mathrm{E}-17$ \\
\hline SR 90 & $1.68 \mathrm{E}-16$ & $1.84 E-16$ & $0.00 \mathrm{E}+00$ \\
\hline Y 90 & $1.62 \mathrm{E}-16$ & $1.77 \mathrm{E}-16$ & $0.00 \mathrm{E}+00$ \\
\hline RU106 & $9.76 \mathrm{E}-15$ & $1.01 \mathrm{E}-14$ & $8.99 \mathrm{E}-15$ \\
\hline RH106 & $9.76 \mathrm{E}-15$ & $1.01 \mathrm{E}-14$ & $8.99 E-15$ \\
\hline SB125 & $1.88 \mathrm{E}-14$ & $1.95 \mathrm{E}-14$ & $1.82 \mathrm{E}-14$ \\
\hline TE125M & $1.86 \mathrm{E}-16$ & $2.23 \mathrm{E}-16$ & $4.10 E-16$ \\
\hline $\operatorname{cs} 134$ & $7.19 \mathrm{E}-14$ & $7.37 \mathrm{E}-14$ & $6.84 E-14$ \\
\hline CS137 & $2.59 \mathrm{E}-14$ & $2.65 \mathrm{E}-14$ & $2.48 \mathrm{E}-14$ \\
\hline BA137M & $2.73 E-14$ & $2.80 E-14$ & $2.61 E-14$ \\
\hline CE144 & $2.55 E-15$ & $2.68 \mathrm{E}-15$ & $7.73 E-16$ \\
\hline PR144 & $1.88 \mathrm{E}-15$ & $1.91 \mathrm{E}-15$ & 1. $52 \mathrm{E}-15$ \\
\hline PM147 & 4. $46 E-19$ & $5.45 \mathrm{E}-19$ & 1. $55 \mathrm{E}-19$ \\
\hline SM151 & $1.13 E-20$ & $7.13 E-21$ & $3.91 E-20$ \\
\hline EU154 & $5.87 \mathrm{E}-14$ & $5.99 E-14$ & $5.54 \mathrm{E}-14$ \\
\hline EU155 & $1.85 E-15$ & $2.22 E-15$ & $2.42 \mathrm{E}-15$ \\
\hline PU238 & $1.68 \mathrm{E}-18$ & $1.06 \mathrm{E}-18$ & $3.77 E-18$ \\
\hline PU239 & $2.67 \mathrm{E}-18$ & $2.65 E-18$ & $3.50 E-18$ \\
\hline PU240 & 1. $66 \mathrm{E}-18$ & $1.09 \mathrm{E}-18$ & $3.69 E-18$ \\
\hline PU241 & $1.75 E-19$ & $1.99 \mathrm{E}-19$ & $0.00 E+00$ \\
\hline AM2 41 & $5.21 E-16$ & $6.74 E-16$ & $8.00 E-16$ \\
\hline CM244 & 1. $46 \mathrm{E}-18$ & $7.07 E-19$ & $3.57 E-18$ \\
\hline
\end{tabular}




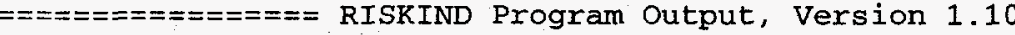

Title : Sample Problem 2, Accident Conditions

Date/Time : 10/30/95 13:14

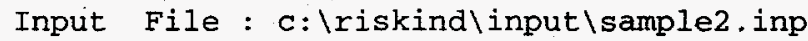

Output File : output Isample2.out

$==============$ Input Parameters - Accident Response Region: $2===============$

Accident Parameters

Physical Release Height [HS]:

1.00 $\mathrm{m}$

Dispersion Model Coefficients [IDISPMOD]: Pasquill-Gifford Accident Analysis Type: Consequence

Accident Response Region Parameters

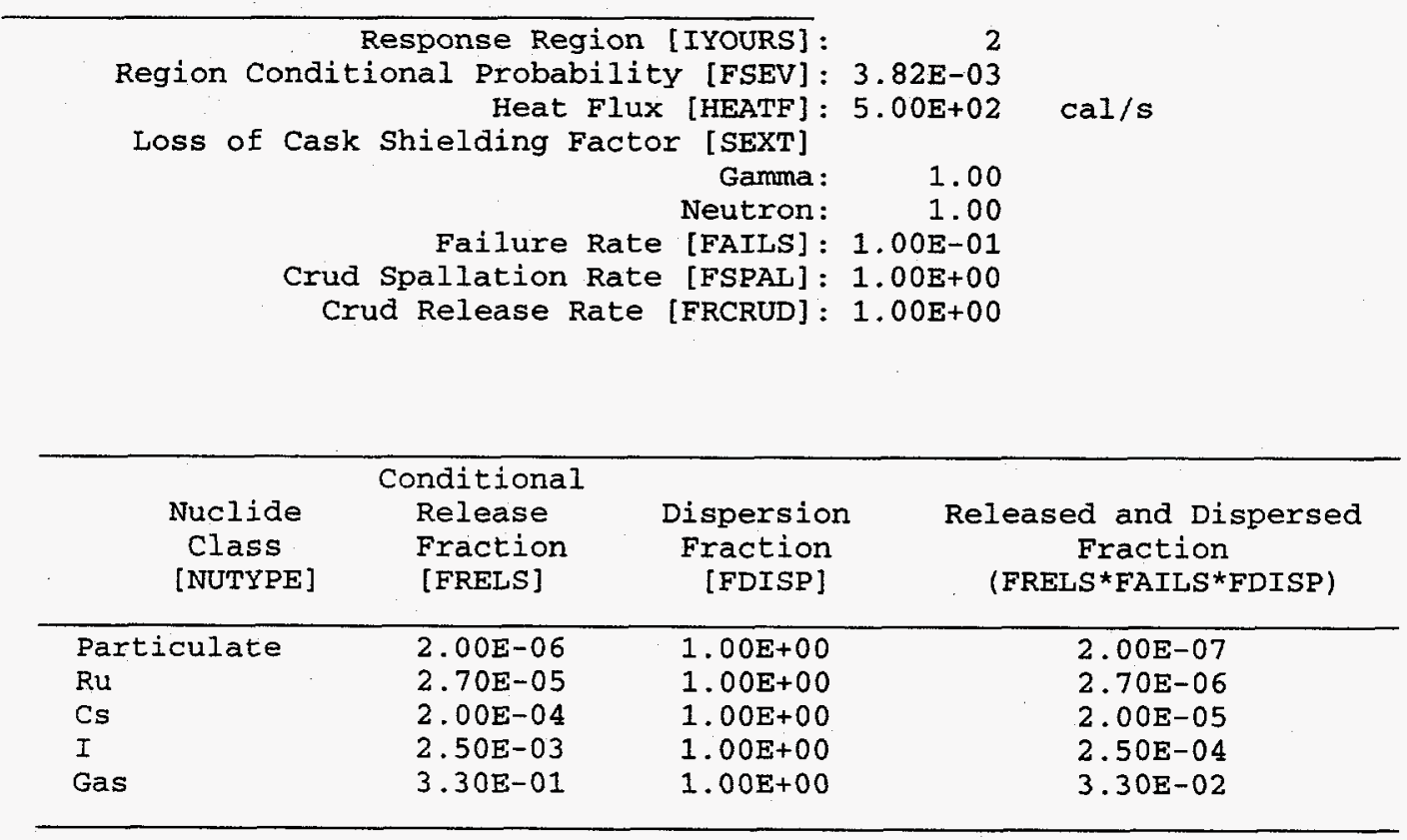




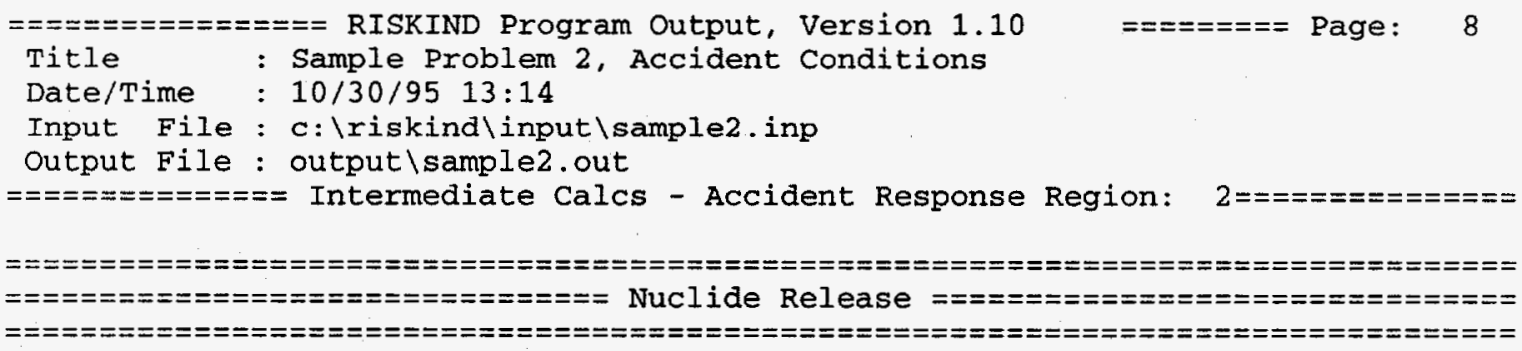

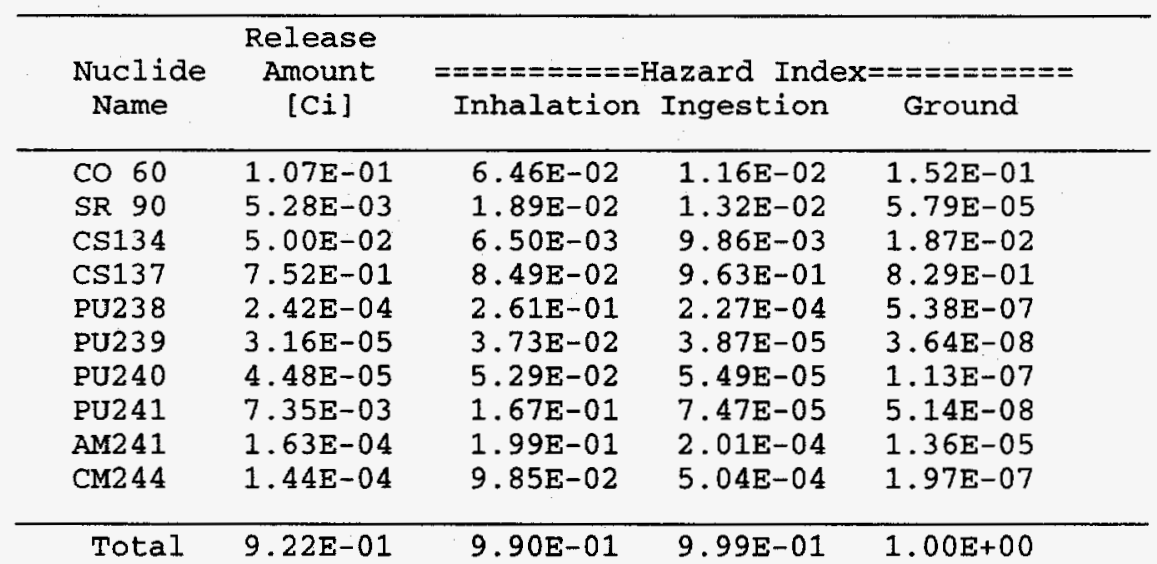


$===============$ RISKIND Program Output, Version 1.10

: Sample Problem 2, Accident Conditions

Date/Time : 10/30/95 13:14

Input File : c:\riskind \input \sample2.inp

Output File : output \sample2,out

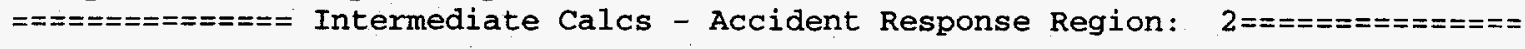

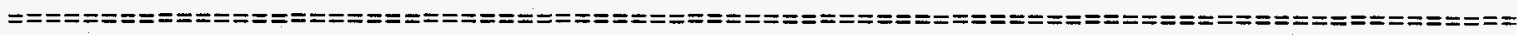

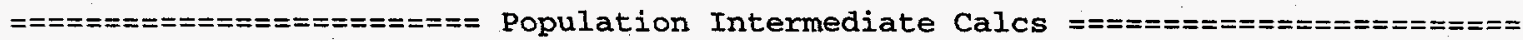

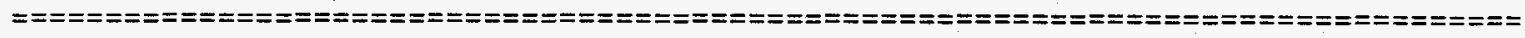

Integral of $\mathrm{X} / \mathrm{Q}(\mathrm{air}): 3.10 \mathrm{E}+00 \quad \mathrm{~s} / \mathrm{m}$

Integral of $X / Q$ (ground): $3.10 \mathrm{E}-02$ unitless

Effective Release Height: $1.49 \mathrm{E}+00 \mathrm{~m}$

\begin{tabular}{|c|c|c|c|c|}
\hline \multirow[b]{2}{*}{$\underset{\#}{\text { Area }}$} & \multirow{2}{*}{\multicolumn{4}{|c|}{ 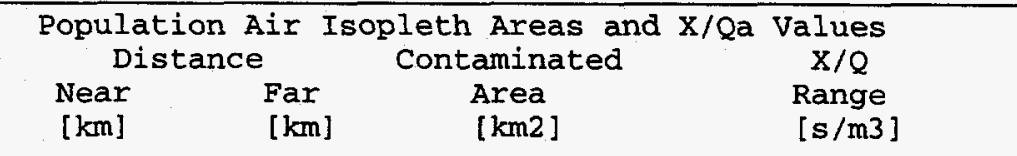 }} \\
\hline & & & & \\
\hline $\begin{array}{r}1 \\
2 \\
3 \\
4 \\
5 \\
6 \\
7 \\
8 \\
9 \\
10\end{array}$ & $\begin{array}{l}2.00 \mathrm{E}-01 \\
2.00 \mathrm{E}-01 \\
2.00 \mathrm{E}-01 \\
2.00 \mathrm{E}-01 \\
2.00 \mathrm{E}-01 \\
2.00 \mathrm{E}-01 \\
2.00 \mathrm{E}-01 \\
2.00 \mathrm{E}-01 \\
2.00 \mathrm{E}-01 \\
2.00 \mathrm{E}-01\end{array}$ & $\begin{array}{l}-3.91 \mathrm{E}-01 \\
-4.00 \mathrm{E}-01 \\
-4.00 \mathrm{E}-01 \\
-4.00 \mathrm{E}-01 \\
-4.00 \mathrm{E}-01 \\
-4.00 \mathrm{E}-01 \\
-4.00 \mathrm{E}-01 \\
-4.00 \mathrm{E}-01 \\
-4.00 \mathrm{E}-01 \\
-4.00 \mathrm{E}-01\end{array}$ & $\begin{array}{l}8.59 \mathrm{E}-03 \\
9.70 \mathrm{E}-03 \\
5.84 \mathrm{E}-03 \\
4.66 \mathrm{E}-03 \\
4.00 \mathrm{E}-03 \\
3.56 \mathrm{E}-03 \\
3.24 \mathrm{E}-03 \\
3.00 \mathrm{E}-03 \\
2.80 \mathrm{E}-03 \\
2.63 \mathrm{E}-03\end{array}$ & $\begin{array}{l}4.43 \mathrm{E}-04-1.40 \mathrm{E}-04 \\
1.40 \mathrm{E}-04-4.43 \mathrm{E}-05 \\
4.43 \mathrm{E}-05-1.40 \mathrm{E}-05 \\
1.40 \mathrm{E}-05-4.43 \mathrm{E}-06 \\
4.43 \mathrm{E}-06-1.40 \mathrm{E}-06 \\
1.40 \mathrm{E}-06-4.43 \mathrm{E}-07 \\
4.43 \mathrm{E}-07-1.40 \mathrm{E}-07 \\
1.40 \mathrm{E}-07-4.43 \mathrm{E}-08 \\
4.43 \mathrm{E}-08-1.40 \mathrm{E}-08 \\
1.40 \mathrm{E}-08-4.43 \mathrm{E}-09\end{array}$ \\
\hline
\end{tabular}


$================$ RISKIND Program Output, Version 1.10

$=========$ Page: 10 Title : Sample Problem 2, Accident Conditions Date/Time : 10/30/95 13:14

Input File: c: \riskind \input \sample2.inp

Output File : output isample2 .out

$=============$ Intermediate Calcs - Accident Response Region: $2=============$

\begin{tabular}{ccccc}
\hline \multicolumn{7}{c}{$\begin{array}{c}\text { Population Ground } \\
\text { Distance } \\
\#\end{array}$} & $\begin{array}{c}\text { Near } \\
{[\mathrm{km}]}\end{array}$ & $\begin{array}{c}\text { Far } \\
{[\mathrm{km}]}\end{array}$ & $\begin{array}{c}\text { Isopleth Areas and X/Qg Values } \\
\text { Contaminated } \\
\text { Area } \\
{[\mathrm{km} 2]}\end{array}$ & $\begin{array}{c}\text { X/Qg } \\
\text { Range } \\
{[1 / \mathrm{m} 2]}\end{array}$ \\
\hline 1 & $2.00 \mathrm{E}-01-3.91 \mathrm{E}-01$ & $8.59 \mathrm{E}-03$ & $4.43 \mathrm{E}-06-1.40 \mathrm{E}-06$ \\
2 & $2.00 \mathrm{E}-01-4.00 \mathrm{E}-01$ & $9.70 \mathrm{E}-03$ & $1.40 \mathrm{E}-06-4.43 \mathrm{E}-07$ \\
3 & $2.00 \mathrm{E}-01-4.00 \mathrm{E}-01$ & $5.84 \mathrm{E}-03$ & $4.43 \mathrm{E}-07-1.40 \mathrm{E}-07$ \\
4 & $2.00 \mathrm{E}-01-4.00 \mathrm{E}-01$ & $4.66 \mathrm{E}-03$ & $1.40 \mathrm{E}-07-4.43 \mathrm{E}-08$ \\
5 & $2.00 \mathrm{E}-01-4.00 \mathrm{E}-01$ & $4.00 \mathrm{E}-03$ & $4.43 \mathrm{E}-08-1.40 \mathrm{E}-08$ \\
6 & $2.00 \mathrm{E}-01-4.00 \mathrm{E}-01$ & $3.56 \mathrm{E}-03$ & $1.40 \mathrm{E}-08-4.43 \mathrm{E}-09$ \\
7 & $2.00 \mathrm{E}-01-4.00 \mathrm{E}-01$ & $3.24 \mathrm{E}-03$ & $4.43 \mathrm{E}-09-1.40 \mathrm{E}-09$ \\
8 & $2.00 \mathrm{E}-01-4.00 \mathrm{E}-01$ & $3.00 \mathrm{E}-03$ & $1.40 \mathrm{E}-09-4.43 \mathrm{E}-10$ \\
9 & $2.00 \mathrm{E}-01-4.00 \mathrm{E}-01$ & $2.80 \mathrm{E}-03$ & $4.43 \mathrm{E}-10-1.40 \mathrm{E}-10$ \\
10 & $2.00 \mathrm{E}-01-4.00 \mathrm{E}-01$ & $2.63 \mathrm{E}-03$ & $1.40 \mathrm{E}-10-403-4.43 \mathrm{E}-11$ \\
\hline
\end{tabular}




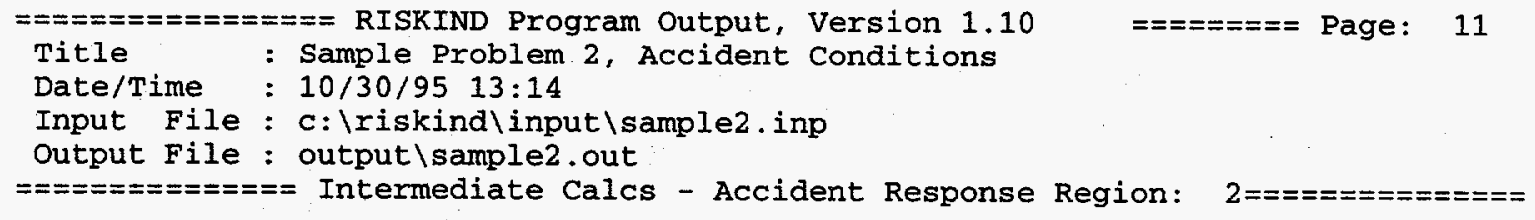

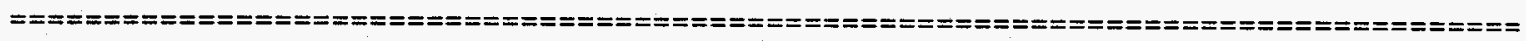

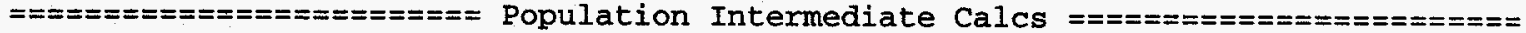

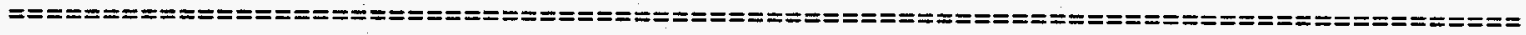

\begin{tabular}{cccccc}
\hline $\begin{array}{c}\text { Area } \\
\#\end{array}$ & $\begin{array}{c}\text { People } \\
\text { Affected } \\
\text { [people] }\end{array}$ & $\begin{array}{c}\text { Area } \\
\text { Dose } \\
\text { [person-rem] } \\
\text { [phort-Term } \\
\text { [rem] }\end{array}$ & $\begin{array}{c}\text { Long-Term } \\
\text { [rem] }\end{array}$ & $\begin{array}{c}\text { Clean-up } \\
\text { Factor }\end{array}$ \\
\hline 1 & $5.15 \mathrm{E}+00$ & $1.17 \mathrm{E}-01$ & $2.28 \mathrm{E}-02$ & $0.00 \mathrm{E}+00$ & $1.00 \mathrm{E}+00$ \\
2 & $5.82 \mathrm{E}+00$ & $4.20 \mathrm{E}-02$ & $7.21 \mathrm{E}-03$ & $0.00 \mathrm{E}+00$ & $1.00 \mathrm{E}+00$ \\
3 & $3.50 \mathrm{E}+00$ & $7.98 \mathrm{E}-03$ & $2.28 \mathrm{E}-03$ & $0.00 \mathrm{E}+00$ & $1.00 \mathrm{E}+00$ \\
4 & $2.80 \mathrm{E}+00$ & $2.02 \mathrm{E}-03$ & $7.21 \mathrm{E}-04$ & $0.00 \mathrm{E}+00$ & $1.00 \mathrm{E}+00$ \\
5 & $2.40 \mathrm{E}+00$ & $5.47 \mathrm{E}-04$ & $2.28 \mathrm{E}-04$ & $0.00 \mathrm{E}+00$ & $1.00 \mathrm{E}+00$ \\
6 & $2.14 \mathrm{E}+00$ & $1.54 \mathrm{E}-04$ & $7.21 \mathrm{E}-05$ & $0.00 \mathrm{E}+00$ & $1.00 \mathrm{E}+00$ \\
7 & $1.94 \mathrm{E}+00$ & $4.43 \mathrm{E}-05$ & $2.28 \mathrm{E}-05$ & $0.00 \mathrm{E}+00$ & $1.00 \mathrm{E}+00$ \\
8 & $1.80 \mathrm{E}+00$ & $1.30 \mathrm{E}-05$ & $7.21 \mathrm{E}-06$ & $0.00 \mathrm{E}+00$ & $1.00 \mathrm{E}+00$ \\
9 & $1.68 \mathrm{E}+00$ & $3.83 \mathrm{E}-06$ & $2.28 \mathrm{E}-06$ & $0.00 \mathrm{E}+00$ & $1.00 \mathrm{E}+00$ \\
10 & $1.58 \mathrm{E}+00$ & $1.14 \mathrm{E}-06$ & $7.21 \mathrm{E}-07$ & $0.00 \mathrm{E}+00$ & $1.00 \mathrm{E}+00$ \\
\hline Totals & $2.88 \mathrm{E}+01$ & $1.70 \mathrm{E}-01$ & & &
\end{tabular}




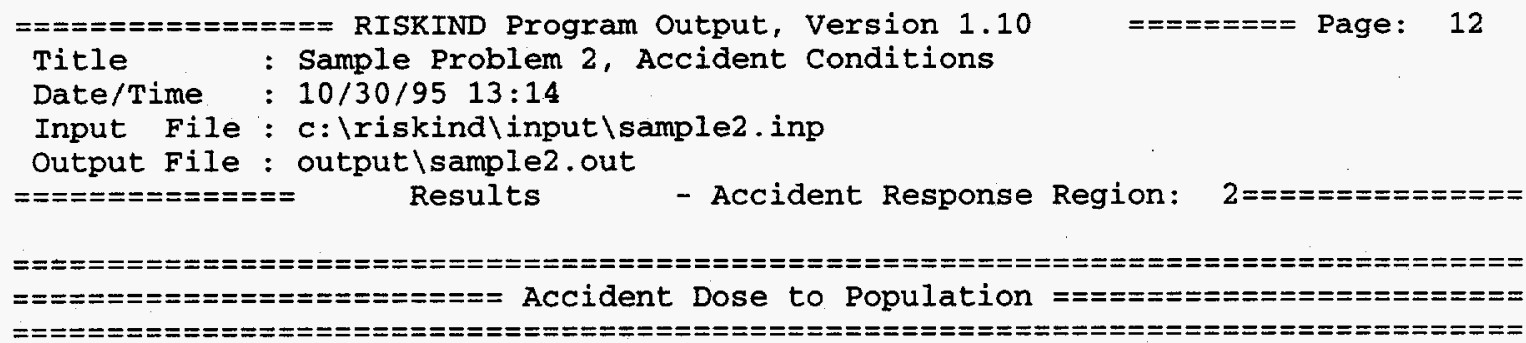

Population Summary Results Per Accident

\begin{tabular}{ll}
\hline Committed Effective Dose Equivalent & $1.70 E-01$ person-rem \\
Expected Genetic Effects & $2.21 E-05$ \\
Expected Non-fatal Cancers & $1.70 E-05$ \\
Expected Cancer Fatalities & $8.50 E-05$ \\
Acute Risk (Expected Fatalities) & $0.00 \mathrm{E}+00$ \\
\hline
\end{tabular}

\begin{tabular}{cccc}
\hline Pathway & Dose per Accident (person-rem) \\
\hline Acute & $1.70 \mathrm{E}-01$ & & \\
Cask & $1.16 \mathrm{E}-04$ & \\
Ground Shine & $1.02 \mathrm{E}-07$ & \\
Inhalation & $1.70 \mathrm{E}-01$ & \\
Cloud Shine & $2.60 \mathrm{E}-04$ & \\
Long-Term & $0.00 \mathrm{E}+00$ & & \\
Ground Shine & $0.00 \mathrm{E}+00$ & & \\
Inhalation & $0.00 \mathrm{E}+00$ & & $0.00 \mathrm{E}+00$ \\
Cloud Shine & $0.00 \mathrm{E}+00$ & & $0.00 \mathrm{E}+00$ \\
Ingestion & $0.00 \mathrm{E}+00$ & & \\
Initial Year & & $0.00 \mathrm{E}+00$ & \\
Vegetable & & & $0.00 \mathrm{E}+00$ \\
Meat & & & $0.00 \mathrm{E}+00$ \\
Milk & & & $0.00 \mathrm{E}+00$ \\
Long-Term & & & \\
Vegetable & & & \\
Meat & & & \\
Milk & & & \\
Water & & & \\
\hline
\end{tabular}

\begin{tabular}{|c|c|c|c|c|}
\hline \multicolumn{5}{|c|}{ Organ Exposure } \\
\hline Exposure Parameter & Marrow & Lung & Intestine & Gonad \\
\hline $\begin{array}{l}\text { Population Exposure: } \\
\text { Long-Term Dose [person-rem] } \\
\text { Maximum Individual: } \\
\text { Brief Dose [Gy] } \\
\text { Brief Exposure Time [d] } \\
\text { Brief Dose Rate [Gy/hr] } \\
\text { Prolonged Dose [Gy] } \\
\text { Brief Exposure Time [d] } \\
\text { Prolong Dose Rate [Gy/hr] } \\
\text { Hazard [Expected Fatalities] } \\
\text { Risk [Ele }\end{array}$ & $\begin{array}{l}2.22 \mathrm{E}-01 \\
1.00 \mathrm{E}-06 \\
1.00 \mathrm{E}+00 \\
4.18 \mathrm{E}-07 \\
5.23 \mathrm{E}-06 \\
3.00 \mathrm{E}+01 \\
7.26 \mathrm{E}-09 \\
0.00 \mathrm{E}+00 \\
0.00 \mathrm{E}+00\end{array}$ & $\begin{array}{l}1.27 \mathrm{E}-01 \\
1.66 \mathrm{E}-05 \\
1.00 \mathrm{E}+00 \\
1.32 \mathrm{E}-06 \\
6.01 \mathrm{E}-05 \\
3.65 \mathrm{E}+02 \\
9.33 \mathrm{E}-07 \\
0.00 \mathrm{E}+00 \\
0.00 \mathrm{E}+00\end{array}$ & $\begin{array}{l}1.50 \mathrm{E}-02 \\
1.74 \mathrm{E}-05 \\
1.00 \mathrm{E}+00 \\
1.07 \mathrm{E}-06 \\
1.82 \mathrm{E}-05 \\
7.00 \mathrm{E}+00 \\
7.00 \mathrm{E}-07 \\
0.00 \mathrm{E}+00 \\
0.00 \mathrm{E}+00\end{array}$ & $2.41 \mathrm{E}-02$ \\
\hline
\end{tabular}


$===============$ RISKIND Program Output, Version 1.10

Title

: Sample Problem 2, Accident Conditions

Date/Time: 10/30/95 13:14

Input File : c: Iriskind \input \sample2.inp

Output File : output \sample2 out

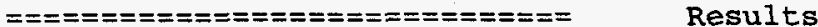

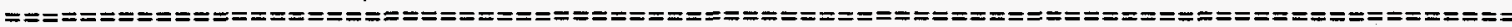

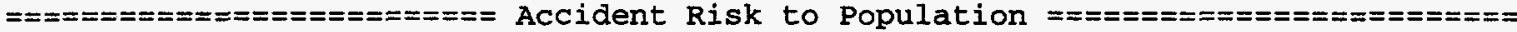

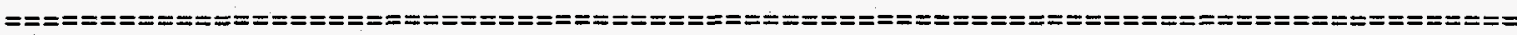

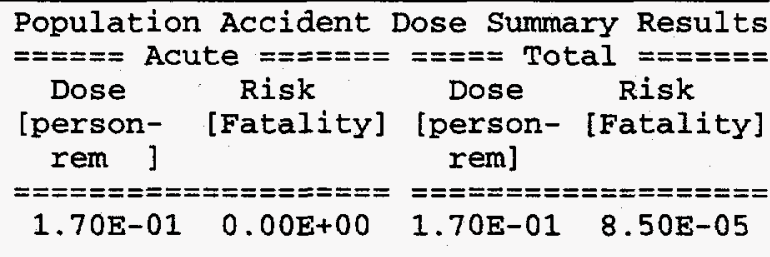




\section{APPENDIX H REFERENCE}

Lawrence Livermore National Laboratory, 1987, Shipping Container Response to Severe Highway and Railway Accident Conditions, NUREG/CR-4829, UCID-20733, prepared by Lawrence Livermore National Laboratory, Livermore, Calif., for U.S. Nuclear Regulatory Commission, Washington, D.C., Feb. 


$$
\text { H-32 }
$$


APPENDIX I:

QUALITY ASSURANCE 


\section{I-2}


CONTENTS

APPENDIX I: QUALITY ASSURANCE ................................................................... I-5

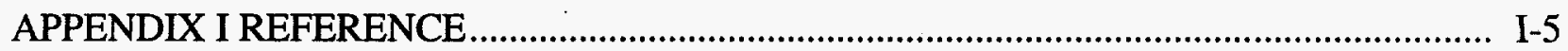

FIGURE

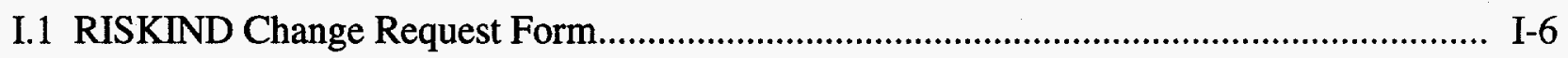


I-4 


\section{APPENDIX I: \\ QUALITY ASSURANCE}

Every effort has been made to ensure that the RISKIND program is an acceptable and useful tool in radiological transportation risk assessment. The RISKIND project is governed by a quality assurance (QA) plan (Software Quality Assurance Plan for the RISKIND Computer Program) at Argonne National Laboratory (ANL). The QA plan governs all aspects of program maintenance and development in accordance with ANL requirements (Environmental Assessment Division Policy and Procedures Software Quality Assurance).

The previous version of the code underwent an independent validation procedure (Maheras and Pippen 1995). Version 1 of the program has undergone a comprehensive external peer review and beta-testing process. User testing, benchmarking against other established codes, and extensive comparisons against parallel spreadsheet calculations have served to validate and verify the models implemented in the program.

User feedback is an important factor in program development so that the program best serves the needs of the user. To assist the authors in providing the highest quality software, a change request form is provided for user feedback (Figure I.1). The completed form, along with any relevant support material such as input and output files, should be sent to the following address:

\section{S.Y. Chen}

Argonne National Laboratory

Environmental Assessment Division

Building 900

Argonne, Illinois 60439

\section{APPENDIX I REFERENCE}

S.J. Maheras, and H.K. Pippen, Validation of the Transportation Computer Codes HIGHWAY, INTERLINE, RADTRAN 4, and RISKIND, DOE/DD-10511, prepared by Science Applications International Corporation, Idaho Falls, Idaho, for U.S. Department of Energy, Washington, D.C. 
RISKIND Change Request (Rev. 0)

1. Submitter's Name: Date:

Organization: Phone:

Address: FAX:

2. RISKIND Version Number:

3. Request Type:

Enhancement/New Feature

Error Correction

4. Description of Request (include error messages, and/or annotated input and output files if applicable; append additional pages if needed):

5. ANL Use Only

Change Request \#:

Received By:

Project Leader:

Date:

Date:

Resolution:

Project Leader:

Date: Modification Form \#:

-C- 


\section{DISTRIBUTION FOR ANL/EAD-1}

\section{Internal}

ANL Technical Publications Services

S.Y. Chen (175)

L. Welko (3)

P. Hollopeter

\section{External}

U.S. Department of Energy Office of Scientific and Technical Information (12)

Manager, U.S. Department of Energy Chicago Field Office

Energy Science and Technology Software Center (2)

ANL-E Libraries (2)

ANL-W Library 